\title{
THE OLIVE
}

\section{BX}

\section{Marvin}
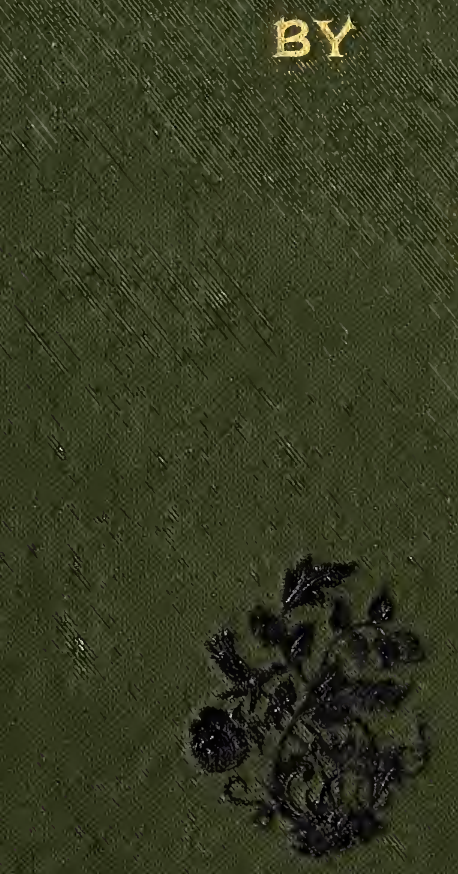

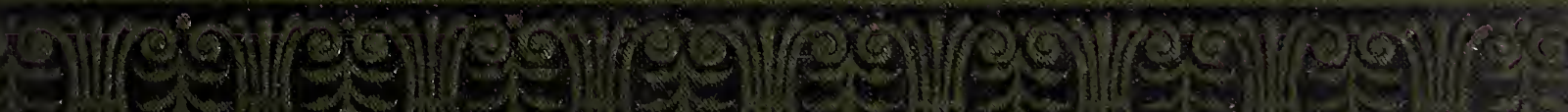

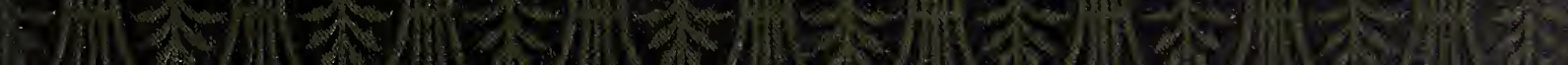
Q

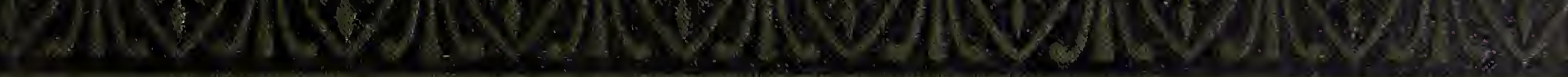


(x)

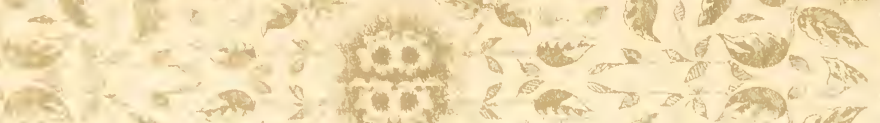

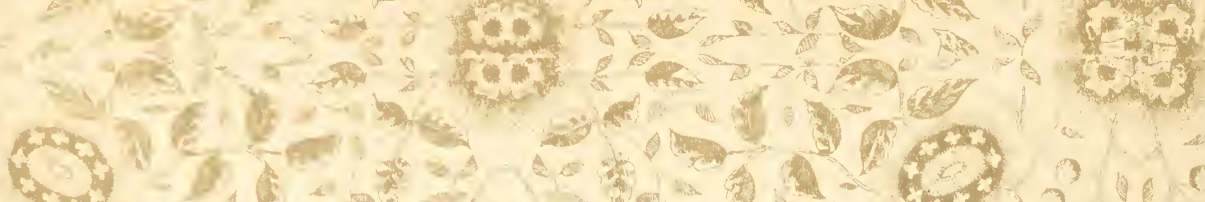

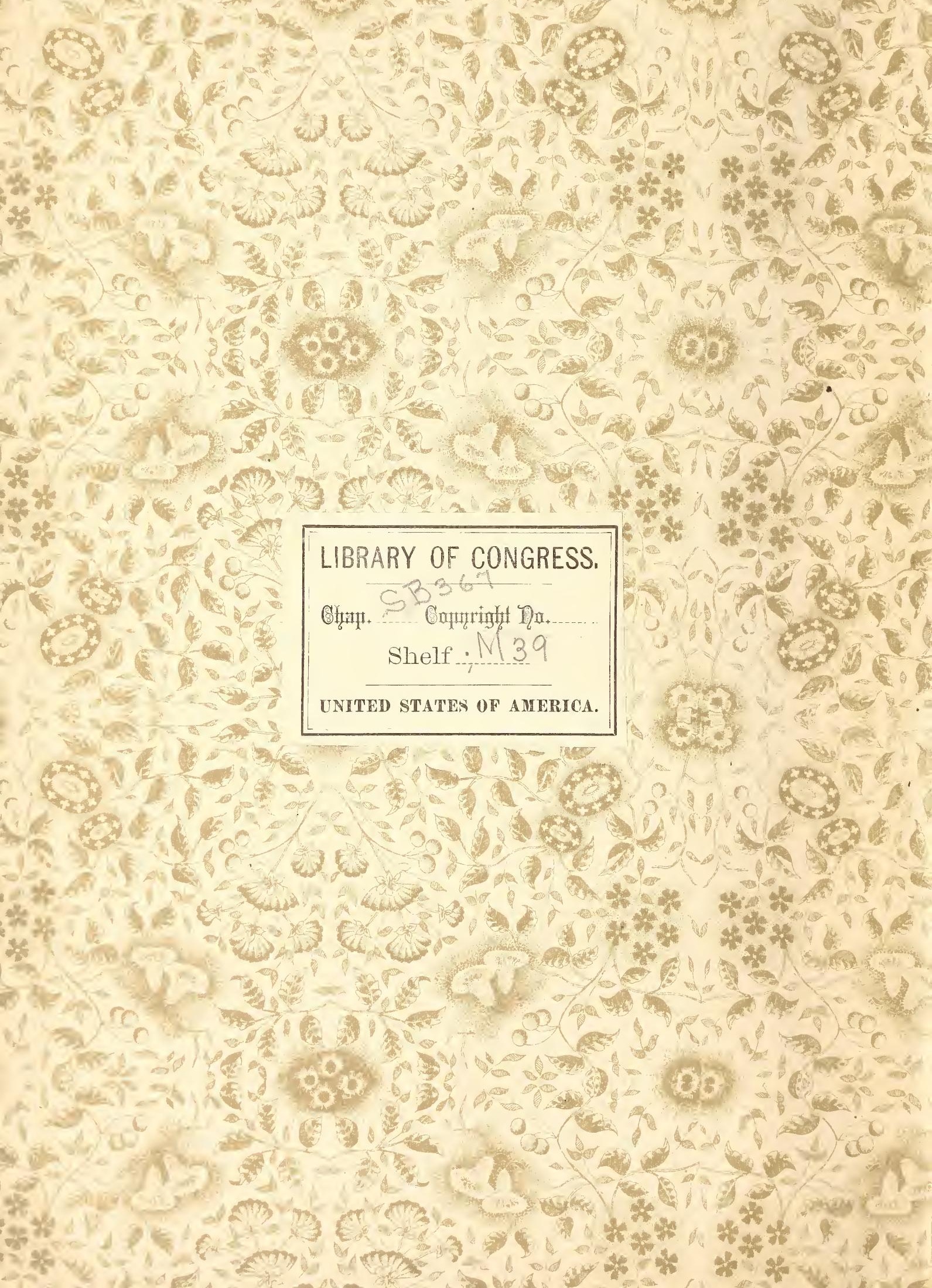

( 



\section{THE OLIVE}

ITS CULTURE

IN THEORY AND PRACTICE
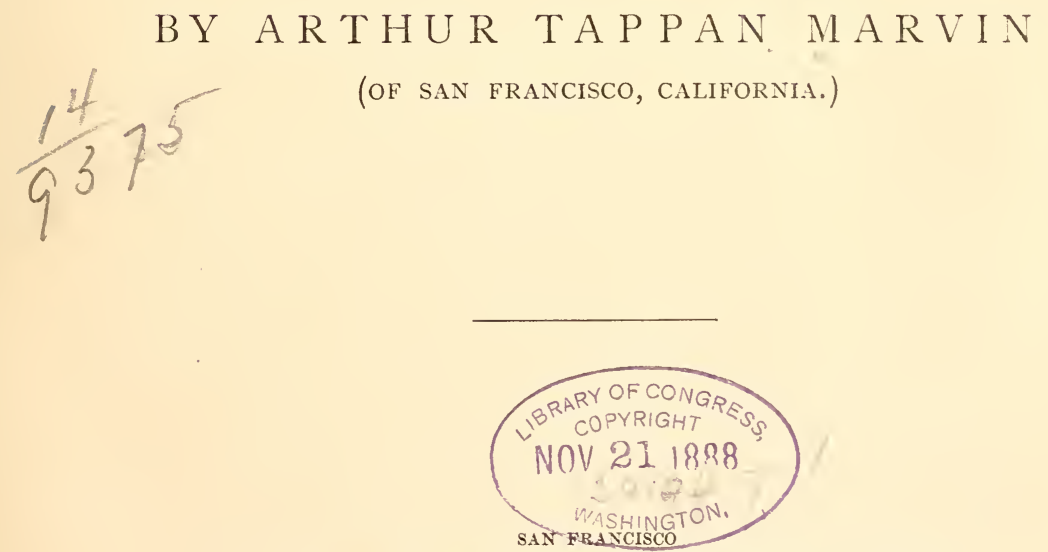

PAYOT, UPHAM \& COMPANI, PUBLISHERS AND BOOKSELLERS

1888 


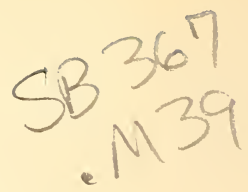

Fntered according to Act of Congress, in the year 1888, by PAYOT, UPHAM \& CO.

In the Office of the Librarian of Congress, at Washington, D. C.

$$
11=31317
$$




\title{
ofntroquetory
}

\author{
Quito Olive and Vine Farm, \\ Santa Clara Co., Cal., July 30, 1888.$\}$
}

Ellwood Cooper, Esq., Santa Barbara.

Dear Sir:--Will you kindly permit me to most respectfully dedicate tn you, as the acknowledged Father of American Olive Culture in California, this little work ?

I do so with no design of covering its defects or inaccuracies (and many such will doubtless be found) with the mantle of your name.

It is a contribution to the local literature on the subject, and must stand on its own merits, if any it has, and take its chance of criticism.

My attention was first attracted to the olive when my friend Mr. Edward E. Goodrich purchased the Quito Olive Farm in December 1882, and began its reform and development under your kind advice and suggestion. 
During his absence in Europe, covering a period of four years, I took a general direction of the place and my interest in the noble tree has ever increased, as my acquaintance with it grew more intimate, although I have no investment in orchard or nursery. My only object in issuing this treatise is to add my mite to the general fiund of information on this most important subject.

After reading your pamphlet and your numerous contributions to the transient agricultural literature of the State, my acquaintance with the Spanish language led me to study the writers in that tongue, and besides some short articies in English (Californian and Australian) I have had the advantage, through the kindness of my friend in translating, of the valuable information contained in the monograph of Professor Caruso of Pisa, the work of Signor Guilio Cappi, and the Manual of Signor Raffaello Pecori of Florence, the leading olive nurseryman of Italy.

This last work is as yet unpublished, but Signor Pecori has been so kind as to furnish Mr. Goodrich with a copy of his manuscript and accord permission to make use of it in the preparation of this work.

Climate and race differences will doubtless lead our culture to vary widely from the European, but the experience of so many centuries will hardly fail to be of some value to the American olive farmer.

I give below the authors consulted, and should add that I have gained many valuable practical ideas from the late experienced and courteous foreman of the Quito Farm, Signor Ludovico Gaddi, a native of the Province of Lucca and one, as the Italians say, "born under the olive."

Let us hope that this tree may soon fill the important place in 
our California fruit culture which for so many centuries it has occupied in that of Asia, Europe and Africa. It seems probable today that this result will be attained, and it will be due to none so much as to yourself.

I am, dear sir,

Yours very respectfully, ARTHUR TAPPAN MARVIN.

Monograph on the Olive, 1883, by G. Caruso, Prof. of Agriculture of the Royal University of Pisa.

Manual of Olive Culture, 1888, by Signor Raffaello Pecori, Nurseryman, Via dei Serragli, No. 64 , Florence, Italy.

The Cultivation of the Olive, 1875, by Signor Guilio Cappi.

Treatise on the Olive in Spain and Mode of Improving it, 1870, by Sr. Don Jose de Hidalgo Tablada, Proprietor.

The Art of Cultivating the Olive, 1840, by Sr. Don Celedonio Rojo Payo Vincente.

The Olive, its Culture and Products, 1878, by William R. Boothby, Esq.

Animal and Vegetable Fats and Oils, Artificial Butter and Lubricants, 1888, by William R. Brannt, Esq.

A Treatise on Olive Culture, 1882, by Ellwood Cooper, Esq.

Prima Arborum, a Treatise on Oil Making, 1887, by Messrs. Samuel Rae \& Co. 


\section{CONTENTS.}

CHAPTER I.

The Olive,

CHAPTER II.

Species

CHAPTER III.

Climate. $36^{\circ}$

CHAPTER IV.

SoIL

CHAPTER V.

Fertilization

CHAPTEK VI.

Multiplication of the Olive. 59

CHAPTER VII.

Consochation. 73

CHAPTER VIII.

Preparation of Ground 78

CHAPTER IX.

Pruning 85

CHAPTER $\mathrm{X}$.

PEsTs 100

CHAPTER XI

Harvest and Product 120

CHAPTER XII.

Extraction, Clarification and Storage of the Oil, .137

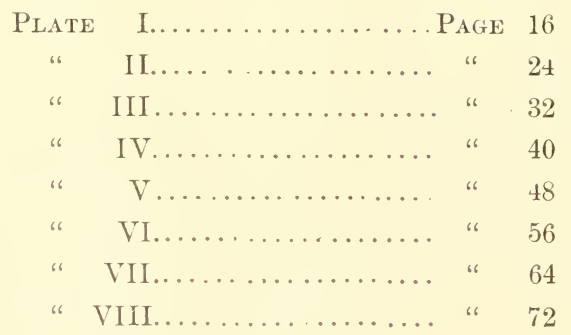

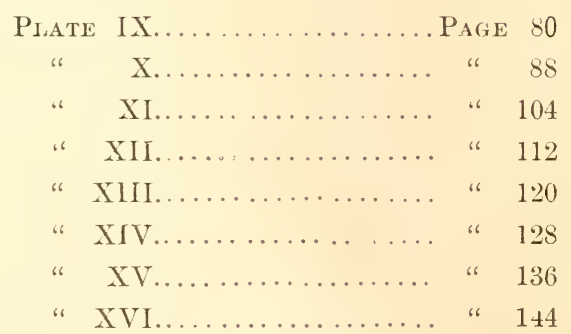




\section{(]) (6) live}

\section{CHAPTER I.}

"The trees went forth on a time to anoint a king over them; and they said unto the olive tree, Reign thou over us."

JUIGES IX: 8 .

The history of the olive is obscure and controverted and is lost in the night of centuries. Its home seems to have been in Southern Central Asia, where it was first domesticated and improved by the Semitic races of that country. Monuments and history show that the wild olive existed on the Grecian coasts of Asia Minor, in the Islands and in Greece itself. Probably the Greeks received its culture from the Semitics. But when, who can tell? In Homer's time, the ninth century, B. C., frequent mention is made of the olive, but always as a foreign importation, which was used entirely for anointing the body and not for food or light. It seems as if in later parts of Homer we see indications of the beginning of its culture, probably on the Ionic coasts and islands, not on the main land. Samos means "planted with olives." As for Miletus and Chios we have evidence of olives from the time of Talete, 639 to $546 \mathrm{~B}$. C. The Egyptian bas reliefs show us how that people extracted oil from the olive before the invention of the stone for crushing the berries. These depict the pressing of sacks of olives to extract the oil and then washing with water till only the clean stones remain.

A certain Aristeo is said to have been the first to cultivate the tree in Sicily and to him is attributed the invention of the crushing stone.

Herodotus telis us that Athens was the seat of olive cultivation in Greece. At the beginning of the sixth century B. C., olive culture is mentioned in the laws of Solon. 
The olive was probably carried by Grecian colonists into Italy, Sardinia, Sicily and Gaul, although it is possible that the Phenicians anticipated them. According to Pliny, in the time of Tarquinius Priscus, 615 B. C., there were no olives in Italy, but five hundred rears later Italy was able to export oil to the provinces. The Greeks, those ministers to luxury, taught the Romans its use in the symnasium, and Pliny complains that the directors of those institutions in Rome had sold the scrapings of the citizens exercising there for sixty thousand sesterces. Ancient medicine was certainly nasty if nothing else. These scrapings of oil and sweat of athletes were supposed to be peculiarly endowed with curative properties and were largely used in plasters and emollients.

Cato thought that the more bitter the olive the better the oil, but at that time the olive in greatest faror in Italy was the Licinian which was the one olive the birds would never touch. This is in all probability the Italian variety known as the Leccino today.

The names of places in Palestine speak a language from which one learns the extensiveness and beauty of the Hebrew olive plantations. The Mount of Olives situated some three thousand paces from the temple, on the east side of Jerusalem, was among the places best cultivated. On its slopes was the plantation called Gethsemane (that is Gath-Semen which means the "oil press") because of the olives with which it was covered and those of the mountain above where they pressed out and made oil in great abundance.

The Bible gives us rarious glimpses of the mode of treatment in harresting and gathering the olive in Palestine.

When thou beatest thine olive tree thou shalt not go over the boughs again; it shall be for tine stranger, for the fatherless, and for the widow.

DEUTERONOMY XXIr, 20.

Yet gleaning grapes shall be left in it, as the shaking of an olice tree, two or three berries in the top of the uppermost bough, four or five in the outmost fruitful branches thereof. ISAIAH XVII, 6.

Rest in the serenth year. In like manner thou shait deal with thy vinevard and with thy olive rard. Exodes xxiI, 11. 
Thou shalt have olive trees throughout all thy coasts, but thon shalt not anoint thyself with the oil; for thine olive shall cast his fruit.

DeUTERONONY XXYir, 40 .

And over the olive trees and the sycamore trees that were in the low plains was Baal-hanan the Gederite, and over the cellars of oil was Joash.

i Cimoniches xxvit, 28.

The Lord called thy name a green olive tree, fair and of goodly fruit; with the noise of great tumult he hath kindled fire upon it and the branches of it are broken.

JEREMIAH XI, 16.

And I heard a voice in the midst of the four beasts say, A measure of wheat for a penny and three measures of barley for a penny, and see thou hurt not the oil and the wine.

Revelation vi, 6.

Here where plagues were sent forth broadcast they were first laid under an injunction not to harm the oil and the wine. Does it not then seem that the land of the olive and the wine is an especially favored one? These Biblical references are interesting for their antiquity and the view they give us of the management of the olive at that remote period. The manner of harvesting, of oil making by treading the berries, of planting on fertile plains where sycamores grow, of seeking the wild olives on the mountains where the birds had scattered the seeds, of the danger of the olive from fire, all this is repeated to-day in the European home of the olive. The oil olive, being essentially a product of civilization, no longer flourishes in Palestine; without man's fostering care it soon reverts to its wild state and ceases to fruit, and finally disappears altogether.

The ancients regarded the olive with reverence and awe. The ease with which it sprang into renewed life, the ritality it possessed, and the hoary age it attained, all led them to endow it with a dirine origin.

The Greeks dedicated it to Minerva, and with evergreen olive leaves bound the brows of brave captains and citizens most marked for virtue and wislom.

The Romans held the olive in a much greater esteem than their simple appreciation of the oil, and mingled the leaves in the triumphal crowns of the defenders of the country.

Professor Caruso says:

"The olive, because of the moderate care which it requires and the copiousness and value of its product, may be considered as a 
Providential tree." He further says that but for the olive a great part of the coasts of the Mediterranean Sea and its dependencies, European, Asiatic and African, which are now covered with its perennial verdure and form the source of the wealth of the people of that region, would be sterile and desert. Few trees can contend with it for the title of primate, and Columella was well advised in proclaiming it the best of his times.

The olive is limited in its possible extension, but still the Italian has already looked forward with dread to its cultivation in Australia, and now California seems likely to prove a formidable rival. But his fears would seem to be unfounded, as the only effect of a supply of pure olive oil in the United States from California, is likely to be a greatly increased demand for the pure article, whether it comes from abroad or at home.

The olive has advantages, however, over most other oil producing trees, such as the walnut, sesame, peanut, linseed, rapeseed, castor oil, and poppy, which, as a rule, demand a rich soil and minute care. Consequently, where the olive prospers it is not worth while to cultivate other trees or plants which produce oil.

The ancients used oil for food, for light, and for anointing the body. It grew to be a maxim in the latter days of the Roman Empire that life was prolonged by oil without, and honey within.

Modern uses are more numerous; for food, for light, for soap, in dyeing, in perfumery, in pharmacies, in manufacture of cloths and for machine oil, especially in cold countries.

The economic future of olive culture seems most promising, since its uses increase steadily, while for food alone the demand is ever greater than the supply, as is proved by the enormous amount of adulterated oil openly sold in all the markets of the world.

THE WORLD'S PRODUCTION OF OLIVE OIL.

Italy comes first as an oil producing country as her export is the largest. This kingdom has yielded in oil as follows, viz: 
Gallons.

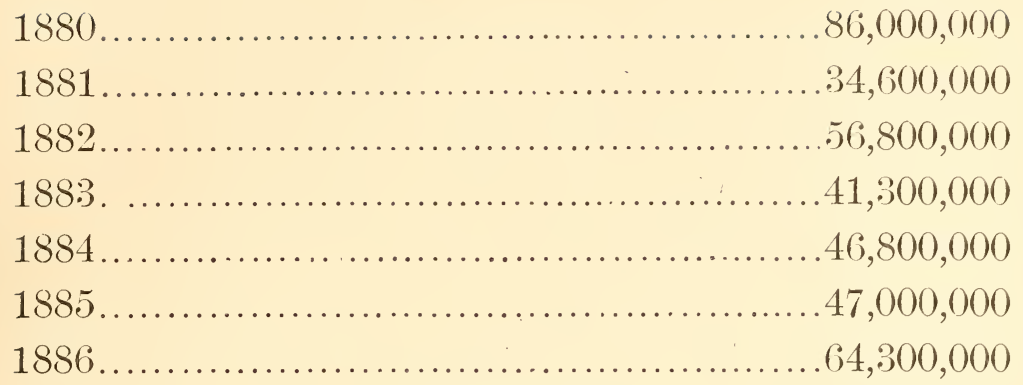

which would average about fifty-four million gallons annually. The export has been steady for the last ten years at about twenty million gallons. The population is twenty-eight millions. The area of the whole kingdom is one hundred and twelve thousand square miles, and that devoted to olives is two million two hundred and fifty thousand acres.

For Spain it is much more difficult to reach the truth. The population of Spain and Portugal is twenty-two millions, the surface area of the two kingdoms is two hundred and thirty-three thousand square miles, more than double that of Italy, and five million acres are given up to olive culture. The very reasonable estimate of Senor Tablada would give a product of one hundred and fifty million gallons of oil for the annual yield of Spain. The export is only ten million gallons. The explanation of this is that the consumption of oil and olives is very much greater there than anywhere else in the world, and also that Spanish oil is made in such a slovenly way that the world will not take it, and it must be consumed at home. Olives are often piled up in a heap and left to rot for six months or a year before being pressed. This suits the national taste; they like strong or rancid oil, but it is not a marketable product and has to be consumed at home.

France has a population of thirty-eight millions, an area of two hundred and four thousand square miles, of which only three hundred and seventy-five thousand acres are given up to the cultivation of the olive. The annual product of oil is only nine million gallons. 
Some of the other Mediterranean countries produce oil, but it is entirely consumed at home or exported from one to the other.

The total production of oil then is:

Gallons,

Italy $54,000,000$

Spain $150,000,000$

France. $9,000,000$

$213,000,000$

of which Italy and Spain together furnish thirty million gallons only for export.

The population of Europe is three hundred and thirty-nine millions of people, more than enough to consume their own oil.

It is plain that France is a large importer. Such is the fact. The entire Spanish surplus and the bulk of that of Italy finds its way into France. Hence the impudence of a French export of olive oil ; its own supply being a failing one and insufficient for domestic consumption.

From these figures it is plain that California has little to fear from foreign competition. In addition to this France has been steadily retrograding as an oil producing country since 179.̀. In the ten rears preceding 1876, serenty-five thousand acres in the Maritime Alps, abandoned olive cultivation for that of cereals, fruits, flowers, the vine and the mulberry, as requiring less care and so yielding a better return.

In Africa also, the cultivation has been generally given up, the climate being too humid and the latitude too far south.

It is quite natural that with the increase of geographical knowledge new and more favorable regions should be discovered where the cultivation of this noble tree may flourish on a greater scale than ever. With reason we flatter ourselves that California is such a spot. Mr. Goodrich, to whose searching observation we are so largely indebted, notices a marked difference in point of size between 
the Italian and Californian trees of a given age. A ten rear old tree in California is much larger in every way than its Italian counterpart. Hence, as was to be expected, its production is also greater.

Our experience with the oljve is as yet largely experimental. But we caunot hope to make a high grade of oil unless we first plant in favorable situations olives of superior qualifications as oil producers. It will be the endeavor of the writer to indicate in the following chapter which these varieties are, together with their characteristics.

The age of the olive tree is known to be very great. It may be said that well cared for trees will live three hundred years. From the first to the twelfth is the period of its infancy, from the thirteenth to the thirtieth its youth, from the thirty-first to the fiftieth a period of growth, and from the fifty-first to the three hundredth the possible period of its life.

Its vitality is really wonderful, and it seems as though it would actually live forever were it not for the attacks of its numerous and persistent enemies, who bore holes in its bark, eat out its lieart, kill its branches and feed on its leaves and fruit; but so great is its hold on life that after all this has occurred, if the dead and dying tree be cut down close to the ground, its vigorous root will give birth to still another tree. It varies greatly in size. In Spain, Nijar, Almeria, one was seen that four feet from the ground measured nine feet nine inches in circumference, and there are well authenticated reports of trees attaining even a larger growth, but of course it is superfluous to say that such a size is abnormal.

What return may we expect from an olive plantation? This is a question that is often asked and one of vital interest.

In Spain olives will average, taking the country orer, thirty-two trees to the acre, and in estimating for oil it is customary to reckon every six trees as good for four gallons of oil. Here we may safely calculate on our trees, areraging one year with another, a gallon of 
oil per tree, and hope for as much more as we please. Also olive culture in Spain is susceptible of improvement. The yield could be much increased by giving more care and attention to the orchards. Their methods are very crude and the people rery poor. But their large experience has demonstrated the futility of planting too near together. This is the crying sin of the California fruit grower. In this way heretofore unheard of pests are evolved, trees are rendered sickly and stunted, and promising orchards become unprofitable. The olive is least able to bear the effects of overcrowding; sunlight and ventilation are absolute necessities to it. Fifty good trees to an acre is a better investment than a hundred poor ones. As the olive is so long in maturing, it is customary to utilize the space between the young trees by growing grapes and the short lived fruits, such as prunes and peaches, to give way finally to the mature tree.

On purchasing the Quito Farm the trees were found to be injuring each other by their proximity, (sixteen and one half feet) and every other one was taken out, deprived of all its branches and replanted. This was done in the spring of 1883. Those replanted trees will this year bear a crop: that is they have been lost to the orchard for the past five years, owing to the error of their having been planted too near together in the first place. This year the trees, by reason of their increased growth, are still too near together, and the process of thinning out will have to be repeated. In this case the economy of planting the trees a reasonable distance apart in the first instance is quite evident.

Mr. Ellwood Cooper has told us that the best result he ever obtained was one bottle of oil from ten pounds and fifty-six hundredths of olives, and the poorest a bottle from twelve and a half pounds. This is twelve and ten per cent. respectively. The best variety among the Mission, the Cornicabra, should give a better result than this. The maximum yield of any olive is twenty per cent. of oil for weight of berries. From that down to ten. An 
THE REPRODUCTIVE ORGANS OF THE OLIVE.

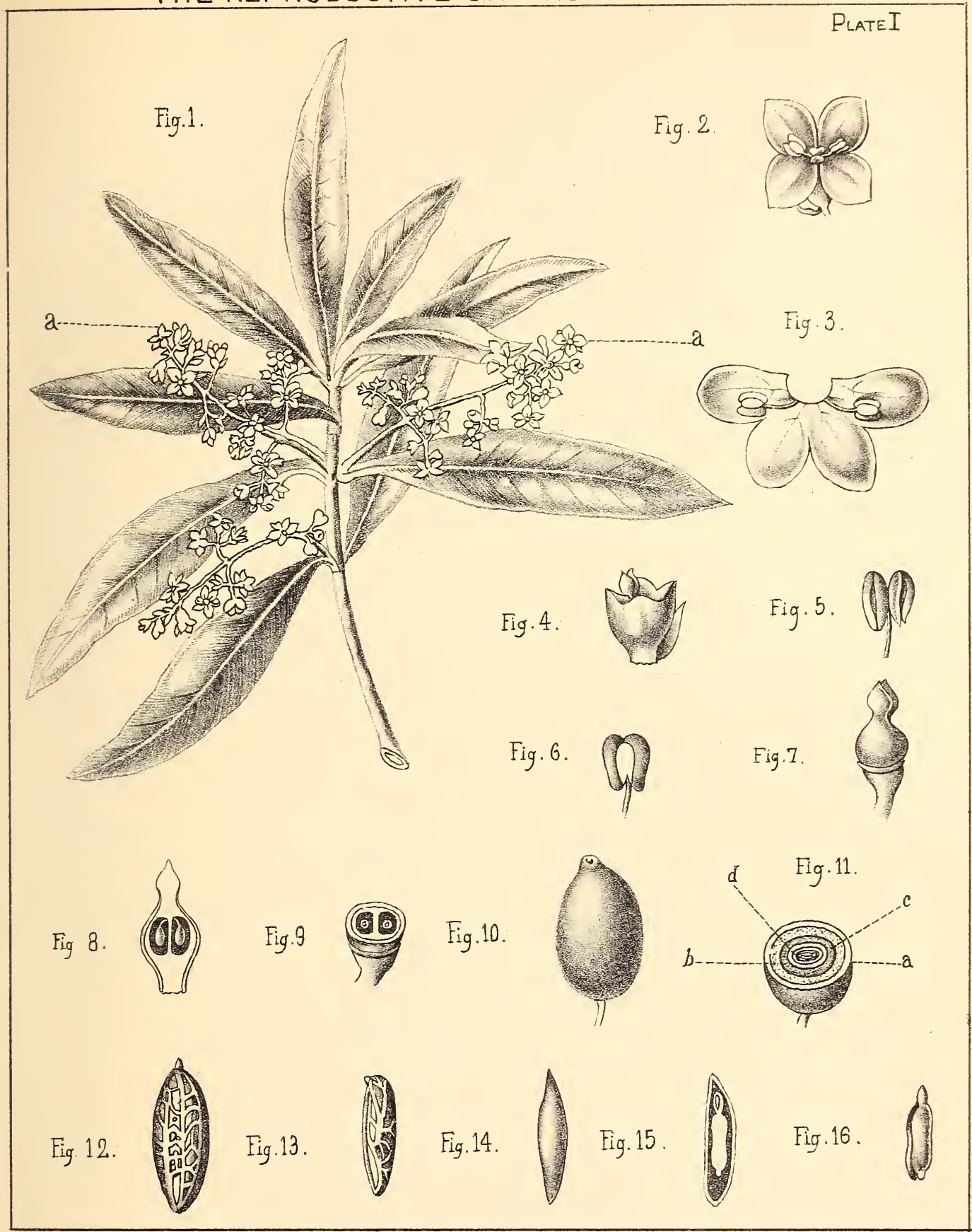

Fig. 1. A branch of the olive in flower, natural size. a a Blossom.

Fig. 2. Inside view of flower, enlarged.

Fig. 3. Corolla cut and spread out to show the insertion of the stamens.

Fig. 4. Flower without the corolla, enlarged.

F1g. 5. Front view of stamen, enlarged.

Fig. 6. Rear view of stamen, enlarged.

Fig. 7. Pistill, enlarged.

Fig. 8. Pistil cut vertically.

Fig. 9. The lower portion of bud cut horizon. tally, enlarged.
Fig. 10. The berry, natural size.

Fig. 11. The berry cut horizontally.-a Epicarp. b Mesocarp. e Endocarp. d Seed.

Fig. 12. The nut stripped of fleshy part, natural size.

Fig. 13. Seed, natural size.

Fig. 14. Seed stripped of its external skin, natural

Fig. 15. Seed stripped of skin cut horizontally,

natural size.

Fig. 16. Germ or embryo split open, natural size. 

olive that will not return ten per cent. of its weight in oil had better be abandoned for one that will. A large and fully developed tree has been known to yield as much as sixteen gallons of oil.

In Florence, Italy, Mr. Goodrich has found it a matter of increasing difficulty each year to get pure oil. In fact the manager of a large olive grove in the vicinity had the hardihood to tell him that he did not believe it possible to procure any there. The output of cotton seed vil in the United States is half a million tons, or seventeen million five hundred thousand gallons. In the late Congressional investigation into the Cotton Seed Oil Trust, it was developed that twenty-seren per cent. is exported to be used as an adulterant of olive oil. In Italy it is poured over the olives in the crusher to thoroughly mix the two oils. Originally cotton-seed oil was used to merely adulterate, which was bad enough, but of late it is pressed on the public with greater boldness.

The British Consul at Leghorn, in his report for 1886, states that the Florentine flasks in which pure olive oil was formerly shipped to the British market are now sent direct to London empty and there filled with cotton seed oil, and he warns the public accordingly. The following is from a late work in the interest of cotton seed oil : "It is hoped that in time the prejudice now existing against cotton seed oil in this country will be overcome and our people, like those of Europe, take to cooking their food in oil instead of using lard. 'That there is a growing demand for cotton seed oil for table use and culinary purposes is evidenced by the increased business of merchants who inake a specialty of filling fancy bottles with cotton seed oil." We are all familiar with the fancy bottles and the blatant claim that they contain pure olive oil. These so called merchants are engaged in deceiving the public, in endeavoring to palm off cotton seed oil for olive oil. Cotton seed oil is refined by treatment with alkaline carbonates and caustic alkalies, and this fact is sufficient to condemn it as a food oil. 
Crude cotton seed oil is a thick fluid of a reddish or dirty yellow color, and if left standing will deposit a slimy sediment. For years the cotton seed oil refiners encountered very great difficulty in disposing of this coloring matter, but this impediment is now overcome in the following manner. To an iron tank charged with ten tons of crude cotton seed oil, is added thirty hundred weight of caustic soda lye. Saponification ensues, and the coloring matter is precipitated. No argument can convince the impartial mind that an article so prepared is fit food for the human stomach. There are many other adulterants which are used in unison with cotton seed oil, such as sesame, palm nuts, hemp, cupra or sunflower, and a host of others of strange origin. It is not safe to say that these supposititious comestibles are always innocuous. Many an oil retains the subtle qualities of the plant which produced it, and it may be that obscure maladies which puzzle the doctor are not unfrequently caused by the detestable practice of supplying for the genuine article something which looks sufficiently like it to mislead, and, it may be, poison the hapless public. A simple and homely test for the detection of adulteration is the heating of oil until it smokes, in some small vessel. The smell of olive oil while suggestive of the kitchen and cookery is not at all disagreeahle, while any counterfeit oil, and especially cotton seed oil, is exceedingly offensive to the nostrils. If placed in a refrigerator, pure olive oil will remain unchanged, or at most throw down a little palmatin, while adulterated oil will thicken and congeal. The persistent adulteration of olive oil will bear its legitimate fruit ; the markets where the world has sought its supply heretofore will become discredited, their wares will no longer meet with ready sale in the face of free supplies of the pure article from California and Australia.

Gasparin makes some interesting calculations as to the consumption of oil in France. In Provence a laborer consumes an average of nine pounds per annum, and the same ratio holds good in Paris. 
The olive grower of California has sixty-five millions of countrymen among whom to market his product. Now if we assume that the consumption may reach only one pound per head annually, it would require ten million gallons to satisfy the demand for the United States alone, or, with an acreage of fifty trees, olive groves covering two hundred thousand acres. Our people have yet to learn to appreciate the olive. It needs no pushing, it will make its way on its merits. It is sufficient to say that the public were willing to pay during all last season fifteen dollars a gallon for an oil they knew to be pure. But increased production will lower the price, and a lower price will stimulate the consumption.

Olive oil has always been greatly esteemed for the beneficial effects derived from its use by the human body. This reputation is sustained by the experience of mankind from the beginning of history. Of late years it has been discovered that it contains cholesterin, which was only known to exist in the animal body, where it forms an important constituent of the gall, the blood corpuscles, and the nerve substance. 


\section{@pecies}

\section{CHAPTER II.}

"The domestic olive represents the artificial type obtained by means of art."

Cartso.

The species of the olive known to exist and the localities where found are as follows:

Ocensica. $\left\{\begin{array}{l}\text { Olea apetala, New Zealand. } \\ \text { " paniculata, Australia. } \\ \text { “ Europea, }\end{array}\right.$

Aurerica.

Olea floribunda, South America.

" Americana; Fla., Ga., Carolina, Va.

" Europea; Chili, Peru, Mexico, Cal, La., Miss.,

Fla., Arizona, New Mexico.

Olea crysophylla, Abyssinia.

" laurifolia,

" verrucosa, Cape of Good Hope.

" verr. (brachybotris)

" capensis,

" foveolata,

" concolor,

" exasperata

" humilis,

" obtusifolia, Madagascar.

" lancea, Mauritius.

“ Europea; Egypt, Tripoli, Tunis, Algiers, Moroc. co, Canaries.

Olea, pauciflora, Penang.

" maritima, Islands, Strait of Malacea.

" microcarpa,Cochin, China.

Asia.

" attenuata, Burmah.

" dentata, "

“ Lindleyi, Bengal.

" fragrans, China and Japan. 
Olea, salicifolia, India.

" dioica,

" cuspidata, Afghanistan.

" compacta, India.

" acuminata, longifolia, India,

" roxburghiana, India, eastern.

Asia.

" heyneana,

" glandulifera, Nepaul, India.

" acuminata,

" Europea; North Asia Minor, Srria, Kurdistan, Transcaucasia, North Persia, southern coast of Caspian sea, the southeast of Arabian peninsula.

Europe. $\quad$ Olea Europea ; the Mediterranean coast and Portugal.

The Olea Americana is known to the lumbermen of the Carolinas and Florida as deril-wood, the grain of the rood being so hard as to resist ordinary tools.

The berry of the Olea Fragrans of China is candied and used among the Chinese as a sweet, and the flowers to flaror and adulterate the finer kinds of teas.

The abore enumeration is given chiefly as a curiosity. The species of interest to us is the Olea Europea, this being the only rariety that has as ret repaid man's care by the increased size and weight of its berry. (See Plate I).

'The olive (Otea Europer of Linnens), according to De Candolle, belongs to order CXITII of the Oleaceae, to the tribe III of the Oleineae, to the genus TI, Olea, to the species X. 2, Europea, and was so called by Linneus to indicate that its home is there, that there it is cultivated by choice and has been held in honor from remotest antiquity. Some consider the name inappropriate on the ground that the olive was brought from Asia, but Caruso holds it to be correct because he believes it to be a native of Europe and the culture, only, brought from Asia.

ITe propose now to endearor to classify the varieties of the Otea Europea in a brief and comprehensive manner.

It is erident that great confusion exists in the nomenclature of 
the olive. The ancient Italian authors enumerated comparatively few, from twelve to sixteen, but a modern writer on the subject in that country has summed up to over three hundred. Each locality where olives have been grown has added a name suggester by chance appearance or local prejudice, until a perfect chaos exists, utterly meaningless to anyone outside of the narrow section where it may be familiar. Take some of the Spanish names for instance, such as the "Rabbit's eye," the "Pillow-case", the "Little round"-these are absurd and convey no significance to anyone not living in the province in Spain where they may be grown. They are evidently given to impart the idea of the shape of different berries and in ignorance of the ract that olives should not be classified by the appearance of the fruit, but by the characteristics of the tree, for the very sufficient reason that trees of entirely different appearance and habits, produce berries very similar in form.

In this State we are likely, as olive culture progresses, to find great difficulty in recognizing what an olive is from its name. We were launched with some Spanish varieties which to us have become Mission, then a number of French plants became known, and lastly the Italian are coming in. The Spanish have never shown the world any good oil, although it could undoubtedly be made there. The quality is probably somewhat affected by the latitude.

The French for years have drawn the bulk of their supply of oil from Italy and to-day the oil provinces of Northern Italy are orerrun with French oil buyers, and bad oil cannot be made good, although the French are adepts at anything of this kind. If their oil has merit it is because it was properly made. Italy is the fountain head. Italy has long been the source of all the good oil we have ever known. Italy has carried the cultivation of this tree to greater perfection than any other country on the globe. How can we then do better than follow the classification of Professor Caruso, Professor of Agriculture of the National University of Pisa, who at the instance of the Italian Government has 
given to the world a monograph on the olive which is perhaps the most profound and exhaustive work on the subject that has yet been written. He separates the olive under three heads as: The domesticated olive, the wild olive, the seedling of the cultivated olive; although two only, that of the domesticated olive and wild olive, would answer all practical purposes. The domesticated olive he assumes to have come from the East. The wild olive he believes to be the tree indigenous to all the coasts of the Mediterranean. The seedling of the cultivated tree is virtually a wild olive, as in only one case of a thousand will the seed ever reproduce the variety from which it came, but constantly returns to the wild type.

The following table will show the olives of Italy, France and Spain, grouped in their relative order of merit as oil olives, and it is interesting to note the position assumed by our own Mission in this comparison with the olives of the world.

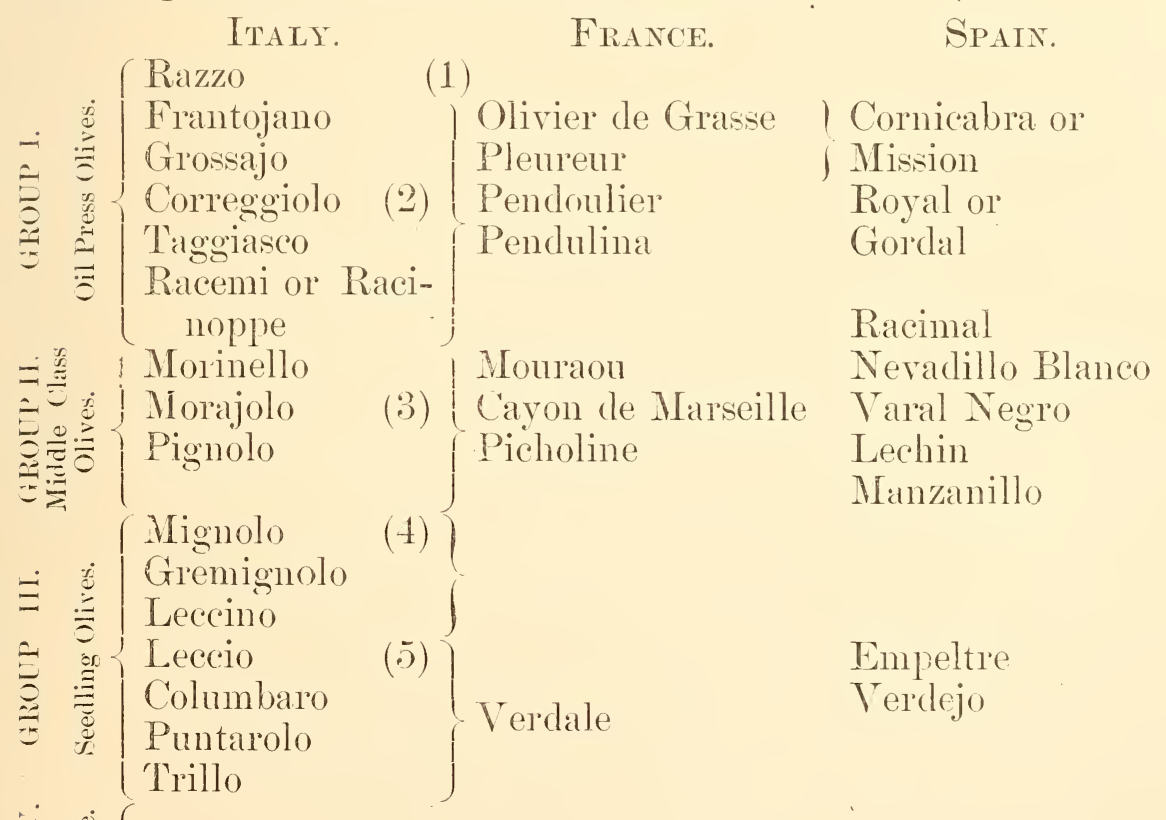

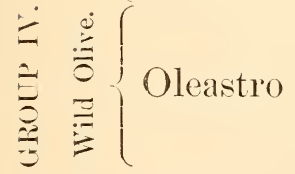

Acebuche 
Group I represents the olive of the oil press, the most dereloped, cultured and domesticated of all olives. The fruit is of rarious sizes, very fleshy and oily. Sometimes, howerer, the olive is not rery oily and then is only good for pickling. It is a large tree and abore all others produces the best olives for oil.

Group II consists of middle-class olires, the tree is more rustic, the branches more robust and erect, the fruit more fleshy. Tree of middle stature.

Group III covers olives obtained from the seeds of domesticated olives; the most rustic of cultivated trees. Its branches are robust and erect, its fruit of various sizes but not rery fleshy. A tree generally not growing very large but sometimes of rather good appearance.

Group IV represents the sarage type which is not worth cultivating because the fruit is small and the stone is large, with little or no pulp. It grows to a bush or small tree of from ten to sixteen feet in height.

\section{DESCRIPTION OF OLITES.}

GROLP I,

\section{The Razzo or Frantojano.}

This is the rariety mainly cultirated in the prorinces of Lucca and Pisa, regions that have a world-wide reputation for their oil and where, also, are found in less numbers the Mignolo, Morajolo, Puntarolo and some Grossajo. The trigs of the Razzo are short, light, numerous and rather reflexed. (See Plate III.) It is cultivated in grores on the Pisan mountains where, howerer, the trees are too near together and as a result they grow too high. It will not bear much pruning; all that is necessary is to keep it freed from the dead twigs, from shoots that are too high and from branches 
THE WILD OLIVE.

Plate.II

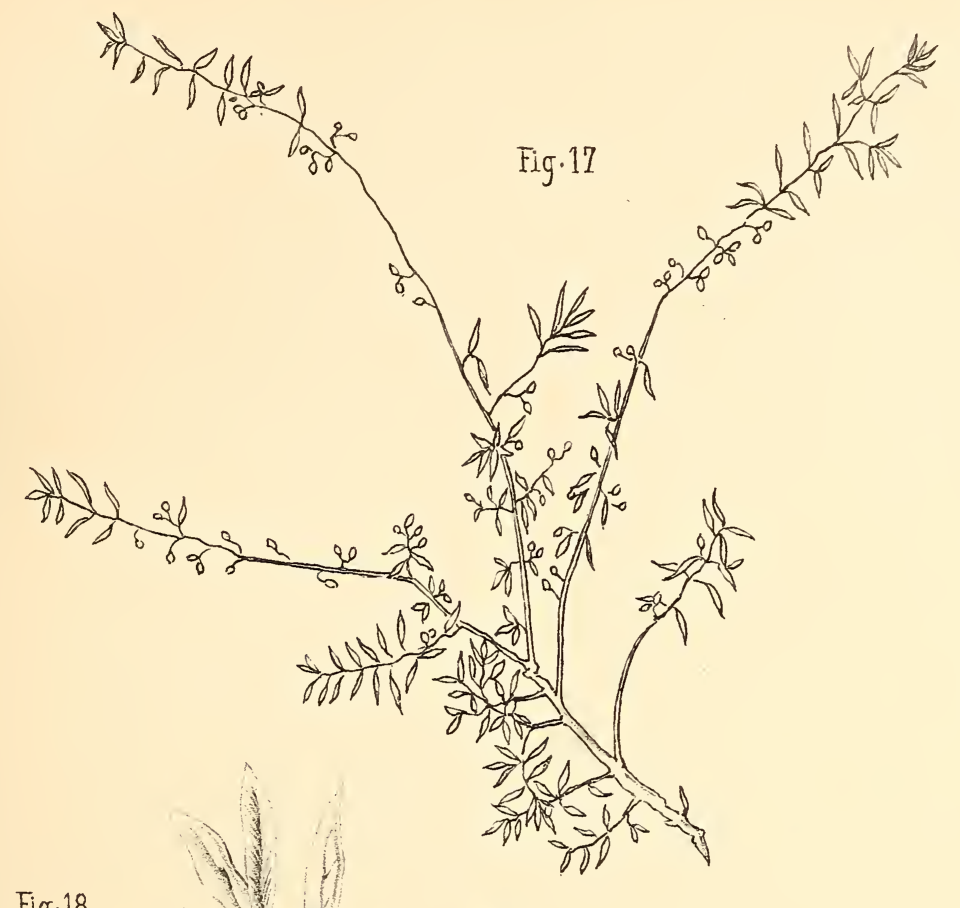

Eig. 19

Fig. 20 


\section{PLATE II.-THE WILD OLIVE.}

Fig. 17. A branch of wild olive showing its appearance, (reduced.)

Fig. 18. A branch of wild olive with berry, (natural s:ze.)

Fig. 19. Longitudinal section of berry, (natural size,) showing mesocarp.

Fig. 20. Form of the nut of the wild olive. 
that disturb the uniform distribution of the fronds. Its leaves are narrower at the insertion than at the apex, of a beautiful green on the upper side and a strong white on the lower.

In deep and rich soils it acquires great stature. Fogs, cold and. variations of temperature do it harm, so much so that it loves protected sites, and the half hill, and in districts most exposed to frosts prefers the west and northwest exposures to defend itself against the danger of sudden thaws. It is immoderately fecund, to the degree that it buds even in the midst of blossoming. It retains its fruit badly, especially in wind or prolonged heat.

'The berries are roundish, fleshy and richer in oil, than any other variety, on which account in the country about Calci, at the foot of the Pisan mountains, the people call them "frantojani" or, oil press olives. They commence to mature from November and December and turn to black and winey black.

\section{Grossajo, Frantojo or Correggiolo.}

This variety is most cultivated in the districts outside of Lucca and Pisa in the best exposures and sheltered spots where the soil is rich. It is as delicate as the Razzo but less fecund and the berry less oily.

It is distinguished from the preceding (see Plate IV) by its numerous long, subtle and flexible twigs, so that its top is rather spread out and makes the appearance of a willow. It becomes a large tree and like the Razzo needs little pruning.

The berries are larger than those of the Razzo, blown up at the extremity, curved like a bow on one side, and for oleosity stand next to the preceding. In comparison with the weight of the nut the flesh is less dereloped than the Morajolo. It matures at the same time as the Razzo, taking first a lilac color then a wine red and even black.

\section{The Taggiasco.}

This olive prevails in Liguria. It is sensitive to cold and fogs, so it prefers the low hills with a sunny exposure and mild temperature 
and defended from the north wind. It sends out a great number of twigs subtle, long and bent back which makes the top look sparse and willow like. It needs little pruning. It is a large tree especially in the spread of its branches. It buds and holds much fruit and carries it easily to maturity if not injured by excessive heat or harsh winds. The berries are fleshy, abundant in oil, middle-sized, pointed and bowed at one side. This olive in appearance seems like the Grossajo or Frantojo.

\section{The Racemi or Racinoppe.}

This olive is of middle stature and is fond of sheltered spots with rich and deep soils. Fogs do not harm it. It is very prolific, produces many blossoms and gives fruit in abundance. The berries form in bunches of five, six, seven and even nine in a cluster, and bend the branches to the ground with their weight.

The berries are long and bulged at the lower end, fleshy, but do not give as much oil in proportion as some of the foregoing. This olive has the peculiarity of fruiting on the wood of the year and is therefore an annual. It has been introduced into California as the Olea Oblonga, in allusion to its shape, but this is a confusion of terms as the real Olea Oblonga is the true Picholine. Besides the Racemi or Racimal is a better olive than the Oblonga or Picholine, and confusion in terms is what we are striving to avoid.

Otivier de Grasse or Plant de Solon is called also Tagbasquo, Cougniale, Otivier a fruit de cornouller, Otivier Pleureur, and is in fact the Olea Europea craniomorpha medio fructu cornu of Gouan, L'olea Europea comiola of Risso, L'olivier Pendulier of Riondet, L'olivo Taggiasco of Liguria and is really nothing else than our old friend the Mission olive.

\section{The Cornicabra or Mission.}

This olive according to Tablada is the largest known. Its limbs are straight and strong. The smaller branches have an inclination 
towards the ground, and even touch it, completely covering in the trunk. The bark is of a gray green. The under side of the leaf is a clear white and the upper a smooth dark green with the fibers well marked.

The berry is an inch and a half in height and three quarters of an inch in diameter. It weighs five grams, is a black red in color and is a clingstone. It gives a good oil, but is late in maturing and needs twelve thousand seven hundred degrees of heat, in order to ripen, from the time the flower appears until the olive is ready for the mill. It needs a careful pruning and frequent clearings. The wiser course is to cultivate thoroughly and give the tree fertilizers rather than to prune closely in order to force the sap into the bearing branches.

In Spain it may be said to be the favorite olive, but in some of the northern provinces where the tree is out of its element it gives no fruit at all but only attains a colossal size and hence is classed by the country people as a wild tree. But as we shall proceed to show it has none of the attributes of the wild tree, so far from it that it is one of the "oil press olives," one of the rarieties most highly domesticated and cultivated that the world knows.

When olive culture and oil making come to be better understood, where each variety is given the treatment it demands and olives are gathered at the moment best suited for making the oil, we shall probably hear less about the lateness of the Cornicabra in ripening under a California sun.

\section{Racimal.}

A medium sized tree with branches that incline towards the ground, and of abundant blossoms. Resists cold and grows steadily in all kinds of soil. This is one of the earliest olires to ripen, gives a good oil in fair quantity, but it is easily detached from the tree, and many berries are lost on this account. It does not produce every year, but is apt to only give a crop every other rear It needs especial care in pruning, for, although it is prodigal of 
leares, the branches grow slowly and if this is not taken into account the tree will be left too bare and its fructification imperilled.

\section{GROUP II-IIIDDLE CLASS OLITES.}

The Morajolo or Morinello.

This olive is more rustic than the Razzo and Grossajo (see Plate T) ; it endures cold and wind better and contents itself with a lean and arid soil. It is the rariety most general in Tuscany. Its twigs are short, subtle and rigid, tending upwards separating themselves little from the trunk and principal limbs. For this reason it has a top gathered in and loves to spread broad branches. It attains only a medium stature and is less noticeable than the Razzo and Grossajo. The leaves are narrower at the insertion than at the apex and have a more pallid tint on the lower side than those varieties. The olives are roundish and a little more fleshr than those of the Razzo. Relatively to its nut it has more flesh than the Grossajo but the oil is less fine. These are the first olives to change color, between October and Norember, dyeing themselves finally a splendid black.

The Houraou or Otivier a fruit rond is called also Mourette Negrette. It is the Olea Europea precox of Gouan and Risso, L'olea media rotunda, nigra et mbra precox of Tournifort and others. It is similar to the Morajolo.

The Cayon de Marseille or Plant d'Aix is the Olea Europea subrotunda of Gouan, and is similar to the Morojolo in rank, form and flower.

The Picholine, Collias or Corrias, Otivier a petit fruit is the Otea Europea Oblonga of Gouan, L'Otivier Iinares et Generenses ex Prorencia of C. Boubier, L'olea fructu oblonga minori of Tournifort. Named for one Picholini a farmer of the last century. This olive grows to be a very large tree when the conditions are farorable to it, otherwise it is of medium size only. It needs fertilizing in abundance. The branches are well set on and easy to direct, but should be renewed from time to time or they will be covered with warts to 
which this tree is much inclined. The principal branches are bent orer with the weight of the fruit which is generally plentiful.

Contrary to the habit of most olives it does not thrive near the sea. About Marseilles a temperature of sixteen degrees Fahrenheit has been known to be fatal to it where in the interior it had successfully resisted a cold spell of six degrees. This olive needs particular care in pruning, so as not to leave the tree too bare of branches, in order to take advantage of its tendency to give abundant crops, but on the other hand the warts must not be allowed to multiply.

This olive seems to be a favorite in France where three varieties of it are known, but is entirely out of favor in Spain on account of its extraordinary tendency to multiply wart excrescences not only on the trunk but even up on the small branches and for which there is no cure but to cut the tree down to the crotch and let it start afresh.

This difference in habit of the same tree in France and Spain would seem to indicate the effect of soil and climate and so much the more so as these warts (which will be noticed in the chapter on diseases) cannot be traced to the attacks of any insect. Still the writer has noticed an olive tree badly afflicted with this disease in the vicinity of San Francisco, but it is doubtful whether it was the Picholine.

The late B. B. Redding, Esq., is credited with the introduction of the Picholine olive into California, after searching Europe for the plant best adapted to our soil and climate. All honor to $\mathrm{Mr}$, Redding for his good intentions. But his knowledge of the olive at that early day must have been limited, and he appears to have fallen into the natural error of supposing that the largest berry was the most desirable; for on his return to this State he transferred a part of his original invoice of "Picholine" olives to Messris. IV. R. Strong \& Co. of Sacramento as the Picholine or Queen olive, a large olive for pickling. Thus proving that his intention was to import the large Queen olive of Spain and also that he was imposed upon. 
The jealousy of the European olive countries has already been noticed and the writer is strongly inclined to think that the olive recommended to Mr. Redding and imported into this State by him as the Picholine, may be one of the various forms of the wild olive. (See Plate II.) Note the similarity of growth, the size of the berry and the stone, and of its general characteristics; its extreme fecundity, its low stature and its hardiness in all situations. Now on the other hand, we know that the real Picholine, in a farorable soil, becomes a very large tree, with its branches all well set on and growing regularly, and not straggling out in the eccentric manner of the wild olive. Without discussing this point farther and granting that the olive generally known in California as the Picholine is all its adrocates claim it to be, and that it is not the wild olive, it seems so near akin to it that it is utterly useless to cultivate it for the production of oil for it will not repay one for the care and space in the orchard given to it. The same quantity of oil is pressed from one Mission olive that is contained in fire Picholines, one dried Mission olive weighing $2 \frac{7}{100}$ grams and five dried Picholines, weighing $2^{\frac{66}{100}}$ grams, showing plainly the difference of twenty per cent. in faror of the Mission olive and exactly the same quantity of oil being produced from each. Hence, the accepted Picholine olive will give only eight per cent. of oil, and that of an inferior quality, being largely made up from the essential oil contained in the stones. But this olive through its extreme rusticity and close relationship to the wild olive is, without doubt, the rery best possible stock upon which to graft, and so, although the introduction of this plant may somewhat retard olive culture in this State, it may eventually prove a benefit.

The Nevadillo Blanco or Doncel is the Olea precox of Gouan. It is a tree of good appearance with the branches well set on and bowed over with the weight of the fruit which it generally bears. It is sensitive to cold and demands sheltered situations. It gives 
much oil of a fine quality. It ripens early, but needs careful pruning as its fruit shoots are somewhat sparse.

\section{The Varal Negro; Plant etranger of Cuers.}

This is a large tree in a favorable soil, limbs straight and long, twigs abundant. The wood is exceedingly hard. It ripens early, but is sensitive to cold and needs sheltered situations. It gives abundant fruit and good oil. It needs frequent and severe pruning to compel it to bear.

The Lechin or Picholine has been fully described.

The Manzanillo; Olea Pomiformis of Clemente; Spherica of Gouan; the French Ampoulleau.

This tree needs a good soil, fertilizers and water if the ground is too dry. Under these conditions it grows to a very large size. The wood is of a dark color. The limbs are long, smooth and curved, but the fruit twigs are apt to shrivel and die after the berries have prematurely fallen. This is apt to occur with the fruit of this tree as the berries are of such very large size and consequently heavy, and so are easily detached. For this reason it is a favorite olive for pickling as then the berries are picked green. The pruning should be limited to frequent trimming and to keeping the tree free from dead twigs and broken branches. It ripens very early and with little heat, requiring only ten thousand, seven hundred and ninetyfive degrees of heat from flower to ripened berry.

\section{ĠROUP III-SEEDLING OLIVES.}

\section{The Mignolo or Gremignolo. (See Plate VI.)}

This olive is cultivated for its rusticity and ability to resist clouds and salt sea winds, and where the Razzo, Grossajo and Morajolo do not thrive, the Mignolo will do well and give abundant crops. Its branches are longer than the Morajolo, less ramified, more rigid and more robust, with a tendency to grow up, on which account its 
top is inclined to grow high. So it requires energetic pruning to keep it down to a convenient height. The tree is not so large as the Morajolo. The leaves are whiter on the lower side, broadened from the middle upwards and very pointed. It flowers generally on the twigs that have filled out a year and are entering into a second year; quite contrary to the Morajolo and other varieties, which bud on wood which is two years old and is entering on a third. For this reason it flowers so abundantly, that it is a matter of doubt whether its name comes from this rich budding or the smallness of the fruit. From its facility in budding and retaining its fruit, it produces olives every year. They are round, and rather lacking in flesh and oil, and for size take a position between the Razzo and wild olive. It begins to mature in December, turning a wine red color. This olive best resists salt wind, dampness and fog.

\section{The Leccino or Leccio. (See Plate VII.)}

In appearance this variety most resembles the wild olive. The Leccino is mentioned by all the ancient Latin authors on the subject of the olive, and is the oldest variety that we are able to recognize. Its twigs are very robust, rigid and very long, and not at all ramified, The angle of insertion being about eighty degrees, hence the top is little united, and bends over much like a willow tree; therefore its name Leccio (Quercus Ilex). It is strong to resist wind and cold and the altermations of freezing and thawing. This was proved in the winter of 1871-72, when many Razzo, Grossajo, Marajolo, and even Mignolo, perished; while the Leccino resisted even a temperature of twelve degrees $\mathrm{F}$. The Leccino leaves are very much broadened in the middle, and are obtuse and sharp pointed, the lower side being pale, as in the Mignolo. It flowers richly, and because of its rusticity holds firmly on to its fruit, and carries it to maturity in bunches of two, three, four and even five berries. It is very persistent to the peduncle, which is sometimes leaved as in the wild olive. 


\section{PlateIII}

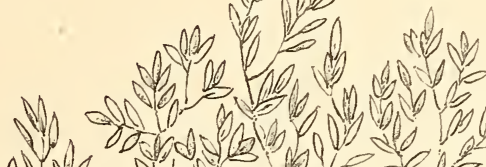
Mo actur

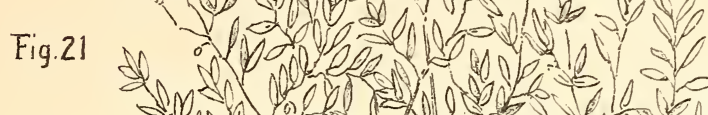
Somen a

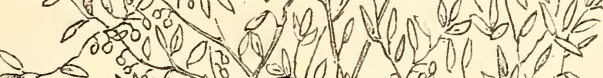
को 60 की

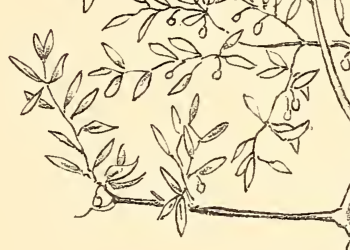

Fig. 22

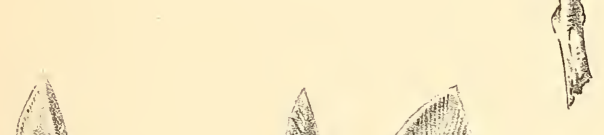
(1)
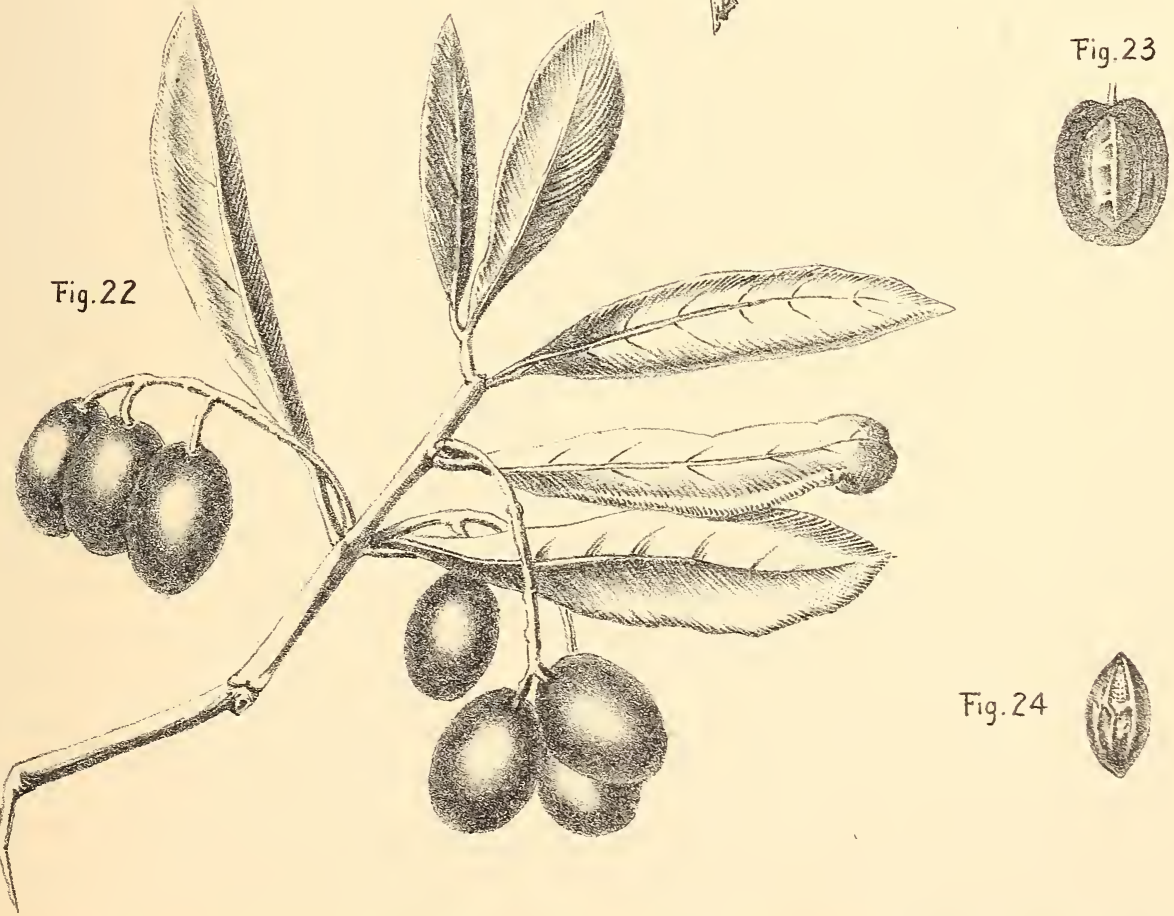

Fig. 24

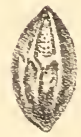




\section{PLATE III.-THE RAZZO.}

Fig. 21. Branch of the Razzo showing its appearance, (reduced.) Fig. 22. A twig with olives, (natural size.)

Fig. 2:3. Longitudinal section of berry, (natural size.)

Fig. 24. Form of nut, (natural size.) 
The berries are as large and fleshy as the Grossajo, but not so rich in oil. It matures toward the end of November, turning black in color. This is decidedly the olive to be cultivated where frost is most frequent and dangerous.

\section{The Puntarolo. (See Plate VIII.)}

This olive has erect twigs, but shorter, less robust and more subdivided than the Lecino; wherefore it forms its top less open, and has a tendency to grow more upward. It is a middle-sized tree, with leaves like those of the Leccino in form. It flowers rather fully and holds on tenaciously to its fruit, carrying to ripeness a goodly number of berries, which are in clusters of two, three and four, on peduncles leaved as are the Leccino. The berries, however, do not cling to the stem as tightly as the Leccino. These are ovate, and so pointed as to give the name of Puntarolo. They have less flesh than the Leccino and contain less oil, mature as late as the Gremignolo, and change as they do.

The Trillo olive has twigs as rigid and robust as the Puntarolo, rather long and little ramified, so as to appear like the Leccino and also a little like the wild tree. It is a middle-sized tree, its leaves broad, sharp and spinated in form, darker on the upper side and lighter on the lower than the Puntarolo, fecund in flower and fruit, which latter comes to maturity in bunches of three and four at very nearly the same time as the preceding variety. The berries hold on better than the Puntarolo, but not so well as the Leccino, and are ovate and pointed like the latter.

The Trillo and others called Morchiacci, and sometimes simply seedlings, are quite like one another in rusticity. Sometimes they endure cold as the Morchiacci, and sometimes the sea wind and cold as the Puntarolo and Trillo.

\section{The Empeltre.}

The Empeltre is a tree of small size, with erect and thinly populated branches, smooth bark, and shows great vigor in closing 
wounds made by the pruning knife. It both ripens early and resists cold. The tree bears fruit at an early age and in great quantity, and gives a good quality of oil, but it needs water fertilizers and a loose, rich soil in order to get the best result from it.

The Verdatier or Verdava, Verdal of Bezier, Verdava of Montpellier, Olea verdala of Gouan, L'olea media rotunda verdior of Tournifort, Verdajo of Tablada;

\section{Similar to Leccino.}

Tablada says of this olive that in Spain it is generally used for pickling, but that it also gives a good oil and ripens early. It will resist even more cold than the Cornicabra, but is found in all parts of the country. It requires a fertile soil and good cultivation, lathough it will accommodate itself to less favorable circumstances, but remember, in return it will only produce accordingly. It will bear vigorous pruning.

\section{The Wild Olive. (See Plate II.)}

The wild olive has twigs very robust, very long, contorted, rigid, little ramified and with angle at insertion of about eighty degrees. The leaves are obovate and very wide in proportion to length, are pointed, extending in a spine shape. The lower side is not as white as in the cultivated varieties. Even on wood that is scarcely a year old, it buds abundantly. It retains an enormous quantity of fruit, which hangs in bunches of three, four and five berries and which cling with tenacity to the stem. The berries mature late, and when fully ripe are black, and winey black. They are small (about .315 of a gramme), rather round and sharp at free end. The fleshy part is so thin as to be more like a thin skin than real meat. On the other hand the stone is very large, the seed well developed and often double. It grows slowly and as regards the appearance of its branches, it has a spiney look and is wonderfully strong against vicissitudes of climate, and in size it only reaches the height of a 
shrub or small tree. It carries to completion a great number of berries. It is well worth using for grafting and counts various varieties dependent on climate and soil.

\section{COMPARISONS.}

First-Form-(putting aside height).

The Razzo and Grossajo are most similar to each other.

The Leccino most like the wild tree.

Second-Form, size, fleshiness of berry.

The Razzo resembles the Morajolo.

The Grossajo " " " "Leccino.

The Mignolo " " " Wild Olive.

Third-Shape of olive and its appearance.

The Trillo resembles the Puntarolo.

CONCLUSIONS.

Olives are better described by the characteristics of the tree than by the form or size of the fruit. Note how very much alike in this respect are the Grossajo and the Leccino. Pendoulier and Terdale, Cornicabra and Verdejo and how far apart they rank in rusticity, stature and oiliness. Looking at the form of the nut we find that it follows invariably that of the olive. Whence it appears not to be true as has been heretofore believed, that the berries which are roundish and enlarged at the extremity vary in form from the nut and are therefore more fleshy and oily than the pointed ones. Greater fleshiness only can increase the oiliness of the fruit and this is entirely independent of the shape it may assume. In truth the richest in oil are the olives of Group I, or the oil press olives, which resemble in form the Morajolo, the Mignolo and even the very wild olive, that is to say are pointed and not round. Hence we are led to believe,

First-That the greater the rusticity of the tree, the less the ramification of the branches and the greater the persistency of the berries. 
Second-That the form of the nut always follows that of the berry.

Third-That the form and size of the berry and nut has no influence on the quantity of oil.

Fourth - That the least fallacious indication of oiliness resides in the thickness and weight of the mesocarp.

The olives discussed are valuable for seed in the following order:

Wild, Group IV, Wild olive.

Trillo,

$\left.\begin{array}{l}\text { Puntarolo, } \\ \text { Leccino, } \\ \text { Mignolo, }\end{array}\right\}$ Group III, Seedlings.

Morajolo, Group II, Middle class.

$\left.\begin{array}{l}\text { Grossajo, } \\ \text { Razzo, }\end{array}\right\}$ Group I, Oil press olives.

The berries most abundant in oil are as follows in order of merit:

Razzo, Grossajo, Morajolo, Mignolo, Leccino and others of the seedlings.

The California Mission olive is known to contain some inferior varieties, but the writer, at this period, is unable to specify them. On the Quito Farm the Cornicabra largely predominates over all others.

CLIMATE.

"Aut praefervidum aut gelidum statum coeli patitur."

Columella

The olive requires a moderate climate, it cannot flourish in or endure extreme heat or great cold. Its zone of cultivation lies between forty-five and eighteen degrees north latitude, and a corresponding belt in the Southern Hemisphere, outside of either of these extremes the tree may possibly live, but will refuse to give any fruit. Indeed, south of eighteen degrees in north Africa it attains a luxurious growth, but only fruits where it enjoys the caressing

* "Nor burning heat nor icy cold endures the olive." 
breeze from the Mediterranean Sea. For successful cultiration the rearly mean temperatures should not be less than 57 degrees Fahrenheit. As to locality where olive culture is possible and practicable. Five hundred and eighty-eight feet of elevation represent one degree of latitude, so Colfax with an elevation of 2421 feet abore the level of the sea and standing nearly on the thirty-ninth parallel of latitude must be debited with a little more than four degrees, which would bring it up to between forty three and forty four degrees, showing that Colfax and places of similar elevation and latitude nearly touch the northern limit of the olive in California. To cultivate it successfully further north a lower situation must be sought. Hence the further south the point of cultiration the greater may be the eleration. In the Sierra Nevada mountains, in Grenada, Spain, in latitude thirty-seren degrees, the olive flourishes at a height of three thousand feet. In Algiers, North Africa, in about latitude thirty-five in the Atlas range, it is found at a height of forty-eight hundred feet.

In Catania, Italy, it is successfully grown at an elevation of three thousand one hundred feet. The olive dearly loves a breeze, not simply air and rentilation but a veritable soft wind. This is therefore necessary to its well doing, especially at the flowering season. A still, intense heat may be fatal to the promise of a crop by burning off the blossoms; for this reason and also to escape humidity it forsakes the plain and seeks the middle hills. The olive aroids the arid tops of wind strept heights but its home is the half hill. Foliow a line of olive trees up a steep and it will be noticeable that those nearest the top are found to be stunted and lacking soil about the roots, the earth haring been carried down the slope by rains and the trees are visibly affected by their situation.

Within the olive zone there undoubtedly are many points where the tree will not thrive because it is exposed to too great cold which must be fatal to it-say anything below fourteen degrees-or, if the heat be too great it eraporates the sap and thus prevents nutrition. 
To temper too warm a climate water seems to be resorted to. In the Island of Candia in the Mediterranean on the thirty-fourth parallel the olives fruit regularly when watered, if they receive no water it is quite doubtful if the flowers set or not. In Athens, Greece, if they are not irrigated their yield is very uncertain. In Africaboth in Moroceo and Algiers-in order to secure a crop it becomes absolutely necessary to give them water. In Valencia and Murcia, Spain, it is the usual practice to water the olive, and indeed with a loose soil and dry climate the irrigated trees respond with the surest crop. But the soil, the climate and the exposure must be the guide and indicate the necessity. Owing to the extreme dryness of the California summer, it is possible it may become needful in certain localities to irrigate the orchard in order to insure a crop. To deal with sections where there are apt to be cold snaps, the only remedy is to chose those varieties more nearly resembling the wild type which are hardier and better able to resist low temperature. The smaller the tree and the closer to the ground it grows naturally, the more likely it is to be damaged by a frost. On the Quito farm the late cold weather: did absolutely no harm although there were trees on the place of not more than three years of age, and the mercury touched sixteen degrees above zero. Even a higher temperature than this has been fatal to olive trees, but that has been the result of a sudden thawing after a cold night. Anything lower than fourteen degrees of cold is too chilling for the olive to endure; such weather not only will kill the leaves and branches, but even the wood itself will succumb. The olive is not so hardy as the grapevine, the latter requiring only ten thousand eight hundred degrees Fahrenheit to ripen its fruit, whereas the olive needs twelve thousand seven hundred degrees, although some varieties will ripen with ten thousand eight hundred degrees, from blossoming time to maturity, among which is the Spanish Manzanillo. To ascertain whether any particular locality in California is suitable for olive 
growing, first consult the thermometer. A mean temperature of sixty-one degrees Fahrenheit, from the first of March to the end of December inclusive, will be sufficient guarantee; or this same mean, from the beginning of the flowering period-say May twentieth to the end of December-will ripen the berries. Where the summer heat is greater the fruit will ripen earlier.

The olive begins to move in March at a temperature of fifty-two degrees, it buds at fifty-nine degrees and flowers at sixty-seven degrees. The blossoms set at a temperature of seventy-one degrees of heat, and to ripen the fruit a minimum of eighteen thousand five hundred degrees of heat is necessary, dating from the period in March when it first began to move. A good general rule to rely upon would be, that where one can obtain a mean temperature for spring of fifty-six degrees; for summer, of seventy degrees; for autumn, of fifty-eight degrees and in winter a minimum of twenty degrees the olive can always be successfully cultivated; bearing in mind, however, that some varieties require more heat than others and that peculiarities in the atmosphere or the soil may make it impossible to grow the olive even with this temperature. To obtain the mean temperature with the necessary exactitude requires careful observation at least three times a day, and a minimum thermometer to show the lowest temperatures during the night and early morning is imperative. A recent invention, however, has simplified this labor very much; it is known as Drapers' Recording Thermometer, and consists of a dial, driven by clock work, which makes a complete revolution in one week and as it revolves under a pen attached to the thermometer proper a curved line in red ink is drawn on the face of the dial, which shows by lines thereon the exact temperature of the air at every hour during the day and night. The only attention this machine requires is to change the dial once a week, to wind the clock at the same time, and to feed the pen with a few drops of prepared ink. The weekly record dial is then filed away, and thus 
with very little trouble the most exact data is obtained for the guidance of the orchardist.

The following tables are intended to show the latitude and degrees of heat required for ripening the olive. In Spain it will be noticed that the temperature averages very high, with the usual result of producing rather too gross an oil.

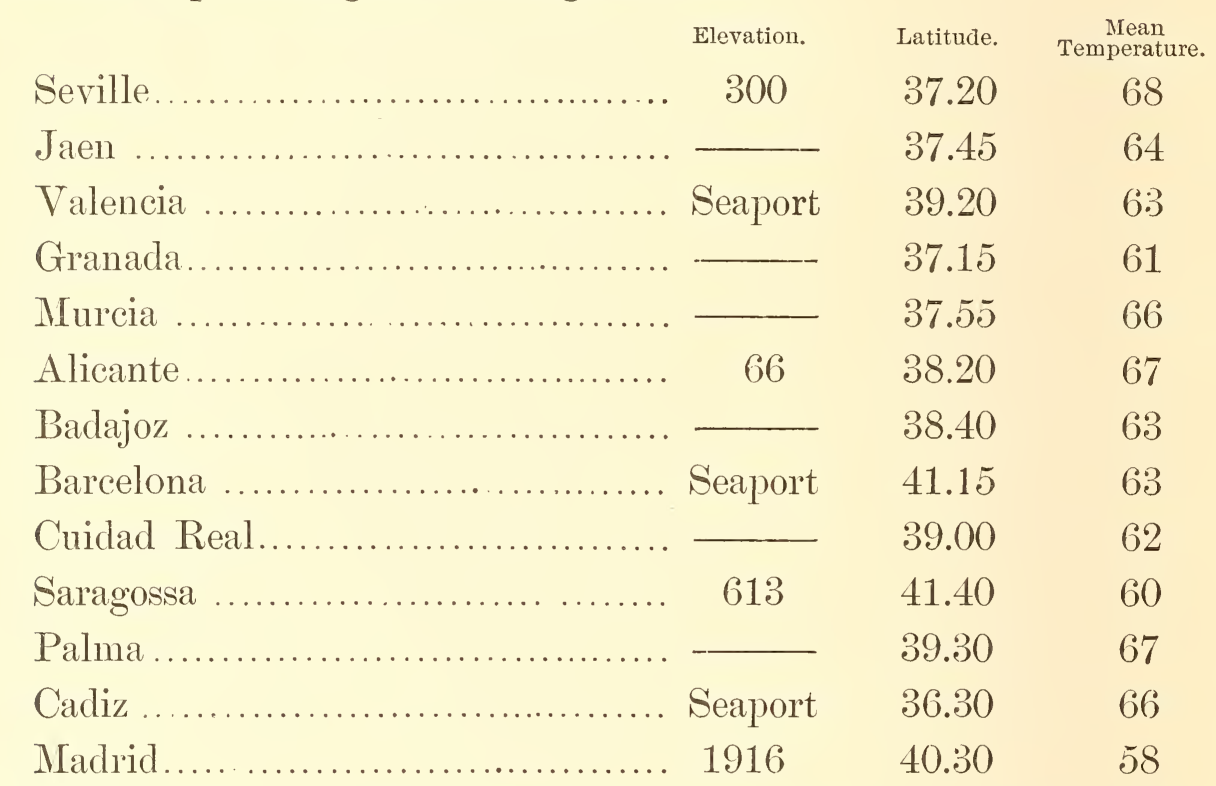

The data from Italy is much more exact, as seen in the following tables on pages 41 and 42. These may be constructed for any locality in California by first ascertaining the mean temperature each month and multiplying it by the number of days in said month. It will be noticed that the temperature of San Jose very nearly approaches that of Florence. 


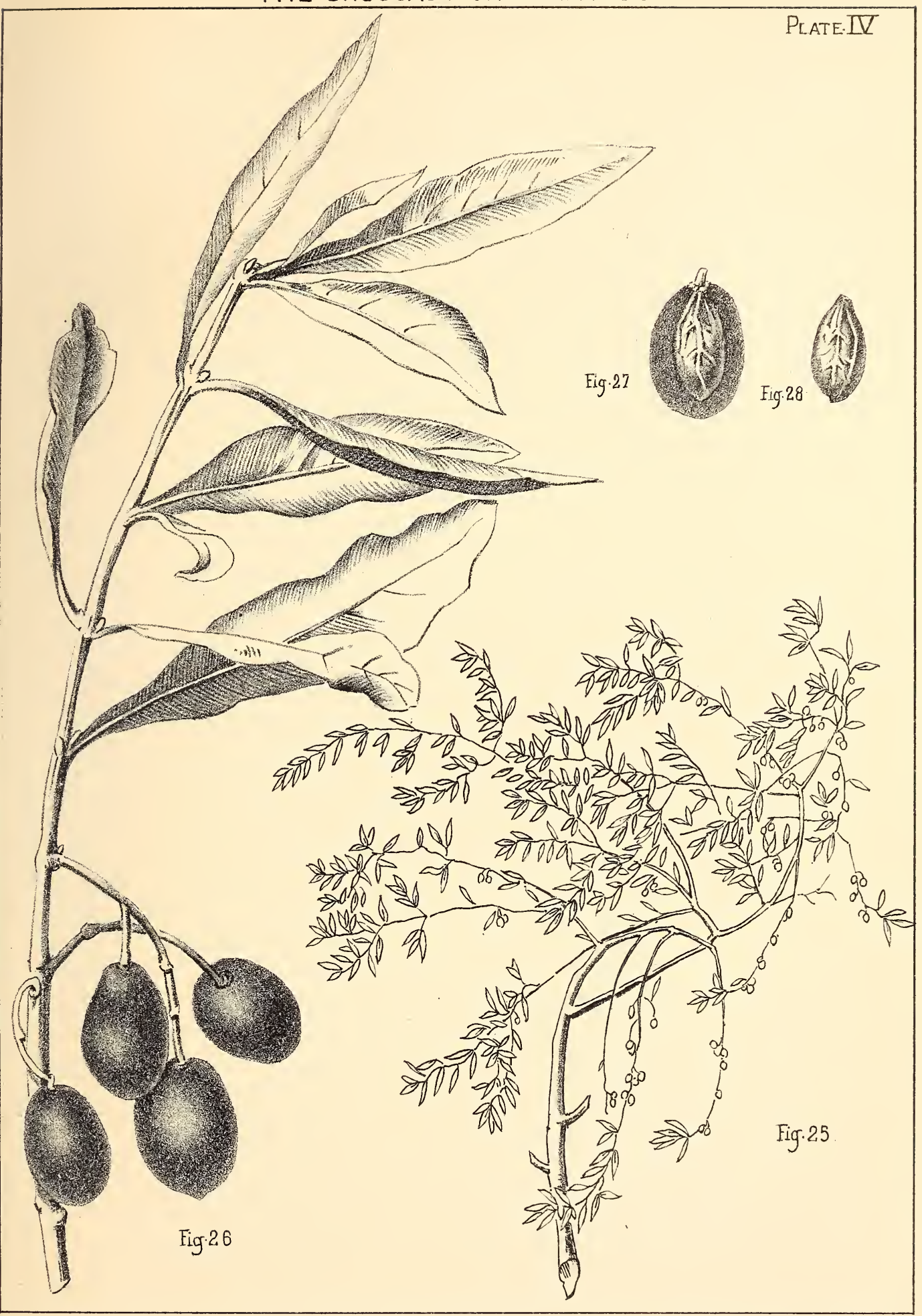




\section{PLATE IV.-THE GROSSAJO OR FRANTOJO.}

Fig. 25. Branch of the Grossajo or Frantojo showing its appearance, (reduced.)

Fig. 26. Twig with olives, (natural size.)

Fig. 27. Longitudinal section showing mesocarp, (natural size.) Fig. 28. Form of nut, (natural size.) 


\begin{tabular}{|c|c|c|}
\hline & 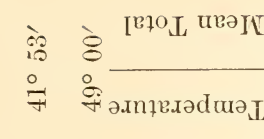 & 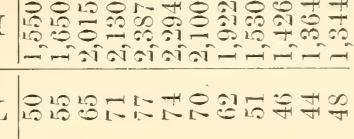 \\
\hline 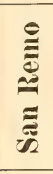 & 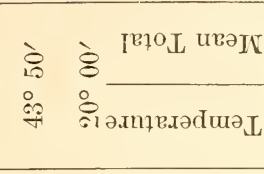 & 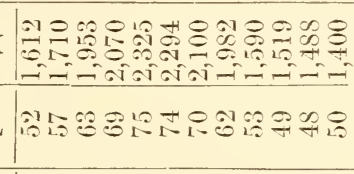 \\
\hline 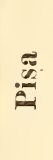 & 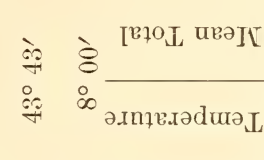 & 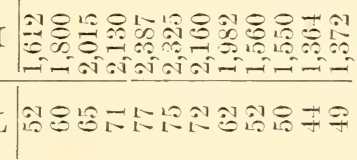 \\
\hline 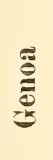 & 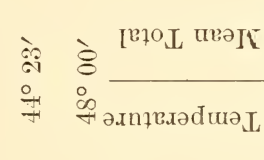 & 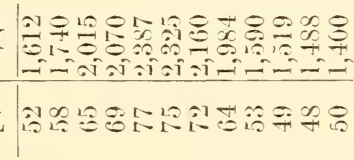 \\
\hline 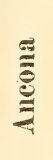 & 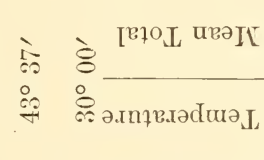 & 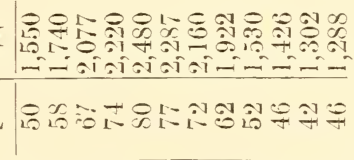 \\
\hline 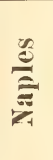 & 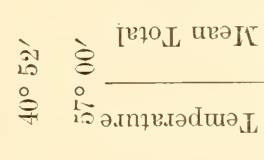 & 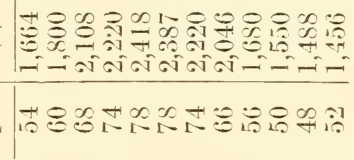 \\
\hline 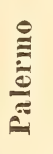 & 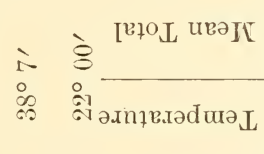 & 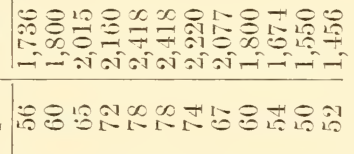 \\
\hline 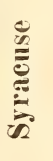 & 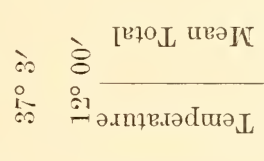 & 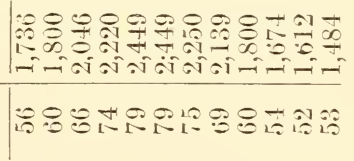 \\
\hline 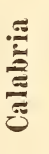 & 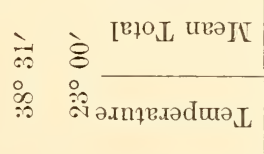 & 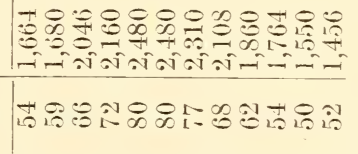 \\
\hline & 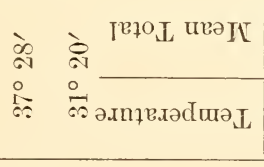 & 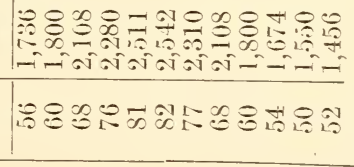 \\
\hline $\begin{array}{l}\text { 国 } \\
\stackrel{4}{3} \\
=\end{array}$ & 总兽 & : \\
\hline
\end{tabular}




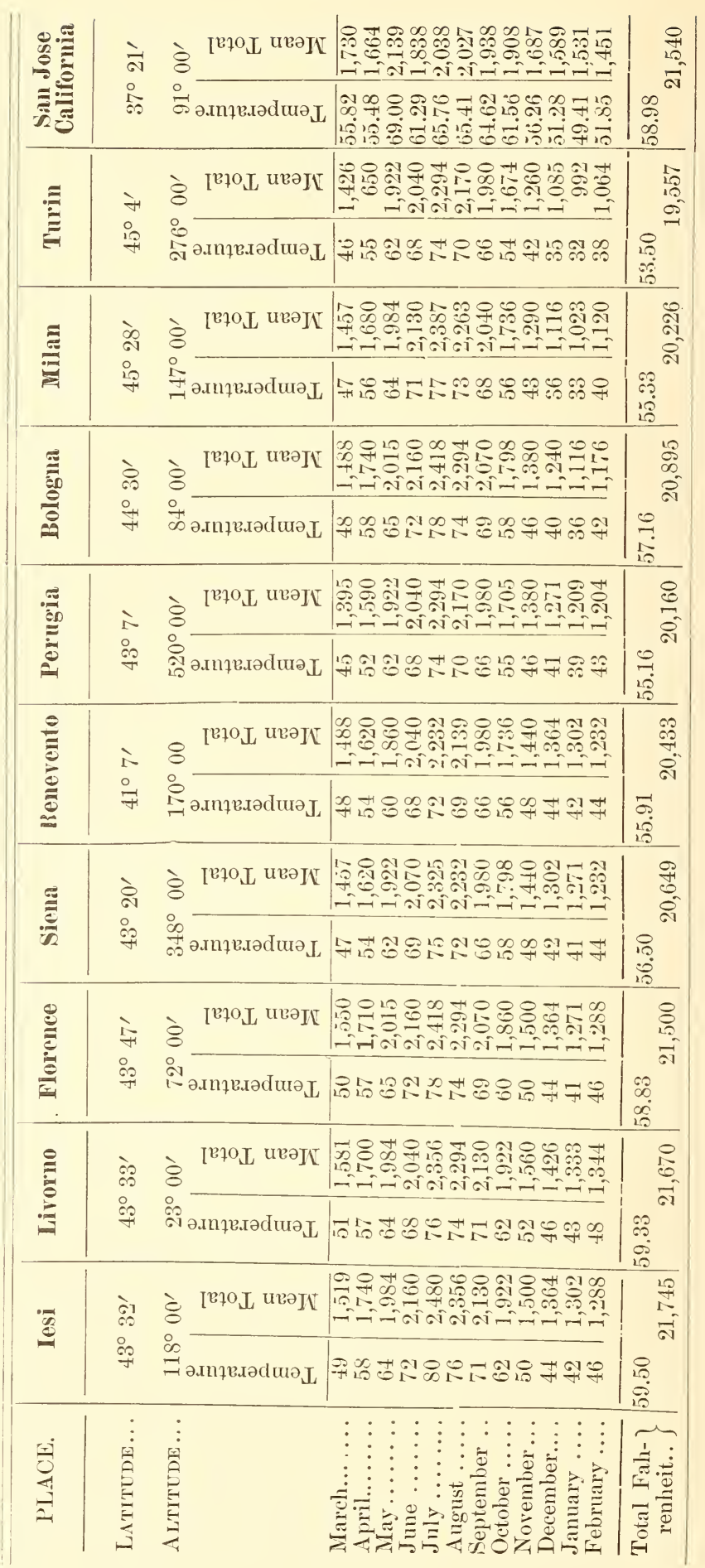


Wherever eighteen thousand five hundred degrees can be accumulated before frost the olive will ripen, so that if this number of degrees is shown by October in any certain locality, then the olive will ripen there in that month; but in others, where frost intervenes, the olives must be left hanging on the trees for a longer period. This, however, should not extend beyond the end of February, as a later date than this is prejudicial to the welfare of the trees. The lesson derived from these tables seems to be that where the sum total of degrees for the year does not reach twenty-one thousand degrees Fahrenheit, the olive fails to ripen; this we see in the following table, is the case in Sienna, Benerento, Perugia, Bologna, Milan and Turin, and also that this is the fact where the temperature falls below fifty in Norember. Thether this will prove to be as true in California as in Italy experience alone can determine.

The following table on page 44 is presented in centigrade degrees, as in Fahrenheit it would fail to indicate the object intended, which is the exact period when the olive ripens. The reason of this is, that in Fahrenheit thirty-two degrees of cold are always included which are unnecessary and confusing in deciding the period when the olive ripens, as only degrees of heat are needed. This period is reckoned beginning from the first of June up to such a date as shall give three thousand nine hundred and eighty-two degrees of heat, which is the amount necessary to ripen the olive. As soon as this number of degrees is reached, even though it be the first of October, there the olive will ripen at that time. To change a daily or arerage temperature Fahrenheit to Centigrade subtract $32^{\circ}$ and divide by 1.8, the result will be Centigrade degrees; thus $52^{\circ}$ Fahrenheit- ${ }_{1.8}^{520}=11.11^{\circ}$ Centigrade.

To change Centigrade to Fahrenheit multiply degrees of Centigrade by 1.8 add $32^{\circ}$ and the result will be degrees Fahrenheit. Thus $20^{\circ}$ Centigrade 20x1.8+32=68 Fahrenheit. 


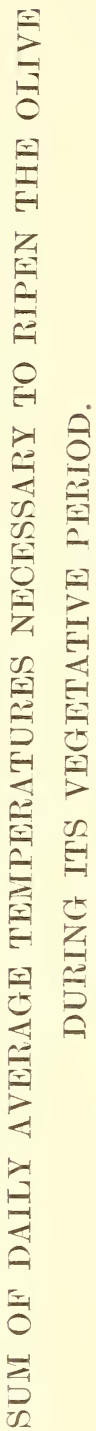

\begin{tabular}{|c|c|c|c|c|c|c|c|c|c|}
\hline 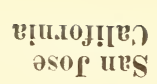 & $\begin{array}{l}-18 \\
0=5\end{array}$ & 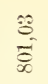 & 商 & 然 & $\begin{array}{l}\stackrel{\Sigma}{\infty} \\
\underset{\infty}{\simeq}\end{array}$ & 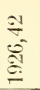 & & & \\
\hline "!̣.ı $\|_{\mathbf{L}}$ & $\begin{array}{l}-8 \\
0.8 \\
0.90\end{array}$ & $\frac{20}{\frac{20}{6}}$ & 商 & 要 & : & Ê & 兹 & & \\
\hline แช'I!IT & 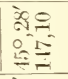 & $\overline{8}$ & $\frac{12}{20}$ & 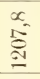 & $\frac{0}{0}$ & 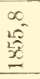 & 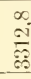 & & \\
\hline หนธิอ[ดด & 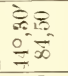 & $\stackrel{\infty}{E}$ & $\frac{0}{0}$ & 8 & : & बी & 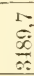 & & \\
\hline 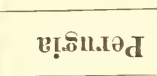 & 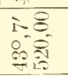 & E⿱ & 要 & 离 & 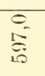 & 趈 & & 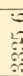 & $=$ \\
\hline оұนәАәШәЯ & 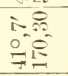 & $\bar{B}$ & S. & $\stackrel{\overline{x^{-}}}{\stackrel{P}{=}}$ & 总 & 告 & & & 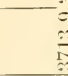 \\
\hline ษแว!S & 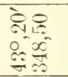 & $=$ & $\frac{0}{5}$ & 8 & $\frac{0}{0}$ & $\begin{array}{l}0 \\
0 \\
0 \\
0 \\
5\end{array}$ & & & 西 \\
\hline әə亡ә.І0 [А & $\begin{array}{l}i-8 \\
\text { ins } \\
\text { min }\end{array}$ & $\stackrel{\infty}{\stackrel{i}{i}}$ & 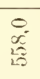 & $\begin{array}{l}x \\
x \\
\text { on } \\
\text { s. }\end{array}$ & 尊 & $\begin{array}{l}x \\
\bar{\sigma} \\
\bar{\sigma}\end{array}$ & & & 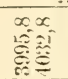 \\
\hline
\end{tabular}

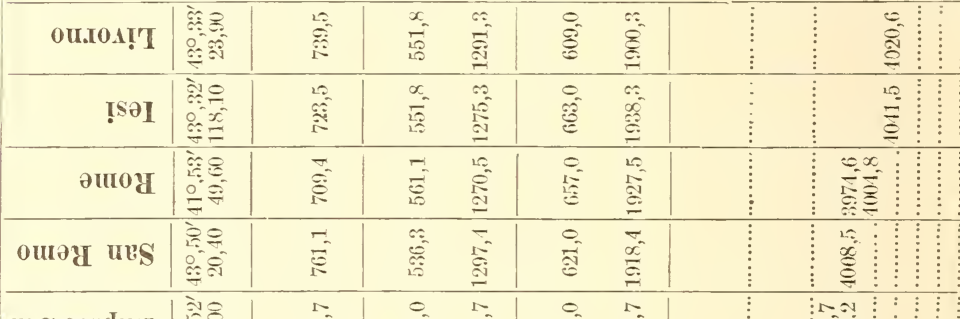

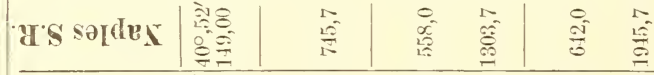

\begin{tabular}{|c|c|c|c|c|c|}
\hline us!d & $\begin{array}{l}m \\
0\end{array}$ & $\overrightarrow{\underline{N}}$ & $\begin{array}{c}3 \\
3\end{array}$ & 疍 & i. \\
\hline
\end{tabular}

\begin{tabular}{|c|c|c|c|c|c|}
\hline иопे! & 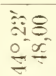 & 总 & $\begin{array}{l}0 \\
0 \\
0 \\
0 \\
0\end{array}$ & $=$ & ì \\
\hline
\end{tabular}

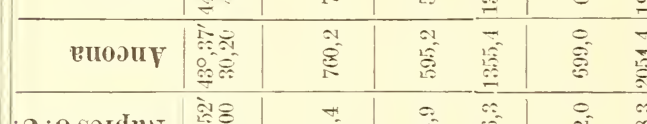

\begin{tabular}{|c|c|c|c|c|c|}
\hline$\cdot 0$ solde & 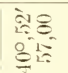 & $\frac{\vec{\sigma}}{\infty}$ & 8 & 突 & î̀ \\
\hline
\end{tabular}

\begin{tabular}{|c|c|c|c|c|c|}
\hline 0UI.IJ['] & 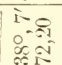 & $=$ & $=$ & $\stackrel{0}{\stackrel{0}{*}}$ & $\begin{array}{l}10 \\
\stackrel{0}{0} \\
\stackrel{0}{0}\end{array}$ \\
\hline 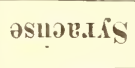 & 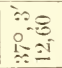 & $\therefore$ & $\begin{array}{l}0 \\
\substack{\infty \\
01 \\
10}\end{array}$ & 앙 & 第 \\
\hline 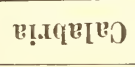 & 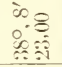 & 宓 & 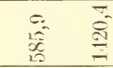 & $\begin{array}{c}0 \\
1=0 \\
0\end{array}$ & 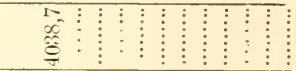 \\
\hline 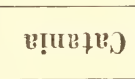 & $\begin{array}{l}0 \\
0 \\
0\end{array}$ & 店 & $\begin{array}{ll}a & a \\
0 & 10 \\
0 & 0\end{array}$ & 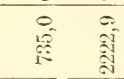 & 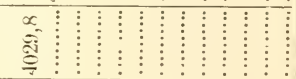 \\
\hline 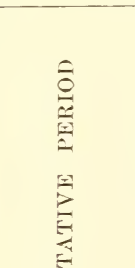 & 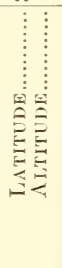 & 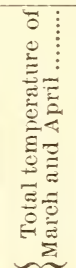 & 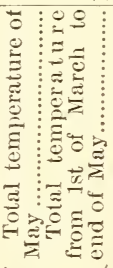 & 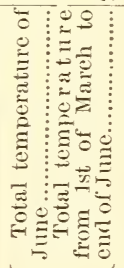 & 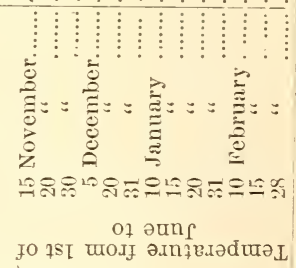 \\
\hline$\frac{1}{5}$ & & 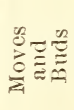 & 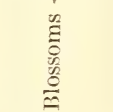 & 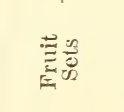 & $\cdot \quad \frac{\vec{z}}{\stackrel{3}{\Xi}}$ \\
\hline
\end{tabular}


The following incomplete list of cities and towns in California and ricinity shows by their temperature that with few exceptions the olive will flourish throughout the length and breadth of the State.

TABLE OF MAXIIUM, MINIMUM AND IIEAN ANNUAL TEMPERATURE, WITH LATITUDE AND ALTITUDE OF POINTS OF INTEREST IN CALIFORNIA.

\begin{tabular}{|c|c|c|c|c|c|}
\hline LOCATION. & LAT. & ALT. & $\begin{array}{l}\text { A VER. } \\
\text { MAX. }\end{array}$ & $\begin{array}{l}\text { AVER. } \\
\text { MIs. }\end{array}$ & MEAX. \\
\hline 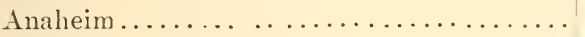 & 33.51 & 133 & 92. & 50 . & 67. \\
\hline 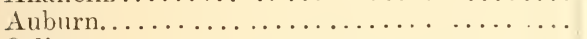 & 38.57 & 1,360 & 83. & 39. & 58. \\
\hline 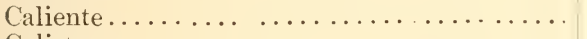 & 35.17 & $1,2.90$ & 83. & 4.5. & 64. \\
\hline 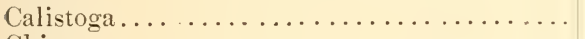 & 38.38 & 363 & 86. & 36. & 59. \\
\hline 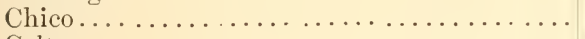 & 39.44 & 193 & 88.42 & 46.08 & 65. \\
\hline 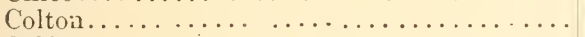 & 34.02 & 965 & 89.42 & 41.66 & 62.08 \\
\hline 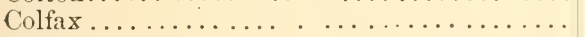 & 39.08 & 2,422 & 85.42 & 41.50 & 56.91 \\
\hline 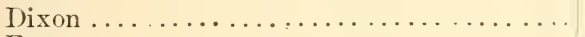 & 36.00 & 25 & $\$ 1$. & 44.92 & 60. \\
\hline Fresno.... . . . . . . . . . . . . . & 36.45 & 292 & 90.12 & $4 \tilde{5}$ & 64.34 \\
\hline Galt $\ldots \ldots \ldots \ldots \ldots \ldots \ldots \ldots \ldots$ & 38.18 & 50 & 88. & 43. & 62. \\
\hline $\begin{array}{l}\text { Gersers } \ldots \ldots \ldots \ldots \ldots \ldots \ldots \ldots \ldots \\
\text { Gilror } \ldots \ldots \ldots \ldots \ldots \ldots \ldots \ldots \ldots\end{array}$ & $\begin{array}{l}35.49 \\
36.59\end{array}$ & $\ddot{193}$ & si. & $\ddot{3 S}$ & $\ddot{3}$ \\
\hline 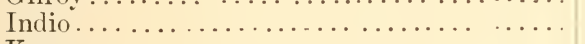 & 33.46 & 20 & 100 & 50. & 73. \\
\hline 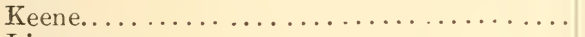 & 35.12 & $2,70 . \overline{3}$ & $\$ 1$. & 32. & 54. \\
\hline Lirermore....................... & 37.42 & 485 & 88. & 39. & 58. \\
\hline 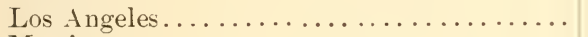 & 34.03 & 293 & 89.67 & 51. & 64.75 \\
\hline 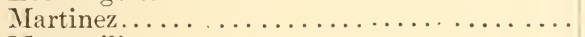 & 38.02 & 10 & 76. & 42. & 56. \\
\hline 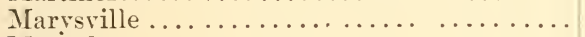 & 39.10 & 66 & 88.17 & 12.75 & 63.58 \\
\hline 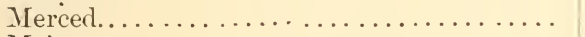 & 37.20 & 171 & 89. & 41. & 63. \\
\hline 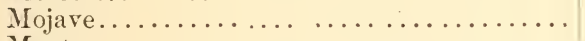 & 35.02 & 2,751 & 87. & 47. & 63. \\
\hline 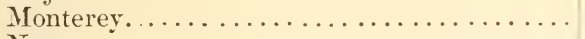 & 36.37 & 5 & 78.50 & 42.83 & 57.40 \\
\hline 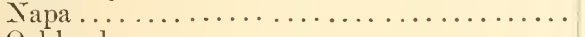 & 38.21 & 20 & 87.58 & 37.50 & 59.19 \\
\hline 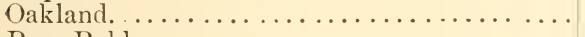 & 37.49 & 12 & 69.33 & 42.58 & 54.75 \\
\hline Paso Robles ........................ & 35.35 & & & & 56. \\
\hline 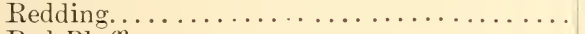 & 40.37 & $5 \overline{7}$ & 86.33 & 43.16 & 61.58 \\
\hline 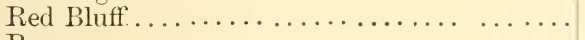 & 39.08 & 308 & 90.50 & 45.67 & 64. \\
\hline 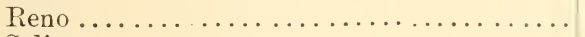 & 39.31 & $4, \pm 97$ & 72 & 32. & 49. \\
\hline 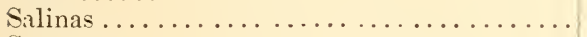 & 36.41 & 44 & 75. & 42. & 56. \\
\hline 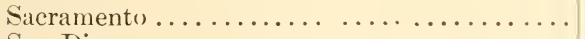 & 38.36 & 30 & 80.58 & 44.92 & 60.33 \\
\hline 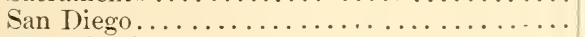 & 32.45 & $\ldots$ & 82.83 & 47.50 & 61. \\
\hline 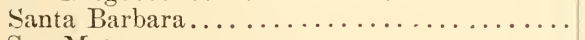 & 34.26 & 30 & $\$ 1$. & 46.18 & 60. \\
\hline 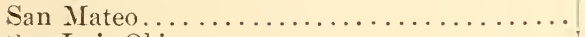 & $37.3 \pm$ & 22 & 78. & 44. & 54. \\
\hline 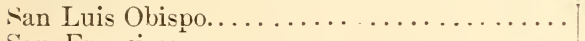 & 35.18 & $\cdots \cdots$ & $\cdots$ & & 56.96 \\
\hline 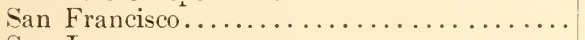 & 37.48 & . . . & 76.25 & 42.33 & 5.23 \\
\hline 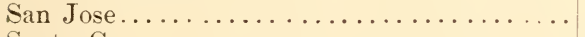 & 37.21 & 91 & 83.08 & 39.83 & 56.75 \\
\hline 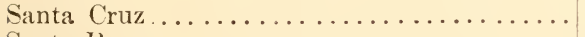 & 36.58 & 18 & 82.67 & $42.4^{\circ}$ & 58.09 \\
\hline 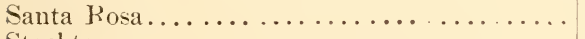 & 37.00 & 20 & 8.5. & 30. & $\bar{i}$. \\
\hline 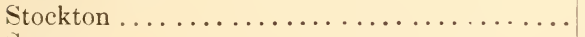 & 37.58 & 23 & 79.50 & \pm 1.50 & 58. \\
\hline 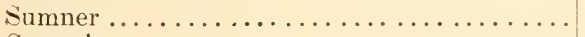 & 35.24 & 415 & 89. & 43. & 64. \\
\hline 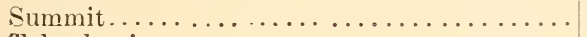 & 39.20 & 7,017 & 58.17 & $\stackrel{21}{.}$ & $40.66^{\circ}$ \\
\hline 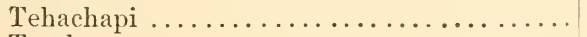 & 35.06 & 3,964 & 78 & 32 & 50. \\
\hline 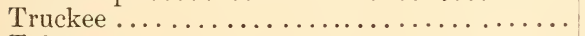 & 39.20 & 5,819 & 68.83 & 21.25 & 43. \\
\hline$\ldots \ldots \ldots \ldots \ldots \ldots$ & 36.13 & 252 & 87. & 4e. & 64. \\
\hline 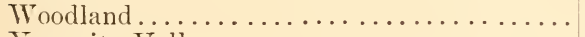 & 38.41 & 63 & 86. & 49. & 61. \\
\hline 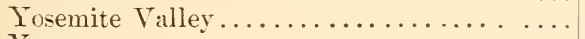 & $37.4^{7}$ & 1 & & & \\
\hline 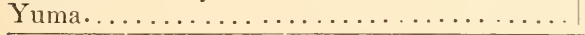 & 32.44 & 140 & 93. & 58. & it. \\
\hline
\end{tabular}




\section{EXPOSURE.}

The situation suitable for the olive in one locality, will not always answer in another. A southerly exposure, where there is a good, free circulation of air, is generally the most desirable, especially as one goes northward. In any latitude, a southern exposure, is best calculated to receive the sunshine from early sunrise to sunset. It receives all there is to give. A northerly exposure receives the sun's rays obliquely, and then only after it has risen high in the heavens; and so, as the sum total of heat is less, the fruit ripens late, and in some cases not at all. An easterly exposure has the full force of the sun all the morning, but after noon, there is either no sunshine, or feeble, slanting rays, so that at the very time when the sunlight is strongest, an easterly position is deprived of its warmth altogether. Of course a westerly exposure is just the reverse of this, and after a morning passed in the shade, the tree is suddenly overwhelmed with sunlight at a time of day when the temperature is the highest. In summer, the variations of temperature in half an hour's time, may be from sixty to ninety-eight degrees. This suddeu change is as harmful to plants as to animals. The more perpendicular the sun's rays are, naturally, the more heat they give; so also the farther north one goes, the more oblique they become and lessen in warmth. Therefore the higher the latitude, the greater the necessity of a hillside to receive the sun perpendicularly. A well-protected situation, with a southern exposure, may be considered equal to a point one degree farther south. The influence of a protection, be it a mountain range, a fence, or a hedge, is felt for a distance equal to eleven times its height, but at the point where the protecting influence is lost, the wind has greater power than if the shelter did not exist. Strong and impetuous winds injure the olive, especially sea winds, on account of their vapor and saline properties. 


\section{@oil}

\section{CHAPTER IV.}

"Cet arbre vient sur tous les terraius."

"And first for heath and barren hilly ground,

Gasparin.

Where meagre clay and flinty stones abound;

Where the poor soil all succor seems to want,

Yet this suffices the Palladian plant.

Undoubted signs of such a soil are found,

For here wild olive shoots o'erspread the ground

And heaps of berries strew the fields around."

VIRGIL GEORGICS II. 249.

The olive will live in almost any soil except a dry and compact, or a humid one. An analysis of the ashes of the wood, leaves, and fruit of this tree give the following result:

\begin{tabular}{|c|c|c|c|}
\hline & WOOD. & IEATES. & FRUIT. \\
\hline Potash. & 20.60 & 24.81 & 53.03 \\
\hline Lime...... & 63.02 & 56.18 & 15.72 \\
\hline Magnesia........ & 2.31 & 5.18 & 4.38 \\
\hline Sulphuric Acid. & 3.09 & 3.01 & 1.19 \\
\hline Silicate............. & 3.82 & 3.75 & 5.58 \\
\hline Phosphoric Acid...... & 4.77 & 3.24 & 7.30 \\
\hline Phosphate of Iron ............................... & 1.39 & 1.07 & 2.24 \\
\hline \multirow[t]{2}{*}{ Chloride of Potassum......................... } & 1.00 & 2.76 & 9.56 \\
\hline & 100.00 & 100.00 & 100.00 \\
\hline
\end{tabular}

The berry, and especially the meaty part, contains a very large proportion of potash, while the wood and the leares abound in lime. This is an important fact. The deduction from it is that a soil, rich in these ingredients, possesses all the conditions necessary for 
the complete development of the plant, and the abundant production of the best quality of fruit. Hence, it is safe to assume, that the olive prefer's a soft, friable, moderately cool soil, and one rich in lime and potash; a permeable soil, such as a limey clay of medium consistency, not inclined to either dryness or humidity. The roots would then encounter no obstacle in extending themselves, and the air and moisture could circulate sufficently. Lime, abounding phosphates, magnesia, with an abundance of silicates of alum and mercury, and a sufficiency of potash and soda, are the chemical and physical requisites which this tree will find most advantageous to its development, and cause it to produce abundantly, and, prorided other circumstances are equal, give the very best oil. It is seen that the olive will flourish wherever its roots will penetrate easily, and there is no deficiency of lime and alkali, such as a loose soil of rocky clay, or sand of rolcanic or granite formation. But, while the olive will subsist on many different soils, and prosper in several, it is not to be concluded that it may be condemned to bare, sterile, impoverished ground, where not eren a forest tree would be nourished.

The latitude must largely guide one in selecting the kind of soil for an olive orchard.

In Andalucia and Valencia, in southern Spain, the mean summer temperature is as high as eighty-two degrees. There, they hold red soils in rery low estimation, and prefer the light colored or white; considering that the red attracts too much heat, and requires too much fertilization and irrigation, without which the tree gives no fruit in that latitude. There, a rery porous soil, giving free passage to moisture, and eraporating freely, requires repeated fertilizing: and watering. Going north in central Spain, the light red soil with a porous tendency to carry off the frequent rains, is preferred, and the white is altogether condemned. Still further north, the dark red and very porous soils are exclusively used. The calcareous soils, through their action on the natural and artificial fertilizers, quickly put into circulation the elements of nutrition of the 
THE MORAJOLO OR MORINELLO.

Plate $\bar{Z}$

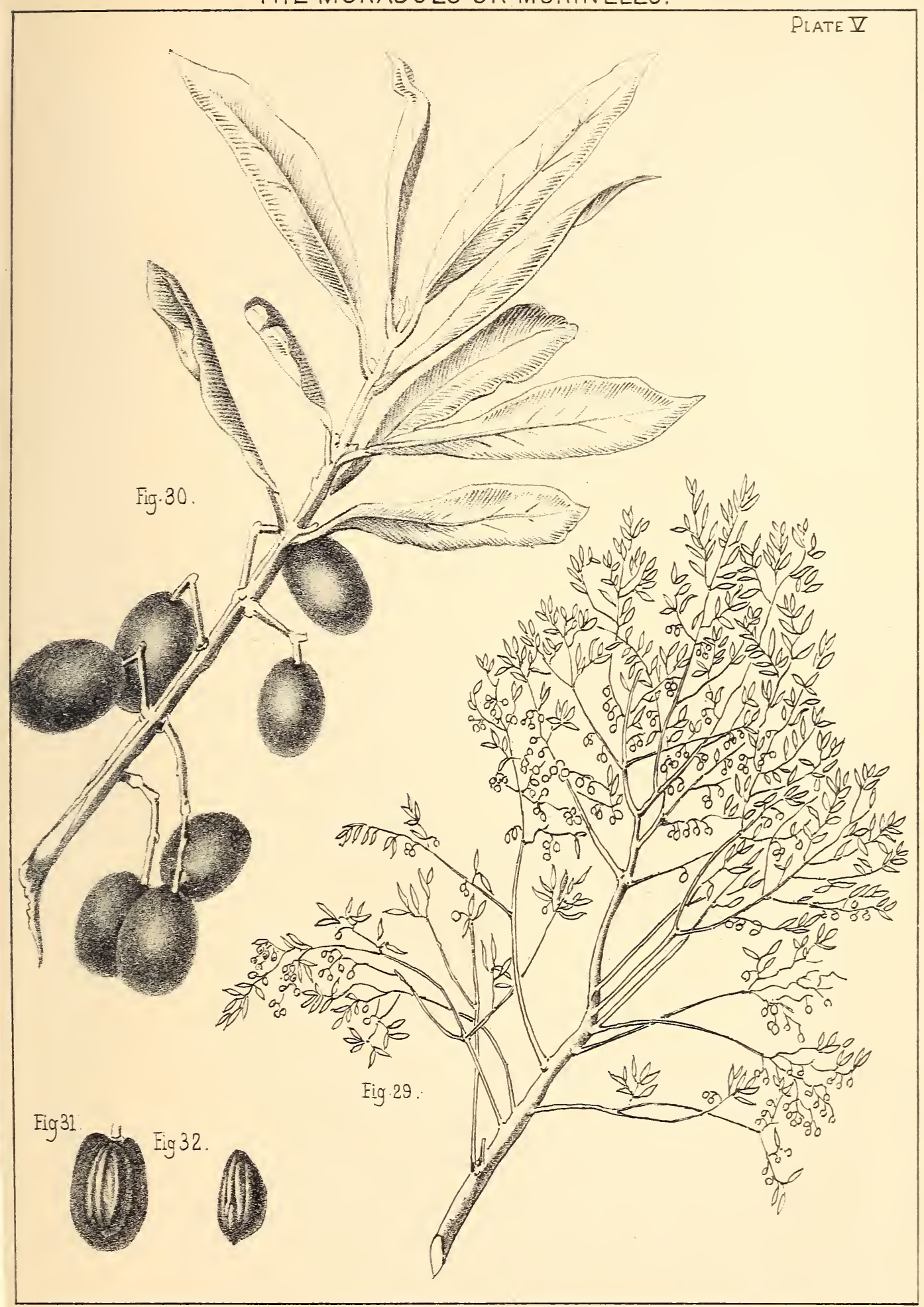




\section{PLATE V.-THE MIORAJOLO OR MORINELLO.}

Fig. 29. Branch of the Morajolo or Morinello showing its appearance, (reduced.)

Fig. 30. Twig with olives, (natural size.)

Fig. 31. Longitudinal section of berry showing mesocarp, (natural size.)

Fig. 32. Form of nut, (natural size.) 
olive, and so promote its growth; but for this very reason require that the trees should be frequently manured in order to obtain an annual product. It is the want of nourishment in the ground, that causes the olive to fruit only every other year, or every third year.

An irrigated soil loses its fertility quicker than one that is not watered; so, where irrigation is practiced, it is necessary to frequently manure. In general, it may be said that the olive requires the same kind of soil as the vine, and in proof of that we often see them grown together. Excessive moisture is prejudicial, and also in a dry, hard soil the tree contracts, splits, and leaves the roots gorged with sap. The most favorable soil is an open, loose and fairly fertile one, and should be of at least a yard in depth to give the roots opportunity to extend themselves.

The olive is fond of a chalky soil, that is, one largely made up of lime carbonates. The carbonate of lime is indispensable to vegetable life; and it is noticed, that the oil from olives grown on a calcare. ous soil, is better than that from a soil lacking in this element. Chalky soils are cold, because they do not easily absorb the heat of the sun. For the same reason red soils are warm, absorbing and retaining a great degree of heat. The best soil for the olive is that in which lime predominates; and where silica exists, and there is no lack of clay. Such a soil would give passage to moisture, and offers no obstacle to the extension of the roots, and at the same time has consistency enough to sustain the tree and preserve the elements of nutrition. The oxide of iron exists in all soils, but where it abounds, the red color declares it. It is favorable to the growth of the olive, particularly in cold regions.

Suppose two adjacent pieces of ground in such a locality; on the red soil the olives will ripen, whereas on a light colored one they will not.

Liebig says, that when at the time of flowering of any regetable, the soil abounds in phosphates, the fruit sets well, and is started on its road with every advantage; and on the contrary, if these are lack- 
ing, the flowers fall off and the tree gives its strength to wood.

The hygroscopicity of a soil, or the property of retaining moisture, is of great value in a hot and dry country. It is well known that the more a soil is manured and cultivated, the more moisture it retains. The following table will show the percentage of water contained in different soils.

\section{Water contained in 100 parts}

Silicious sand .25

Gypsum .... .27

Calcareous sand. .29

Dry chalk .40

Chalk, somewhat more fertile...................... .50

Clay soil....................................... .60

Clay, pure. ....................................... 70

Calcareous soil..................................... .85

Manure................................................ 1.90

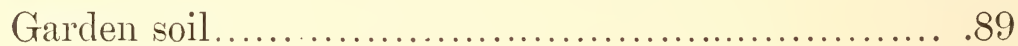

Arable land ............................................ .52

The capacity to absorb humidity from the atmosphere varies with different soils. The following are the results of experiments.

Absorbs in 24 hours.

Silicious sand .0 of water

Calcareous sand 1.5 " " "

Gypsum 0.5 " "

Dry chalk. 13.0 " "

Chalky earth. 15.0 " "

Clayey earth 18.0

Clay.... 21.0 "6 6

Fine calcareuos earth. 15.5 " " "

Magnesia 38.0 " "

Manure 48.5 " "

Garden earth. 22.5 " "

Ordinary earth. $11.0^{66} \quad 6$ 
Absorbtion is greater by night than by day, and recently cultivated ground is the most receptive, as it exposes the greater number of particles to the action of the air.

As the earth grows dry, its capacity to absorb moisture diminishes. So we observe that ground frequently and thoroughly cultivated retains moisture the longest.

THE DRYING QUALITY OF SOILS.

Silicious sand in four hours evaporates

Of 100 parts

of water

Calcareous " " " " "

88.4

Gypsum " " " " ، " ،

75.9

Dry chalk " " " " " " "

71.7

Earthy " " " " "

52.0

Clayey soil " " " " "

45.7

Clay " " " " " " "

34.6

31.9

Carbonate of lime in four hours evaporates $\quad 28.9$

Manure

20.5

Magnesia

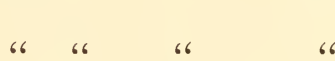

10.8

Garden earth " " " " " " " "

24.3

Arable hand

$6 \quad 66 \quad 6$

32.0

These figures indicate what we see in practice, that the more sandy the soil, the sooner it dries. Some soils when they dry, actually diminish in volume, and through splits and cracks expose the roots of the tree. Sandy, limey and gypsum soils do not have this drawback; the others vary in the following degrees.

Carbonate of lime soils loses

Of 1000 narts.

Dry chalk

50

Earthy “

Clayey soil

Clay

Magnesia

Manure

Garden earth 
Different soils retain heat in proportion to their weight; a pebbly soil retains heat longer than one of fine sand. Chalky and clay soils quickly lose heat; and, on this account, the former is called an early soil, and the latter a late one. The color of the soil has much to do with the absorbtion of heat. In any given earth there is a difference of fourteen degrees, Fahrenheit, between the extremes of color.

The ancients thought that the olive would not grow unless it had the sea air, and laid down the rule, that it should not be planted more than ninety miles inland. The Arabic and Latin authors follow the same recommendation; but it has been well established, that the olive can be grown at any distance inland, provided the soil and climate are agreeable to it. Pliny remarks, the olive of the low land is more liable to disease, than that grown on high ground. 


\title{
efertilization
}

\author{
CHAPTER V. \\ "Quite opposite to these are olives found, \\ No dressing they require and dread no wound; \\ No rakes nor harrows need, but fixed below, \\ Rejoice in open air, and unconcern'dly grow. \\ The soil itself due nourishment supplies; \\ Plough but the furrows and the fruits arise, \\ Content with small endeavors, till they spring, \\ Soft peace they figu re and sweet plenty bring. \\ Men olives plant, and hymns to Pallas sing."
}

Virgil, Georgics II, 586.

So says Virgil, seemingly indicating that the soil of Italy at that time was richer and stronger than at present., for later experience has overwhelmingly demonstrated that fertilization is indispensable to the olive.

The analysis of the wood, leaves, and fruit of the olive, given in the preceding chapter, is equally applicable when considering the proper methods of fertilization. Lime for wood and leaves, and potash for the berry, seems to be the lesson it teaches.

It is no more possible in olive cultivation, than in the growing of any other vegetable, to year after year draw certain ingredients from the soil, without ever returning them again, and expect the trees to keep on giving fruit without receiving the nutriment they crave.

Fertilization is indispensable to maintain the olive in a prosperous and fruitful condition. In rich soils it may for a certain time be omitted, but a continued neglect will diminish the productiveness; and fructification will become infrequent and unremunerative, in places where the tree is seldom or never fertilized. The lack of 
manure, is one of the causes of the plant becoming weak and sickly, and bearing heavily only at long intervals. To fertilize an olive tree well, it is sufficient to restore to the ground the refuse from the oil making and the ashes of the branches from pruning. The most valuable fertilizer, is the water pressed from the olive. It is heavily charged with vegetable matter, black in color, and should be collected in a vat at the time of oil making. 'To this should be added the pomace, after all the oil is extracted. To increase the quantity, and at the same time add to the richness of this manure, grind into the mass marine plants for their potash, or in the absence of these, ferns, rushes, cornstalks, wheat and barley, straw, dregs of pressed grapes, vine twigs, or broom corn. Good, but in a lesser degree, because poorer in mineral properties, are husks of decayed olives, scrapings from threshing floors and refuse of whatever nature. These ingredients are very advantageously mixed during fermentation. As each, or any of these materials are thrown in, add a layer of earth. Keep this receptacle covered till the rains are well over, and then let the summer sun have access to it and the fermentation be thorough. The water will now have precipitated all valuable matter, and if it exists in too great quantities, let some run off; but enough should always be left in the vat, to allow the mass to take up moisture in place of that which is given off in fermentation. Care should be taken to locate this putrifying mass at a distance to leeward of the dwellings, or sickness might easily result from it. By September it can be cut out with a spade, like peat, and will make the very best of fertilizers for the olive orchard. But this is a powerful agent and should never be applied to the trees until thoroughly fermented in the manner described. If used as manure without fermentation, or mixing with other ingredients, the result would be the roots would be burned and the trees killed. The writer has seen the branches on young trees wither and die from coming in contact with pieces of sacking saturated with olive water and oil, 
and which had been used to protect the tree from rubbing against the stake to which it was tied.

The proper season to dress the olive, raries according to the climate, the soil, and vield of the plant. In a mild climate, howerer, the dressing may be applied in autumn and winter, whilst in more northern regions, it would be best given after all danger of freezing was past. The olive may be dressed in two ways-If the compost be plentiful, and the trees near together, it should be applied by scattering it about the orchard, and afterwards turning it under with a spade, a hoe, or plough; or, it should be done by digging holes about the tree, in a radius of from two and a half, to four and a half or six feet, according to the age and size of the tree. These holes should be from twelve, to sixteen inches deep, and should be dug some weeks before the dressing is applied, in order that the soil about the roots may be fully aired.

In localities where compost is scarce, it is well to alternate fertilization by plowing under lupins, beans or other regetable matter of easy growth. If the dressing of the soil is done biennially, one half of the ground could be plowed under as stated. It triennially, the plowing under could follow, and a third of the plantation be plainly worked. If quadrennially, the surface should be clivided in four sections, of which the first should be manured, the second worked, the third plowed under, and the fourth worked.

The nature of the fertilization that is necessary, cannot be exactly determined by the ashes of the rood alone, as the proportions of these may vary from a multiplicity of circumstances. The surest test for the fertilization, is the knowledge of the loss to which the tree has been subjected in fruit, leares, and wood; and the object should be to restore to the soil that which has been taken from it in producing these. No manure should be applied till it is thoroughly fermented. To throw unfermented, or indeed anx manure, close up against the trunk of the tree, is to do harm instead of good. With the rain fermentation starts again, and the heat generated is preju- 
dicial to the tree as well as being a centre for the propagation of harmful insects. The suckers about the root are nourished to the detriment of the tree. The roots of the olive lie remarkably near the surface and these are the parts of the tree needing fertilization which should never be attempted nearer than a yard from the trunk. In cold regions, that is on the northern limit, sheep and goat dung is found to be an excellent manure; in temperate parts, stable ordure is good, and in hot regions cow dung is the best. It has been calculated that two hundred and twenty pounds of manure are equivalent to one gallon of oil. The foliage which falls naturally and decars under the trees every year, is eleren pounds per tree. The weight of these leaves is to the weight of the fruit as 71 is to 100 .

The leares taken off with the branches in pruning, supposing that operation is performed frugally and regularly, amount annually to. a little more than a pound per tree. This foliage which is not restored to the soil, represents a weight of 5.50 per 100 and this is the 1Sth part of that which clothed the whole plant. The rood lost to the olive by meteorological accidents, and by pruning, may be estimated at seven pounds to the tree. The wood and leares obtained by pruning are to each other as the number 78 and 22 are to 100 . That is to say, in one hundred pounds of prunings there would be 22 pounds of leares to 78 pounds of wood. With these data for a basis, the actual annual loss of the olive may be estimated as follows:

The olive consumes in fruit per tree, $15 \mathrm{lbs}$.

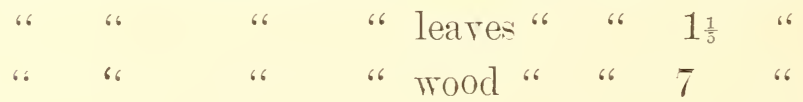

Manure is the dressing most commonly used for the cultivation of the olive, and is best administered when mixed with other fertilizers. Each year the amount of compost necessary to restore to the soil the principles essential to fertility, would be thirty-six pounds per tree, and that, a tree of medium size and one moderately pruned. 
THE MIGNOLO OR GREMIGNOLO.

Plate VI

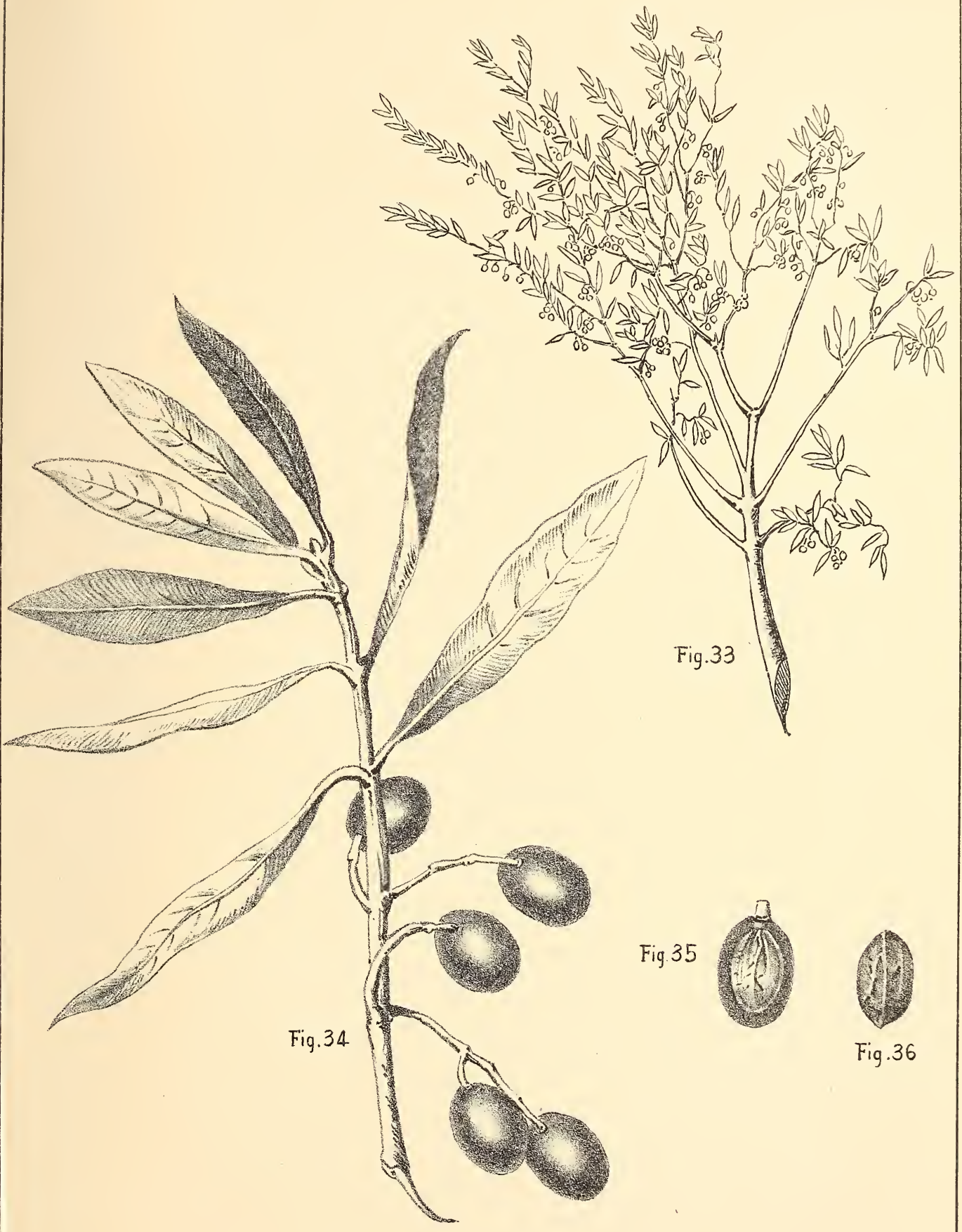




\section{PLATE VI.-THE MIGNOLO OR GREMIGNOLO.}

Fig. 3:3. Branch of the Mignolo or Grenignolo, showing its appearance, (rerluced.)

Fig. 34. Twing with olives, (natural size.)

Fig. 35. Longitudinal section of berry, showing mesocarp, (natural size.)

Fig. 36. Form of nut, (natural size.) 
To restore the same fertilizing principles with the foliage of the tree, alone, it would be necessary to yearly use at least fifty-two pounds.

Without manure the olive gives but a small crop of berries. Anything that can be used to enrich the soil is valuable; decayed vegetable matter, night soil, old rags, shoes, bones, hoofs, guano, fowl dung, are excellent manures. Green manure, in the dry summers of California, can be employed to great advantage.

During the early autumn rains, plants of rapid winter growth, such as beans, lupins, vetches, are sown in the orchard and turned under in the spring, thus giving a cheap manure without any cost for carriage. Whatever may be the nature of the manure, it is important not to place it at the foot of the trees, but to bury it at a slight depth from one to two yards distant from the trunk, digging a shallow trench for the purpose. It is a matter of absolute necessity to manure the olive, under penalty of losing all produce if abandoned to itself, and remembering also, that the produce will always be in proportion to the manure applied. In fact some writers say, that if the olive is not largely manured it had much better be pulled up altogether.

M. Riondet says: The expense of cultivating the olive varies greatly. If they are never manured, or pruned, the cost will not amount to more than eight dollars per annum, per acre, or sixteen dollars for two years, for this is the period that always enters into these calculations, since the tree ordinarily only gives a crop every second year. If it is desired to have regular and abundant crops, we should not fear to spend eighty dollars per acre every two years.

In the winter, after an abundant crop, it is necessary to manure the orchard heavily, at an expense of twenty-four dollars per acre, pruning, will cost sixteen dollars per acre, ploughing, sixteen more to which add for the expense of gathering and taking the crop to mill, another twenty-four dollars, and so we reach the sum of eighty dollars per acre for a period of two years. There will be a product of one thousand one hundred and thirty-two gallons of olives, per 
acre, every two years, which should be the equivalent of one hundred and fifty-four gallons of oil, per acre, for each period of two years. This will not come far from an annual average of one gallon per tree, and if the olive grower could assure himself of such a yield, he might well be satisfied. 


\section{Multiplication of the Glive}

\section{CHAPTER VI.}

"Quin et condicibus sectis mirabile dictu Truditur e sicco radix oleagina ligno."

Tirgil, Georgies II, 30.*

The olive is propagated in many different ways, by seed, by cuttings, by truncheons, by grafts, by suckers, by knots, by layering, and by pieces of the root.

SEED.

The best method, in spite of all that may be urged against it, because the natural one, is the planting of the seed. All others are mere continuations of a life already existing but with each seed is produced, in the manner intended by nature, a new tree. The nonsuccess that has attended many efforts to raise the olive from seed in California, undoubtedly arose from faulty handling. Some go so far as to claim that the Mission olive contains no germ. This is absurd. The Mission olive contains well developed seeds in the same proportion that all others do, viz., the poorest olive for oil or pickling is the best for seed. The olive nearest approaching the wild type, the olive that contains the largest seed in proportion to the herry, is the best for planting. One tenth of the stones of the wild olive have a double germ and this is the best of all olives for seed, second the Mignolo, third the Razzo, Leccino, Puntarolo and Trillo, fourth the Grossajo and fifth the Morajolo.

* Some cloren stakes, and (wond'rous to behold) their sharpened ends in earth their footing place, and the dry poles produce a living race. 
A tree grown from seed, has a long tap root, and a very straight smooth stem, which shows the v:gor of the plant; while a tree raised in any other way has not these advantages. Its pivot root gives it a force that other trees do not possess. It is more productive, will resist diseases better, and is a hardier tree than one raised from a cutting.

When the ground is loosened by rain, and the tree is loaded with fruit, a heavy wind sometimes overturns the olive, this could not happen to a tree from seed, its tap root takes too firm a hold. This accident occurred on the Quito Farm in the winter of 1886, and the trees which were so unfortunate had to be replanted and cut back to the crotch being lost to the place as fruit bearers for the next four years.

Again the time lost in raising from seed is more apparent than real, for, after the early years of its life, the advantages are wholly in favor of the tree raised from seed. The weight of opinion, derived from an experience of centuries, favors this method.

In 1882, the Congress of the Italian Agriculturists, meeting at Bari, arrived at the following conclusion :-That persons be recommended to raise their olive trees from seed, in preference to any other method.

If proof were needed that the olive will grow from seed in California, we have it in the fact that various parties have successfully raised the Mission olive in this way. Whatever seed may be sown, the resulting plant will be the wild type, and should be grafted, in the nursery, when from two to three years old.

By actual count on the Quito Farm, one hundred Mission olive pits gave fifty well developed germs.

To hasten germination the seeds should be stripped and soaked in lye for two or three days, then dried and placed in a dry spot, or disposed in layers in a box with dry sand, being well covered with earth to keep out water. When the time comes for sowing, sow the seeds without detaching the sand that clings to them. 
Some writers suggest that they should be fed to domestic fowls as the best way to strip them; and passing them through a goat is said to be the best mode of all. Olive seeds unstripped never germinate in less than eight, nine and twelve months, and when the berries are under ripe even in two years, and sometimes not at all. Care should be taken in selecting berries for seed, to choose only such as are thoroughly ripe.

To save loss of time, and assure oneself of there being a seed in the olive, break it with a hammer, strike a single light blow so as not to injure the seed, or a still better but slower way is to use a rice. So treated the buds will come out in thirty to forty days.

For bed, dig a foot deep, manure it richly, plant the cracked seeds at a depth of two inches and about four or five inches apart. - Where there is no danger of winter frosts, the planting may be done in October and November, but where this drawback is feared, February and March would be the better months. Careful cultivation is necessary. When the trees are six to eight inches high, that is, when about a year old, they should be transferred into a nursery. In transplanting, the roots injured in the process should be trimmed down, and the lower one-third of the tap root cut off at the point where it begins to grow noticeably small. Also the lateral branches should be cut off, leaving only a leaf on the main stem where the branch intersected. This increases the growth of the young plant and makes a straighter and finer trunk. If the laterals are left on, they receive the nourishment first from the roots to the detriment of the plant. If cut off later, as must be done, the wounds to the tree are larger, and so the tree is harmed. The leaves must be left on, as they fill the necessary office of absorbing the carbonic acid, so necessary to the life of the plant. With the young tree raised from a cutting, on the other hand, it is unnecessary to take off the lateral branches, the aim being to stimulate root making; the cutting having none.

In transplanting to permanent position from the nursery, there 
are two methods of treatment each having its advocates. One is to cut off all branches in order that the strength of the tree may go entirely to root making, and the other to leave the five six or seven branches forming the head.

In the first instance the new branches are apt to put out half way up the stem, when the plant has to be cut down to them, and the result is that the head is formed too low. On the other hand in transplanting with the head formed, these branches are apt to suffer at first from lack of nourishment, and so check the growth. The good of the tree would be consulted by taking off all branches, but if the head can be left on, fruiting will be anticipated by about two years. In truth the good features of each method may be adopted by leaving the head on, but clipping the branches very short. The tree may also be compelled to branch at the desired height by bending down the little branches forming the head, and tying them to the trunk during the two years preceeding its removal from the nursery. This will cause the sap to accumulate there, and when the tree is deprived of all its branches at the time of transplanting to a permanent position, the new branches will come out there in preference to any other part of the tree. But the tree is the more vigorous as the trunk is kept short. In setting out in permanent position in orchard if on level land plant, from two to four inches deeper than in nursery, and if on a hillside from four to eight inches. A layer of chaff or cut straw placed about the tree just before filling up the hole, wlll serve to retain the moisture in the soil. In removing trees from the nursery to final locality, mark the south side so that they may be replanted in the same position. If this is not done the tree often remains stationary for a long time. Some writers have advocated reversing the former position with the idea of equalizing the growth, but this appears to simply stop the onward march of the tree where it might be gaining all the time; or were any equalization of growth necessary it could be accomplished in the pruning. The young 
trees should be topped with an inclination of south to north and the cut always covered with grafting wax. A grove of olive trees should be planted so that at the spring equinox no tree will cast a shadow on its nearest neighbor from south to north.

\section{CETTINGS.}

This mode of propagating the olive is popular in Spain and in certain parts of Italy and Sicily. It was also known to the ancients. But in many localities it has been abandoned as being too uncertain. For cutting take clean and well sized branches of from one to four inches in diameter, and cut in one foot lengths. These should be prepared in winter, before regetation commences and the buds more, but if ther are not immediately planted, they should be kept corered in a moist, cool place. The essential conditions for rooting are, moderate moisture in the soil, a subterranean temperature of about forty-one degrees $F$.. with an atmospheric arerage of from fifty to fifty-two, thus giving time for the roots to form, extend and strengthen in advance of the first dryness of spring and early summer. Cuttings put in in April or Mas, root quicker but demand more frequent irrigation. Those will do best, which before being cut off from the mother branch, have been either ringed, or burned, or skinned, below a bud, so as to form a knot above the wound. There are many different ways of putting out cuttings. They may be planted in a trench well manured, each two making a triangle. the bottom of the trench being the base, and the two cuttings meeting at a point and being corered with from three to four inches of earth; when the young shoots hare attained sufficient size to transplant, they may be torn away with a quick jerk, generally bringing with them a strip of bark which will suffice as a root, and learing the parent cutting in place, where it will immediately produce more shoots which may be treated in the same way.

Tery good results have been attained by planting a cutting horizontally, and covering it with four inches of earth; by some this 
method is preferred to any other. It is desirable that the cutting should be entirely covered with earth, as otherwise the sun will check and burn it, so as to make any good result impossible.

For California orchards, where as speedy an issue as possible is desired, if two cuttings are planted together in the spot where the future tree is intended to grow, the outcome will probably prove satisfactory. The two cuttings should give birth to at least one tree, and this never being disturbed by transplanting, will make an extraordinary growth. Should more than one tree make its appearance, the extra ones may be used to supply those that fail altogether.

The smaller the cutting the greater is the necessity for planting it horizontally.

\section{TRUNCHEONS.}

The question is often asked, how long before the olive will bear fruit? In answer to this, it may be said, that it depends very much upon the size of the wood planted. A truncheon sometimes bears in the following year from that in which it was put into the ground, and generally in the third year. But it must be well understood that it is at the expense of the tree. Cuttings, insomuch as they are so near the surface of the ground, demand greater care than truncheons, being exposed to danger from animals and frost. But if they survive these early perils, the vigorous shoots of the cutting soon equal the truncheon in size, and at the end of fifteen years pass it in the race. The tree grown from a cutting is lustier, better shaped, and more productive than that from a truncheon. The latter solely has the advantage of bearing more fruit in its youth, but it is at the expense of its growth.

An olive truncheon, is a limb of the thickness of a mans arm, and from seven to ten feet in length, of new smooth wood, free from warts or scratches, the most vigorous and healthy scion of the tree it is proposed to reproduce.

From this, it will be evident how difficult and costly it is, to ob- 


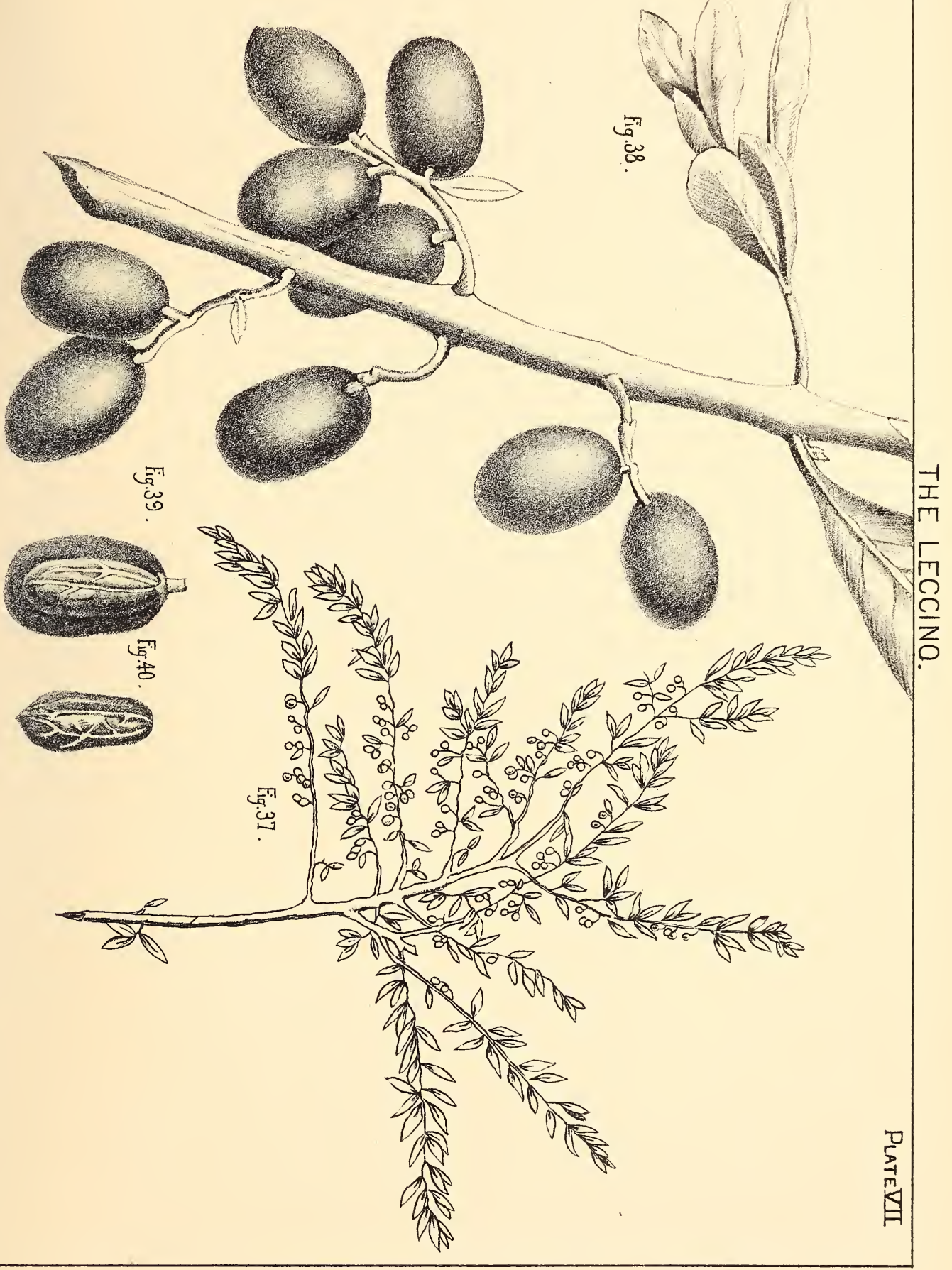




\section{PLATE VII.-THE LECCINO.}

Fig. 37. Branch of the Leccino, showing its appearance, (reduced.)

Fig. 38. Twig with olives, (natural size.)

Fig. 39. Longitudinal section of berry, showing the mesocarp, (natural size.)

Fig. 40. Form of nut, (natural size.) 
tain any number of truncheons that should unite all these qualities; especially as the tree has to be pruned, with this object in riew, for three or four years beforehand. As may be imagined, a tree that has been robbed of three or four truncheons, is not improved in appearance, and it takes much time to cover up the space left bare. The limbs once cut off, should be placed in the holes prepared for them as soon as possible; so much so, that both acts should be performed simultaneously, but if through an unaroidable delay, owing to distance of transportation, or some similar cause, the truncheon should have dried somewhat, soak it in water for a day or two, and then put it in wet earth to a depth of two, or two and a half feet. But after all said and done, do not fail to plant it as soon as possible. Supposing everything to be ready, first throw a shovel full of well fermented manure into the bottom of the hole already prepared; this being the more necessary the less fertile the soil, orer this an inch and a half of some of the best top soil, then place the truncheon upright in the center and cover with good top soil taken from another spot, press down with the feet, and leave a slight depression about the plant, if there is a prospect of rain, or if it is proposed to give it water. After watering, or a rain, the ground which has settled should be replaced, and then heaped as high on the plant as possible. The warmer the climate, the more necessary this will be found.

In the south of Spain, and Portugal, where this method is practiced, it is customary to build up on the plant, a corer of mud to a height of five feet learing only one foot of it exposed, where it buds.

The advantage of covering a plant in this way, is plain, as we know it eraporates its moisture, and having no roots to absorb with, the more sun and air it receires, the faster it loses the elements that are to help its growth. So truncheons are often seen with the upper part dead, and dry from the heat of the sun; then, they bud from below. When covered, this rarely happens. Half way 
up the mud cover, a little hole is made, through which to give them water during the first year.

Where irrigation is practiced, they do not need to be covered; but otherwise eren a layer of grass and weeds, to prevent the direct action of the sun and air on the bark of the truncheons, is of great use. The height which the truncheon should show above ground, should be forty to eighty inches, the greater, in the warmer climate, and the less, in the colder place. 'The growth of the truncheon is such, that it gives a crop in the third year; whereas the cutting does not bear until from the sixth to the eighth, and then not so plentifully as the truncheon. But the olive tree from a truncheon does not root as well, and is never as vigorous, as that grown from a cutting.

To grow truncheons, instead of despoiling and deforming the trees, is the much wiser course. For this purpose make a trench twenty inches deep. Select branches that will average more than two inches in the narrowest part, and cut them into lengths of twenty inches. Place these upright in the trench, one yard apart, and cover with earth. If on watering, or after a rain, the upper ends are uncorered, carefully cover them again, to protect them from the sun. Towards the end of spring, the truncheons will sprout, and the thicker, cleaner, and newer they are, the more vigorous will be the shoot.

As soon as the young sprouts are seen, the ground should be spaded over, the earth carefully scraped away from the plants, and fresh earth added. In the beginning of July, the ground should be worked over, and again in the early part of August. In parts of the country where irrigation is necessary, they may be irrigated, but generally frequent cultivation, and freedom from weeds, is sufficient to insure a favorable growth. In the spring of the second year, open the trench, uncorering the mother cutting. Sever at the neck of the plant all superfluous shoots. The aim should be, to leave one, two, or three, vigorous ones so distributed around the parent cutting, 
as not to interfere with each other. In the spring of the third rear, again open the trench, and cut off any sprouts that may have started on the mother cutting. Also, if the lower branches of the two or three shoots of the year before, interfere with cultivation, or are growing out of proportion to the tree, prune them as may be necessary.

In the month of March of the fourth year, the plants will be sufficiently advanced to serve as truncheons. Again the trench is uncorered, until the union of the truncheon with the wood originally planted, is risible. Seizing this, with a steady pull, tear it from the mother, and with it, will come away some roots, and part of the original bark and wood. These are most necesary to its perfect rooting. We now have a truncheon, and it must be planted in the manner heretofore described.

The original wood, from which there has been torn one, two, or three young trees, will put out fresh shoots immediately, and go on producing other trees, and the treatment must be the same as that already described.

Fig. 1. Crowa Grafting.

A.-The stock.

C. - g. The graft.

e. e'. e".-The scions inserted.

B.-The incision in the bark of the stock to admit the graft.

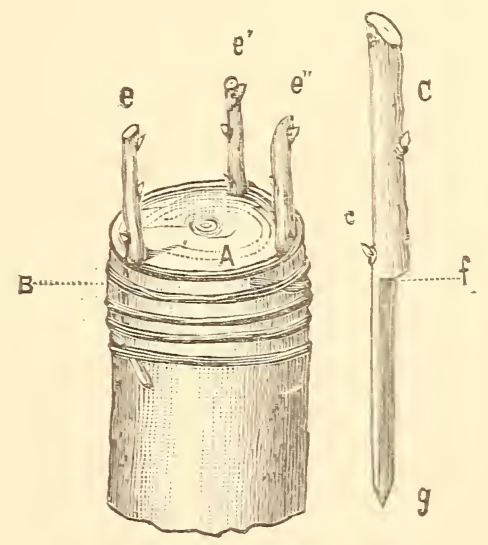

GRAFTS.

The olive can be grafted in sereral wars; two methods are the most appropriate-crown and shield grafting. In crown grafting the operation is performed when the buds are grown a third of an inch long. Cut horizontally the head of the stock, or the branches only of the second or third order, according to the age of the tree, 
at about eighteen inches from their spring. Then, cut through the bark to the wood, in a vertical line, about two and three-quarter inches long.

Cut the lower part of the graft in a pointed form, with a notch on the upper part. Raise the bark of the stock, and introduce the graft, between the bark and the wood; surround with a bandage, and cover with mastic. This sort of grafting is used for old olive trees. If more than one is used, a clear space of three inches should be left between each.

FIG. 2.

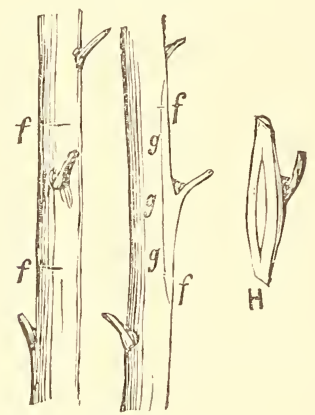

$f$ f. The bud selected.

f. g. g. g. f. Side view of bud.

H. The bud.
FIG. 3
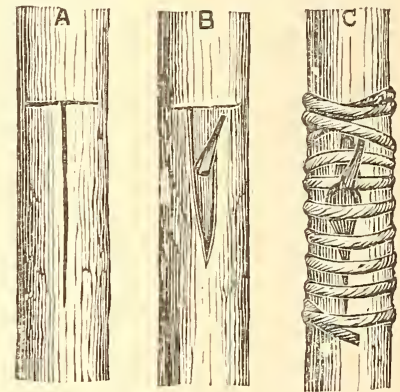

A. The Cut.

B. The bud inserted.

C. The binding and securing of the bud.

BUDDING OR SHIELD GRAFTING.

The piece cut from the bark to form the graft is most frequently in the form of a shield. This piece of bark must have upon it, near its center, an eye or bud.

These grafts, are especially used for young stocks, or branches from one to four years old, having thin, smooth, and tender bark. Shield grafting, with a dormant bud, is practiced towards the end of the summer, according to the vegetation of the subject. The head of the stock must not be cut off until the following spring, when it will be seen whether the graft bud has been successful.

The following are the principal points to be attended to.

1st-Cut from the olive tree a branch having some leaves, or eyes at its base, or buds well developed. Take off the leaves, leaving 
only a small piece of the stem of one of them, to hold the shield by, between the fingers. Keep the grafts, or buds, when thus prepared, in a dark, cold, and damp place, until the time that they are required for placing upon the stock.

2d-Make an incision in the form of the letter $T$, penetrating to the wood, and separate with the spatula, the two lips of the bark towards the top.

3d-Separate the shield from its branch, in such a manner, as to take off with the bark, the smallest portion of the wood, preserving in every case, the green tissue behind the bud. Unless this be attended to, the success of the graft is impossible.

4th-Slip this shield into the incision, between the bark and the wood; then bring the edges of the bark together by means of a ligature, in such a manner, that the base of the bud presses closely to the wood of the stock. This is an essential point.

5th-Sometime after budding, look at the buds, and slacken the bandages if they become too tight.

6 th-On the arrival of spring, if the buds have taken effect, cut off the stem or branches of the stock about three inches abore the bud. This is done to stimulate the development of the bud.

7th-Cut the head of the subject grafted the following winter. The first or crown grafting, is employed on the large trees from the Esterel to Genes. In Provence, Arignon, and Gard, shield graftingis preferred. At Grasse, they graft the young trees at the age of five or six years, in spring time, when the sap mounts, and when the bark is easily detached. They choose the graft from the gourmand shoots of two years old, the wood well grown and bark smooth; selecting those in which the eyes are well marked. According to the size of the branch, or of the trunk of the tree, they place two. scions judiciously. The scions having been placed, the whole is enreloped with clay, and confined with a bandage. The best time $\mathrm{j}$ s the spring, when the trees are always large and full of branches; some branches are left ungrafted as ducts for the sap, the accu- 
mulation of which, at the shoots placed in the crown would be harmful. At Grasse, these branches are called des respirails, and are cut off or grafted the following year.

In Bouche-du-Rhone, shield grafting is the most common ; it is now as in the time of Columella, greffe a l'empatre.

Grafting on very young trees, is rarely profitable, not from any difficulty in the process, but because, as the roots require a long time to take hold of the soil, an abnormal disturbance of the sap occurs, and the tree sometimes makes a stunted growth.

The Abbe Jamet says:- "I never graft before the sixth year. At " the time of gathering, I accompany the man in charge. I examine "the trees, and mark those, of which the shape, the barrenness, or " the variety does not suit me. The year following, fifteen or twenty " days after flowering, I place two shields upon each of the branches "forming the head of the tree. Above the graft, I girdle the "branch, and take off the bark. The object of this gird"ling is to stop the ascending sap, and to bring it to the shoot and facilitate its starting.

The branch above the graft may be left one or two years, according to the vigor of the subject. Its leaves and shade will be beneficial to the graft.

The best time for winter pruning is that which follows frosty weather, and which precedes the first movement of vegetation. By early pruning, the sap is made to act upon the buds unfavorably situated upon the tree, it brings, them out, and also developes latent buds upon the old wood. Thus, by early pruning, it is possible to prevent the tree being covered with naked stems. It may be advantageous to wait even to the period when the shoots begin to lengthen upon trees that possess too much vigor, and which would not otherwise be easily put into a fruit bearing condition.

Grafting in wet weather is to be avoided, as the tree is likely to run, a fine day in spring is the best. The new shoots are not generally touched until the year following the lopping of the branch 
after the graft has taken. Manured and placed in good earth, the olive requires only three years to form after having been grafted.

The graits should be taken from that part of the tree which is opposite the mid-day sun. They are chosen from the shoot that would bear fruit the following year.

Those who graft the young tree upon the trunk and not upon the mother branches, take the scions from the shoots which are about to flower.

SUCKERS, KNOTS, LAYERS AND ROOTS.

The knots, or knobs seen on the trunks of olives that have attained any age, are caused by brushing off the suckers that put out on the trunk. The bark forms over the wound made, and a slight excrescence is raised, which persistently sends out further shoots, and the same process being repeated a multitude of times, the final result is a knob, or egg, of varying size. These, cut from the tree and planted at a depth of from four to six inches, give birth to an innumerable quantity of young plants, and is the favorite mode of propagating in certain parts of Italy, having superseded that by cutting's altogether.

The sucker is a developed egg or knob, having germinated while on the tree.

These knobs should be cut from the tree with a sharp instrument and the wound carefully smoothed over and covered with clay or grafting wax. A mixture of cow-dung and clay make a cheap substitute for the latter. But the weight of opinion is against this mode of propagation. The wounds caused the tree are grierous and hard to be borne. They give an opening to the "Lupa" or rot which is ready to attack the olive on the slightest provocation. Only a doomed tree should be dismembered in this way.

The suckers about the root of an olive may be laid down and covered with earth and will give further plants.

The underground portion of the olive tree is composed of two 
parts, quite distinct, the roots properly so called and which do not shoot of themselves, and the foundations formed of a ligneous mass of tubercles, from which spring the roots in one direction, and the stem in another. Pieces split from this woody mass of the size of the palm of the hand, and an inch and a half thick, planted four inches deep with the back uppermost, will give a great number of young plants. But so will the parent root if left in place. When from any cause whatever, a tree has been marked for destruction, if it is cut off below ground and covered with earth, it will send up quantities of new shoots which may be pulled off as young rooted trees, and their places will be many times supplied with others. 
肯

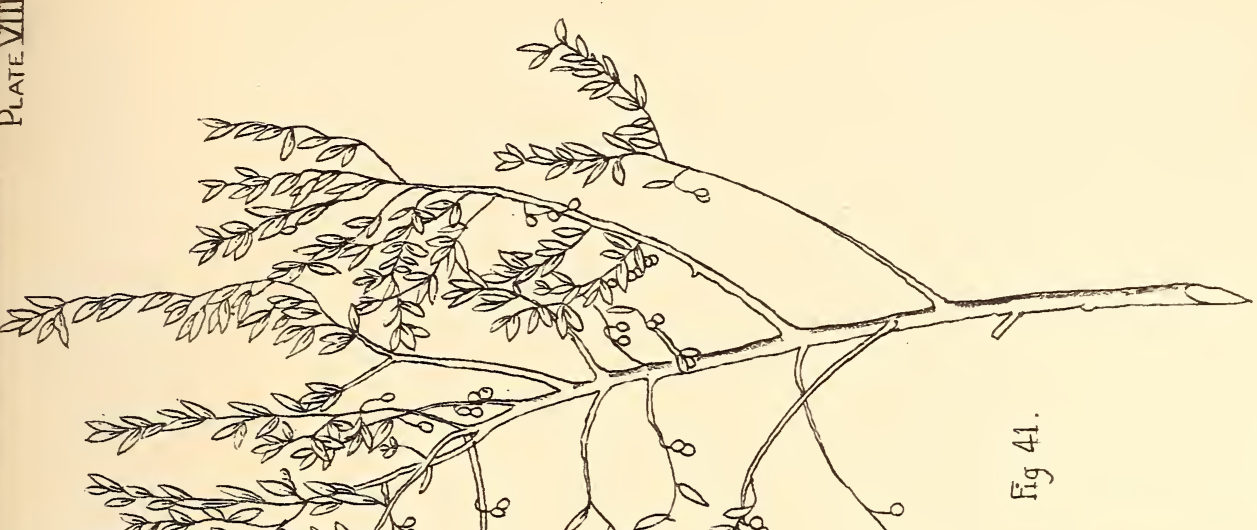
Dlo fo

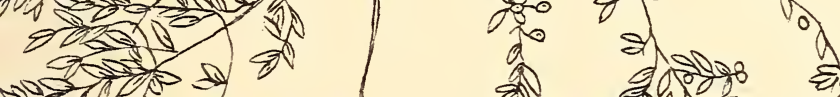
की

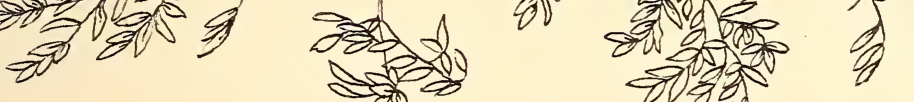

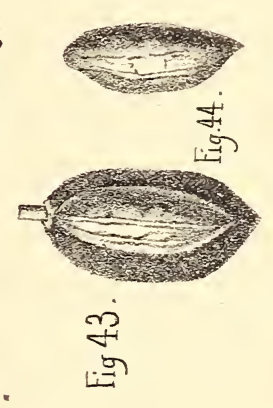




\section{PLATE VIII.-THEPUNTAROLO.}

Fig. 41. Branch of the Puntarolo, showing its appearance, (reduced.)

Fig. 42. Twig with olives, (natural size.)

Fig. 43. Longitudinal section of berry, showing the mesocarp, (natural size.)

Fig. 44. Form of the nut, (natural size.) 


\section{Gonsociation}

\section{CHAPTER VII.}

"Marry the olive and the vine."

The soil which suits the vine is also good for the olive. This is what is seen throughout the greater part of Italy; there they say the olive does not prosper in celibacy. The deep soils can well support both. Consociation offers the great advantage of getting some return from the soil during the lengthened youth of this tree, which when it has grown to a sufficient size, the vine plot commences to age, and, disappearing by degrees, leaves the olive sole occupant of the soil. When the olives grow to a large size, and are planted near to each other, or in places where the ground is poor, other crops are not usually grown. With these two exceptions, the ground under the trees is generally utilized. At Grasse and Nice, they associate together the olive and the fig, and other fruit trees; as also the vine. In such cases the trees are planted in rows, about twenty feet apart, and the intervening space is sown one year in beans, or maize, and the next year in corn. The Inspector General of the Government Plantations of France says: This system cannot be sufficiently applauded, both because, in many years of failure, all the interest of the capital in the ground would not be lost, and because the olive trees would benefit from the earth given to the other plants; and even, because the more distant the trees are planted in the rows, the more are they loaded with fruit, and pay better.

Signor Cappi also says: This culture may very well exist, and has been used in various provinces of Italy, especially in vast plains, with excellent results. On plains they should be planted twentyfive feet apart, and not less than fifty feet between the rows if vines are cultivated. Experience, some say, has shown that the olive cultivated alone, in rich soil grows vigorously; makes each year a number of new shoots, but gives little fruit, as the sap being too active to 
fix the blossom, is carried to the extremities, and the flower falls. To obtain good trees quickly, one should never sow underneath them at first, but however afterwards, to get good fruit it is advantageous to do so; but only then the year of the crop. Thus one should prune, manure, and cultivate to force shoots or young wood to bear fruit,

The season following, sow under the trees to moderate the flow of the sap, stay the growth of wood, and cause the blossom to set. In an indifferent soil this would be hurtful, as there is never an excess of vegetation. However, in similar conditions, in place of sowing an exhausting cereal, they sow vegetables, beans, lupins or peas. Green crops, as manure, are often dug in, and thus the olive during summer, finds sufficient subsistence to help it to bring a crop to maturity.

In growing other crops with the olive, it derives benefit from the frequent labor that the ground receives in their cultivation, as it loves to vegetate in a soil often stirred and largely manured. Few trees to the acre will produce a much better result than many.

The olive crop is a precarious one and therefore he will be wise who associates his olives with other fruits, that he may have a harvest. For level ground an acre can easily carry forty seven olives, forty seven fruit trees, such as figs, peaches, prunes, mulberries or whatever may be suitable to the neighborhood and three hundred and two vines, thus:

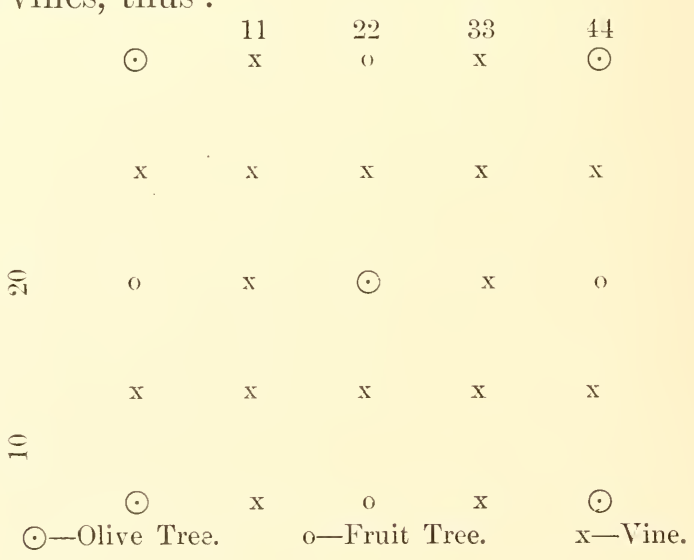


Trees to be set out on the quincunx the olives to be forty-four feet apart one way and thirty the other. This will give a far better result than crowding an acre with over a hundred olives trees. The olive under favorable conditions is a prolific bearer but too much crowding stunts the trees and exhausts the soil. The result is seen in weak and puny trees that bear no fruit. The olive must have sunshine and ventilation and it cannot get it in an orchard where there are one hundred trees to the acre. For a few years all will go well, and then about the time that the trees should give a good return it will be found that the branches interlock and that the orchard forms so dense a mass of foliage that the sun cannot penetrate it, and half the trees will have to be taken out, and replanted some where else, and there will be the loss of about five year's time resulting from cutting back well grown trees; this would be in consequence of crowding on level ground, but on hilly land, where the olives rise in tiers, one above the other, an acre will readily carry eighty trees.

The consociation of the olive with other fruits will prove beneficial from every point of view. The olive crop is an inconstant one, the natural tendency of the tree is to only bear heavily every other vear, it has many enemies, and until the fruit has formed, nothing is assured.

Too great heat at the critical period of blossoming may be fatal to the hopes of an abundant yield and varying seasons will give different results. The Italians have an expressive proverb which says:

"If the olive buds in A pril,

You will gather by the barrel;

If in May appear the buds,

Yon will gather by measureful.

But if it lingers until June,

The harvest will be but a fistfull."

Again,

"Golden is the olive of the early budding,

Silver that which comes after,

The late one is worth nothing." 
The earlier the olive buds, the earlier it flowers, the quicker the olives grow fat, the better they encounter the inclemencies of the season and the better secured is the product.

Consociation pays because as the olive comes to full fruiting slowly, it offers a new mode of lessening the unproductiveness of the early years and of reducing the expenses of the olive orchard. It may endure only until the olive comes into bearing or may be permanent.

The question of consociation or not, depends upon climate, soil and exposure. In very steep, stony, shallow ground, with a rocky subsoil, sandy or in any way arid soil, it is advisable to undertake only the cultivation of the olive, because the other plants would succeed badly and would not pay for the necessary attention.

On the other hand fertile and rather level lands permit the fruitful presence of other plants, while the olive enjoys greater space and light, both being indispensable elements to its prosperous life and copious production. Since the olive is more secure as to its crop, south of its region as against climatic dangers, and to the north, runs greater risks of loss of crop because it matures late and the tree itself may suffer or even be killed by frosts, it follows that consociation in such countries (giving to the olive all the light) contributes to the more secure ripening of the fruit and to its greater production. In the case of loss of crop or trees, there is something left to the husband-man. Reasons therefore for the consociation of the vine are:

1st-Vines come to fruit in the third year and to maturity in the fifth. This is an advantage from the side of expense and return on capital.

$2 \mathrm{~d}$-The vine can be planted with the same preparatory labor as the olive.

$3 \mathrm{~d}$-Cultivating the vine at least three times during the year, is an indirect benefit to the olive, the more so as the epochs of these labors occur at seasons opportune for both plants. 
4th-The heavy work of pruning and harvest can be done at different times so that they do not interfere with one another. In fact the pruning of the vine may precede that of the olive and the vintage comes when the olive begins to turn. Thus the consociate cultivation of the olive and vine will enable one to keep the same laboring force right through the year and avoid the constant shifting of hands which is so great a drawback.

5th-The olive and vine being so different in size, the tree only affects unfavorably the nearest vines.

6th-Being both potash plants they prosper in the same land and are benefitted by the same manure.

7th-If the consociation is temporary, the vines will gradually pass away by the time the olive, at thirty years, has reached its normal development, but will have in the meantime contributed largely to pay the expenses of the place if they have not entirely done so, and if the consociation is permanent a certain number of vines are up-rooted and a broad belt left to olives. 


\section{Preparation of the Ground}

\section{CHAP'TER VIII.}

"O, dig a hole, and dig it deep."-Old Play.

The selection of the spot for an olive orchard having been made, the surface should be cleared of all woody plants and roots, and then plowed as deeply as possible. If the plowing can be done with the first rains, say in November, and the ground left exposed to the elements till planting time comes, which should be after all danger from frost has past, it will receive an atmospheric fertilization which will be so much gained. But let the plowing be deep, twenty inches if possible, remember that centuries may pass before it can be done again. Any expense incurred in this direction is money well laid out, and will pay for itself many times in opening the way for the perfect rooting of the future olive.

On the other hand, shallow plowing and a dry season might well result in young olives casting their leaves and fruit, from the impospossibility of the young rootlets penetrating the hard unbroken soil.

The plowing finished, the holes for the trees are next in order, these may be of various shapes, square, rectangular, and lastly the trench.

Of the holes, the square is the best, and to obtain the very best result should be three feet deep, and three feet wide at the surface. If the ground in question has not at least a yard of soil, the olive will not flourish there, as when the tap root encounters an obstruction it bends up and the lateral roots develope in its place, and as the growth of the tree is always equally proportioned between its root system and its branches, the obstacle encountered by the pirot roots becomes immediately apparent in the appearance of the tree. The stem, which corresponds to this root, ceases to grow with its previous vigor and force. The trunk loses its smooth, ash colored bark, and its base is covered with a variety of protuberances, which. 
bulge out and indicate the disproportioned circulation of the sap. So the appearance of a tree alone indicates whether the soil is a congenial one or not. But the straight stem, smooth, ash colored bark on the trunk, green bark on the branches, a round and exactly proportioned top is only to be expected from a tree raised from seed.

FIG. 4.

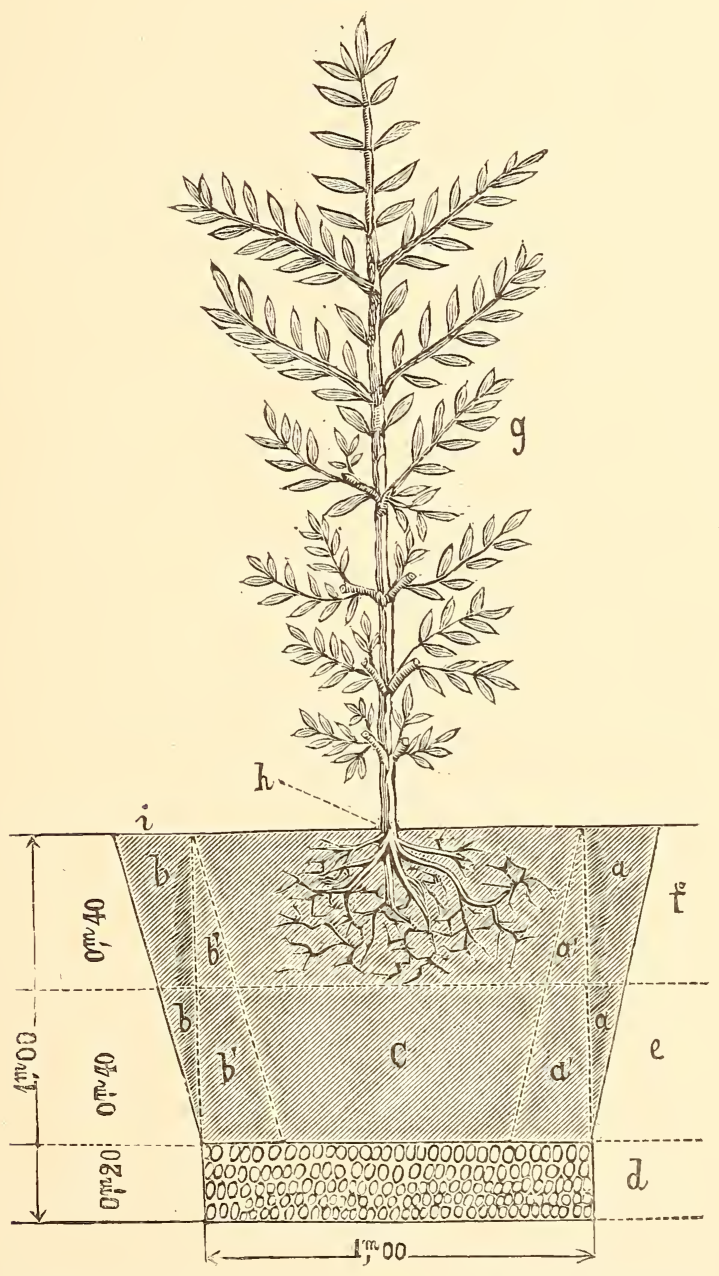

PLANTING OF THE YOUNG TREE. ONE METRE IN DEPTH.

d. Layer of stones and sticks.

$e$. Strata of earth upon which the roots rest.

$f$. Strata surrounding the root system.

c. Central part underlying the root, which should consist of well worked earth.

g. The plant itself interred as it stood in the nursery. 
In the bottom of the hole put a layer of stones and branches mixed, in order that the drainage and ventilation may be perfect. In many dry soils, of course this would be entirely unnecessary, and in setting out an orchard on a large scale, would add very greatly to the expense, and is only indicated here in order to show to what perfection the transplantation may be carried.

At the same time, we do not think that any money expended on these preparatory labors will be thrown away, but believe that the future will largely recompense them. Let then the layer of stones and branches fill the bottom of the hole to a depth of six inches, and on top of this, a layer of well aired good soil. If the soil is sticky, it is well to mix it with such mineral ingredients as ashes, sand, or lime. In loose soil clayey material should be used instead. In both cases it is advantageous to place under each plant a few shovelfulls of old, well fermented manure, then the plant itself, and if water is to be conveniently had, five or six gallons can be used to advantage in settling the roots. The ground immediately below the roots should be composed of soft, loose earth mixed with manure, for this is the part first to embrace the young and tender fibers, and from which, they will radiate into the more compact earth, as they gather strength. When the planting of the tree is complete, a stake is driven by its side and secured to it by a cord, but to guard against injury to the delicate bark, a wisp of straw should be placed under the cord.

Except where the soil is sandy and loose, or subject to persistent dryness, the plants should not.be set deeper than sixteen inches.

It is shown by observation that the volume of a piece of ground worked over decreases one twelfth in a year, by the progressive diminution of the porosity. Thus a hole dug to a depth of one yard with sewerage of eight inches, and covered evenly, would at the end of a year have sunk three inches, and the plant placed in the hole would have sunk proportionately.

It follows then, that a plant placed in its accompanying sod, in 
THE PHLOEOTRIBUS OLEAE.

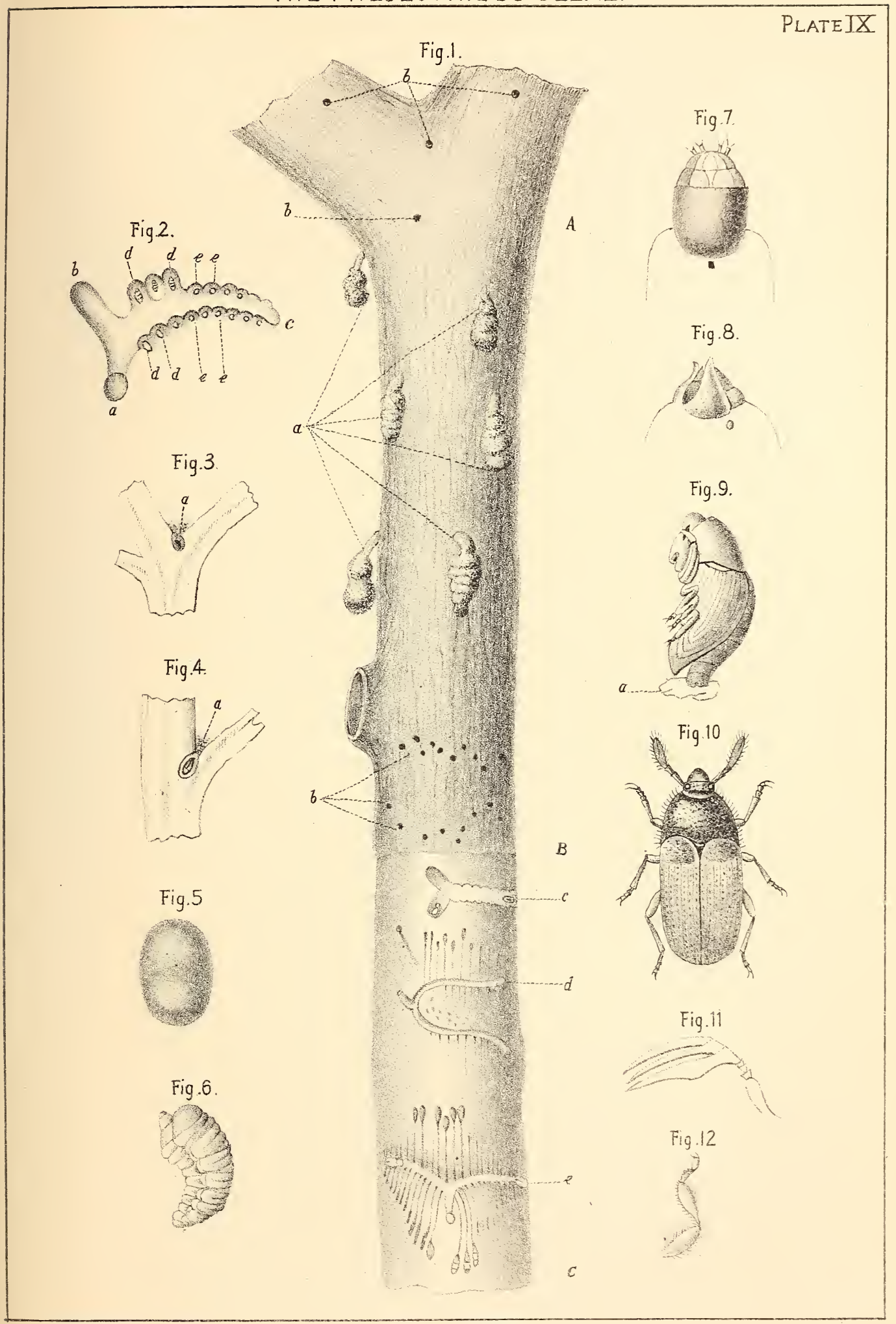




\section{PLATE IX.-THE PHLOEOTRIBUS OLEAE.}

Fig. 1. Portion of dry branch of olive A, B. a, excrescences formed by excrement and borings from wood of the year hanging from the openings of the galleries which the Phloeotribus dig out, at $b, b b$ holes made going in. B to $\mathrm{C}$ bark stripped off, $c, d, e$, show galleries made by the Phloeotribus; $c$, gallery commenced showing niche enclosing eggs; $d$, two galleries dug by two females going in at same entrance flanked by laterals dug out by the larvæ; $e$, two similar galleries of which some complete laterals show the chrysalides, because formed by the larve which were the first to open it.

Fig. 2. The galleries $c$, of previous figure enlarged; a, ingress; c, gallery in which female stays while excavating and depositing eggs; $d, d, d$, niches with larvæ enclosed who have commenced to dig out the lateral galleries; $e, e$, which contain the eggs; $b$, remains short and without laterals because dug out by a male.

Fig. 3. Branch of olive in crotch of which is seen a Phloeotribus at work digging a tumnel; on pulling him out, the hole is seen filled with borings and excrement.

Fig. 4. Branch similar to preceeding showing Phloestribus (enlarged,) in a nest covered with borings and excrement.

Fig. 5. The egg (enlarged.)

Fig. 6. The larva side view (enlarged.)

Fig. 7. Head of larva, seen from above, (much enlarged)

Fig, 8. Same hear, side view.

Fig. 9. Chrysalis with strip of wood from tree a, adhering.

Fig. 10. Insect (enlarged.)

Fig. 11. Antenna, (very much enlarged.)

Fig. 12. Tibia and tarsi of hind feet, (enlarged.) 
level ground, will at the end of a vear be three inches deeper than when put out. Planting at more than the ordinary depth will be injurious to the plant, and will often cause its death. For the perfect development of the olive, the soil must be pervious to the air, which is indispensable to the respiration of its whole organism.

Experiments have shown how the development of the same plant can be retarded or advanced, by planting it alternately deep and shallow. From these experiences it is conclusive that to condemn the olive to too great a depth in the ground is a grave error.

The rectangular hole of two feet long, and two feet deep, and a foot wide, will probably be the one commonly used in California, as it is much the cheapest.

Instead of holes a continuous trench may be dug, not less than three feet in depth, and the trees set out in it at the proper distance apart. Here the tender roots encounter no obstacle, the trench giving them free play each way and the result is, an astonishing development of the young tree. These trenches have proved particularly good on side hills. When we reflect that the life of this tree that we are starting on its road, will cover centuries, any expense incurred in promoting its growth at the beginning seems slight in comparison.

The wild seedling olive is unknown in California, but as the seed of the cultivated type almost invariably produces that of the wild, not many years will pass before these will begin to spring up on the hills about our valleys. The birds will be the disseminators. The writer has noticed the robin in particular. On cold winter days in the Santa Clara valley, this bird leaves the hills and appears on the Quito Olive Farm in great numbers, eating any fruit that offers itself, olives among others. The Spaniards are led to claim that the olive is indigenous to Spain because it is found growing wild on all their mountains, perhaps some future Californian will make the same claim for us, for the seed of the olive will certainly be spread far and wide in this way. 
The olive orchard should be plowed or cultivated at least four times during the year, but not to a greater depth than five inches, or the surface roots may be injured.

As soon as the berries are picked which may be in December, January or February, the tree rests. Its labors have not been light in sustaining and nourishing its burden of fruit so long. As soon as it is relieved of its heavy load it begins to recuperate and prepare for the following May when it will blossom again. The orchard should first be pruned and cleaned, and then plowed in order to give the trees the greatest possible assistance.

To keep down the weeds, it will be necessary to plow again before flowering time arrives, but on no account should any cultivation be attempted while the olives are in flower, as the exhalations from the ground, caused by turning over the soil, are very prejudicial to the tree when in this condition. Until the flower has withered and fallen off and the new berry has formed, nothing should be done that would cause any emanations from the soil.

The olive buds first, then flowers, fecundation becomes complete when the pollen comes in contact with the flower eggs, to which it communicates the power of freeing the embryo and transforming itself into seed. To judge whether this has successfully taken place or not, an inspection of the withered blossoms under a tree will demonstrate. If the corolla only has fallen, making a flat, star-shaped flower with a well defined hole in the center, all is well; but if the pistil is attached to it, then fecundation has not taken place and the crop has aborted. This may happen from a variety of causes, and it is the critical period to the olive grower. Too great heat, a late frost, excess of rain, heavy winds, a lack of certain necessary elements in the soil, or an excess of these, may singly or in combination, bring about this untoward result. The first, or too great heat at the time of blossoming, will probably be the source of greatest danger to the California grower. The olive in flower is said to be able to endure a temperature of one hundred and seven 
degrees Fahrenheit, without receiving any damage. One hundred and ten degrees Fahrenheit proved injurious to the prospect of a crop on the Quito Farm in May, 1887, cutting down by two-thirds what promised to be an unusually large vield. It is the still, burning heat that does the harm. For this reason, rising ground or the middle hills are sought for the olive, where it may get the benefit of every passing breeze.

It is a sign of good fructification when the tree covers itself with blossoms to its rery summit, as it prores its capacity to nourish flowers so far from the trunk. The flowers having fallen and the new berries formed, the olive orchard should be cultirated for the third time, and still again in the early part of September. The ground immediately about the trees should be dug orer with the split spade or earth fork, taking care not to injure the lateral roots which lie near the surface.

\section{TRANSPLANTATION.}

Care should be taken in transplanting young trees to conrey with them as much of their native earth as possible, some laceration of the delicate capillaries is unaroidable. A spade is the proper tool to use. If the tree is then kept for twenty, thirts, and eren forty days in a dark place, it will be found to be exceeding $I_{r}$ beneficial to it. The activity of the functions of the plant having been greatly diminished in the leares, the root system is correspondingly stimulated, and will produce new shoots, which by their absorbing potrer, will contribute greatly to the rigor of the young plant. The breaking of the extreme ends of the roots, occasions no harm since the absorbent surface of the roots is confined to the parts prorided with hairs, which are found in the middle of the roung fibers. The exposure of the extreme ends or eren cutting them, will not affect the freshness or vigor of the plant, but if the middle part be wounded, the injured fibers should be cut off immediately, in order' that the sound part may not suffer by contact. 
From the cut, new and numerous roots will spring, and for this reason the top of the plant should be thinned out, in order to maintain the equilibrium between the parts above and below ground. The pruning should be from the year old branches or two years old at most. The topping of the trees is proper in two cases only.

First: When the root system, not having been properly protected, has been robbed in great part of the sapillaries, which are intended for its nourishment from the soil.

Second: When the plants have been crowded in the nursery, and have long slender trunks, and are likely to be exposed to high winds.

In transporting the tree without sod about the roots, which is the custom where any distance is involved, it is necessary to top the tree to offset the loss suffered by the roots.

"A tree topped,

Is a tree insured." 


\section{pruning}

\section{CHAP'TER IX.}

"Quien quiere aceite, labra; quien quiere mas, estercola; y quien quiere mucho mas, corta" จ poda a su tiempo." Vicente Payo.*

The olive should be pruned every two years, but the process will have to be varied with the species cultivated. Some varieties need the knife, others require it but little. Still it is necessary to prune the olive, but skill, knowledge, and attention to the wants of the tree, are needful to secure the best results.

Some of the old world saws embody this truth and in few words gives us the experience of centuries.

"He who plows, hopes; he who manures, begs; but he who "prunes the olive, obliges it to produce."

"For the olive and the oak, the spade below, and the hatchet "above."

"Strip me and I will dress you, make me poor and I will make "you rich."

No one would think of adopting these maxims literally in their treatment of the tree but their tendency is evident.

TO SHAPE THE YOUNG TREE.

When the young tree has attained a height of from four to. five feet, and has a sufficient number of lateral branches, present-

*He who wishes oil, cultivates; he who wishes much oil manures; He who wishes an abundance of oil prunes at the right time. 
ing the appearance of Fig. 5, cut off the top at $\mathrm{A}$ in the early spring, leaving the three topmost branches on each side, and shorten the lower ones. Each branch is developed during the year as shown in Fig. 6, and is hen cut again at $A$, and

FIG. 5.

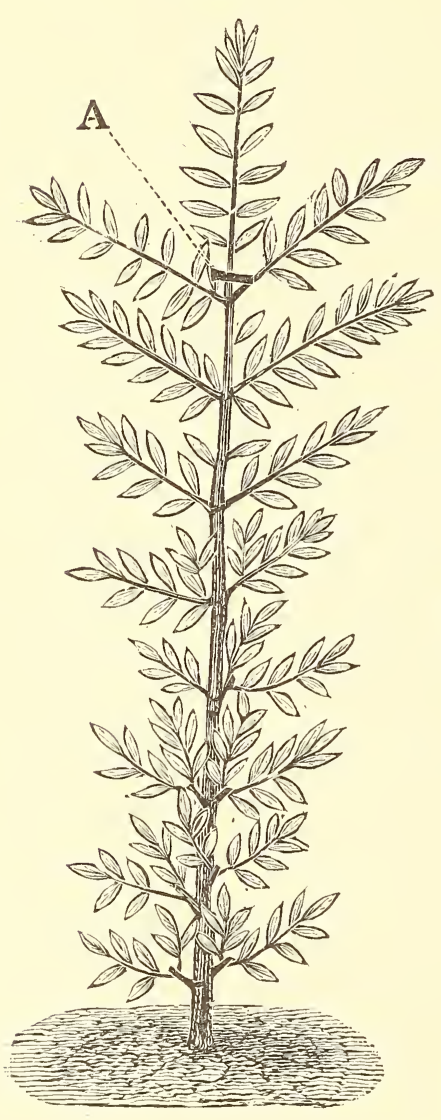

FIG. 6.

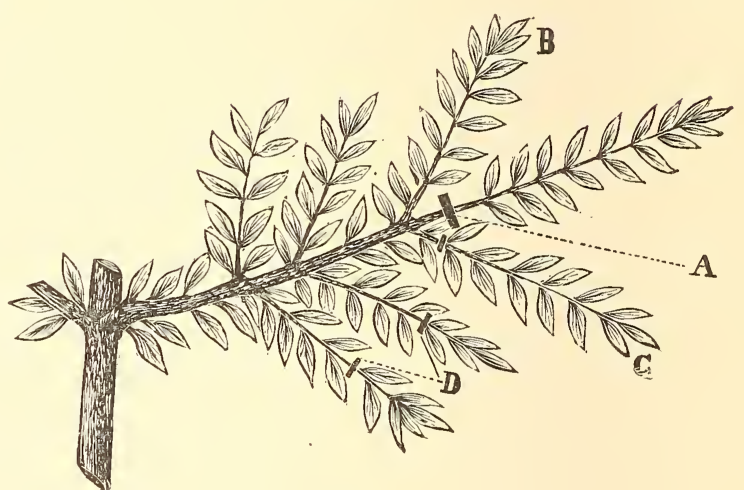

the shoots $\mathrm{C}$ and $\mathrm{I}$ are shortened. The upper shoot $\mathrm{B}$ is started out by this process, and it appears the following year as in Fig. 7, and it is again cut at $A$. This causes the two upper shoots BB to develop; and at the end of the year they appear as shown at AA in Fig. 8. This is their position at the fourth years pruning, and each of them is cut at $\mathrm{B}$; and $\mathrm{D}$ is shortened, and $\mathrm{C}$ is allowed to develop. By this time the tree has a spherical or vase form, and 
FIG. 7.

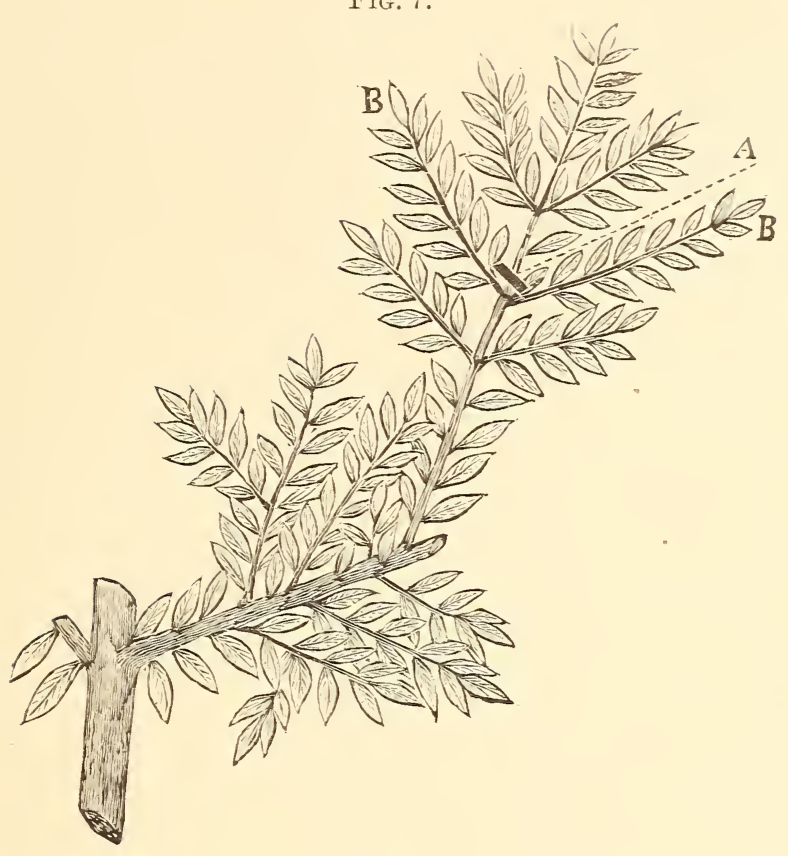

FIG. 8.

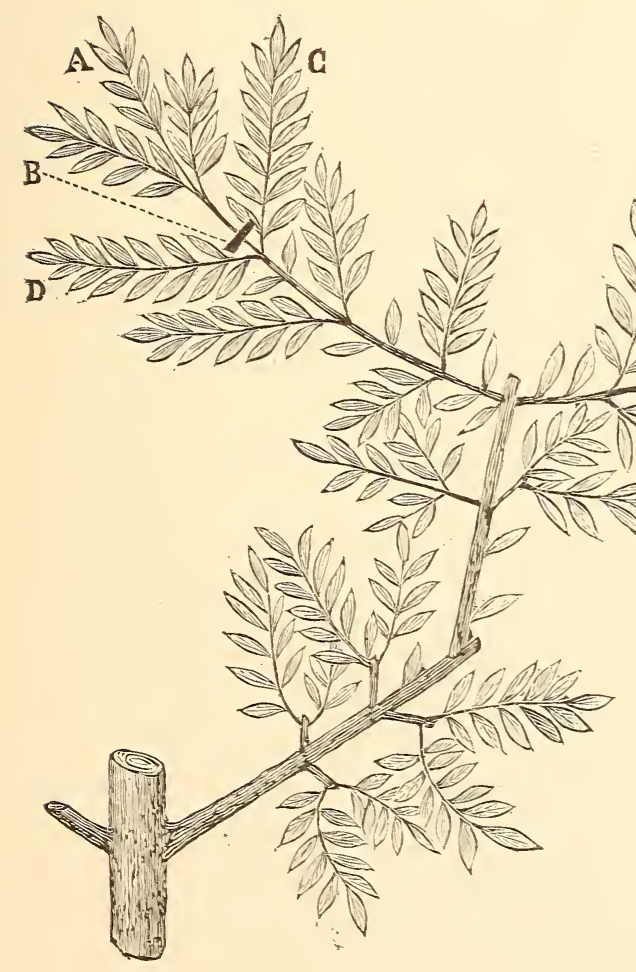


exposes much surface to the sun, which is the object desired. The olive produces fruit on two years wood only. This point the pruner should always bear in mind, and direct his efforts to multiply these shoots in order to increase production.

The aim should be to distribute the sap equally throughout; keep the extension of branches within proper limits, and give air to the interior. Take out the dead wood and fruitless branches, called "gluttons" because they take to themselves the best forces of the tree. Cut out those parts that are not sound or are subject to canker. Do not allow the branches to cross each other; favor new shoots by lateral pruning when there are vacant places to fill. In Provence, contrary to the custom elsewhere, they prune their trees each year, keeping them near the ground. This practice besides rendering the fruit more abundant and fine, permits a more careful gathering by hand. The trees thus treated will not last so long it is true, but this inconvenience is largely compensated by the other advantages attending this mode of pruning.

The olive has precisely the same mode of vegetation as the peach, with this difference only, that new shoots are easily formed from old wood. The branches and roots of a tree are proportional, contributing mutually to the growth of each other, and therefore the one suffers if the other is cut. If the strong branches of a vigorous tree are pruned very long, the roots are strengthened, the said branches increased in size, the tree runs to wood and does not fructify. If on the contrary they are pruned very short, and the lesser branches taken off also, the tree is weakened and the roots with it. It is necessary to take off the lesser branches of a vigorous olive tree, and also the strong branches to a reasonable length, always with the idea of preserving the proportion between the roots and branches.

The tree is nourished by its sap; this commences to move with the increase of temperature in Spring, generally in March. Drawn from the soil by the roots, it circulates throughout the tree with increasing freedom as it approaches the extremities, where the tender twigs 
THE HYLESINUS OLEIPERDA.

Plate Z

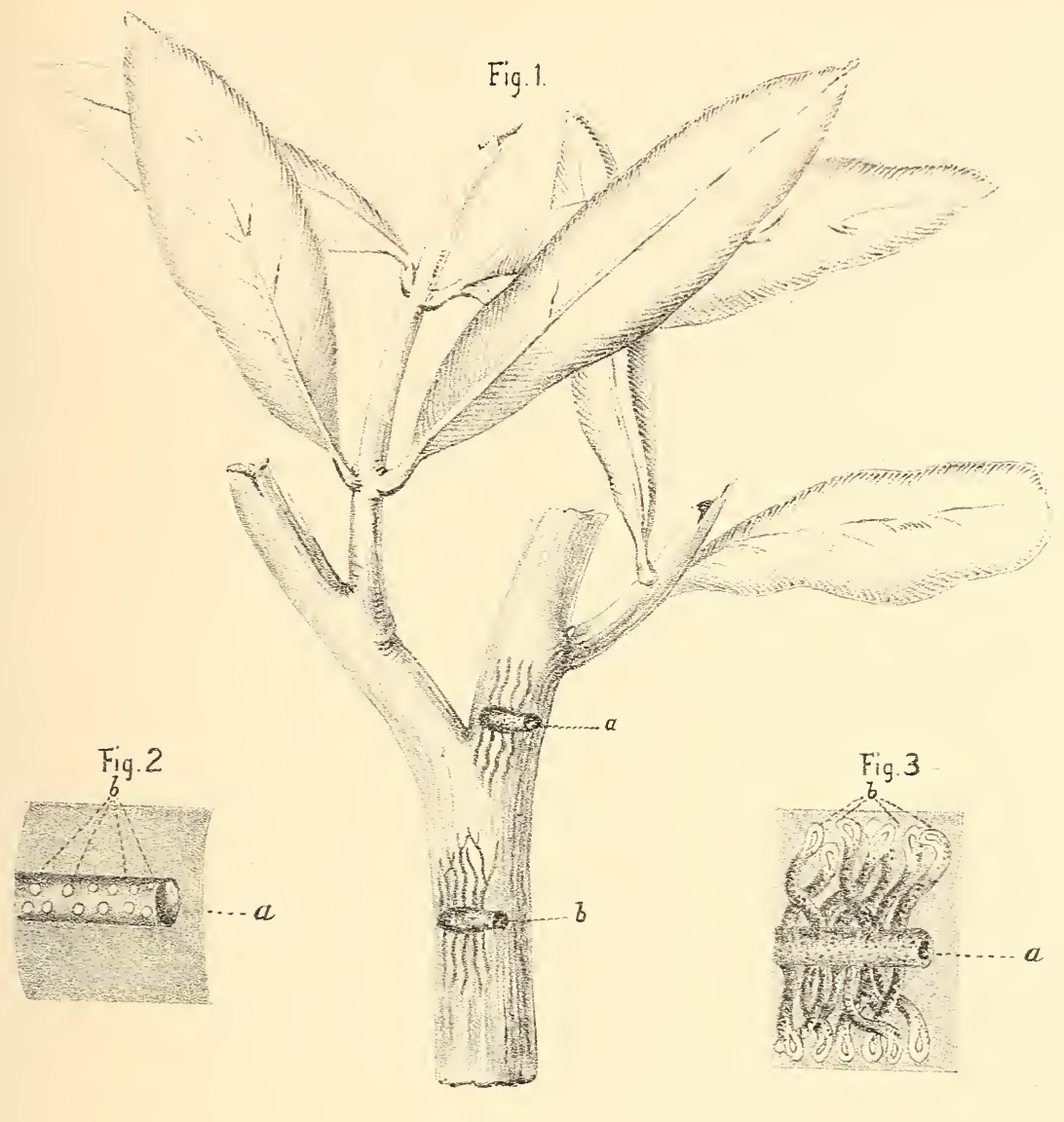

Fig. 4

r.jo

(1)
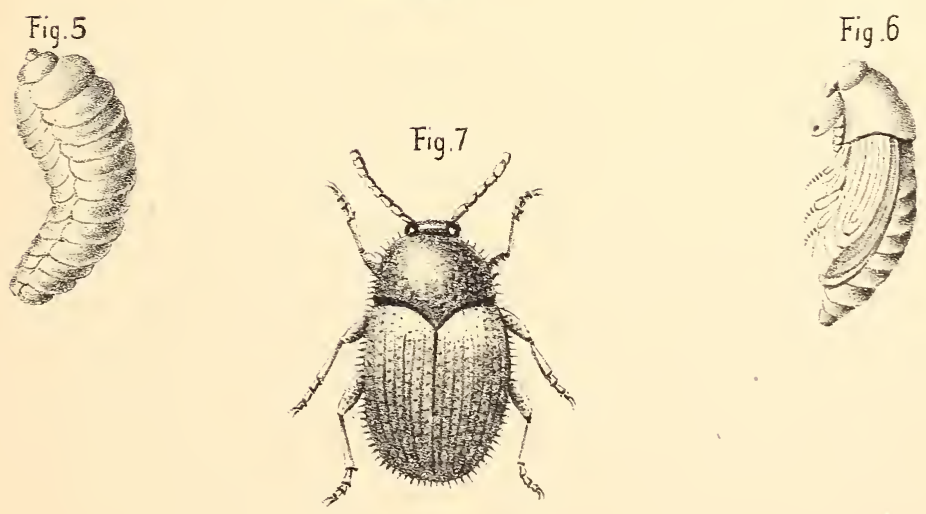


\section{PLATE X.THE HYLESINT OLEIPERDA.}

Fig. 1. small branch of the olive attacked by the Hylesinu at points $a$, and $b$, recognized by the hole through which the insect penetrated and by the reddish spots which show the locality of the gallerie:-

Fig. 2. A -mall piece of the bark showing the inside work with principal gallery a, and the egg: in place $b$, (enlarged.)

Fig. 3. A -mall piece of the wood stripped of bark showing the main gallery $a$. and the secondary galleries b, dug out by the larre, (enlarged.)

Fig. 4. The egg (enlarged.)

Fig. 5. The larra (enlarged.)

Fig. 6. The chrysalis (enlarged.)

Fig. 7. The insect (enlarged.) 
present less opposition to its course than the older wood. Having reached the leaves, the lungs of the tree, it undergoes some change in its properties and then returns to the roots again; so we have the ascending sap and the descending sap.

The descent of the sap can be verified and turned to advantage. It is claimed that the tree can be compelled to bear fruit whether it will or no. Having selected a fruit branch, ring the bark near its base, making a perfect ring whose ends meet. A double-bladed knife with the blades about half an inch apart is the proper instrument to use. The descending sap will be forced into fruit and the yield of that particular branch will be in marked contrast to its neighbors. The upper side of the ring will exude sap and it will finally swell into a circle there showing its desire to come down. It is claimed that this ringing of the bark of minor branches can be done annually without any detriment to the tree. It will be better to select horizontal branches, as without the bark and with a weight of fruit, vertical branches are apt to be broken off by the wind. But as much is required from a tree by this process, so, more than usual care must be expended on it in cultivation and manuring. The tendency of a tree is to reach the height of its species, and as only the rertical branches are useful for this purpose, the sap always tends to nourish the upright branches at the expense of the horizontal and lower ones.

It is necessary to avoid pruning too long, which would carry the sap to the extremities of the branches to the detriment and destruction of the center. On the other hand too short pruning would force the sap into a small number of buds that would be found on the young branches and flowing back to the old, would result in false wood, that is, branches out of place and contrary to nature. If one side of a tree grows with too much vigor the strong branches should be pruned short but the feeble ones left long in order to encourage the sap to flow into them, and on the other hand the reverse should be done with the feeble side, the weaker branches 
should be cut off, leaving only enough for appearance sake, and the stronger ones pruner long.

The action of the sap on the buds of a vertical branch is in proportion to their distance from the base of that branch. So the new shoots produced by the buds of a pruned branch will be stronger the nearer they are to its base. But if a branch is bent over, or arched, the bud in the highest position will produce the strongest germ, and the rest will be weaker the nearer they approach the extremity. In horizontal branches the case is different. The buds on the upper side are generally stronger than those nearest the ground. So, if the last bud on a branch is on the lower side, and the next to the last on the upper, the latter will be the stronger.

All branches that grow strong where they should be weak, and vice versa, are contrary to nature and should be cut off. The leaves have a powerful influence over the quantity and movement of the sap. This is augmented or diminished in proportion to their number. If an olive is robbed of its leaves, the flow of the sap is checked and the fruit falls. So where a tree has an excess of vigor, it may be contained within more reasonable bounds by thinning out the leaves.

The wild olive tree, or the tree from seed, if never transplanted, its tap root unclipped, is perfectly proportioned, its stem is straight, its bark smooth, its branches arch in beautiful equality, making a perfectly formed crown. But in the cultivated tree, the tree from a cutting, the tree that has already felt the knife, the order of nature has been disarranged and the tree, far from making a regular growth, if left to itself, will often take a most uncouth and ill-proportioned shape, and in appearance alone calls for the pruning knife.

The first six branches left on a young tree, three on each side, become the principal or primary branches of the tree, from these grow others called the secondary which in turn produce those of the third order. From these spring a multitude of small branches and twigs of one, two and three years of age. Those of two and three 
years are the fruit branches, those of one year will bear the following season.

The lower and horizontal branches produce the fruit in an olive. So a very general rule for pruning would be to preserve all lateral branches possible, with a due regard to the proportion of the crown, and to cut away those that are perpendicular to the trunk. The branches called "gluttons" are peculiar to the cultivated tree and need to be cut away, as they merely rob the plant of just so much vitality, without any compensation whatever. The glutton is a degenerated fruit branch, or one that appears where a fruit branch should be. They may be recognized by the speed with which they grow, by the broadness of their base, and by the appearance of the bark which, though green, is not smooth and shining, but rough and seamed. In shape also they are not rounded, but flattened on one side or the other. The color of the bark on the lower side is likewise of a dark brown. These distinctive characteristics are consequent to the over abundant flow of the sap, which the glutton draws to itself.

Though every two yeurs is generally considered often enough to thoroughly prune an olive, there is abundant work for the knife each year after the crop is gathered, in taking off the dead, weak, and sickly branches, to the end that the sap may go to fruit, and not be obliged to keep useless wood in life The tree so treated will be better able to resist frost, will bloom and yield more heavily, and its olives will contain more oil than do those of one that does not receive this care.

The olive is exceedingly subject to a species of dry rot, and unskillful pruning may actually cause it.

Branches should be cut perpendicularly to the trunk, and from the lower side to the upper, as otherwise, in falling, a strip of bark is apt to be carried away and a grievous wound caused to the tree. The cut should never force the bark out but always press it in.

It is better to avoid taking off large limbs, as the surface exposed 
by the stump of the branch is a source of danger to the tree. The larger this surface, the more difficult for the bark to close over it, and like injuries to the human body, unless the wound is thoroughly healed, it may cause the death of the patient. For this reason. if the cut is made perpendicularly to the tree, it presents less surface for the sun and rain to corrode, and for the fatal rot to take hold of, and finally eat out the heart of the tree. The cut should be made as cleanly as possible, and some of the wood scooped out in order to help nature cover it again with the bark. The who? should be covered with grafting wax or a mixture of cow-dung and clay.

If the olive is pruned while the sap is rising; or still worse while in flower, each branch lopped off is a mortal stab, a wound through which the tree will loose its life blood. The sap will run heavily for some days, especially if they are damp and rainy, no time being afforded nature to close the outlets made with the pruning knife.

The tree will have lost, to no purpose, that which might have nourished it, its vigor will be observed to diminish from that time forth, and little by little it will dry up and die.

Thus the very great importance of early pruning is inculcated, in order to give time for the closing of the cicatrices before the rising. of the sap in March.

Experience shows that an olive, although it may not have been pruned in many years, and has not strength to put out new shoots, will flower and fructify every year. But in the majority of instances the flower does not set, or if the fruit forms it soon falls off. All this because the sap canals in the branches are obstructed, if not obliterated, and the tree cannot receive sufficient nourishment to maintain its produce.

On the other hand, if a tree is observed to make wood heavily, and to grow barren and give no berries, it is a sign that it has been over pruned. Such cases are rare, but when they occur the remedy is to make the tree fast for a while, neither cultivate, nor fertilize 
nor prune it, for several years, when the good effect of this treatment will be apparent.

The top of an olive, the parts to which the sap flows with most abundance and activity, should be considered as a vigorous tree, while the lower part which receives less, as a weak tree. So the pruner should take off the strong upper branches and leave the lesser ones, and reverse the process with the lower part, lopping off the puny branches and leaving the more vigorous.

To prune in winter at a period of frost is dangerous. The limbs are exceedingly brittle at this time, and break off at the slighest provocation.

When the tree is provided with sufficient branches to clothe it, the real work of the pruner begins, which is to oblige it to bear fruit. To open a tree to sun and air is not to strip it of all shade. Its leaves are necessary to prevent the scorching of tender bark and young leaves by the sun. The variety should indicate the treatment. The Spanish Manzanillo, which has been planted to some extent in California is sparse of leaf and requires the knife only to a limited degree, and then principally in cleaning rather than pruning. All pruning that is ill timed or out of season does harm, and may be an actual draw back by obstructing and impeding the natural flow of sap. Still the olive with the tremendous strides that its regetation makes, really demands the knife. If left to itself its center becomes a mat of cris cross branches, its growth ceases, and it falls a prey to a variety of diseases. There are two classes of branches that the olive should be deprived of:

First, the irregular, the unfruitful, the diseased, the dead or dying.

Second, all useless branches, over and above what the tree is able to carry, even though they should be the fruit branches of the following year, and all the "gluttons."

An olive tree that is heavily loaded down with branches or with fruit, is in a far from healthy state and by its appearance alone 
accuses the ignorance of its owner. If it has more branches than its strength is able to nourish, it becomes weakened, if more fruit, the latter appear poor, weazened, and half ripe. The last is damaging to the crop, buc the first ruins the tree.

THE TIME TO PRUNE.

This must vary with the climate, soil and rariety to be dealt with. It seems quite clear that no pruning can be done to adrantage with the crop still on the trees, so it must be put off till the berries are gathered. 'This would give a period from October to March in which to carry on this necesssry labor.

The year in which an olive orchard is thoroughly pruned is one of a light crop, the real benefit received from this process, not being manifested until the following year. So in an orchard of any extent it would be better to divide it into halves or even thirds and to prune one of these parts each year.

It is greatly to be desired that the clippings should not be allowed to lie about under the trees but should be immediately burnt on the spot. The tendency with us will probably be to save as much arailable wood as possible for future cuttings; in that case such wood as is selected for this purpose should be disinfected and the remainder burned. In this way a multitude of noxious insects, adhering to the bark and leaves, are destroyed at once; and if not so treated, live to propagate, and renew their attacks on the trees in increased numbers.

Pruning, as we have seen, consists in keeping the trees well shaped and in good disposition for bearing the most fruit. But it sometimes happens that more heroic remedies are demanded.

When an olive orchard appears to be healthy in every respect but gires no fruit, it is owing to one of three causes. First; That the trees are too near together. Second; That the sap has been corrupted and makes only wood, and Third, that there are trees or plants in the vicinity that do them harm. 
When the trees are too near together, the ground is unable to sustain so many and it is necessary to transplant a portion of them. When this necessity is apparent every third, or every other tree will have to come out. This is likely to be the experience of many olive growers in this State. Fortunately the tree will bear it.

The first step is to cut the tree down to the crotch leaving four arms or stumps, the nucleus of the future primary branches of the new tree. It is then dug up with as much earth as possible and transported to the hole already prepared for it. In the spring of 1SS:, fifteen hundred olive trees between ten and twenty rears of age were thus transplanted on the Quito Farm, with a loss of only six trees. When the sap has become corrupted it is necessary to take off one of the primary or mother branches in order to check the tendency to make only wood. When the trees have been damaged by the proximity of others prejudicial to them, such as the pine or the cork oak (the latter breeds a worm, about its roots which is fatal to the olive) the weakly parts will have to be severely pruned. When they are attacked by an infinity of little shell like warts which spread up from the trunk to the lower branches, there is no remedy but to cut the tree down to the crotch and allow it to begin orer again. But it must not be forgotten that this treatment is an extreme measure, and only to be availed of when all others have failed.

The primary, or mother branches of an olive, are its arms, and are not to be lopped off without a good and sufficient reason. Although the tree may grow and flourish for many years, its new branches never will have the strength and exuberence of their predecessors.

That one of these branches appears to be ailing, is not cause enough to cut it off. Manuring and cultivating about the tree may give it all that it needs. Watch it till spring, and then if it fails to flower, it had better be condemned.

Thus we have seen that in pruning there are three different degrees, the cleaning, or light pruning; the pruning itself, and the 
more serere measure of cutting back. It is necessary to clean up the trees with the knife after the crop is in, every year, say in January or February, and if the operation is carried a little further, and the tree is really pruned every year, it will be found advantageous.

If the regular pruning is deferred to periods of two or three years, the wounds given the tree have to be so much the larger, and are so much the more difficult to recorer from, or detract so much from the force of the tree. Then also, the season after a full pruning is one of a very light crop, making a rery heary crop the second rear. This results in making either a rery expensive crop to gather, that is if it is done carefully, or if not, by being done hurriedly, the branches are broken and damaged, and the prospect of the next years fruitage is destroyed.

The olive is sometimes called a biennial, but a moments reflection must convince anyone familiar with the tree, that it is an annual. Does it not make a yearly effort to flower and fruit? Then encourage it and the result will be an annual crop. Annual pruning will give a moderate crop every year, will distribute the labor of pruning and harresting more evenly, and will be most advantageous to the trees.

Light pruning necessitates heary manuring in order to successfully carry the excess of wood and branches. Real scientific pruning can be safely said to be almost unknown. There are more humbugs in this branch of horticulture, than in any other. Because a certain line of treatment may be desirable in a giren locality, it does not follow that it is so in another. Certainly a rery undesirable arrangement would be that the pruner should hare the wood, as he then sets to work and makes all he can, utterly regardless of the result to the trees.

Successful pruning is founded upon the following propositions: First: That the olive fruits on two years old wood only.

Second: That the flowers do not develop except when exposed to the sun for a number of hours of the day. 
Third: That the horizontal are the fruitful branches, and the vertical branches are sterile.

Fourth: That too many branches in fruit results in a poor crop and over taxes the tree.

Fifth: That the pruning should vary according to the rariety.

Sixth: That the soil, exposure, and altitude, all affect the growth and fructification in a different manner. The richer soil can supFIG. 9.

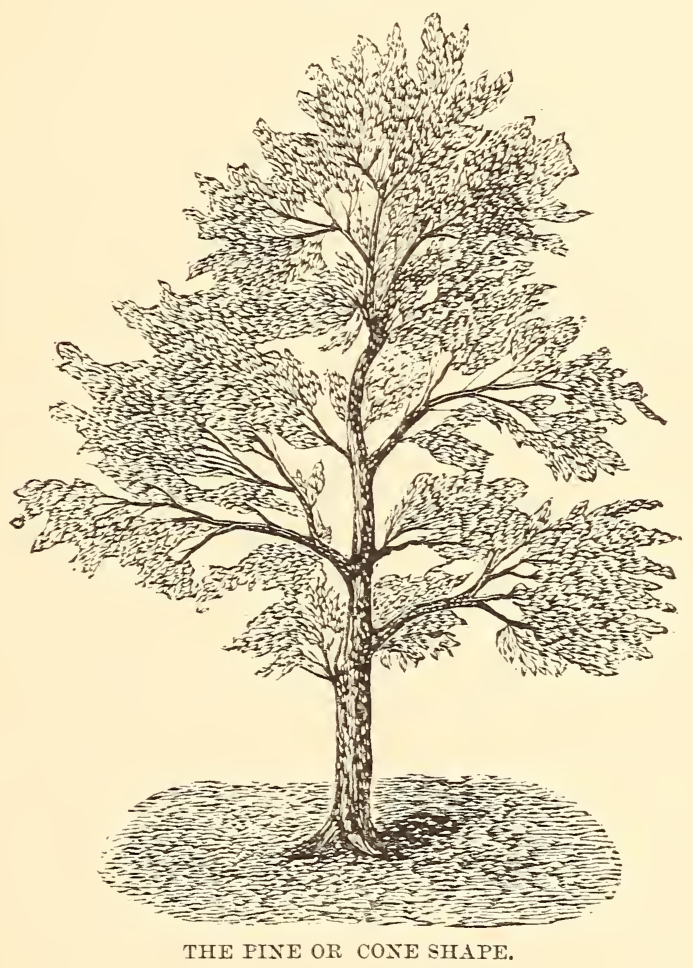

port more vegetation, and hence, in such soil, the tree will require only light pruning, while on a poorer soil, full pruning is necessary including even the horizontals, which have borne fruit some rears back.

Trees with a southern and eastern exposure can be allowed to grow higher, than those with a northern and western exposure, as the outlook is warmer. 
Trees on the plain can be permitted to grow taller than those on the hills, in order to throw them open to all the air and sun possible. On the other hand, those on the hills are kept lower, so that they may receive the reflected heat and escape the wind and its drring effect.

The olive if kept low will have more vigor than if allowed to. grow high, but do not oppose the nature of the tree too much. If it is of a variety that attains a great stature, to a certain extent it must be allowed to have its own way.

FIG. 10.

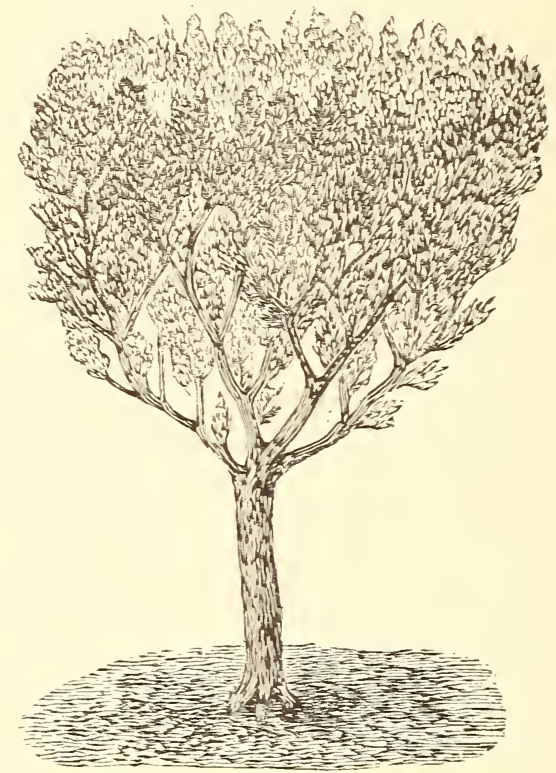

THE BASKET OR GOBLET SHAPE.

The pendant branches which guard it from the heat of the sun, should be preserved as much as possible. When a tree has produced hearily, the horizontal, or fruitful limbs, should be pruned to a certain extent.

A good rule for a well-pruned tree is, that one should be able to put the hand into the interior of the tree without holding off the other branches. 
The olive is given four different shapes:

The natural, or uncorrected form.

The Pine or Cone shape.

The Basket or Goblet shape.

The Umbrella shape.

The objections to allowing it to grow at will are, that it grows too high, its upper branches are mere "gluttons," or suckers of sap, which rob the lower, or fruitful part of the tree, of what might result in well developed fruit: that the sun and light are kept out, the principal agents of fructification, resulting in the fruit being found only on the outside of the tree, where the sun and light have access to it. Neglected in this way, the tree finally, tired of its efforts, refuses to give a crop oftener than every alternate year.

The Pine or Cone shape is better, but the best form, and almost the only possible one for large trees, is the Basket or Goblet shape. This exposes the largest surface to sun and air. The Umbrella shape is the worst of all, as it can only be achieved by directly opposing the habits of the tree. The round well-opened crown will be the most natural way to shape trees of small size.

The character of the soil must be taken into account in fixing the height and forming the crown of a young tree. In a poor and arid soil, it will be best not to make the trunk higher than from three to four feet, as in such a soil, the limited nutritous qualities will, with difficulty reach its branches, if placed too high. On the other hand, if the soil is rich, the crown may be placed from five to. six feet from the ground. 


\section{Deot?}

\section{CHAPTER X.}

Macbeth, "What! will the line stretch out to the crack of doom!"

Macbeth, Act Ir., Scene I.

The writer regrets the necessity of introducing any new pests to his readers, but if we are still spared the visitation of some, time in his course may bring them to us.

The olive is subject to a diversity of maladies, of which some are derived from the action of insects and parasitic plants, others, from meteorological influences, and still others, from improper methods of cultivation, such as excessive or defective nutrition.

The insects which are most harmful to the olive are the following: COLEOPTERA-BeETLFS.

Apion Yorax

Mecinus circulatus

Phloetribus oleae

Hylesinus oleiperda

Polycaon confertus.......................Twig borer

Psylla olivina

HEMIPTERA-BEgs, LICE.

Coccus oleae................................ Black scale

Lecanium oleae............................ Black scale

Cisticoccus pollinii

Trips oleae............................... Olive louse

Aspidiotus Conchiformis.................. Apple scale

Aspidiotus Rapax...................... Greedy scale

Aspidiotus Perseae.................... Red Bay scale 
HYMENOPTERA- SAW Flies, WAsps, BeEs.

Cynips oleae

Pteromalus quadrum

LEPIDOPTERA-MOTHS.

Prays oleellus Olive motle

DIPTERA-FLIES.

Dacus olea.... Olive fly

Of these insects, the most dangerous are the Twig borers, the Psilla, the Moth and the Fly; the scale insects and the olive louse come next.

APION VORAX.

Among the very small insects which damage the olive there arc three curculions, two of the Apion genus and a third of the Mecinus.

The first of the Apion kind, has the antennæ, eight-jointed; the first joint is long and conical, the second a trifle shorter, the third still shorter than the second and the remaining five are very short, gradually broadening towards the extremities into a solid pointed club. The rostrum, cylindrical and arched, jaws short, eyes lateral, protruding and round. Thorax conical, body curved and convex, compressed anteriorly.

Winged, shell very small and pointed, shield wing ovoid, larger at the base than the thorax, jaws elongated and truncated, femora puffed out, tarsi spongy beneath, with the first two joints conical, penultimate expanded, heart-shaped and bifurcated, the last cylindrical, enlarged at the extremity and furnished with two hooks.

The insect is about half an inch in length, body blackish, thorax gray on upper part, shield wing ridged with blackish green, sparsely sprinkled with dirty white hair, femora deep yellow, tarsi gray.

The other Apion differs from the one described, by having the first joint of the antennæ somewhat longer, the second shorter than the first, and the other six so short as to be almost globular; the rostrum less arched, the hind legs having a sort of stinger or tooth, The last joint of the tarsi rather long and cylindrical, with the feet. 
very close together. It is entirely black and sparsely sprinkled with whitish hair, and is about half an inch in length.

The third curculion, the Mecinus Circulatus has the antennæ inserted in the middle of the rostrum or proboscis. The antennæ is fire-jointed, the first rery long and conical, the others transversal and short, the club oral and nearly solid. Rostrum not rery long, strong, slightly inclined, cylindrical and not dilated at the extremity. Body oblong, cylindrical and winged. Thorax cylindrical and much compressed in front. Shield triangular, paws or feet, hard and inserted rery near together. The shield wing elongated and crlindrical. The tarsi spongs beneath the first two joints, triangular, penultimate expanded and the last one elongated and cylindrical.

This insect is a trifle more than one-twelfth of an inch in length. Chestnut colored with stripes of a lighter shade along the edges of the shield wings and about the head. The feet are dark, as are also the tarsi.

The three abore described curculions in their last stage attack the buds of the tender branches, and gnaw the shoots at the forks, digging a nest in which they conceal themselves. Here the female deposits her eggs and the resulting larræ imitate the habits of the Phlœtribus whose description follows.

PHLETRIBLS OLE.E.

(See Plate IX.)

The egg (Fig. 5) of this insect, is oblong in shape and of a rellowish white color, and a little orer an hundrerlth of an inch in diameter.

The larva (Fig. 6, 7, S,) at its greatest size is an eighth of an inch in length, is oblong and soft, with callous head; body composed of fourteen rings, one cephalic, three thoracic, and ten abdominal of a dirty white color, with reddish jaws; the palpi, short and small, the antennæ just visible, with a considerable enlargement near the mar- 
gin of the fore part of the head, the eyes scarcely discernible, placed behind the insertion of the jaws, the thorax fuller than the rest of the body, the upper thorax a little larger than the next two rings taken together, more convex and without the transrersal wrinkles of the abdominal rings.

The chrysalis (Fig. 9) oroid, oblong, with head inclined towards the breast, shield wing fluted and embracing the abdomen at the sides, the feet exposed and drawn up on the ventral part of the body. Antennæ inserted in the front of the head passing below the eyes and the sides of the thorax, folding under in such a way that the end of the proboscis or club reaches to the fore feet. It is a dirty white in color with reddish eyes and jaws.

This insect is distinguished from the Hylesinus principally by the antennæ of nine joints. The first six are simple, the last three are dilated into a three-bladed club (Fig. 11). The body is convex and oval, and of a blackish brown color, and covered with an ashy yellow down. Antennæ and tarsi deep yellow, upper thorax broader than it is long, and unequally speckled; the shield wing is orer twice as long as it is wide, rounded at the extremities and covering exactly the abdomen with nine lengthwise flutings delicately speckled; the feet robust and rather short, the femora of a brilliant black in color.

The Phløtribus count two generations.

\section{FIRST GENERATION.}

In the autumn and winter each insect hides itself in a nest dug in the forks of the bearing branches (Fig. 5, 4). In the first dars of spring, the insects abandon the nests to mate, after which they assault the dead branches, where the bark is very smooth, and dig a trench in which to deposit their eggs, (Fig. 1, 2,) gnawing obliquely first the bark and then the ring of the rood until they have a road from a twelfth to an eighth of an inch in width, they then retrace their steps, following always the ring of the wood. The female now commences to deposit her eggs singly to the right and left. 
forming for each a niche which is enclosed by a partition made of bits of rood agglutinated with saliva, and in twenty or thirty dars, from thirty to thirty-two eggs are deposited.

Sometimes two females will enter at the same aperture and after the first part of the gallery is completed will bore in opposite directions, often taking the form of a $\mathrm{T}$ (Fig. 1. e.) or a $\mathrm{Y}$ (Fig. 1. d.)

The working of the insect is manifested by a small tumor or windgall resembling soap foam which issues from the holes made by them on entering. These excrescences are composed of excrement and fibres of the rood mixed with salivary fluid. The eggs hatch in fifteen days from the time they are deposited. The larvae nourish themselves from the fibre of the wood boring secondary tunnels, the first perpendicular, with parallel ones between, resembling much the reeds of an organ (Fig. 1. e.)

The greatest length of a gallery or tunnel never exceeds three quarters of an inch and is less than one-twelfth of an inch in diameter. The number of the lateral tunnels are not usually more than twenty on the same line or thirty on two lines. When the female has finished depositing her eggs she crawls to the external orifice of the gallery and dies.

At the end of thirty or forty days the larra having reached the maximum stage of development, bores into the bottom of its own gallery, an oral niche (Fig. 1. e.) in which it remains immorable and without food for eight or ten days. From this stage it passes into that of the chrysalis casting its abdominal appendage. At the end of another ten days (Fig. 10) the chrysalis becomes a perfect insect which proceeds to gnaw the nerr wood of the tree, and the bark about its cell, emerging according to the season, in April or May. It flutter's for a short time about the tree and then settles down, and bores a hole at the fork of a bearing or blossoming branch, which being deprived of its necessary nutriment soon languishes and dies. In a fer days the mating takes place and about the first of June the boring of the tunnels for the depositing 


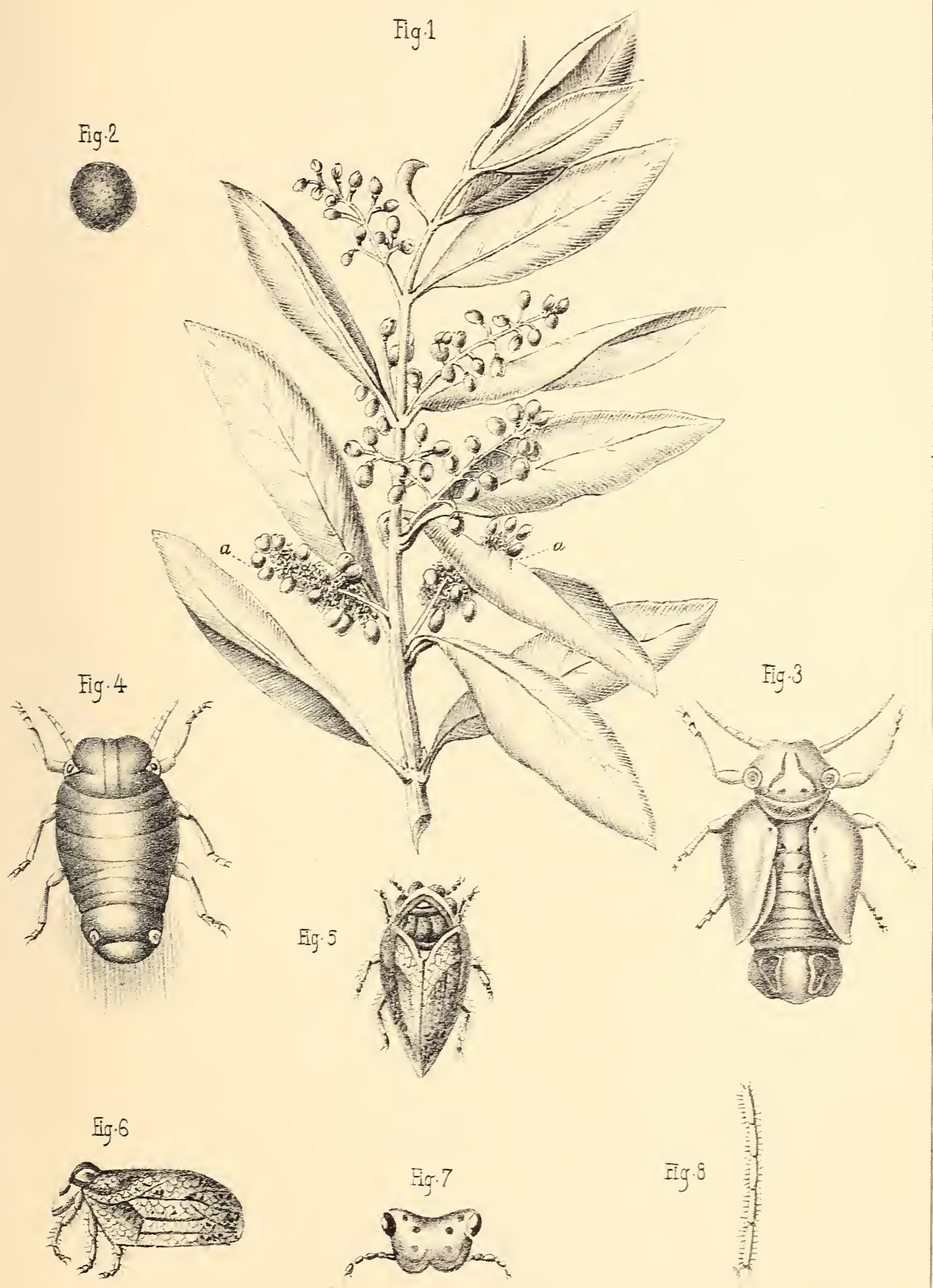




\section{PLATE XI.THE PSILLA.}

Fig. 1. An olive twig full of blossoms, $a$, a, shows the cottony material deposited by the Psilla enclosed therein.

Fig. 2. The egg (enlarged.)

Fig, 3. The larva (enlarged.)

Fig. 4. The chrysalis (enlarged.)

Fig. 5. The insect, seen from above (enlarged.)

Fig. 6. The insect, side riew (enlarged.)

Fig. 7. The head, front riew (enlarged.)

Fig. 8. The antenna (enlarged.) 
of the egos and rearing the young, follows, as has been heretofore described.

THE SECOND GENERATION.

The offspring of this second generation appear about the last of August and first of September, and prepare a nest as did their predecessors, in the bearing boughs of the tree, where they pass the autumn and winter preparing for reproduction in the coming spring.

The damage from the Phloetribus is considerable. Those of the first generation destroy the blossoms; and those of the second destroy the fruit, as they always attack bearing branches. The drying up of the leaves and fruit on the tree may usually be traced to these insects. Since they are reproduced only in the dry branches or those which are perishing, the best method to impede or diminish their propagation consists in keeping the trees perfectly free from decayed limbs. As soon as a limb shows signs of languor it should be removed and burned.

\section{HYLESIYUS OLEIPERDA.}

(See Plate X.)

This injur:ous insect is designated by rarious names in as many localities. In organization and habits it bears a close resemblance to the Phloetribus. Indeed the egg, larva, chrysalis and insect are nearly identical in form and size. (Fig. 4, 5, 6, 7.)

The larva in this case being a trifle larger and the antennae of the insect having eleren joints instead of nine. The fundamental color of the insect is lighter than that of its thorax. The body is a twelfth of an inch in length. Before the middle of July the Hylesinus has reached its perfect derelopment, and from this time on, its methods are precisely those of the Phloetribus, and its treatment should be the same.

THE POLYCAON CONFERTLS.

This insect is the common twig borer of California, and similar' to that found on the oak tree. It attacks the olive early in April, 
boring in the forks of the young wood. If discovered in time it can, to a great extent, be gotten rid of by shaking the trees both night and morning. The Polycaon is not a very dangerous pest, althougin it causes more or less injury to the tree, which may result in the loss of several of the minor branches.

PSYLLA OLEE.

\section{(See Plate XI.)}

The egg of the psylla is spheroidal in shape, and of a diaphanous white color, a little over a hundredth of an inch in diameter. (Fig. 2.)

The larva (Fig. 3) is a depressed ovoid, oblong, the head bi-festooned in front, the last abdominal ring is very much larger than the others. It is rather soft and of a greenish white color, the eyes red, the extremities of the antennæ and tarsi, black. It is completely covered with a cottony substance which is thick and long on the abdomen, and falls behind in a fringe.

The chrysalis (Fig. 4) resembles the larva in its general appearance, differing from it in the shield wing, which is oval and ridged, covering the sides of the abdomen, greenish in color, with last abdominal ring brown or nearly black, the shield wing of a yellow brown color. The insect (F1g. 5, 6) has a wide head, triangular in shape, the upper part curved in, and square at the corners, with a deep scallop nearly bi-secting the lower part, the eyes oval, placed at upper corners of the head, the antennx (Fig. 8) six jointed; the last one terminating in two short bristles, the upper thorax very short, the lower thorax large, convex, twice as long as it is wide, and nearly hexagonal. Upper wings or shield wing, oval, rhomboidal, much longer than the abdomen and meeting in a sort of roof at the upper margin of the skull; a sinew, starting from the point of the shoulder, is visible, which bi-sects it. The lower wings are shorter than the upper ones. Abdomen small terminating in a blunt point, and in the female provided with a distinct 
borer. The feet are short and robust, and the head is of a light green color.

The Psylla counts two generations which succeed each other in the spring, during the evolution of the blossoms. At the commencement of the warm season some of the insects die, while others of both sexes remain through the summer. During the autumn and winter they seek shelter on the under part of the leaves, or stalks of the tender shoots, and shield themselves there as best they may from the storms.

As soon as the olive blossoms in the spring, the mating of the Psylla takes place, and the female deposits her eggs on the flowering branches, enveloping them with a cottony material. The larræ soon appear, separating themselves at once from the cottony covering, and attacking the blossoms from which they draw their aliment. In twenty days from hatching, they transform themselves into perfect insects. In the warmer localities the Psylla appears about the middle of April, but in rery forward seasons it frequently happens that the second generation is at work by the last of that month. The Psylla of the first generation commence the work of propagation at once by attacking fresh branches, and continuing without stoppage, till the first of July. A part of the insects then die, whilst others survive until the succeeding spring. The larva and the chrysalis prefer remaining in the same place; when molested they move with difficulty, and even the insect when disturbed will neither hop nor fly with much agility.

'This insect nourishes itself by sucking the honey of the blossoms. The blossoms attacked by it either wither away, or are slow of development, and produce few olives, and these few of a poor quality.

The early spring rains, if followed by high winds, have a tendency to dislodge the cottony substance containing the eggs or larræ, and many of them perish in this way, but the radical remedy for their distruction is to cut away the infected branches, although this method is both difficult and costly. All branches 
pruned away should be burned at once. Another way is to spray the tree, of course before it is in blossom, either with a solution of whale oil soap, and lye, or still better, use high fire test kerosene, mixed with ten times its volume of water.:

\section{COCCUS OLEAE.}

\section{(See Plate XII.)}

The characteristics of this insect are the following:

The egg is orange color, oblong-ovoid in shape (Fig 4). Larvi, (Fig. 5, 6, which hatches in fifteen days from deposit of egg, is very agile in movement, body a depressed ovoid-oblong; composed of eleven rings; one, cephalic, three thoracic which are the largest, and seren abdominal short ones. The antennæ silky and nine jointed, (Fig. 12), the first of which is short and thick, the second very small and the third is the largest of all. After the last al. dominal ring there is a wedge shaped appendage and from the posterior angles of this ring start two bristles as long as the abdomen.

The tarsi which forms almost a continuation of the tibia have two joints, the last of which has two small claws and two filaments, ending in buttons. The outlines of the body are fringed with short hair, general color pale yellow, the eyes brown.

When the first shedding takes place the chrysalis becomes fixed and adherent. The body gradually extends iself and the caudal filaments drop away. 'The figure and transformation varying according to the sex. The male chrysalis after the first moulting has the form of an ellipse, with a ridge running lengthwise the centre of the back, with two other ridges crossing it at right angles. This lengthwise ridge is cut off square near the head and from it spring two other smaller ridges which terminate in eyes. The rings of the body are indistinct, the margins are spread out like a plate, they are rounded at the bottom and lightly fastened together. The antennæe

* Kerosene is given the preference as a wash for olive trees, but care should be taken that the quality is first-class. It should be carefully experimented with before being used, in order to see if it will hold the water in solution, for if it does not, it may result in killing the trees. See Mr. Ellwood Cooper's relation of his experience, before the Fruit Growers' Convention, held in Santa Barbara, April 12, 188s. 
and feet are not risible from a back view. Elevated portions of the body are reddish colored, the expanded portions rellow, and the eres black.

After some dars the second shedding takes place. When the chrrsalis has reached its full development it is a little more than a twelfth of an inch in length. Then comes the last transformation, the shell bursts and the perfect winged creature appears. (Fig. S.)

The female chrysalis differs from the male by haring a wider bodr, and the lateral posterior lobes undivided. It is agile and active. The antennæ and feet extend besond the margin of the body but in repose are drawn in and cannot be seen from a back riew. The segmentary divisions are the same as in the larræ. When sufficiently dereloped to reach a twelfth of an inch in length, it assumes an elongated octangular figure. When in motion the feet are not visible berond the bodr, the antennæ alone orer-reaching it. The back has a ridge running lengthwise. with two other ridges crossing it as has been described in the male. In this stage it is torpid. The last moulting now takes place and it passes to the stage of the perfect insect. (Fig. 9, 10, 11.)

The male insect (Fig. S) has a slender, elongated body, eves rery distinct, antennæ delicate, thorax well defined, abdomen long. and ending in two filaments twice as long as the bodr, and furnished with a stiletto shaped appendage. The wings are colorless and transparent and have two thick sinews running lengthwise through them. The body is of a reddish rellow in color and the eves are black.

The female insect has an oroid-oblong body with skull and segmentary division outlines evenly fringed. There is a notch at each ere and one at the caudal extremity. The antennie and feet are concealed by the expansion of the sides of the body. Betreen the posterior lobes and the anus there is a space triangular in shape, in which by the aid of a microscope, two symmetrical lobes can be seen, and in the center a caudal appendage. The back is of a greenish 
color marbled with black, the ridge down the center being of a lighter shade.

From a rentral view the rings of the body can be plainly seen, and also the feet, antennæ and borer; all of which are of a pale vellowish green color; the eves are black. The length is from a fifth to a sixth of an inch.

As soon as the female is perfectly developed, it becomes sedentar's, attaching itself to a leaf or the wood of a branch and deposits its eggs, first covering itself completely with a cottony substance, which exudes from its body. In this hiding place it empties itself of from four hundred and fifty to five hundred eggs. The larræ, as soon as hatched, break through this corering and scatter broadcast, the mother remaining for some time longer, the substance surrounding her hardens and forms a shell which she breaks through and abandons. The time of the metamorphosis is not constant; from May to September, insects, larre and eggs can be found at the same time.

This insect draws its nourishment from the sap of the tree, and the branches attacked will wither away. It frequently occurs, that on branches selected by this parasite, the black smut or Rust is generated. Its destruction is not difficult, it only being necessary to spray the tree, at different seasons of the year, with kerosene mixed with water, or some preparation of whale oil soap. Should these remedies be ineffectual, the diseased limbs should be cut away and burned.

The presence of ants on a tree are an indication that these insects are about. The ants are very fond of them and are a valuable auxiliary in their destruction.

LECANIUII OLEAE.

(See Plate XII Fig. 17, 18.)

The larræ resemble greatly those of the Coccus oleae just described, with this difference in the female; in the adult stage it 
has the aspect of a tortoise shell, and is of a dark chestnut color, very convex, with the ridge in the middle of the back and the two lateral ones very distinct. As soon as the larva hatches, it leaves its covering and the mother dies. The habits of this insect and the methods for its destruction are the same as given for the Coccus oleae.

\section{CISTICOCCUS POLLINII.}

On the branches that are somewhat languid where dried berries and leaves are adherent, can be found in the forks, and at the stem of the leaves, small excrescences, like a grain of corn, the color of the dry wood. On opening one, an outside shell is seen, and in this is a soft heart shaped body or sack which is orange color and enveloping as many as thirty eggs. In April the egg has the germ well developed, and in May the larva appears. It is oblong-ovoid, and has the antennae and feet shorter and more robust than the Coccus oleae just described. The antennae are six jointed and terminating in a group of bristly hair. The femora are very large and on the last abdominal ring there are three short appendages, each terminating in a short bristle. The ultimate transformation of this insect has never been ascertained. The damage done by it however is identical with that of the Coccus oleae, and the proper method of destroying it is to cut off and burn the infected branches.

\section{TRIPS OLEAE.}

This insect is also called the olive louse. The damage caused by it is very similar to that previously described.

The larva is soft, oblong, and narrow behind, orange colored, antennae whitish, feet black. The head is square in front, curving in at the top, the eyes protruding, and placed midway the length of the head; antennae short and thick, rings of the thorax large. The abdomen has eight rings which are fringed on the sides with stiff hair. Feet and femora robust, tibia as long as the femora, tarsi short and thick, and like the tibia, terminating in short fine bristles. 
The perfect insect has a slender elongated body, head cylindrical, longer than wide, protruding eyes, antemnae nine jointed, upper thorax almost hexagonal, wider than it is long, abdomen wider in the middle than at the base, and composed of segments posteriorly rounded, and in the female ending in the ovary, which is nearly horn shaped. Upper wings nearly reaching to abdominal extremities, fringed with long hair, reaching about two-fifth the way round the body, under wings plain and shorter, the feet robust, the femora swollen, the tibia small at the base and enlarged at the extremities, the tarsi short and thick, double jointed and finished with two delicate claws. General color a splendid black, the antennae rellow, the upper wings a dirty white. The length of body nine hundredths of an inch.

The Trips exist in the clefts of the branches and among the buds; and if there are many of them, they will extend themselves to the under-part of the leares. They are agile and fly well. The female deposits her eggs wherever she happens to be, and the larræ remain in the same place. About a month is necessary for the different changes to take place. In the spring and autumn they produce sereral broods. At the beginning of winter, those that survive, conceal themselves under the bark, or in its crevices and rest quietly till the following spring. When the Trips are in great numbers and invade many branches, the trees infested should be shaken, first spreading a cloth beneath, to gather up the larve, chrrsalides, and winged specimens that may fall. If the branches have been long infected it will be better to take them off outright and burn them. spraying with kerosene in the autumn before these lice have thoroughly secreted themselves under the bark, will probably answer ever? purpose.

The Apple, Greedr, and Red Bay Scale insects have all been noticed on the olire in California, but so far as known do not seem to have inflicted much injury on the trees, and are easily exterminated by the application of the nsual remedies. 
BLACK SCALE OR COCCUS OLEA AND LECANIUM OLEA.

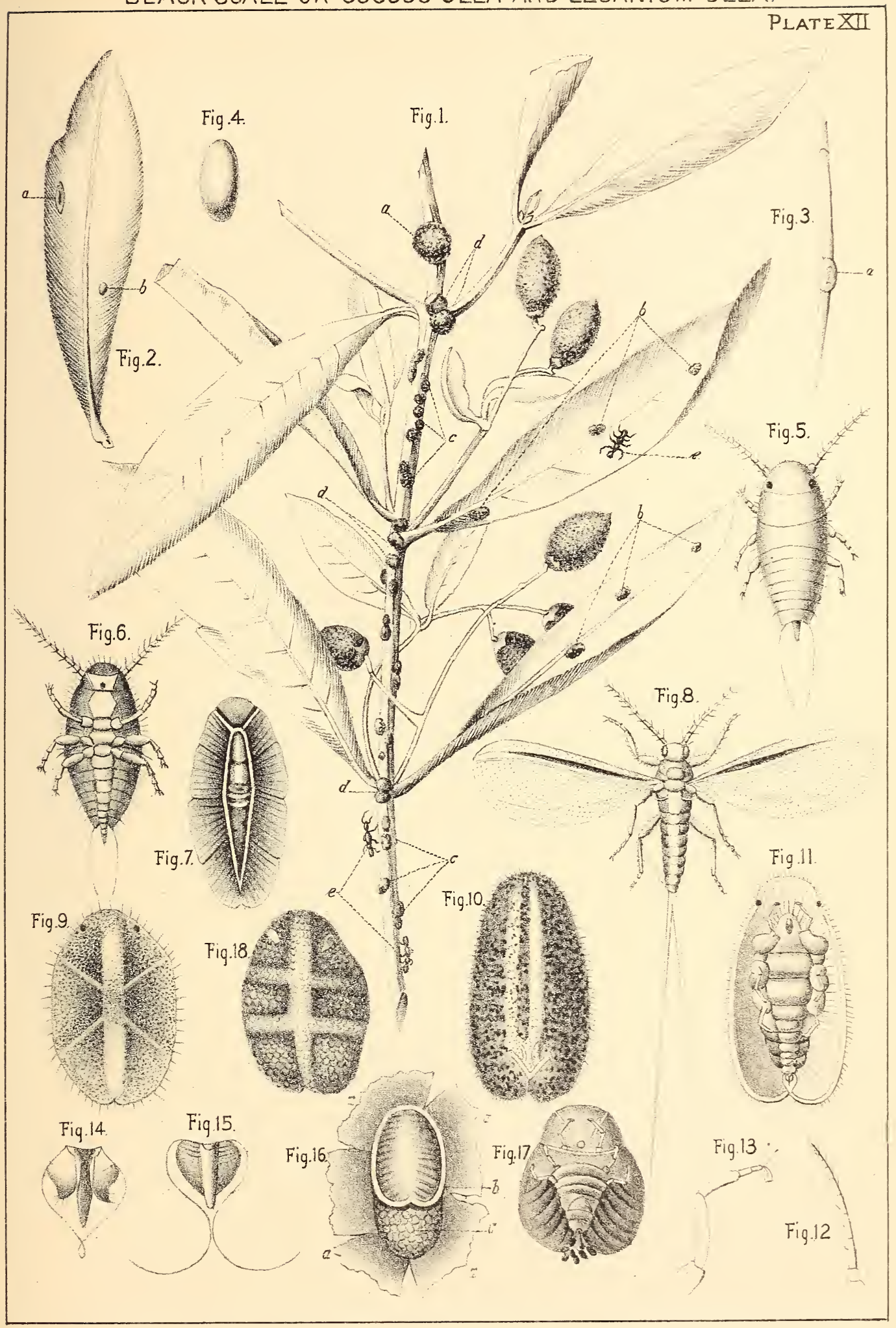




\section{PLATE XII._COCCUS OLEAE AND LECANIUM OLEAE.}

\section{BLACK SCALE.}

Fig. 1. Small branch attacked by scale, $a$, small woody excrescence which sometimes appears on olives attacked by this insect; $b$, $b$, leaves which show on lower side some young scales covered with cottony substance; $c, c$, the shells of dark brown which cover the females and their eggs as yet unopened ; $d, d, d$, other old shells, in which are eggs, the larve having gone out; $e, e$, ants searching for scale of whom they are very fond, (natural size.)

Fig. 2. Leaf showing on lower side two scales $(a)$ male $(b)$ female, (natural size.)

Fig. 3. Twig showing at (a) shell of dead female scale.

Fig. 4. The egg (increased.)

Fig. 5. The larva just closed in, seen from above (enlarged.)

Fig. 6. The same seen from below (enlarged.)

Fig. 7. The male in chrysalis stage (enlarged.)

Fig. 8. The same as insect (enlarged.)

Fig. 9. The young female (enlarged.)

Fig. 10. The adult female, seen from above (enlarged.)

Fig. 11. The same seen from below (enlarged.)

Fig. 12. Antenna, (enlarged.)

Fig. 13. Foot, (enlarged.)

Fig. 14. View of anus, from above, (enlarged.)

Fig. 15. Same from below, (enlarged.)

Fig. 16. Female at point of hatching, seen from bekow.

Fig. 17. Female laying eggs, seen from above, (enlarged.)

Fig. 18. Adult female, seen from above, (enlarged.) 


\section{CYNIPS OLEE.}

This insect has long antennæ which are enlarged slightly near the ends with fourteen or fifteen joints according to sex. 'The upper' wings have three small cubical cells at the base. The borer at base of abdomen is placed between two blade shaped appendages. The female bores into the branches and deposits her eggs. The resulting larvæ gnaws the bark, wood, and even the pith, digging little winding tunnels. The buds on the branches attacked soon wither away.

This insect reaches its perfect development about the beginning of summer. 'The methods for its destruction should be the same as for the Hylesinus oleiperda.

\section{PTEROMALUS QUADRUM.}

This insect has antennæ like an elbow, having nine joints, the first long and the last oval. The head is large and broad, the abdomen of the female prolonged into a conical point. Wings without radiating cells. Tarsi with first joint the longest. Borer scarcely visible. Head a splendid bronze green. Upper wings transparent, without sinews, and with two black spots in each near the outer edge. The Antennæ and feet black. Tarsi deep yellow. Its habits are about the same as the insect just described.

PRAYS OLEELLUS.

\section{(See Plate XIII.)}

This formidable enemy of the olive is known as the olive moth. The egg is globular in form (Fig. 7), and its surface is composed of minute tubercles. In color it is milky white, and is about a hundredth of an inch in diameter.

The larva (Fig. 8, 8a, sb) has a long, soft body, with fourteen rings, one cephalic, three thoracic, and ten abdominal. It has three pairs of true feet in the thoracic rings, and five false pairs in the third, fourth, fifth, sixth, and tenth abdominal rings. 
The head is horn shaped, broader than it is long, with a convex bulb on each side. Two indented lines, starting from the base, cross in the middle of the back of the head, and form a $\mathrm{V}$ in front.

There are five or six little dots on either side of the head. The antennæ are very small, with three joints. The first thoracic ring is flat and smooth. The second and third have a transversal crease, on each side of which are two minute tubercles, each containing a bristly hair.

The first eight abdominal rings are uniform; they are broader than long, with three tubercles on each side, each holding a bristle. The ninth ring has six hairy tubercles equidistant from each other. The last ring is rounded and shield-shaped in the back, and has two false feet, which are larger than the others, and which project on either side.

When the larva is first hatched, its color is an ashy green, with the head light red. The first thoracic ring contains two brown spots, and the feet are black. As the larva increases in size, these colors become more decided; the head changes to a bright red, the back of the first ring inclines to a pale yellow, and the spots on it become black and nearly square. The last abdominal ring in some larvæ becomes brown, in others not. Subsequently a darker line appears each side of the center of the back, extending from the second thoracic to the ninth abdominal ring. These lines continue to darken, and between them will appear a pale yellow streak. The backs of the first thoracic and last abdominal rings become a straw color. Some larvæ do not change color till after their transformation into the pupa stage. Their greatest length is one-third of an inch.

The pupa is elongated, (Fig. 9, 9 a, 9 b,) and gradually tapers downward in a conical shape, rounded in front; the wings, antennæ, and eyes are visible. In its first days, the color is a light green, but grows darker as did the larva. Its length is about a quarter of an 
inch. The cocoon which envelops the pupa is composed of silky filaments so finely woren as to be transparent.

The moth (Fig. 10, 10-1, 10 a, 10 b,) has a rounded head corered with narrow scales. Antennæ wiry, with globular joints. Tpper edge of upper wings fringed with soft hair, lower edge bare. Lower wings shorter than upper, and fringed all around with hair which is longer on the upper than on the lower edge. Half way the length of the posterior tibia, are two long spurs. Body, antennæ and feet, covered with ashy gray scales. Upper wings a whitish ash color, with a silvery gloss, with a disk-shaped black spot midway the wing, near the lower edge, and another less marked near lower outside corner. The remainder of the wing is dotted with very minute black specks, irregularly placed. The lower wings of a uniform dark ash color. Length, a quarter of an inch, with the wing folded, nearly half an inch with the wings spread. The foregoing is a description of the moth in its tprical condition and in a state of perfect preserration. The upper wings sometimes rary in the number and size of the spots.

There are three generations of the moth.

First: The winter generation, which draw their nourishment from the leares and tender buds.

Second: The spring generation, which devours the germ of the blossom even before it opens.

Third: The summer generation, which attacks only the kernel of the seed.

In February the eggs of the first generation are seen on the under part of the leaf (Fig. $1 a$ a,). In the last days of that month the larva hatches and commences to consume the foliage (Fig. 1 b,) making galleries under the epidermis of the leaf which takes the color of the dry leaf and becomes transparent. Later on, this gallery is burst by the young grub, which continues to prey upon the leares, (Fig. $1 c$,) enveloping itself in silken threads, as a screen against external agents. Some larre consume the entire web of the leaf 
(Fig. 1 d.) and all shum the direct action of the sun. At the end of twenty-fire or thirty days (about the last of March) the larra commences its transformation into the pupa, wearing on the same leaf (Fig. 1 e), a cocoon which takes about twenty-four hours. In another twenty-four hours the last change takes place, and they acquire the semblance of the pupa (Fig. 9, $9 a, 9$ b.) They remain in a lethargic state for twelve or fourteen dass, when the moth appears, which is about the first of April. The moths live a month or more, and from the middle to the last of April ther flutter about the olive in the evening when the sun is gone. During the day ther remain quiet among the leares and there the female deposits her eggs.

The larræ of the second generation hatch in the first half of May and assault the floral cluster, penetrating within the blossom and consuming the pistil and gemmules (Fig. 2) $a$ a). One larva can in this way destroy twenty or more blossoms. In the first half of June they change into pupæ and in seven or eight days after into moths. These live a little more than a month and towards the beginning of July the female deposits her eggs one by one, piercing the calix of the berry. It is seldom that two eggs are deposited in one berry.

\section{THIRD GENERATION.}

The egge which have been deposited in the olive hatch in about ten dars, and the larve penetrate into the seed of the berry and consume first the skin about the kernel, and eventually the whole almond. (Fig. 5, e, d.) When they have attained their full derelopment they issue from the fruit by boring a hole in the softer part of the seed near the stem, which being thus weakened causes the olive to fall from the tree.

The larra weares its cocoon at once, on either fruit, stem or leaves. In eight or ten dars, that is, from the last of September to the middle of October, the moth of this third generation will appear. from which the generation of the following February will have 
origin. The damage caused by the moth we have already staterl. Those of the first generation injure only a portion of the leaves, those of the second consume the blossonis which would be transformed into fruit, those of the third take the fruit itself.

The different methods that may be suggested to combat the moth may be reduced to these three:

First-To cut away in February and March the branches which shelter the first generation. Their presence can be detected by the appearance of the leaves, which become transparent.

Second-By gathering the olives of August and September as soon as they commence falling, the larvæ at this time being inside the fruit, and the subsequent treatment, in the usual way of oil making, will accomplish its destruction.

Third, The instincts of this insect, as well as others of its kindred, to hover about a flame, can also be utilized as a factor in its extermination. Fires can be built among the trees about sunset, or may be carried in suitable vessels from place to place. Meanwhile the trees should be shaken to dislodge the insects and attract them to the light.

This last operation must be performed either the last of April, from the middle to the end of June, or from the last of September to the midlle of October, when the insect is in its last phase as a moth.

\section{DACUS OLEE, OR OLIVE FLY.}

\section{(See Plate XIV.)}

This is perhaps the most injurious to the olive of all insects, on account of the facility with which it multiplies, and the damage it can cause in a brief period of time. We may also add that it is the most common, the most numerous and the most invincible of all its enemies.

The egg (Fig. 9) is ovoidal, elongated in form, and of a milky white color. Length about one-fortieth of an inch. The larva (Fig. 10, 10 a, 10 b,) is conical in form, elongated, and is composed 
of fourteen rings. The mouth is furnished with two sharp, scaly black hooks (Fig. 10 a,) and on either side the base of the second ring there is a calix-formed papilla, (Fig. $10 \mathrm{~b}$,) the edges of which are scalloped. The twelfth ring is the broadest of all. The thirteenth has small papillæ on each side. The last ring is the smallest and from a back view shows the anus and two lower false feet. The tracheal canals run in a flexuous line to the thirteenth ring where they connect, near the papillae, with a transversal canal. The general color of the body is a dirty white. The teguments are so transparent that the tracheal and alimentary canals can easily be observed. The papillæ on the second and thirteenth rings are reddish in color. Maximum length a trifle over a quarter of an inch. The pupa is an elongated ovoid in shape. The first and last rings are visible only from a ventral view. (Fig. 11, 11 a, 11 b.) The papillæ of the second and thirteenth rings retain their primitive form. All the rings are fluted transversely.

In the first period the pupa is of a dirty white tinge, but changes to a light yellow, the papillae remaining red as does the orifice of the anus. Its length is one-serenth of an inch.

The head of the perfect fly (Fig. 12.), is a little broader than the anterior part of the thorax. The eyes are large and black, antennae three jointed. Its color is sometimes a light straw, and at others a deep yellow.

Of the three joints (Fig. 12 a.), the first is short, the second a little longer, the third twice as long as the second, and ending in a flexuous bristle, longer than itself.

Upper thorax gray, with three lengthwise black lines. Back of abdomen, specked with black, with a lengthwise band, and lower erlges of the first two rings a deep yellow. Ventrical, a dirty dark yellow. Wings glossy, with blotches of brown in apex, sometimes another blotch on lower edge, at the extremity of the anal nerve.

The roots of the wings are a pale yellow. Feet light, tarsi a little darker. The borer and orisac (Fig. 12 b.) is about the same 
length as the abdomen, and is a dark red. The point of the borer is black. The male differs from the female by the absence of the borer, and by having the posterior margin of the third abdominal ring fringed with black hair turned backwards. The body is one-sixth of an inch in length.

The date of the most copious hatching of these insects is rariable. When the olive has reached its greatest development (about the end of July) the flies just transformed from the pupa appear. Copulation then takes place, and the female, choosing the ripest fruit, deposits her eggs there, usually one egg to each berry. (Fig. I $a$. c. b.b).

In less than twenty four hours an amber spot will appear on the surface of the olive where the egg was deposited, which will turn darker after a little time. The spots can be seen only when the berry is green, as it grows ripe they are hardly discernible. Each female deposits about one hundred eggs. In ten or fifteen days these eggs hatch. The larva, with the hooks of borer, attacks the pulp of the fruit, and then makes its way into the seed, boring a winding tunnel. The pulp of the berry above the tunnel will become reddish wrinkled and transparent, thus showing the presence of the enemy. The larva lives from thirty to forty days. Some change into the pupa form inside of the seed and also into flies, but the greatest number abandon the berry by making an aperture through the pericarp and change into pupae either in the ground, or in the crevices on the trunk of the tree.

The flies appear after thirty or forty days. The duration of the three periods, that is the egg, larra and fly may vary as much as twenty days from the foregoing, as eggs deposited at one time may be hatching for twenty days consecutively, and eggs, larrae, pupac, and flies can be found at the same time.

The pupae of the last generation do not change in the given time. that is in thirty or forty days but remain in that state through the spring till the fruit has reached some size and the prosperity of their 
offspring is assured. Then the fly appears; it usually lives from twenty to thirty days on the trees, passing from branch to branch and sucking the sap wherever found. It is rather torpid during the cool weather but very agile when it grows warm.

The damage caused by this fly consists in the consumption of from one-third to one-half the pulp of the berry, thus diminishing the yield of oil and in leaving inside the seed a mass of excrement, which deteriorates its quality.

There are three expedients for combating the olive fly:

First-To gather the fruit as soon as it is barely ripe, and crush it at once, thus destroying the larvæ and pupæ within and preventing further multiplication. The localities most afflicted by these pests are those where the harvesting of the olive is protracted through the winter and part of the spring, either from lack of sufficient help, or to make the white oil, as is done in Lucca and on the Riviera. These, in fact, are the regions devastated most frequently by this fly.

Second.-To keep the trunk of the tree clean and to spray the trees after the harvest is over with something strong enough to kill the pupae, and taking care that not even one berry remains on the ground.

Third.-To cultivate the ground well about the tree, after first shaking it and thus to bury all olives containing eggs, larvae, or pupae. The fruit when picked should not be kept in heaps, or the heat engendered will cause the flies to hatch immediately.

This closes the list of insects that are known to prey upon the olive. Some we already have with us, others a close degree of scrutiny may reveal, and still others let us hope we may ever be spared.

PARASITIC PLANTS OR VEGETABLE ENEMIES.

The olive tree is also subject to injury from the action of several parasitical plants of which the principal and best known are the following. 
THE PRAYS OLEELLUS OR OLIVE MOTH.

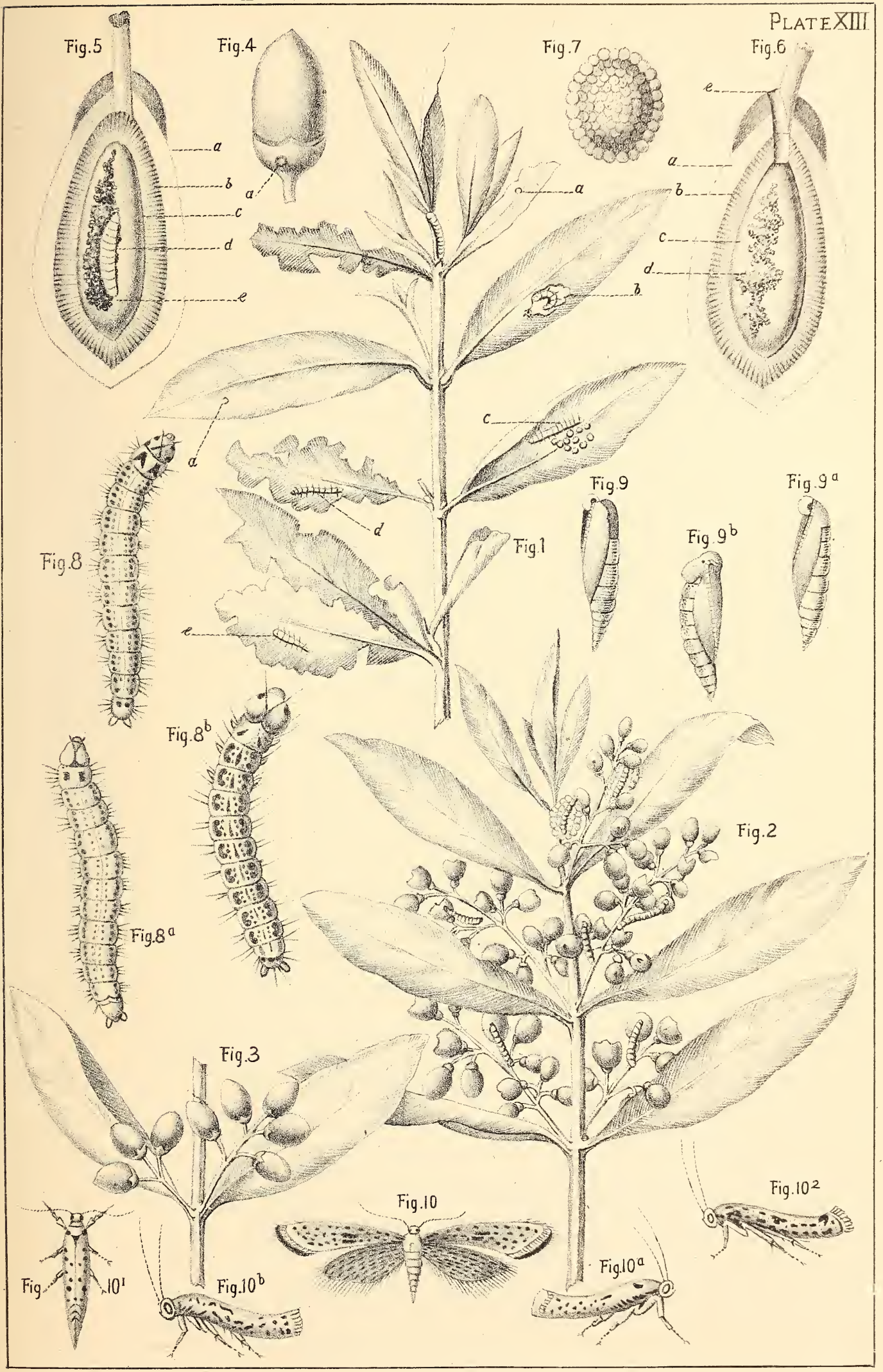




\section{PLATE XIII.-PRAYS OLEELLUS.}

THE OLIVE MOTH.

Fig. 1. Branch attacked by the first generation of moths, $\left(a . a_{0}\right)$ eggs deposited on lower side of leaf, $(b)$ larra which feeds on the leaf, $(c)$ a dult larva which does the same.

Fig. 2. Infested by the second generation on the blossoms when forming.

Fig. 3. Infested by the third generation at work on the fruit.

Fig. 4. Young olive enlarged to show position of egg of this insect.

Fig. 5. Full grown olive cut in two, inhabited by larva, $(\alpha)$ pulp, (b) nut, $(c)$ seed, (d) larva of the moth which has already consumed a part of the seed, (e) part of seed bored and full of exerement of the larva.

Fig. 6. Full grown olive (enlarged), from which the larva has departed to become a chrysalis, (a) pulp, (b) nut, $(c)$ seed almost empty only the outer skin remaining, $(d)$ excrement left by the larra, (e) exit of larva.

Fig. 7. Egg (enlarged.)

Fig. 8. 8, Sa, 8b, Larve in three stages of development.

Fig. 9. 9, 9a, 9b, Chrysalides corresponding to larvæ 8, 8a, and 8b. (enlarged.)

Fig. 10. 10, 10a, and 10b, Moths with stages of development. $10(1)$, the same with wings closed, $10(2)$ the same seen from the side. 
AGARICUS MELLEUS.

(Root rot.)

This fungus has a flat, thin, scaly top with a fluted expanded margin and spongy stalk. On first appearing, it is whitish, but afterwards becomes mottled with red. Spore a floury white. The hairs which are found on the head are black. It is found at the hase of coniferous and fruit trees as well as the olive tree.

Its vegetable system is wrapped about the subterranean part of the tree, and its presence can be recognized by an abundant discharge of resinous matter on the trunk and principal roots, especially of coniferous trees, and by a white creeper which develops beneath the bark of the roots and trunk, and by brown filaments resembling fibrous roots which spread out and run over the ground.

The creepers which are first seen are produced from the germination of the spore. Developing from this, the parasite shews itself on the roots, in the form of a filament or creeper, the outer covering: being smooth and dark, while the pith or marrow is white. These creepers take root in the wood, penetrating the pith and spreading out until in the form of a membrane, they fix themselves in the regenerating zone. By some writers this root rot has been given the name of Rhizomorpha subcorticallus. In a fresh state it has an agreeable odor and seen at a distance in the dark it has a phosphor. escent appearance.

The regenerating zone attacked by the Rhizomorpha ceases to be prolific as the formation of new wood has been interrupted.

The cellular and fibrous elements invaded by these tendrils turn brown.

After this plant has devastated the lower part of the trunk of the tree, it spreads upward to the surface of the ground, showing itself in the autumn through crevices in the bark. The decay of the Mulberry, Chestnut, Fig, and sometimes citrus trees, it is believed is principally due to this fungus. The tree withers gradually without apparent cause, the climate and chemical or physicial con- 
ditions having no part in its decline. The propagation of this disease through the creeper, can be effected by the contact of healthy with infected plants. Infection through the spores commences in the trunk, and is transmissible by the wind.

Where this malady is suspected, if it exists, an examination will show the fungoid growth of the Agaricus melleus. The only radical treatment for this parasite is to uproot the infected trees at once, and burn at least the affected parts. The extirpation of the mushroom will prevent propagation by spores. Other trees should not be planted immediately in ground from which diseased ones have been removed.

FUMAGO OLEE, BLACK SHUT OR RUST.

(See Plate XT.)

This is an epiphyte fungus which attacks the branches and foliage of the olive more especially on the under parts.(Fig. 1.) It consists of black sooty blotches which form an incrustation more or less dense, which is smooth on the adhering side and scaly on the outer side. The black powder, greatly magnified, is seen in (Fig. 2.) The trees attacked by this black smut, languish as it impedes the exhalation of the leaves. It manifests itself mostly on plants that have not sufficient light, or which are situated in soil that is poor, or low and humid. Sometimes it follows immediately the invasion of the scale which have enfeebled the branches or where the Honer dew prevails. These are conditions favorable to this fungus.

Some entomologists claim that the scale is the cause of this fungus. This is a question in olive culture that has been wiclely discussed and has occupied the attention of European experts for the last hundred years with the result that it may now be stated positively that this fungus can be propagated without the aid of the scale insect. The black scale and the black fungus are two separate and distinct pests to which the olive tree is subject and though they are often seen together, have origins entirely distinct. 
The black fungus is due solely to local causes. 'There is eithel' too much dampness or not enough light. The infected branches should be cut off and burned and the tree sprayed with kerosene as heretofore described. No olive tree on ground high enough for a sufficiencr of air and ventilation was ever afflicted with this pest. The cultivation of the soil prorokes moisture and stimulates the regetable growth of the tree, so where the black fungus appears, cease this cultiration, do not stir up the soil, but on the contrary check the excessive growth and humidity, by allowing the surface of the ground to harden. Prune the trees so that each may have a maximum of light and air. If the excess of moisture cannot be remedied by these means, the soil must be drained.

VISCLY ALBLY, MIsTLETOE.

The mistletoe is propagated from one tree to another by its seed. It extends its green roots through the branches from which it draws its nourishment, greatly enfeebling the tree. The only method of destroving it is, to cut off the branches on which it has effected a lodgment, and burn them.

\section{LICHENS AND MOSSES.}

It is erroneously claimed by many writers that the moss substance which grows upon the trunk and branches of the olive and other trees is a parasite. Instead it is composed of moss and lichens. the principal ones of which are Parmelia, Lecanara, Terrucaria, etc. among the lichens, and Hrpsum, Leskea, Brym and Orthotrichum among the mosses.

These last are cormus fungi, and all are epiphytes and live on the outside of the dead bark and exercise no parasitical influence. Ther shield the bark from the sum, but the humidity ther engender is a frequent cause of rot, and they also serre as nesting places for hurtful insects. For these reasons it is well to liberate the trees from them by scraping the infected parts, or spraring with a solution of lime. 


\section{HONEY DEW.}

The Honey dew consists of a gummy sugary perspiration on the leares, especially on the under side, on the flowers, and on the young branches. This substance sometimes forms itself into a rarnish uniform in its deposit, and at others into drops like dew. This disease attacks the Olive, Poplar, Linden, Orange, Walnut, Willow and Elm trees and also the grape vine. The real cause of it is unknown. Some writers think that the viscous matter is exuded from the cochineal insect which infests the plants, but others have observed that this disturbance exists both on trees in the open air, and on those enclosed in greenhouses where there were no insects.

The popular idea is that the humor emitted by the morbid leaves is a production of the plant itself, caused by the unfavorable influence of a hot, dry soil. Admitting this to be the probable cause, the remedy would be copious fertilizing and to prune the tree so as to keep the top in proportion to the spread of the roots.

SCAB.

The scab manifests itself in wart-like excrescences as large as waInuts, often affecting the youngest and most slender branches. The plant imporerished by this pest takes on a languid appearance and sometimes dies. Ordinarily this eril is met with on soil that is low or too rich and not sufficiently rentilated, or where trees are placed too near together, in trees excessively pruned, or in those maltreated in the gathering of the fruit by beating with poles.

Some writers hold the opinion that the scab is caused by either a regetable or animal parasite, but the most diligent microscopic observations have never revealed the presence of an insect, either before, after, or contemporaneously with, the apparition of the small protuberances. The cause therefore must arise from some disturbance of the functions provoked principally by contusions, either from hail storms or by poles in beating down the fruit, by excessive pruning, or by absence of light and air. The contusions of the cortical 
tissues and of the regenerating zone has the same effect that the puncture of an insect would, and at times produces the enlargement of the zone and sometimes the enlargement of the herbaceous tissues. These enlargements in time extend to the wood under the bark and cause the bark to draw away thus affording a receptacle for different insects. This would however be an effect and not a cause of the evil.

Some orchardists remove the protuberances by shaving them off with a sharp knife, but this does not restore the tree to health as this cutting does not remove the primary cause. The first method for its cure is to keep the trees wide apart, well lighted, to prune sparingly, and to abolish the barbarous usance of beating the trees when gathering the berries.

Senor Tabladla says he found an insect eight hundredths of an inch in length in the act of making these warts and cured the tree by cutting them off.

\section{THE OLIVE ROT.}

\section{(See Plate XVI.)}

The rot is the gangrene which appears on the trunk and larger branchas of the olive tree. At times it is so extensive as to consume nearly all the cylindrical part of the wood leaving the larger branches hollow and rendering them an easy prey to the action of the winds.

When a wound is made on the olive tree either by the breaking of a limb or by pruning, and is not at once shielded from contact with the air, a prosess of canker is initiated, provoked by the humidity found there, the action of insects and the spores of certain lichens or creepers. Trees improperly pruned are usually the ones attacked by the rot. To prevent it, an olive orchard should be placerl on well drained soil and receive plenty of light. The trees should not be bruised and when a branch. is cut off the wound should be immediately covered with grafting wax or a mixture of cow dung and clay. When the rot has taken hold the diseased part 
should be cut away till the sound wood is reached and this should be well spread with grafting wax.

\section{INSECTICIDES.}

If the orchard is sprayed once a year it will be sufficient, and the best time is in the winter after all danger from frost has passed. Whale oil soap is an excellent remedy but it has not the efficiency of kerosene. It will kill the coccids but has no effect upon their eggs. Kerosene pure and simple would be a dangerous and entirely unnecessary remedy to use, but diluted ten times with water it becomes much less expensive and by far the most efficacious.

The United States Department of Agriculture has published the following recipe to make thirty gallons of wash.

\section{EMULSION.}

Kerosene, 2 gallons .67 per cent.

Whale oil soap, $\frac{1}{2}$ pound

Water, 1 gallon .33 per cent.

Boil the soap in the water till entirely dissolved then add it to the two gallons of kerosene, and churn the mixture thoroughly for five or ten minutes. The emulsion if perfect forms a cream which thickens on cooling, and should adhere without oiliness to the surface of glass. Any danger in the use of kerosene lies in the faulty or half-made enulsion. The soap may be of insufficient strength through exposure or some similar cause, when an increase will oblige the oil and water to emulsify, and will also make the emulsion nearly permanent.

The percentage of kerosene should not exceed eighty per cent., as the oil weighs six and a half pounds to the gallon, while water weighs eight, and more cannot easily be held in suspension in water. On the other hand in the process of emulsification, kerosene loses a portion of its value as an insecticide, and emulsions containing less than thirty per cent. of oil, although they may not separate 
when diluted with water, are nevertheless too much weakened for effective use against scale insects.

The reason that high fire test kerosene is recommended as an insecticide is, that the lighter oils with which it is associated in a crude state, have been eliminated by the refining process, these being exceedingly deadly to vegetation, leaving the refined kerosene which should always be used for this purpose. The heat of the sun increases to an injurious extent the action of kerosene, and stronger solutions than that above given if used at all, should be applied on cloudy days or in the evening.

Experiments with different grades of refined oil, the Elaine amongst the number, show that they all emulsify equally well if the alkali contained in the soap is of sufficient strength. But the Elaine separates the soonest.

The kerosene wash should be applied in a fine spray from the center of the trees, and not the least of its recommendations will be its very great economy.

In addition to insect pests and vegetable parasites, the olive tree numbers among its enemies the blackbird, the robin, the starling, the jay, and the crow, as they are all eager devourers of its fruit, but it is aided and greatly assisted by the nightingale, the titmouse or tomtit, and the woodpecker, as they never touch the berries, and are insect eaters only, and should therefore be encouraged in the orchard. The predatory birds should be fired at in the air, so as not to wound the trees with the shot. The pugnacious English sparrow, by driving away all other birds, especially the little tomtit, is an enemy particularly to be marked for destruction. 


\section{Hazvest anส proaluet.}

\section{CHAPTER XI.}

"L'uliva quanto piu pende piu rende."*

THE FORMATION OF THE OLIVE AND ITS FATTY SUBSTANCE.

Dr. A. Funaro, of Pisa, from some very interesting experiments conducted by him at that place in 1878 , has been able to prove that the nut is the first part of the fruit to form. The olives experimented upon were gathered from a farm near Pisa, at intervals from July 10th to February 25th, and carefully analyzed, with the object of studying the formation of the fatty material This fact had already been stated by Prof. A. Roussille.

On the 25 th of July the nut itself was not perfectly formed, but on the 10th of August it was quite perfect, though tender, and could not be detached from the fleshy part.

On the 25 th of September it had reached its full development. Then commenced the increase of size and weight of the pulp, and the rapid increase of the fatty matter, while the quantity of water diminished slowly, oscillating according to the atmospheric conditions of the days when the olives were gathered. These, after the 10th of August, increased gradually until the 10th of September. Between the 10th and 25th of September they almost doubled in weight. One hundred olives which on September 10th weighed 75.94 grams, on the 25 th of that month weighed 144.22 grams. After this period the increase of weight was gradual, but only slight, up to the 25th of October; after that date a progressive and slow decrease set in.

*The longer the olive hangs, the more it renders. 
THE DACUS OLEA OR OLIVE FLY.

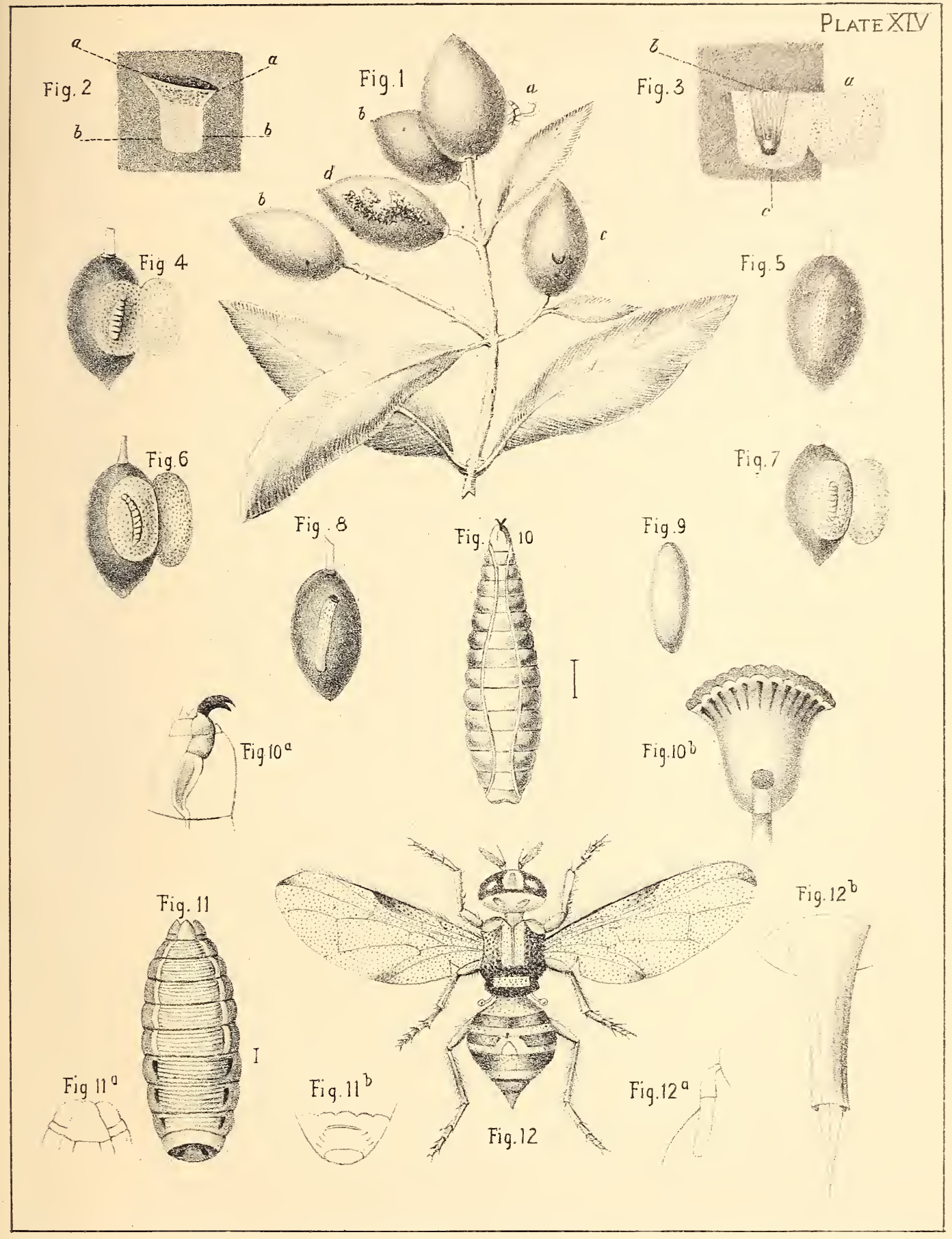




\section{PLATE MIV.-DACUS OLEE.}

THE OLIVE FIY.

Fig. 1. Branch with fly in act of depo-iting egg at $(a),(b b)$ showing spots where eggs have been deposited, $(c . d$.$) showing gallery$ cut by the larre with purple lines.

Fig. 2. Piece of pulp increased in size, a, a, wound made by boring. b, b, corresponding to cavity which contains the egg.

Fig. 3. Same with the skin raised to show the carity containing the egg at $c$.

Fig. 4. Green olive showing larræ.

Fig. 5. Mature olive with transparent lines showing gallery.

Fig. 6. Same open showing larra.

Fig. 7. Same open showing chrysalis.

Fig. S. Same open showing hole of exit of larra.

Fig. 9. Egg (enlarged.)

Fig. 10. Larra enlarged, 10 a, two first rings with claws, side view; (enlarged), 10b, Papilla at the base of which opens the anterior extremity of tracheal canal.

Fig. 11. Chrrsalis (enlarged), 11a, the first ring still more enlarged, 11b, (the last ring enlarged.)

Fig. 12. Female insect, (enlarged) 12a, antenna side riew, (enlarged) 12b, borer, (enlarged.) 
In fact the same one hundred olives

On the tenth of October weighed.................161.7.

" twenty fifth of October . ....................163.93

" tenth of November..........................117.5.3

" twenty fifth of November...................128.88

" tenth of December...........................136.50

" twenty fifth of December....................136.40)

" tenth of January .............................163.85

" twenty fifth of January...................109.85

" tenth of February...........................132.50

“ twenty fifth of February...................131.6.

The variations are due to the quantity of water contained in the pulp according to the hygromic condition, the winds, the rain and the hoar frost which coincided with the gathering.

On the twenty fifth of November the olives were empurpled, and had a reddish pulp, on the tenth of December they had turned black and the pulp was still more highly colored, and on the tenth of February the pulp was entirely of a winey red.

In one hundred parts of these olives the following proportion was found in weight of water, of dry material and of fatty material. 


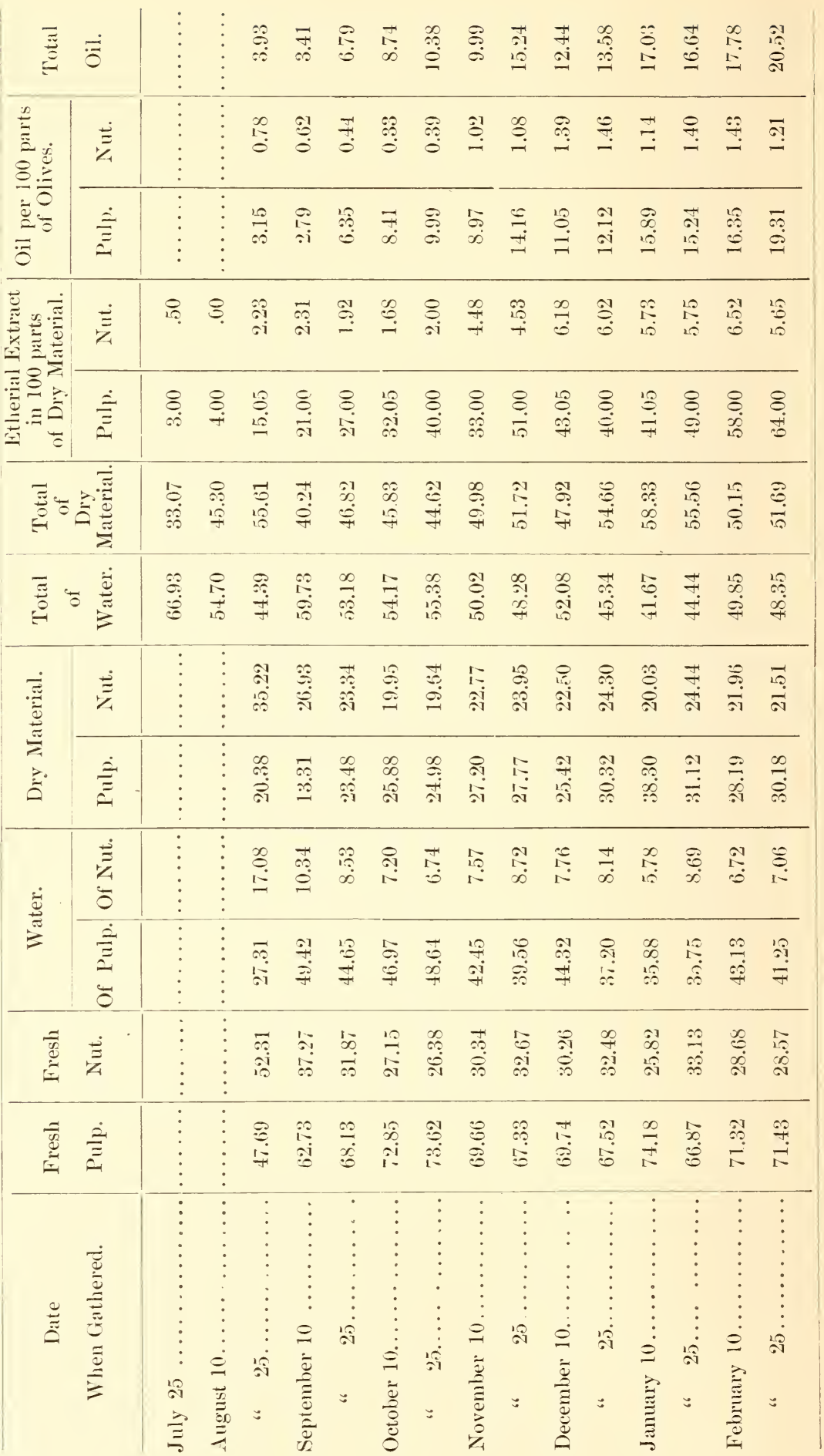


Whence it is clear that in the berry the quantity of water after the tenth of September diminishes gradually. From 59.7: per cent. it falls to 48.35 by the end of February thus losing about 19 per cent. or one-fifth of its weight. The percentage of oil, especially of the pulp, increases notably from the end of September to the end of November, but after this time the increase is small. The Italian country folk have a proverb which justly says: "At Santa Reparata (8 Oct.) every olive berry is oiled." From this time the pulp grows softer, and squeezed between the thumb and finger, some little globules of oil can be seen.

By the investigations of Signor Harz, of Vienna, confirmed by those of Roussille, it has been shown that the fatness of the olive is formed in little special cells of secretion precisely as the chlorophyl or green coloring matter is evolved and these are distributed through the berry side by side. When the fruit is still young these cells contain a material which is not fatty, nor is it starch, or any of the hydrates of carbon similar to these substances but instead is charged with nitrogen and contains a substance which in the process of ripening, takes on the character of a tough gum, wax, and fat. Finally this compound material, as maturity approaches, liquifies becomes oil and working from the inside, outwards, the membranes of the little cells themselves are gradually dissolved and the berry is filled with oil.

Messis. Roussille and Funaro have also discovered that while the fatty material of the pulp is always on the increase up to maturity, that of the leaves on the other hand, is almost constant and always in such quantity as to overthrow the belief that there may be any connection whatever between them. The former undoubtedly is formed in the berry as Harz discovered by microscopical observation.

Funaro has further proved that the sugar of the leaves only appears when the oily substance is perfected, that is to say when the plant is near the term of its vegetative period and the fruit is well 
developed. In truth it is not found before November, the season when the oily material is formed in notable quantity, and on the other hand it is met with in December, January and even in February an epoch in which the vital functions are at the minimum of activity.

The conclusion from this is, that the sugar existing in the leaves has $n$ o part in the formation of the fatty material, and it is not to be considered other than as a product of metamorphosis of other hydrates of carbon of secondary importance for oily plants.

\section{WHEN TO GATHER THE OLIVE.}

The time in which to harvest the olive varies according to climate and the product desired. It may depend absolutely on climate, as the maturity of the olive is hastened and more oil is obtained where the temperature is high and vegetation has the advantage of a vivid light.

So the olive matures earlier and carries more oil at the extreme south of its zone, but the oil is fatty, high-colored and only useful in manufactures or as an illuminant, being utterly useless for food. For the latter purpose it should carry little fat or color.

Hence it follows that the northern part of the olive zone produces the finest oils at full maturity, whilst towards the south to secure the same result it is necessary to anticipate and to harrest while the berries are still yellowish or just turning purple.

So in northern Italy and southern France a fine table oil is obtrined from olives that are black and fully matured, and the famous white oil is made by allowing the berries to become over-ripe and deferring the harvest till March, April and even May.

On the other hand, in southern Italy and Sicily a fine oil is obtained by early harresting, mature berries giving an oil that is exceedingly gross, dense, highly colored and of a disgusting taste. So when seeking to produce an oil for table use, the effect of the climate may be modified to a certain degree. 
The so-called white oil is preferred simply because some markets demand it, but it is undesirable from every point of view. As it is made from orer-ripe fruit it soon becomes rancid, and lacks the delicate flavor of oil made at just the proper time. But worse than all this it is made at the expense of the tree, for it is evident that the sooner the tree can be reliered of the burden of its crop, the better it will recuperate for the following season.

It is doubtful whether the olive produces more oil when picked barely ripe, or at full maturity, or when it commences to fall from the tree. The usual belief is in favor of a deferred harrest, and the country people express it in the couplet that heads this chapter.

The longer the olive hangs

The more it renders.

This is an illusion. The longer the berries hang on the trees the greater is their exposure to a variety of perils; the birds derour many, more are beaten off by storms, and unless they are taken off the ground immediately, acquire an earthy flaror which renders them unfit for oil making. Another serious danger is that of being touched by frost which diminishes the yield of oil. But eren supposing all olives to remain on the tree up to the point of full maturity, they are not making any more oil but are losing water. They become softer inasmuch as they lose in bulk, thus increasing the relative but not the actual quantity of oil.

We may therefore draw the following conclusions;

First: That the greatest absolute quantity of oil is to be obtained when the olives are ripe.

Second: That in a late harrest there is no gain in quantity but an actual loss in quality.

Third: That in anticipating maturity in southern countries, it is possible to reduce the tendency to grossness, high color and bad taste and so produce a finer oil.

HOW TO HARTEST THE OLIVE.

From very ancient times the olive has been gathered by beating the trees with poles and so knocking the berries to the ground. 
'The temptation to do this is great. It is evident that it is the cheapest way to get in the crop. But it is penny wise and pound foolish, If the crop of that year was the only one to deal with, well and good, there would be nothing to say against it, but the beating makes it impossible for the tree to bear the following year.

Hence it is plain that instead of being the cheapest mode of dealing with a crop, it is the most expensive as it is one of the direct causes of the olive bearing only every other year.

Each leaf shelters a bud which in time will be a twig or a blossom, if the leaf is knocked off the bud is killed, for its life depends upon the preservation of the leaf, and these leaves are more plentiful on the fruit branches than any other part of the tree. No matter how carefully the fruit be poled off, damage is sure to be done. Olives should be picked by hand from ladders.

If the berries are to be immediately crushed they may be thrown upon a canvas cover placed about the tree to receive them; but if they have to be carried any distance or kept for any length of time it will be best to handle them more carefully, as the bruises received on being thrown to the ground cause an early decay of the berry to the great detriment of the oil.

Different kinds of olives ripen at different periods and in order to make the best oil the berry should be gathered at the exact period of its maturity and at no other. So a very large olive orchard should be made up of different varieties coming in at successive periods, but a small one should consist of only one variety.

Soil and locality also affect the quality of the oil. The same olive on different soils or on a hill and on a plain will give a very different oil; and these should not be mixed, but made separately, or the quality of the whole may suffer.

The olive takes on four changes of color, although all the varieties do not strictly follow this rule: Green is followed by yellow, then a reddish purple which is succeeded by a wine red and lastly a black red or glossy black. If the berry is left upon the tree the 
skin finally wrinkles and the color becomes a dull black. This is the state in which it is popularly supposed to give the most oil, which we have already shown to be a fallacy but even granting it to be true, the quality is inferior, the flavor gross and the oil soon becomes rancid. An olive is fully ripe when on being squeezed between the thumb and finger the soft pulp shows no white, but for many reasons, as we have seen, it may be desirable to forestall this period.

No time can be set when an olive crop should be harrested. It may vary by weeks from one season to another, and it is far better on every account to anticipate, than to defer the harvest. The berries should be carefully gone over and all leaves and dirt picked out; the former giving a bitter taste to the oil and the latter lessening the quantity as well as lowering the quality.

What will an olive orchard produce? As we have seen, it is customary in Spain in estimating the annual oil product of an orchard to calculate that every six trees will give four gallons of oil. This at first glance appears to be a very small yield, but it must be remembered that it is an estimate applied to the whole face of the country, that olive trees are very numerous in Spain and many orchards are very old and in a poor state of cultivation. Also that it is a general annual estimate independent of fluctuations from year to year.

A careful observation of the olive districts in Italy by Professor Caruso, extending over many years, shows that the greatest production is found in Sicily, but not the finest quality. The Sicilian product runs as high as ninety gallons of oil to the acre, falling to fifty in Liguria and the Neapolitan States, which would give a mean of serenty gallons to the acre for the whole of Italy.

Mr. Cooper makes the statement that on a piece of two acres of ground seren year old trees areraged one hundred and twenty-two pounds of olives per tree.

On the Quito Farm, Mission olive trees which were grown from 
cuttings put into the ground in the spring of 1883 , and transplanted to position, have now, July, 1888, a fair showing of fruit, one-half the total number of trees carrying berries on them in varying quantities; and those trees grown from cuttings put in at the same time, and which from their position it was unnecessary to transplant, have attained a much greater size, and carry a correspondingly increased crop. Hence we may conclude:

First-That the olive in California will give a remunerative crop in seven years from cutting.

Second-That we may reasonably expect to secure from seventyfive to one hundred gallons of oil per acre from our olive orchards. The newness of the soil, coupled with the youth and vigor of the trees, assure us that we make no mistake in such an estimate. 


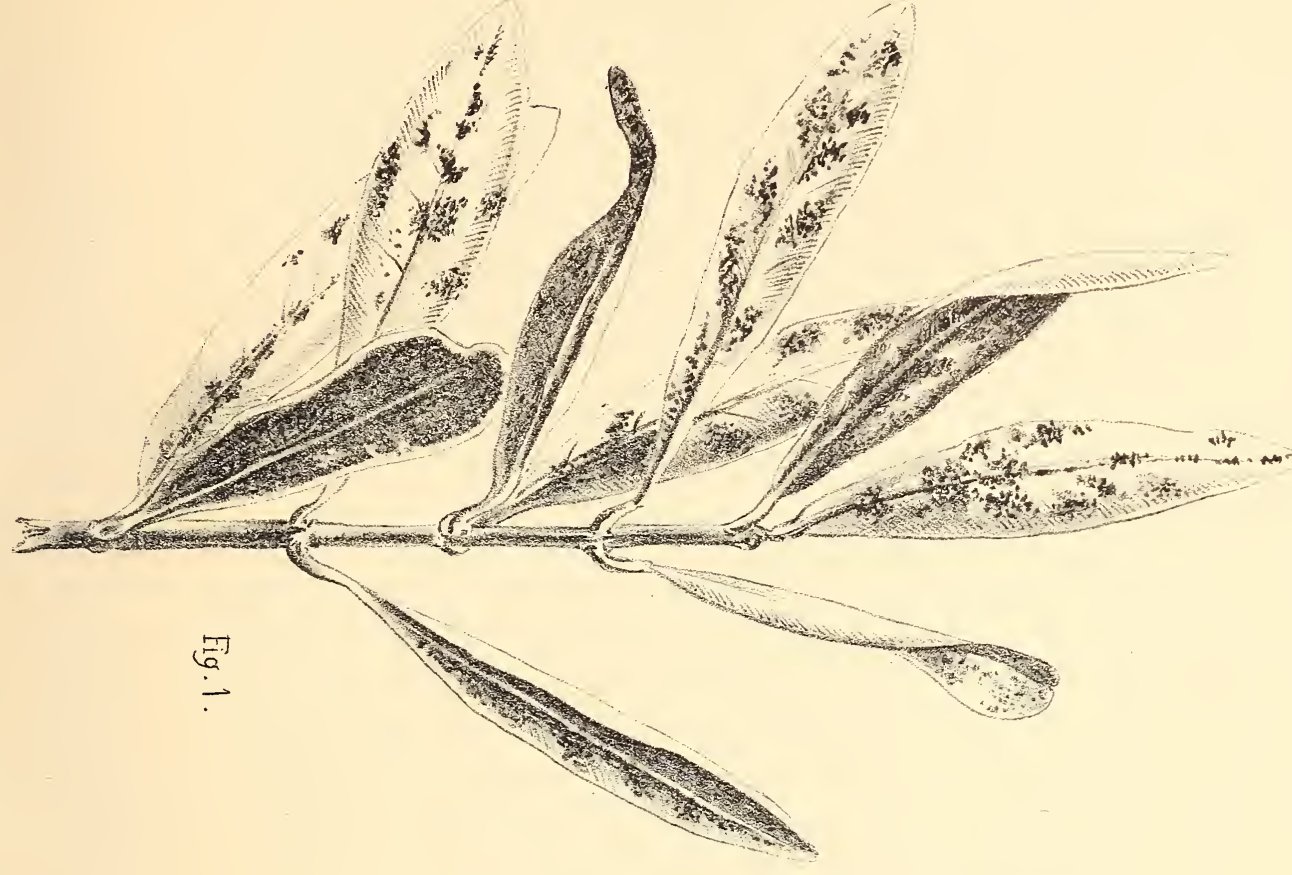

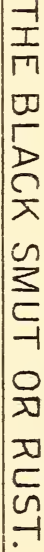
$3=35$

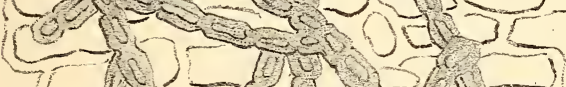
C.

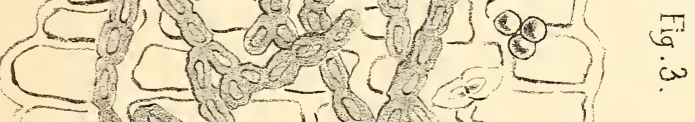
an 150

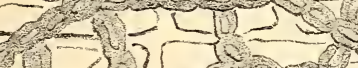
$40=-\lambda$,

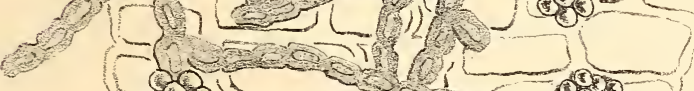
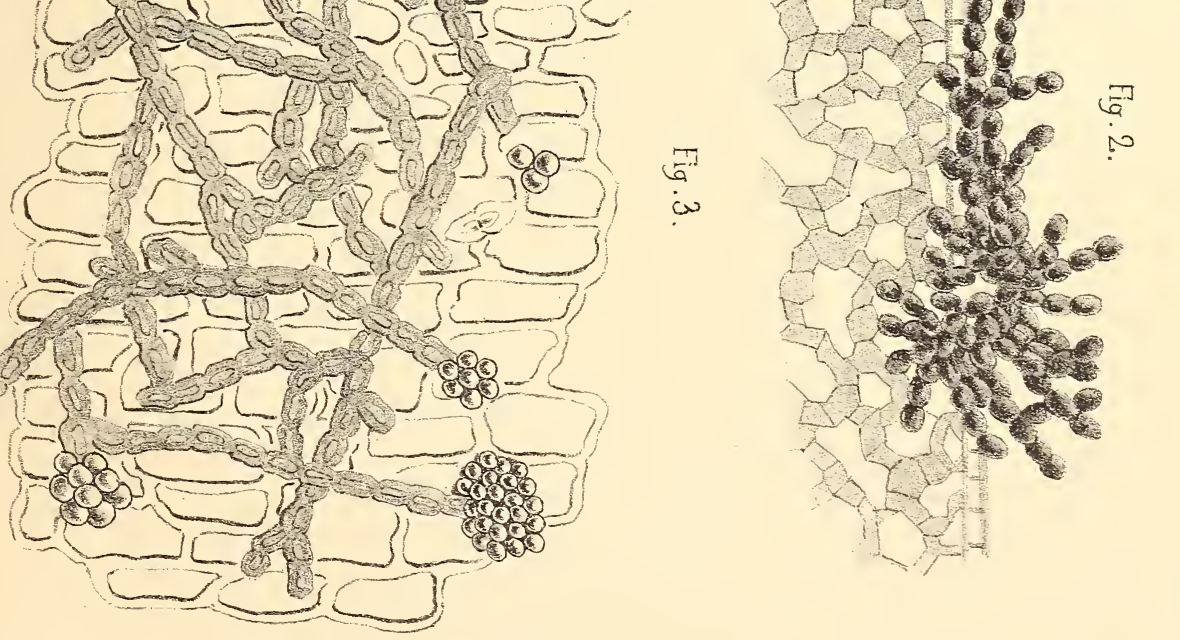


\section{PLATE XV.-THE BLACK SHUT OR RUST.}

Fig. 1. An olive twig attacked by the rust, drawn from life, (once enlarged.)

Fig. 2. Section of an olive leaf attacked by the rust, showing the parasite, (enlarged four hundred times.)

Fig. 3. The rust on the berry. 


\section{Extraction, פtorage and Glaritica- tion of the Gil.}

\section{CHAPTER XII.}

"And wine that maketh glad the heart of man, and oil to make his face to shine."Psalms 104 rs. 15.

A short quotation from the distinguished Prof. Cupari, of the University of Pisa, will give a clear idea of what is somewhat inaccurately called oil making, and correct a common error in regard to the process. He says, in his lesson on agriculture, "Olive oil is not like the juice of the grape, which requires a chemical process to transform the sugar it contains into alcohol, in order that it may become wine; the oil is there, ready made within the fruit, and the utmost that ean be done is to extract it, just as it is, bursting the cells within which it is enclosed, by crushing the olives and then pressing them." "Olive oil is found, not made."

One may fail to extract it, one may injure it in the process, it may lose in quality or eren become rancid by careless handling or storage, but the one and only object of the oil mill is to extract, clarify and store the oil, while experience and skill will undoubtedly add much to the result of a given olive harvest, the fact remains that the oil is made and in the berry. A mortar and pestle will crush olives and the oil and water can be strained out, through cloth or crash by hand. The difference is not of process but of quantity to be dealt with. This should be clearly understood in California, as this interest grows. It is not beyond credence that the happy possessor of a few producing olive trees would be willing to derote the time and labor necessary to extracting his own oil for honsehold use, with the simplest of home machinery and especially when the physician tells him the value of olive oil as both medicine and food; 
and the gourmet of the many additions it may make to the home menu; while the analyst warns him of the detected adulterations not merely of so called imported oils, but of adulterations passed off on the community as "California olive oil.":

The analysis of the berry shows the following result :

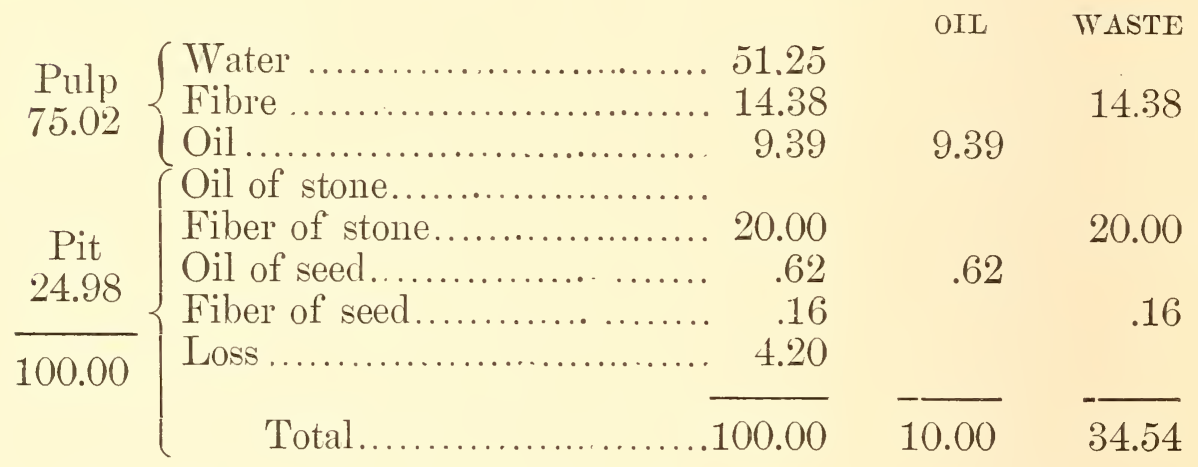

The following is the chemical analysis of the olive:

Potash 57.336

Soda .

5.170

Lime. .

5.115

Magnesia

0.130

Oxide of Iron.

0.305

Chloride

0.111

Phosphoric acid

0.929

Sulphuric acid

0.533

Siliceons acid ...

0.356

Carbonic acid...

29.985

100.000

THE COMPOSITION OF OLIVE OIL.

\begin{tabular}{|c|c|c|c|}
\hline & $\begin{array}{c}\text { Stearine } \\
\text { C. }{ }^{17} \mathrm{H} \cdot{ }^{110} \mathrm{O} .^{6}\end{array}$ & $\begin{array}{c}\text { Palmatin } \\
\text { C. }{ }^{51} \mathrm{H}^{98} \mathrm{O} .{ }^{6}\end{array}$ & C. ${ }^{57} \mathrm{H}^{.04} \mathrm{O}^{6}{ }^{6}$ \\
\hline \multirow[t]{2}{*}{$\begin{array}{l}\text { Carbon ................ } \\
\text { Hydrogen .............. } \\
\text { Oxygen ............... }\end{array}$} & $\begin{array}{ll}76, & 6 \\
12, & 4 \\
11, & 0\end{array}$ & $\begin{array}{ll}75, & 9 \\
12, & 2 \\
11, & 9\end{array}$ & $\begin{array}{ll}77, & 4 \\
11, & 8 \\
10, & 8\end{array}$ \\
\hline & $100, \quad 0$ & $100, \quad 0$ & $100, \quad 0$ \\
\hline
\end{tabular}

* See the late statement by the Horticultural Society of the adulterations practiced in San Francisco. -Pacific Rural Press, July $7 \mathrm{th}, 1888$. 
The oil of the pulp is rich and of a delicious flavor, that of the stone is dark and cloudy, that of the seed contains essential oil, while the skin in its little cells contains an essential and resinous oil in small quantities. These oils of stone, seed and skin, far from adding to the oil of the pulp, would be a serious injury if not in such small quantities. From this it is obvious that in cultivating olives for oil, the varieties with much pulp and proportionately small seeds, should be selected, as is always done in the true oil countries. The proportion of oil to berry as given by reliable authorities runs from ten to twenty per cent. in weight.

The Messrs Rae of Leghorn, olive oil exporters, in their pamphlet on the olive, give fourteen to twenty per cent. and eighteen to twenty for the finest oil varieties. Mr Cooper's best result as given, was ten and twelve per cent. Mr Ludovico Gaddi, and the agricultural manager at Santa Clara College, as well, estimate that forty pounds of berries will produce one gallon of oil, which is about eighteen per cent.; but this of course refers to well diried berries.

It should be said that California olive culture is so comparatively recent and limited, that reliable statistics can hardly be expected. But it may be safely asserted that certain exaggerated statements which have appeared in print, as to percentage of oil to berries, will not be verified even in this exceptional soil and climate.

In view of the fact that the processes of the oil mill, are simply to "extract" the oil, the clarifying, whether by simple deposit or by passing the oil through refining material, being but a part of the general work of separating the oil from the solid and watery parts of the berry, it is evident that unless some mechanical difficulty renders delay necessary or convenient, the berries will yield a better oil if this be extracted immediately or very soon after their gathering. That this is true is now admitted by all writers of value, and by all manufacturers of the fine grades of oil. . The belief that olives retained for long periods in the store house produce as good an oil, and much more than the freshly worked-a belief held by the rus- 
tics in the times of Cato and Columella, and controverted by both these writers-still holds its own among the more ignorant peasants and notably in Spain, where olives are often stored for months and occasionally for a year.

Again, the immediate extraction within twenty four hours as advised by Messrs Rae as the best usage of Tuscany, will not always be possible as such a complete system demands very abundant facilities of machinery and labor. No one who has engaged in oil extraction will be inclined to deny that the process is, at least, somewhat more difficult with absolutely fresh olives. While the immediate expression of oil is undoubtedly the best system, and growing in favor and practice, it must be admitted that, in all probability the greater proportion of olive oil and even the higher grades of oil are made after the olives have been partially dried. The question is, how to avoid any danger to the olive, if drying is found necessary or convenient. The purpose of drying is to remove as much of the water of the olive as possible. Evidently any tendency to softening will be simply the beginning of decay and will injure the quality of the oil, and any possibility of mould must be avoided.

The Italian system is to spread the freshly picked olives on floors of porous brick, not more than five inches deep and allow free passage of air above them, while two or three times a day, they are carefully and gently raked over. If drying is decided upon, or the olives must await manufacture, this is the simplest and safest way for a natural process.

Mr Ellwood Cooper of Santa Barbara has adopted a system of artificial drying of his own invention, similar to fruit dryers, which he has described in his work on olive culture and which he finds satisfactory. Naturally this avoids certain difficulties in fresh pressing. and certain dangers in natural drying.

The first process of the oil mill is the crushing of the olives. The crushing machine generally used, consists of a circular tub or trough of stone or bricks covered with cement, having a stone floor on 
which revolves a heary stone wheel on an axle, one end of which is attached to and works on a pin or pivot set in the eenter of the trough. This mill wheel crushes and grinds as it rolls over the olives, which are constantly pushed by a scraper into its path. This may be worked by hand, by horses, or oxen, by steam or water power. The stone should be non porous lest it absorb oil which may become rancid.

The size of the crusher will vary with the needs of a given mill. Presses are of various kinds. The Italians, Spaniards and French generally use a screw press (descending.) This may be worked by hand, by horse or ox power, by water or steam. In any case the pomace is put into sacks of jute called "bruscole," which are then piled up, eight, ten, or a dozen high, or into a steel eage with or without erash to contain it, and placed under the descending screw of the press.

Mr. Cooper uses a beam press such as is used in cider making. The pomace is held in place by wooden crates and Russian crash. He suggests the oleomargarine press as probably the best for olive oil expression. In both Italy and spain powerful hydraulic presses are used either with the jute sacks or the iron cage. 'They are similar to the hydraulic presses of the wineries, and in fact these latter can be used for oil extraction.

The objection to the hydraulic press is, that with it one runs the risk of suddenly applying too great pressure and what is needed in expressing olive oil is not sudden, but gentle and constantly increasing pressure. If the pomace of olives is suddenly subjected to extreme pressure, no oil at all will flow; for this reason hydraulic presses have been altogether abandoned in some parts of Spain, as in ignorant hands they did not give satisfactory results. The great advantage of the beam press is, that it is impossible to apply the pressure in any other way but by a stearly and gentle increase, as more weight is placed on the end of the beam. But after all, in intelligent hands the hydraulic press is preferable, for if it is 
properly used, the amount of pressure required may be exactly graduated. In the first pressure, usage differs as to the employment of water. It must be clearly understood, that the olive berry contains a large amount of water from which the oil separates itself when the mixed liquid is allowed to rest after the expression, and that the employment of water is not for an adulteration, or other improper purpose, but simply to free the oil and water in the berry and ease the process of pressing. Doubtless oil extracted without the use of water is appreciably finer to an expert "olive oil taster," but it is doubtful if very much of such oil reaches the market. The usage of mills differs. The most extreme divisions of oils would be, that of the first crushing and the first pressure; that of the same pomace crushed a second time; that of the same pomace treated with cold water ; that of the same pomace treated with hot water ; that of this pomace ground fine, placed in an agitator and heated with water, until the stones fall to the bottom and are carried away, and the water and lighter matter passed into settling tanks, where the oil is skimmed off, while a little more is made by another pressure; this is called washed oil. This same pomace instead of being treated as above, may be treated by the bi-sulphate of carbon process at special factories, with a larger percentage of oil as a result. Finally a low grade of oil is skimmed from the water used in collecting the oil, and which is carried out of the mill and deposited in tanks called from the low quality of the oil, " the inferno."

The term "Virgin oil" is used so variously, that it is difficult to define it with accuracy. It is used for the first run of oil whether made with or without water; it is also sometimes used for early oil - the first of the season; the most exact use seems to be the oil which flows either without any pressure by the weight of the pornace in the racks or the cages, or just as the pressure begins to tell. Watching the press one sees pure oil and water run out, and if this is taken from the receiver at once, the oil and water separate quickly, and the oil is exceedingly rich and fine. As the pressure goes 
on the liquid becomes tinged with purple from the coloring matter in the berry.

Admitting the definition as correct, we should have five possible qualities of palatable oil, and two, suitable only for manufacturing purposes. It is unnecessary to say that Virgin oil as defined above is not an article of trade. A little is probably made on large estates, for the proprietors, and for their friends consumption, nor is it necessary to say, that the four possible edible oils are reduced to two or three.

If a run is made without water, the second run will probably be made with hot water, or two runs without water and then the hot water or with cold water at once, and then hot water. Cold water is not injurious, but oil gathered by the hot water process is not as fine, and does not keep as well as that expressed without water or with the use of the cold. Extreme heat is dangerous to oil at all stages of expression and storage; and for this reason Italians doubt the safety of artificial drying even where they consider drying necessary or advantageous. After the expression of the oil, it separates from the water and small particles of the berry which have passed the sacks or cage, and rises to the surface, when it is carefully skimmed off and placed in other vessels to settle; thence drawn off again from the surface, and clarified by being passed through a layer of filtering cotton, filtering paper, or even bone charcoal. It is then fit to place in the storage receptacle. During the process of crushing, pressing, depositing and clarifying, too extreme cold chills the oil and checks its flow and clarification, and in cold weather it is desirable to have moderate artificial heat in the mill. When clarified, the oil should be put in a cool place, and in cool receivers, of which tanks of tiles, brick lined with marble, or glass, and the Italian glazed terra-cotta lined tanks are the best. The Italians use wooden tanks lined with tin and also brick tanks lined with a fine cement. Trood is not desirable, the oil which soaks into it is liable to turn rancid. Again wood alone, lacks the coolness required, at least in an Italian sum. 
mer. A sufficiency of pure water and extreme cleanliness, are essentials of oil production for table use. Not only must the water used on the pomace be pure, but all the different parts of the machinery must be kept clean by constant washing, and mere water is not sufficient. The best cleaning methor seems to be, washing with hot water and soda ( $1 \frac{1}{2}$ ounces to a gallon of water) then, with fresh hot water remove the soda, and finally rinse out well with cold water. These washings must be frequent and careful, of machinery crusher, press, sacks, cage and crash, receiving vessels, and everything with which the oil comes in contact. Smoke from fires must be prevented, and smoking must be forbidden in the mill, oil takes a taste very readily, and the mill should be at a distance from barn and stable. It is a common thing in old Italian mills to have the horse power in the mill. This is of course very undesirable.

The alterations to which olive oil is subject are various, and although numerous cures have been suggested, no remedy has ever yet been successful when once the alteration has commenced Sometimes the disagreeable taste can be so disguised that it is not perceptible to the consumer; but that is only a temporary expedient, and cannot be termed a remedy. The most dangerous as well as the most common of the maladies to which olive oil is liable are:

Natural Rancidity.-This can be imparted not only by the carelessness of the maker, or by the uncleanliness of the utensils used in making, or storing the oil, but also through the nature of the soil in which the trees are growing. If the earth is very rich, and the growth of the trees is exceedingly rank or strong, this forced vegetation will produce fruit that will impart a peculiar taste to the oil, which will at once be detected by a delicate palate, and in a short time it will become so rancid that its market value will be greatly depreciated.

Taste of the Worm.-This is only observable when the fruit has been attacked by the Dacus oler. Sometimes the oil is so injured that it can only be used for industrial purposes. 
THE OLIVE ROT.

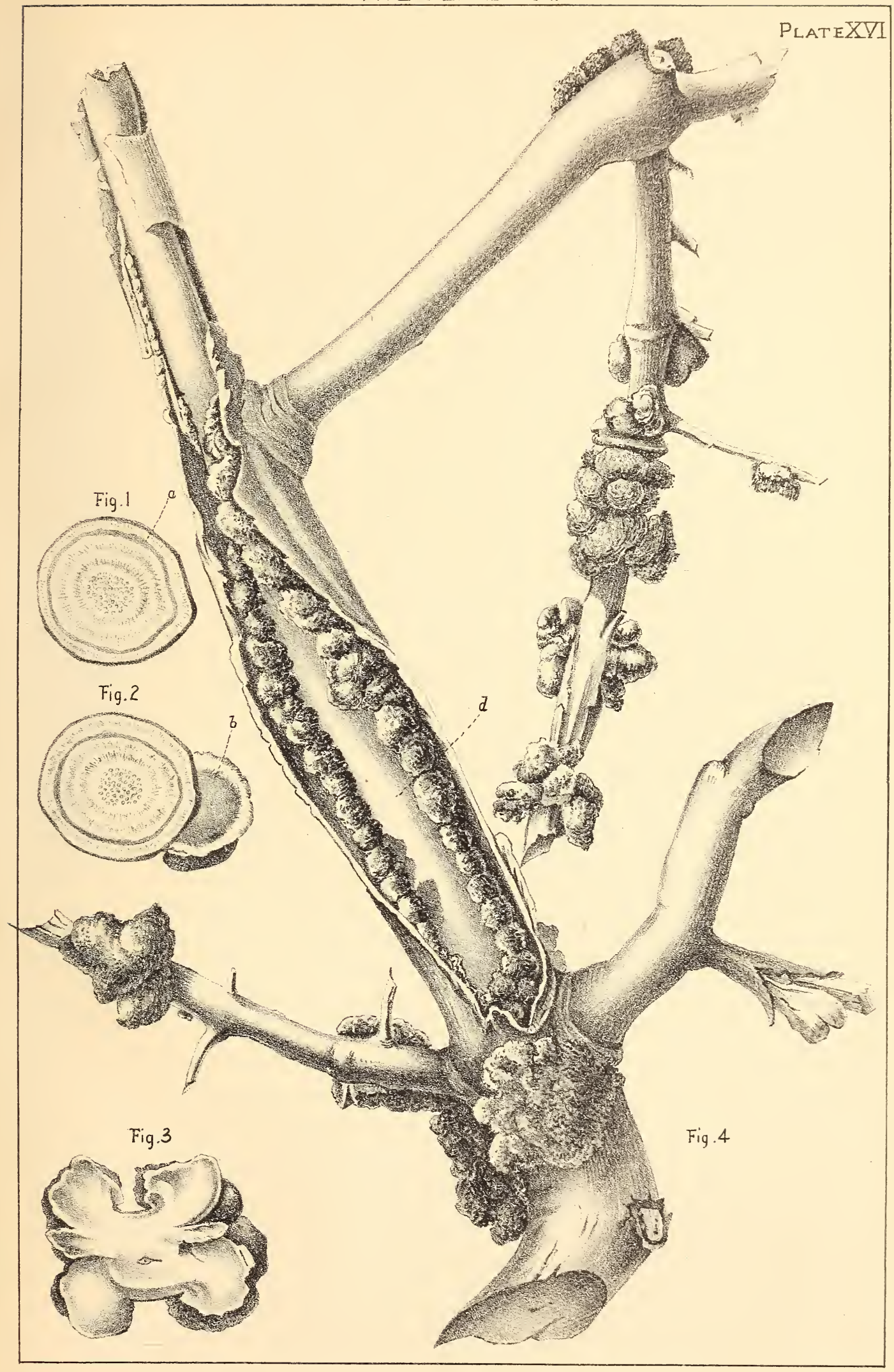




\section{PLATE XVI.-THE ROT.}

Fig. 1. A section of an olive branch recently attacked by the rot (a) increase of cambium, (enlarged nine times.)

Fig. 2. Another similar section, showing herbaceous growth, (nine times enlarged.)

Fig. 3. Transverse section showing the tubereles of the rot have reached the heart of the tree.

Fig. 4. A diseased branch (natural size) showing at $d$ how the bark splits from the wood, leaving it intact. 
Dry Taste.-When a very dry season occurs, with frequent and intensely hot winds, the growth is checked, the stem of the fruit is dried, and the berries get hard, dry, and shriveled. In this case the oil acquires a peculiar woody flavor, which, however, is not detected by all consumers.

Acquired Odors.-The oil will most readily absorb any odor to which it may be exposed, and when this is derived from tobaceo smoke, onions, manure, etc., it greatly deteriorates its value. A smoky chimney in the neighborhood of the room where the oil is being made, or any lack of cleanliness, will injure the oil greatly.

Taste of the Cask.-This can be transmitted either by the vessels in which the oil is placed, if not made and kept scrupulously clean, or by contact with the tools and other appliances used in making it.

Absolute Rancidity.-Many things contribute to rancidity in olive oil, such as excessive heat, contact with the air, want of regular racking, contact with metals that can be dissolved by the natural acids of the oil, and other causes too numerous, and not of sufficient importance to mention.

It hardly seems possible to exaggerate the importance to the United States of olive culture as an added agricultural interest, productive of an article of such high value for medicinal use, and of such varied benefit as food, both in the every day dishes of a family table and the luxurious plats of the artistic chef.

While California is the most favored of the United States for the culture of the olive, there is a large Territory besides capable of it, and, although the home demand will probably grow eren more rapidly than the production, it seems safe to assert that pure olive oil can be produced in the United States with profit, at a price so reasonable as to put it on the list of our exports. Olive culture is still in its infancy, but it seems as if the time had fully arrived for its importance to be recognized by National and State Gorernment, and indeed the Agricultural Department at Washington has commenced its study. As a culture it is one of the most ancient, and 
the experience of the old countries must be of great value in the development of an extensive olive interest here. What might not be the value to this State of the knowledge, skill, and experience of a trained expert on the culture of the olive and the processes of oil expressing, if the services of such a one could be secured for a sufficiently extended time to allow of a fair application of his knowledge to the new country, soil, climate and conditions! Certainly such an experiment would be less costly in the end, and more satisfactory, than any attempt to send an American abroad to study the culture. It is more than probable than in many places the variations of conditions of climate and soil may compel deviation from the standard methods of other oil countries as the interest develops, and still it is necessary to know their rules, the result of so many years experience. Considering the wonderful adaptability of the American mind to the new, and its tendency to improve methods and processes where invention can suggest more convenient ways or labor-saving machinery, we need not fear to prophecy some great advance in olive culture and in oil producing processes as they become American interests. 


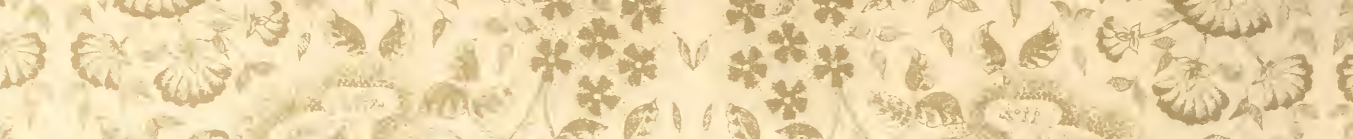
4. 0 (7)

60 6 b. (2) 1 J. E 30.0 1 $(+6+5)$

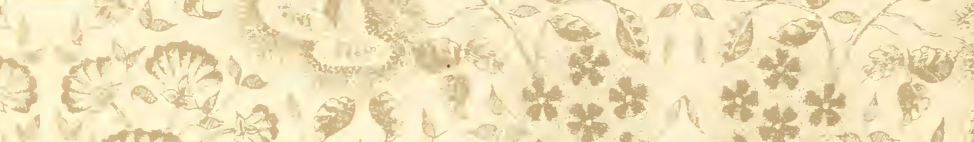

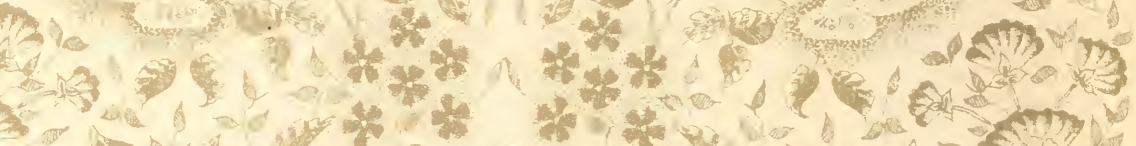

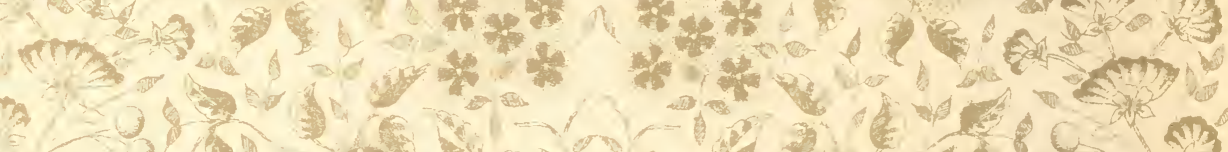

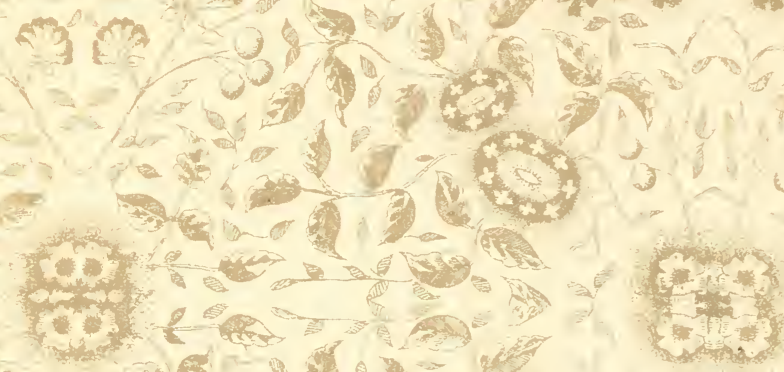

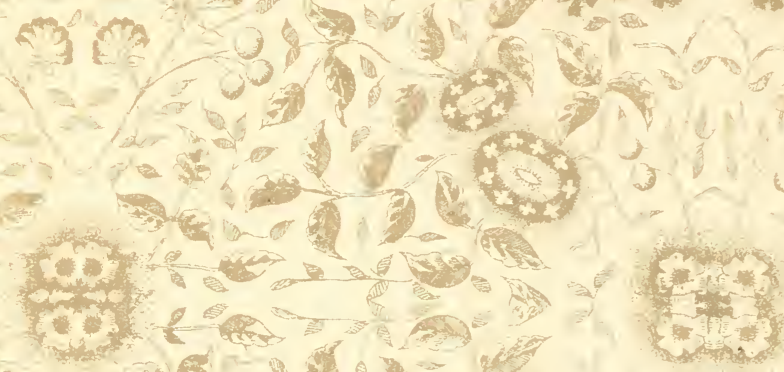

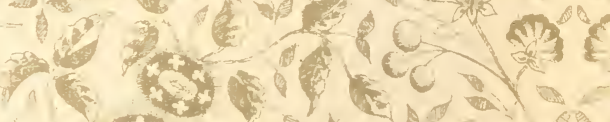
$20 y+20 y=3$

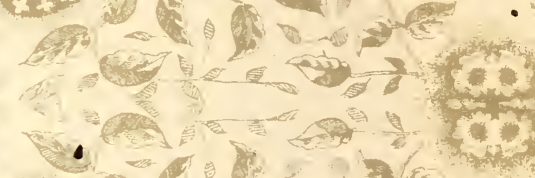
a 10

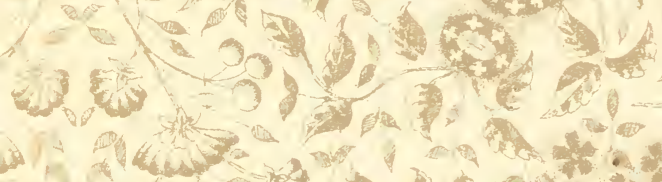

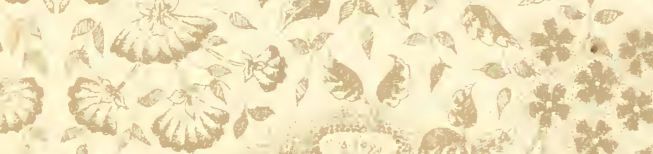

no.

(1)

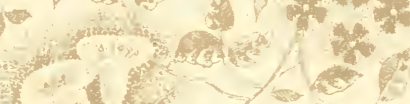
on (3) $x^{2}$ A. 0 / a (6)

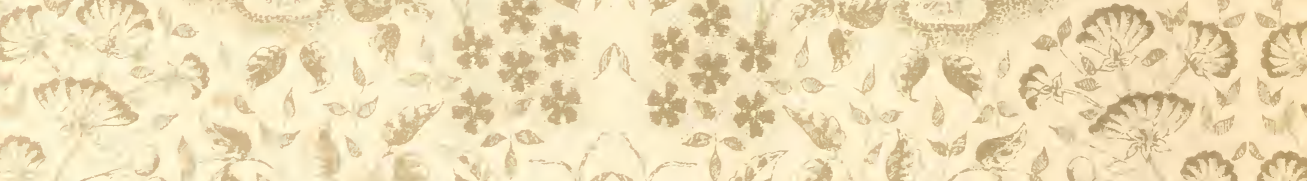

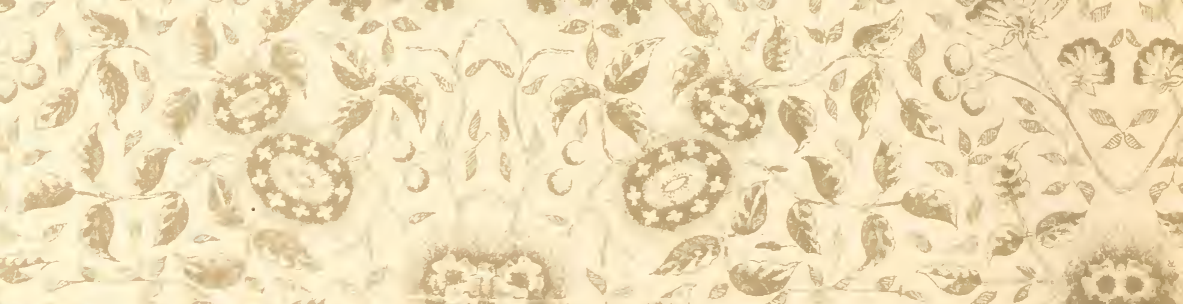


LIBRARY OF CONGRESS

||||||||||||| || || || || || || || || ||||||||

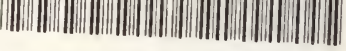

00009176962 
APRIL2013

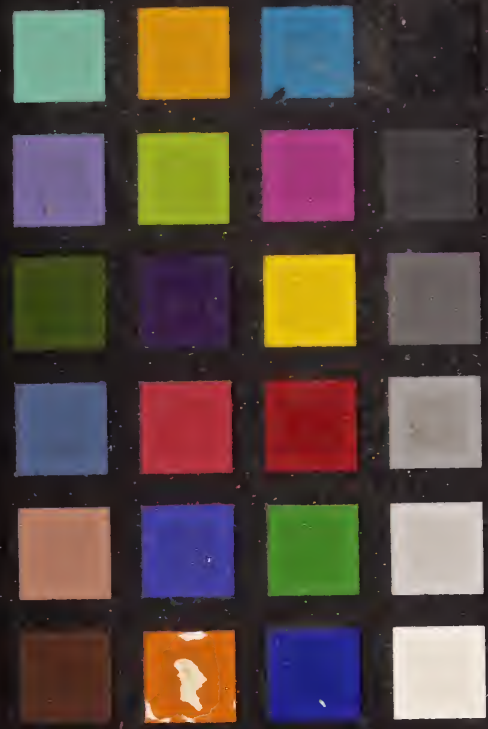

The olive: its culture in theory and practice Marvin, Arthur Tappan 7292025

The Library of Congress [12] oliveitsculturei00marv Jun 12, 2014
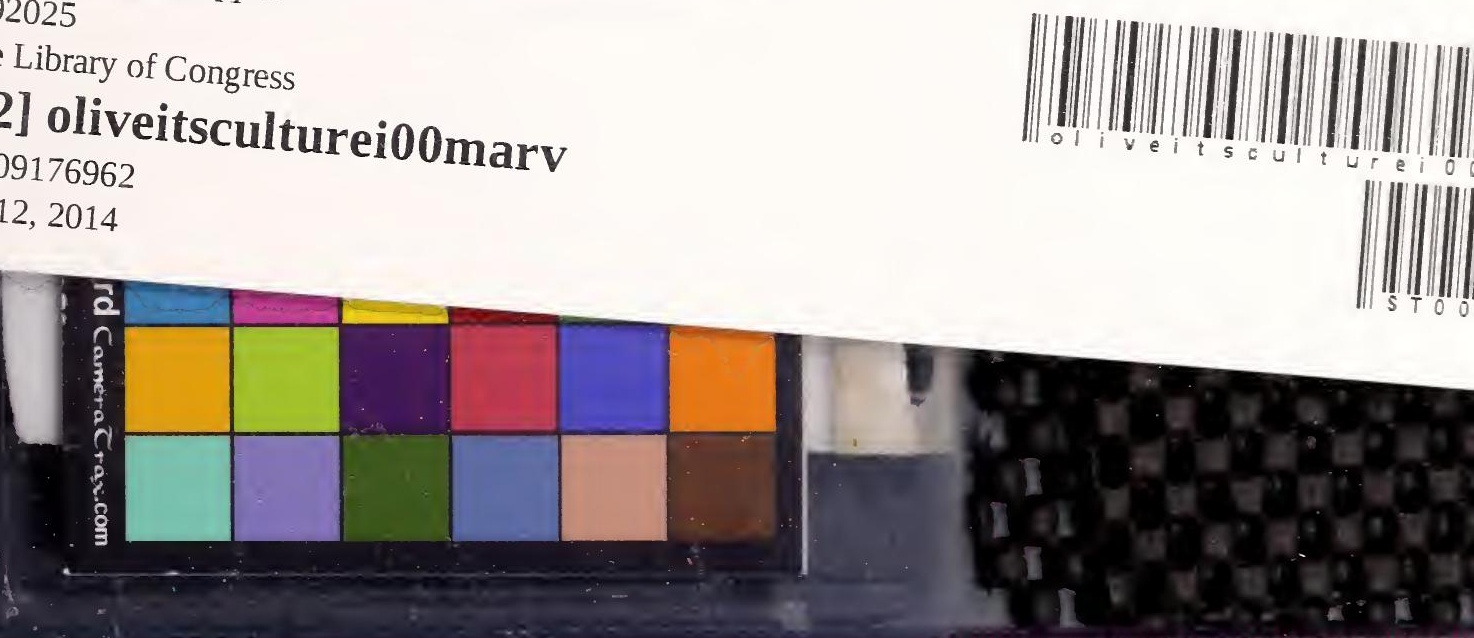
La «Progress» y la «Governor» de Hornsby, por el Sr. Temple, de Córdoba.

La «Dodge,» por el Sr. Hall, del Rosario.

Cuadro de «Samuelson.»

Una de «Alexander Jack \& Sons.»

Pero solo entraron nueve al concurso, no habiéndolo hecho las demas, probablemente por falta de caballos ó de conductores apropiados.

Habíase dividido de antemano el trigal en que debia hacerse el ensayo, en pequeñás áreas de 10 varas de ancho por 300 de largo, y cada máquina se colocó frente á la que la cupo en suerte.

A una señal convenida, se pusieron todas en movimiento y fué ciertamente aquel un momento de grande solemuidad y espectativa.

Fácil fué ver desde luego que todạs marchaban con regularidad. A medida que adelantaban, como cortadas por una mano invisible, caian las espigas sobre una plataforma preparada para recibirlas; y de esta plataforma, las arrojaba un rastrillo movido por la misma máquina, dejándolas arregladas en gavillas á iguales distancias con la mayor simetría.

Antes de mucho habian terminado su tarea en el órden siguiente :

La Wood en......... 2.5 minutos.

La Governor de Hornsby 28.

La Dodge . . . . . . 29.

La Bookeye. ...... 31.

La impresion en todos los que asistian á esta prueba no pudo ser mas satisfactoria, siendo para aquellos que nunca habian tenido ocasion de presenciar el trabajo de estos instrumentos admirables una verdadera revelacion. 
Examinado prolijamente el terreno, se vió que con corta diferencia todas habian hecho un trabajo satisfactorio. El trigo habia sido perfectamente cortado; pocas ó ningunas espigas se advertian en el suelo, y las gavillas se encontraban convenientemente arregladas. Para todos quedó demostrado que uno de los mas difíciles problemas de la agricultura estaba definitivamente resuelto. Con cualquiera de las máquinas que se habian ensayado, podia el labrador recoger su cosecha en un brevísimo tiempo, disminuyendo inmensamente los peligros, y los gastos que hacen muchas veces ilusorias sus ganancias.

En un ensayo tan limitado, no es posible, en mi opinion, dejar establecido el mérito relativo de cada máquina. Que una llenase en menos tiempo su cometido, bien pudo depender de que tuviera mejores caballos ó los apurára mas. Y la que quedó rezagada de unos pocos minutos, acaso encontró algun entorpecimiento en su camino.

Aun mas, dada una perfecta igualdad de condiciones, no basta que una máquina corte mas rápidamente que otra, para que pueda considerarse superior, y recomendarse como tal. Es esta, apenas, una de las muchas calidades que deben tenerse en cuenta.

«El juicio de las máquinas agrícolas,-dice Mr. Grandvoinnet, en su interesante informe acerca de las máquinas agrícolas exhibidas en la última esposicion universal de Paris,-es la tarea mas pesada que pueda imponerse á un hombre de conciencia. Así, continúa, cuando tomamos en cuenta la carga impuesta á los jurados de instrumentos y máquinas de agricultura, nos llena de satisfaccion que haya en nuestro país tantos hombres animosos que se sientan bastante capaces para echarla sobre sí. "

" ¿Cuál es la regla que debe seguirse en el juicio de las máquinas agrícolas? se pregunta el mismo Mr. Grandvoinnet. 
$\mathrm{Y}$ despues de muy oportunas consideraciones, reasume su pensamiento en esta forma:

"Para que una máquina sea aceptada en la práctica, no puede haber sino una ó mas de las razones siguientes:

" $1^{\circ}$ Que el costo real del trabajo hecho por ella, sea inferior al costo del trabajo que puede ser hecho á mano.

"2 Que el trabajo hecho por la máquina, sea mas perfecto que el hecho á mano.

" $3^{\circ}$ Que el trabajo hecho por la máquina, sea hecho con mayor rapidez.

"La perfeccion del trabajo y la rapidez con que es hecho, no siendo en realidad, en virtud del axioma inglés, que el tiempo es dinero, sino una disminucion en el precio de costo del trabajo, estas tres razones que aconsejan el uso de una máquina, pueden reducirse á una sola máxima, que será la base del juicio comparativo acerca de su mérito:

» El precio del costo real de la suma de trabajo hecho por una máquina, es el solo criterio de su utilidad. »

En efecto : si una máquina no hace el trabajo mas barato que el que se hace á mano; si no lo hace mejor; si no lo hace mas rápidamente ; en una palabra, si tomado todo en cuenta, no lo hace mas económicamente que el que se hace á mano, nada aconsejaria su adopcion, y si por un error deplorable, fuese adoptada, muy pronto desapareceria en la práctica. Por el contrario, una máquina no es definitivamente adoptada, sino cuando satisface á alguna dé las tres condiciones arriba espresadas; pero entonces, es para no desaparecer jamás.

De manera que, si la perfeccion de una máquina se representa por 100 puntos, por ejemplo, estos 100 puntos corresponderán á la suma de dinero que el uso de esta máquina importa para el agricultor, y podrăn ser divididos entre las diversas calidades de la misma máquina, esto es, entre 
las diversas ventajas que su uso ofrece. Si se tratase de una máquina de trillar, por ejemplo, la cantidad de trigo que trilla en un tiempo dado, el grado de limpieza en que lo deja, la mayor ó menor rotura del grano, serian los puntos á considerar para apreciar su mérito.

Siguiendo este sistema, que me parece el mas racional, la Sociedad de agricultores de Francia, que presidia Mr. Drouyn de L'Huis, en el último concurso de segadoras que turo lugar el año próximo pasado, juzgó que, para apreciar el mérito de una máquina de segar, debian tenerse en cuenta las calidades siguientes :

$1^{\text {a }}$ La regularidad del trabajo.

2 La manera como hace la gavilla.

$3^{\text {a }}$ La manera como hace el corte mas ó menos alto.

$4^{\mathrm{a}}$ Que no desgrane el trigo.

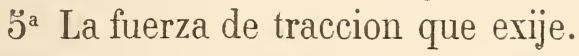

$6^{\varepsilon}$ La cantidad de trabajo que hace en un tiempo dado.

$\tau^{\text {a }}$ El precio relativo de la máquina.

$8^{\text {a }}$ Su mecanismo.

Y fijando 100 puntos para representar la perfeccion de la máquina que reuniera á entera satisfaccion estas diversas calidades, los dividió en la forma siguiente:

20 por la regularidad del trabajo.

20 por el engavillado.

12 por la facilidad de arreglar el corte.

10 por el no desgranar.

10 por la traccion.

10 por la cantidad de trabajo hecho en un tiempo dado.

10 por el precio de la máquina.

8 por su mecanismo.

En los ensayos que tuvieron lugar en Senlis y Petit-Bourg, la máquina Progress de Hornsby obturo \%先 de estos 100 puntos, y el primer premio, debido sobre todo á la 
regularidad del trabajo, á la facilidad para arreglar el corte, al no desgranar, y á sus calidades de traccion y escelencia de mecanismo, aunque el engavillado no hubiera alcanzado la perfeccion que fuera de desear, ni hiciera el trabajo tan rápidamente como otras segadoras. - Es de esperarse que el jury formado de personas competentes, al juzgar el mérito de las diversas segadoras que entraron al concurso, haya tenido en cuenta estas diversas calidades, que no era fácil fueran apreciadas por los que asistiamos á aquella fiesta como meros espectadores. Una objecion, sin embargo, se hará á su fallo que no será fácil salvar.

Es la gloria de la máquina de cortar alfalfa de Hornsby, haber alcanzado el primer premio en el concurso de la sociedad real de agricultura de Inglaterra despues de nueve dias de ensayos consecutivos. Los representantes de la misma máquina,-la de cortar pasto,-_rehusaron tomar parte en el concurso de los agricultores de Francia á que he hecho referencia, si la duracion de los ensayos no era, por lo menos, de cinco ó seis dias, no considerando sérias las pruebas que se limitáran á uno ó dos cuartos de hora.

Sin duda que es esto exagerado: no podrá menos de reconocerse, sin embargo, que la prueba de unos pocos minutos, no es bastante para poder apreciar el mérito relativo de una máquina, sobre todo cuando todas han llegado á un grado de perfeccion capaz de satisfacer á los mas difíciles y exigentes.

Las nueve máquinas que entraron al ensayo se encontraban en este caso. Todas llenaron á entera satisfaccion su tarea. Debo, sin embargo, observar que se objetó á las de construccion inglesa, las de Hornsby, Samuelson, etc., todas de hierro, su peso escesivo, y que la opinion se dividió entre dos de construccion americana, la Wood, 


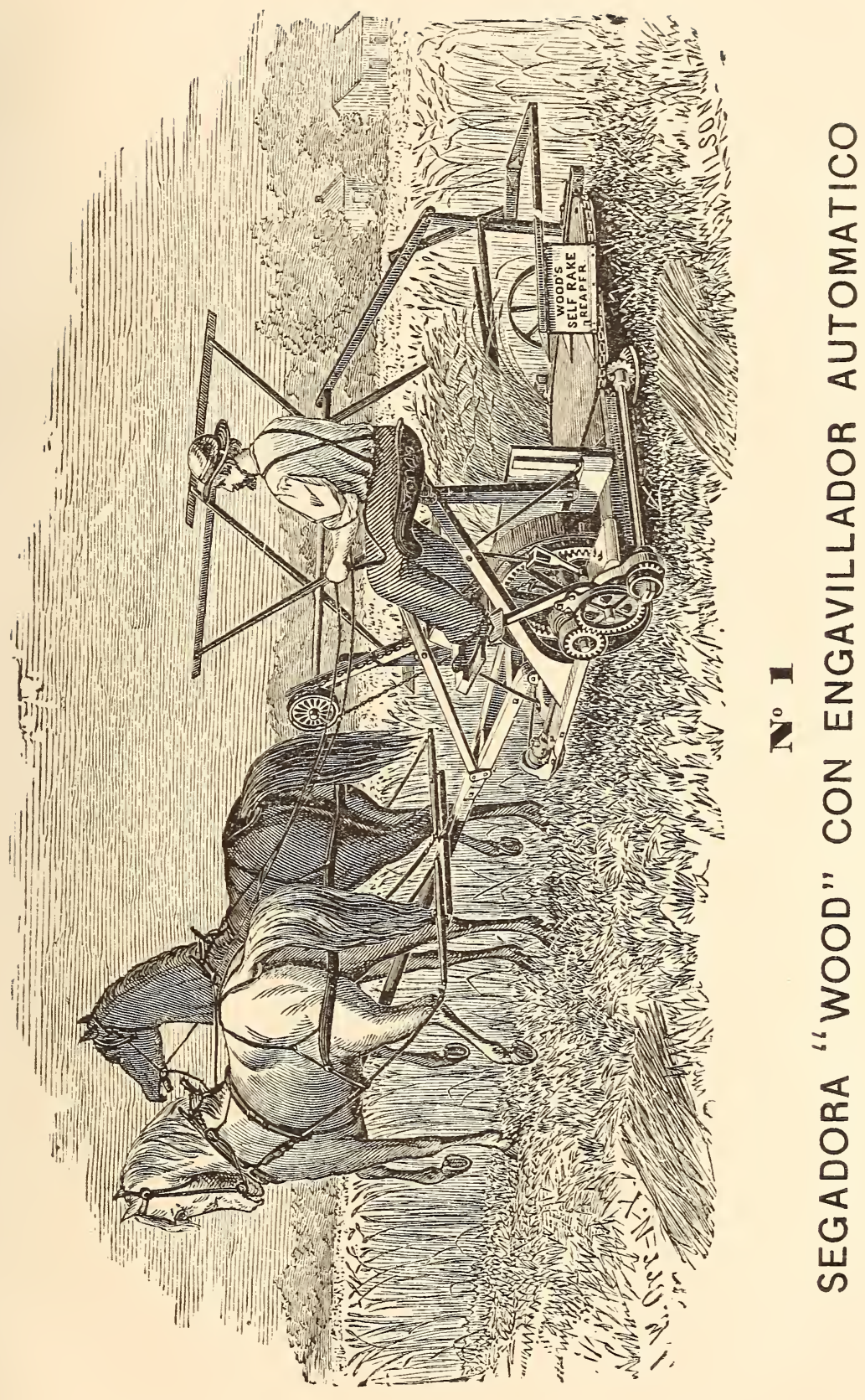



y la Bookeye. La de Dodge, tambien americana, no es sinó una perfecta imitacion de esta última, sin mas diferencia que tener la cuchilla cortadora atrás.

La Wood (L. 1) se distingue entre todas por la regularidad de su marcha; por el admirable mecanismo con que atrae las espigas sobre la cuchilla, y hace la gavilla por un movimiento automático que imita de la manera mas ingeniosa la accion del brazo del hombre. La Bookeye (L. 2). por su ligereza de traccion (poco peso), por la solidez y perfeccion de su mecanismo, circunstancias muy importantes entre nosotros, donde son difíciles las reparaciones, y escasos los buenos bueyes ó caballos; y finalmente, por la facilidad sin igual con que se adapta á cortar trigo ó alfalfa, sin mas operacion que cambiar una barra de hierro, sacando ó poniendo un perno.

Son estas dos máquinas las que gozan de mayor aceptacion en esta Provincia.

Cada una tiene sus calorosos apasionados. Parece que en algunos puntos está mas generalizada la Wood, y que las colonias de Santa-Fé prefieren la Bookeye. Por mi parte, puedo agregar mi testimonio personal en favor de esta última.

Dos años ha, durante la guerra del Paraguay, sembrámos doscientas cuadras de alfalfa en nuestro establecimiento de Campana. La semilla no era buena, y el primer corte vino con una abundancia estraordinaria de nabo y de mostaza. La fuerza de estas plantas era tal, que un hombre á caballo no podia abrirse paso al traves del espeso tejido de sus ramas. La tarea de cortar semejante masa de vejetacion parecia inabordable. Con $5 ّ$ máquinas Bookeye, si bien con no poco trabajo, se llevó á cabo, sin embargo, sin mas pérdida que la de algunos dientes de la cuchilla, que no resistian á la dureza de los troncos, ya secos en una gran parte, y de un grosor estraordinario. 
Aunque no entró al concurso, merece una mencion especial una máquina, tambien de Wood, por su construccion original y el doble objeto á que era destinada. Impulsada para adelante por cuatro caballos, al mismo tiempo que cortaba las espigas á la altura de dos piés, mas ó menos, por medio de una faja de lona que jiraba á la manera de una cadena sin fin, las echaba sobre un carro, que la seguia á la par. (Lám. 3).

Fácil fué ver en la práctica que se exigia demasiado. Era difícil manejar los cuatro caballos obligados á una tarea á que no están acostumbrados. Vencida esta dificultad, quedaba otra todavía, era preciso que el carro que debia ir recojiendo las espigas, marchara al mismo paso que la máquina, y siempre á la misma distancia-0tras veces sucedia que una ráfaga de viento hacia volar las espigas. Pero no era esto lo peor. La máquina que tenia que cortar muy arriba, dejaba un gran número de aquellas espigas que no se encontraban á la altura requerida.

Fué evidente para todos que este mecanismo complicado no podia tener entre nosotros una esplicacion práctica-Podrá, tal vez, servir en aquellos paises donde se practica la agricultura que se llama intensiva, es decir, aquella que aplica mucho capital á una superficie pequeña, y en casos escepcionales; cuando todo el trigo estuviera perfectamente igual, á la misma altura; y en momentos en que no soplara viento alguno.

Es ya bastante exijir de una máquina que corte y que engaville, y que lo haga bien.

Nada es, sin embargo, imposible á la ciencia en nuestros dias.

En el último informe del Departamento de agricultura de los Estados Unidos encuentro que en 1869 se concedió patente á una Segadora que ataba las gavillas. El trigo caia 


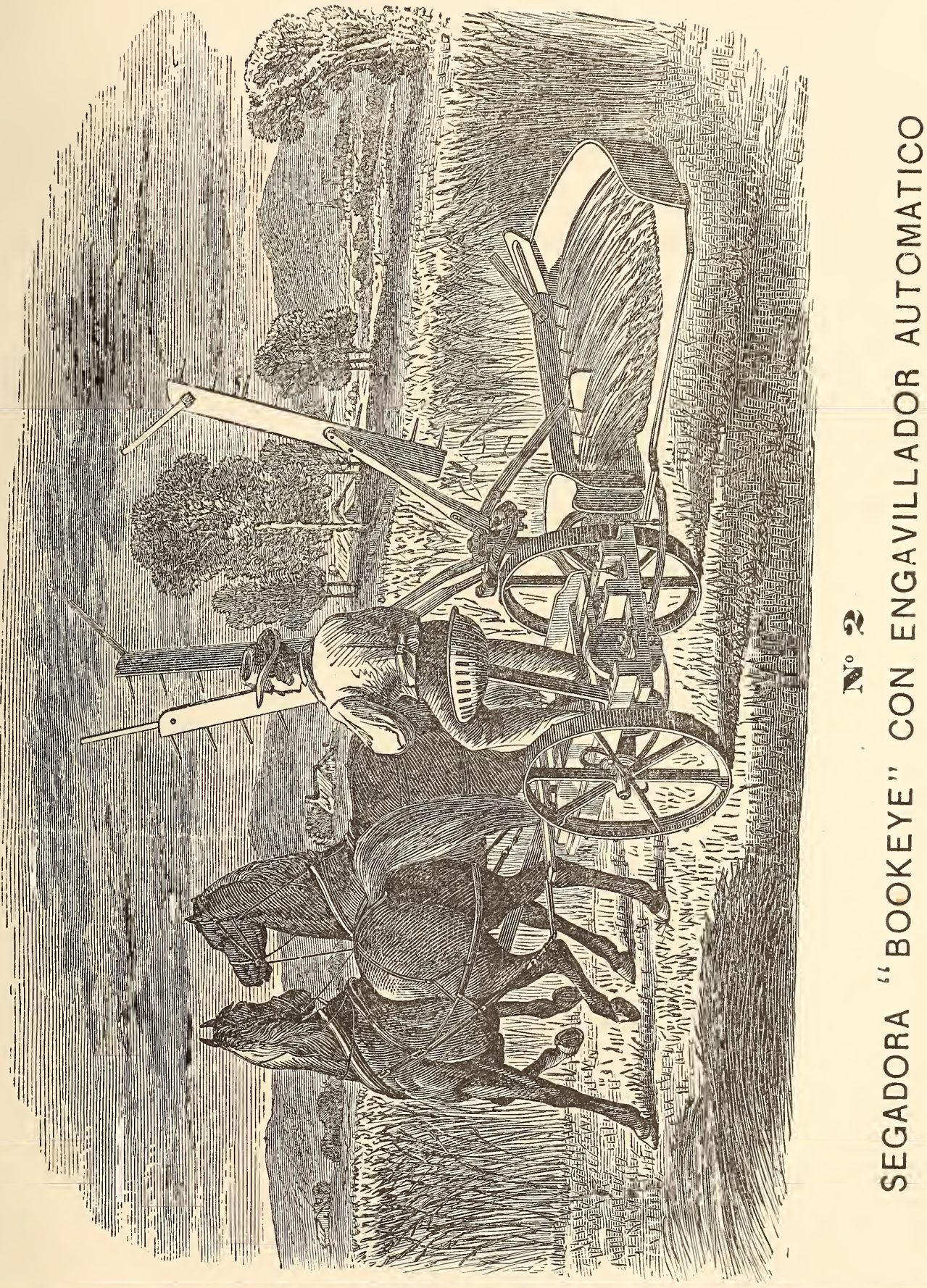



sobre una plataforma en forma de plano inclinado, y se detenia ante un obstáculo. Cuando el conductor juzgaba que se habia reunido bastante, por un movimiento del pié que apretaba un resorte, retiraba el obstáculo, la gavilla caia entonces á un cajon, y al caer, dos brazos de hierro le ponian una ligadura, y la dejaban atada. Segun el informe de que tomo esta noticia, el ensayo de esta máquina fué satisfactorio; no la veo, sin embargo, recomendada en ningun catálogo, y esto me induce á creer que en la práctica no ha correspondido á las esperanzas que hizo nacer la primera prueba, como con tanta frecuencia sucede.

Seáme permitido ahora con motivo de esta máquina una reminiscencia histórica que no carece de interés.

Esta máquina de segar, que consideramos hoy tan gran novedad y tan gran progreso, era familiar á los antiguos Galos! Y aquí sí que viene bien exclamar con el filósofo : Nihil novum sub-sole, nada hay nuevo bajo el Sol.... ni aun en materias de máquinas... y de segar. Segun la deseripcion que nos ha dejado Plinio, la máquina de los Galos estaba montada sobre dos ruedas y su parte de adelante á la altura de un metro, se encontraba armada de una larga série de pequeños dientes destinados á cortar las cañas del trigo. Al ser empujada por bueyes ó caballos, las espigas caian á un cajon colocado atras de. las partes cortantes. Palladius hace los mayores elogios de esta máquina que, dice, haber sido muy comun y muy apreciada en aquellos remotos tiempos.

« Los habitantes de las llanuras de la Galia, dice este distinguido escritor, se sirven para su cosecha de un aparato con cuyo ausilio el trabajo del buey se sostituye al del hombre. Consiste este aparato en un carro montado sobre dos pequeñas ruedas, y cuyoś cuatro lados están guarnecidos 
de tablas inclinadas hácia adentro, de manera que la parte de arriba es mas espaciosa que el fondo. El lado de adelante es mas bajo que los otros, y está armado de dientes encorvados para arriba y colocados de manera que detengan las espigas. Empujado contra el trigo por un buey, que debe ser muy manso y obediente á la voz del conductor, la paja se enreda entre los dientes del peine, se rompe, y la espiga cae dentro del carro. El conductor que dirije la operacion sube ó baja el peine segun la altura de las espigas, y en unas cuantas idas y venidas todo el trigal queda segado. Este sistema es usado en los terrenos llanos, y en aquellos en que se hace poco caso de la paja. "

La máquina de los Galos seria el gran desideratum para nosotros, que para nada utilizamos la paja.

IQué ventaja no seria tener que trillar solo las espigas, que la misma máquina habia ya recojida!

Es singular que esta idea de los bárbaros de la Galia, que sin duda se perdió en la oscuridad de la noche que siguió á la caida del Imperio Romano, haya necesitado veinte siglos para aparecer de nuevo.

Fué recien en 1808 que Smith de Dealton y el Escosés Bell tuvieron el pensamiento de cortar el trigo mecánicamente. La máquina que para este objeto construyeron era tambien empujada contra el trigo, y ponia en movimiento una cierra circular contínua. A pesar de la gran velocidad que se procuró dar á esta cierra, la máquina de Smith necesitaba ser puesta en movimiento, y al menor inconveniente se atoraba (permítaseme esta espresion técnica) y era necesaria mucha pérdida de tiempo y mucho trabajo para darla nuevo impulso.

Era en América donde la tierra abunda y faltan los brazos, donde con mas urgencia se sentia la necesidad de recoer con prontitud y á poco costo el grano que forma el prin- 


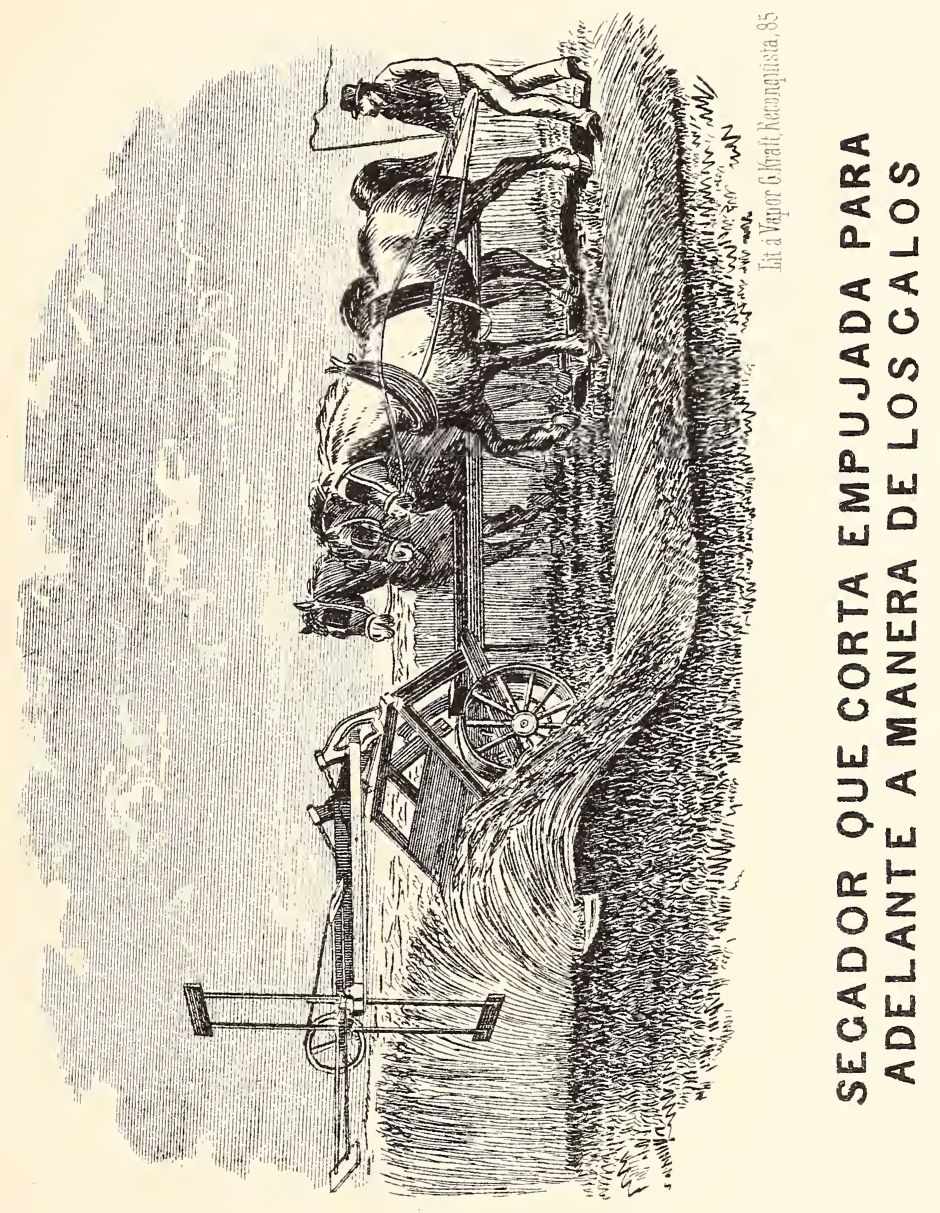



cipal alimento del hombre; y era de esperarse que el génio Americano, tan fecundo en grandes invenciones, no faltará á tan imperioso llamamiento.

En 1831 Mac-Cormick, de Chicago (Illinois), modificó de tal manera la segadora de Bell, que con razon puede decir que la creó de nuevo.

En vez de ser empujada contra el trigo, lo que exige caballos en estremo mansos y diestros, su segadora era tirada en la forma ordinaria. Mac-Cormick comprendió por primera vez que una rueda que gira sobre el suelo al rededor de su eje, es una máquina á la que puede ser aplicada una resistencia proporcionada á la fuerza de traccion, ya sea que esta resistencia provenga de un peso colocado sobre el vehículo que gravite sobre la rueda, ya á un organo mecánico que tome su movimiento del mismo eje y ejecute diversas funciones. Sobre este sencillísimo principio, hoy fecundo en sus aplicaciones, fundó todo el mecanismo de su segadora, que es el modelo que han seguido despues todos los constructores, trayendo cada uno, con el contingente de su inteligencia, mejoras importantes, que, luego que espiren los diversos privilegios que las han agrantido, han de conducir al fin á darnos una máquina que nada deje que desear.

La fuerza de traccion que hace jirar las ruedas de la máquina, se comunica por medio de ruedas dentadas, que admiten distintas combinaciones, á un eje del que arrancan todos los movimientos necesarios para ejecutar la cosecha; á saber, cortar el trigo; inclinarlo sobre una plataforma para que caiga á ella por su propio peso; formar la gavilla y arrojarla al lado de la máquina.

La otra innovacion de II ac-Cormick, no menos feliz, consiste en sostituir la cierra circular de Smith por una cuchilla armada də- dientes triangulares que juega con 
gran velocidad por un movimiento de va y viene, entre unas puas de acero, en forma de punta de lanza, cuyo objeto principal es garantir la cuchilla cortadora de los troncos, huesos ó alambres, que rara vez dejan de encontrarse aun en los terrenos mejor preparados. Esta cuchilla, que se apoya en una de sus estremidades sobre una pequeña rueda, es arrastrada por la máquina á uno de sus costados á la altura de dos, tres ó mas pulgadas de la tierra, de manera que corta el trigo con toda su paja. Con facilidad puede arreglarse de manera que lo corte mas ó menos bajo. El movimiento de vá y viene es infinitamente superior al circular, y se puede decir que está definitivamente conquistado.

El perfeccionamiento de estas máquinas ha sido lento. Un arado, una máquina de trillar pueden ensayarse en cualquier tiempo; pero solo hay 1.5 dias, y á lo sumo 30 , para apreciar las ventajas ó defectos de una segadora.

La máquina primitiva de Mac-Cormick, que tan profunda sensacion causó en la primera Exposicion Universal de Londrés, 18:1, se descomponia con frecuencia. El trigo cortado debia ser recojido inmediatamente por medio de un rastrillo, para que no, lo pisaran los caballos en la vuelta subsiguiente. ¡Cuántos progresos no señalan las máquinas que hoy poseemos! El trabajo que hacian antes varios peones penosamente para dejar espedito el camino, lo hace hoy con toda facilidad la misma máquina, arreglando perfectamente las gavillas, de. manera que queda libre el paso para la vuelta sucesiva. Segun esté mas ó menos espesa la cosecha, puede arreglarse el mecanismo de manera que las gavillas sean mas ó menos grandes. Aun mas, el conductor sin moverse de su asiento, con solo apretar ó largar un pequeño resorte, puede aumentar ó disminuir su tamaño. La construccion de estas má- 
quinas es bastante sólida, y deja ya poco que desear. Todo está perfectamente previsto y combinado, hasta la manera de salvar un obstáculo que inopinadamente se presentára en el camino, y de trasportarse al lugar del trabajo como un vehículo cualquiera. Manejadas por un obrero medianamente cuidadoso, duran en servicio activo por muchos años, sin exigir costosas reparaciones, y solo de vez en cuando, el cambio de alguna pieza rota ó gastada, de que siempre tienen abundante repuesto las casas introductoras.

La máquina de Nac-Cormick parece ser tơdavia la que goza de mayor reputacion en los Estados-Unidos. Es sensible que no se introduzca entre nosotros. La fábrica de Chicago construye 40,000 al año. En la última Exposicion Universal de Paris, fué la que obtuvo el primer premio, mereciendo su autor el honor de ser declarado bienhechor de la humanidad; la mas grandiosa recompensa á que pueda aspirar el hombre sobre la tierra. Y á la verdad, que bien lo merecia por los incalculables beneficios que su invencion ha venido á derramar sobre el mundo entero.

La máquina de segar, comola de coser, tambien invencion Americana, son en efecto, de aquellos descubrimientos que influyen directamente en los destinos de la humanidad.

La máquina de coser, bajo su humilde apariencia, importa la emancipacion de la mujer. Con su auxilio la mujer no necesita ya estar encorrada todo el dia, pasando una puntada tras otra. En 1 hora y $14 \mathrm{~m}^{\mathrm{s}}$, p. ej., podrá coser una camisa que hubiera necesitado $14 \mathrm{~h}^{\mathrm{s}}$ y $17 \mathrm{~m}^{3}$ con el trabajo de la aguja. Por otra parte, esta máquina ha de producir infaliblemente el efecto que las demas han producido siempre.

Al mísmo tiempo que la baratura aumentará sin límites 
la demanda por los objetos del vestido, el salario de la mujer se elevará. En la gran fábrica de ropa hecha de Hayem de Paris, las costureras que trabajan con la máquina ganan $\underset{2}{2} \mathrm{fts}$. al dia, mientras que las que trabajan con la aguja, sola ganan 15 c., y este hecho se reproduce en todas partes. Los efectos de esta máquina los palpamos diariamente. Ella ha venido á completar los progresos inmensos que han hecho en nuestros dias la produccion de las materias destinadas al vestido del hombre y la industria de los tejidos. Basta salir á la calle para advertir la inmensa mejora que á otra vista se ha operado en el vestido de las gentes, sin que sea necesario ir á buscar objetos de comparacion allá en el siglo conocido por él de los perfumes, por el uso escesivo que hacian de fuertes esencias aun las personas acaudaladas, para disfrazar el mal olor consiguiente al uso contínuo de una misma ropa. Si recordamos que hace apenas un siglo no se conocia el algodon; que la seda venia de la India en caravanas á lomo de camello, á traves del desierto, con recargo inmenso de costo, y que solo podian usarla los grandes potentados de la tierra; que los tejidos de hilo debian ser por demas escásos, cuando todavia en el siglo XIV fué motivo de grande escándalo en la Corte de Francia, el lujo desmedido de la reina Isabel de Baviera, esposa de Cárlos VI, que se permitia tener dos camisas de hilo en su guarda ropa; y finalmente, que, aunque el arte de la costura, cuya inversion se atribuye á Enoch, 3400 antes de J. C., era conocido desde la mas remota antigüedad,-nuestra aguja de coser no se conocia antes del siglo $\mathrm{XV}$, lo que hace suponer que antes de esta fecha los vestidos se cosian, haciendo primero un agujero con la punta de algun instrumento, á la manera que hoy lo practican los zapateros ó. talabarteros; si se recuerda todo esto, decia, se compren- 
derá sin dificultad la terrible desnudez en que debia vivir el hombre antes de los tiempos, sin disputa, mas felices que hemos alcanzado. La produccion estraordinaria de las materias testiles; la admirable rápidez y baratura con que por medio de las máquinas mas ingeniosas se convierten estas materias en tejidos; y por último, la facilidad sin igual con que la máquina de coser, complemento de todos estos progresos, convierte en vestidos estos tegidos, han puesto en nuestros dias al alcance de los mas desválidos, los medios de llenar una de las primeras necesidades de la vida. Con esta mejora han disminuido notablemente muchas de las enfermedades y de las horribles pestes que afligian al hombre en los siglos pasados, y que no tenian otra causa que el desaseo en que vivia.

No son menos sensibles los beneficios que ha reportado la humanidad de la invencion de Mac-Carmick.

Facilitando de una manera prodigiosa una de las mas pesadas tareas de la agricultura, la segadora ha hecho posible sembrar grandes superficies, $y$ ha alejado, acaso para siempre, la terrible calamidad del hambre, que con tanta frecuencia asolaba hace apenas medio siglo las poblaciones de la Europa. Algunos datos estadísticos darán una idea mas acabada de las ventajas conquistadas por este admirable instrumento.

El distinguido astrónomo que dirige el observatorio de Córdoba, Mr. Gould, estimaba ha pocos años en 175,000 el número de máquinas de segar en actividad en los Estados-Unidos. Esta cifra debe haber doblado desde entonces, pues se calcula en 100,000, el número de segadoras, que 170 fábricas fundadas para este solo objeto, construyen cada año. Un viagero dice que son tan comunes en las chacras Americanas como los arados.

El trabajo que una cantidad dể máquinas semejantes 
puede hacer, escede todo cálculo. Trescientas mil máquinas representan, por lo menos, el trabajo de 3.000,000 de hombres, y pueden cortar cada dia la estension de 400 á 500 leguas cuadradas sembradas de trigo! ¡Qué inmenso ahorro de salarios! En una sola cosecha, se ha estimado en no menos de 100.000,000 de duros!

Estas cifras colosales esplican la grandeza á que han llegado nuestros hermanos del Norte, y ponen de manifiesto la causa que, aparte de la sabiduria sin igual de sus instituciones, mas ha concurrido á crearla.

Los productos de la agricultura de la Union Americana abastecen los mercados del mundo entero. Y sin embargo: solo un $10 \mathrm{p} \%$ de su poblacion se ocupa en los trabajos de la tierra; mientras que la Francia ocupa en estos mismos trabajos la mitad; la Bélgica, un $40 \mathrm{p} \%$; la Inglaterra, un 20 ; y están muy lejos de producir tanto. No es necesario decir que este hecho portentoso es debido á los prodigios de la ciencia de la mecánica. ¿Para qué operacion por sencilla que sea, no han inventado los Americanos una máquina? Y cuando la esperiencia ha consagrado sus ventajas, su uso se hace tan general como el de las segadoras.

Ante la magnitud de resultados semejantes, se comprende la justicia con que el inventor de la segadora ha sido colocado entre los bienhechores de la humanidad, y no pareceria permitido entrar á discutir las ventajas de su invencion. Diré, sin émbargo, dos palabras para satisfacer á aquellos que van aun mas lejos que Santo Tomás; para aquellos que, debiendo ser los primeros en el ejemplo, ven el progreso, y ..... no lo creen.

Guiada por un solo hombre, y cambiando bueyes ó caballos una vez al dia, la segadora puede cortar y engavillar sin grande esfuerzo, des cuadras en diez horas de trabajo. La facilidad con que se maneja es tal, que, cuando los ciu- 
dadanos Americanos fueron llamados á la defensa de las instituciones de su patria durante la última rebelion, las madres, las esposas y las hijas de los que cambiaron por la espada las pacíficas tareas del labrador, - pudieron levantar con su ausilio las cosechas, que hubieran quedado de otra manera abandonadas. Calculando el salario del hombre en 30 pesos, y su mantencion en 10; el uso $\delta$ alquiler de los bueyes ó caballos, en 20; y por último, en 80 el interés y amortizacion del dinero empleado en la máquina, -el costo de cortar una cuadra será 70 pesos. Es sabido que cortada á mano, no cuesta menos de 200 á 300 pesos, segun el año.

Háse calculado que el corte por la máquina, produce un aumento en el rinde de 90 hectólitros por hectárea; es decir, una fanega y media cuartilla por cuadra. Sobre una estension de 6 millones y medio de hectáreas que siembra de trigo, la Francia ganaria 5 millones y medio de hectólitros, que representan el valor de $\mathbf{1 1 0 . 0 0 0 , 0 0 0}$ de francos, y que serian bastantes las mas veces para llenar el déficit de las malas cosechas, que tanta alarma producen en aquella nacion, hasta el estremo de comprometer la tranquilidad pública.

A la diferencia en el precio del corte, que no puede estimarse en menos de 200 pesos, habria pues que agregar el aumento en el rinde, que importa otro tanto, y tendremos enfónces, por lo menos, unạ ganancia de 400 pesos por cuadra en favor de la segadora, comprendido el interés y amortizacion del capital empleado en ella.

Pero todo esto es muy poca cosa, en comparacion de la ventaja inapreciable para el labrador, de poder recojer su cosecha con la rapidez necesaria. Si el tiempo es dinero en las circunstancias ordinarias de la vida, lo es doblemente en los dias premiosos de la cosecha, en que el 
retardo de una sola hora, puede hacer perder el fruto de todo el año.

Para terminar mis observaciones sobre estas máquinas, diré que el Sr. Roldan, Rivadavia 343, que, entiendo, tiene el privilegio de introducir las de Bookeye, por arreglo especial con el constructor, las vende en esta plaza por los precios siguientes:

Máquinas de segar trigo .. 8,500 $\$ \mathrm{~m} / \mathrm{c}$. ó sea $340 \mathrm{ps}$. fts. Id. de cortar alfalfa. 6,500 « « 260 «

Id. combinadas para trigo y alfalfa........ 9,000 « « 360 «

La casa de los Sres. Drysdale, Moreno 66, que creo tambien, por un convenio igual, es el único introductor de la «Wood», la espende por los precios siguientes:

Para trigo. $-9,000 \$ \mathrm{~m} / \mathrm{c}$. ó sea $360 \mathrm{ps}$. fts.

Id. alfalfa. $-4,000$ « $\quad$ \& 160 «

Combinadas para trigo y alfalfa. $-10,000-400$.

No obstante que estas máquinas pagan un crecido derecho á su introduccion-25 $\mathrm{p}_{\mathrm{o}}{ }^{\circ}$ sobre un aforo de 150 ps., - y que los gastos de flete y descarga deben ser considerables, personas que las han hecho venir directamente, me aseguran que la diferencia entre el precio de fábrica y lo que piden aquí los introductores, es enorme.

Las ventajas del uso de estas máquinas admirables son tan evidentes y tan al alcance del menos advertido, que solo la falta absoluta de recursos puede esplicar, que la mayor parte de nuestra cosecha se haga todavia por medio de la hoz. Por otra parte, son tambien tan evidentes las ventajas que reportaria la República de la estension de su agricultura, y del aumento de su produccion, que admira no se haya pensado en poner al alcance de nuestros la- 


\section{$-43$}

bradores elementos tan indispensables, y sin los que es imposible el principal, sinó el único ramo de nuestra industria agrícola capaz de un desenvolvimiento considerable.

Las circunstancias dificiles porque ha pasado el Tesoro Nacional en los últimos años, pueden esplicar que se hayan gravado con tan fuertes derechos objetos, que por su rolúmen vienen ya recargados con gastos que doblan casi su valor. Es de esperarse de la ilustracion de nuestros legisladores, que tan luego como la situacion financiera de la Nacion mejore, esos derechos si no desapareciesen del todo, sean reducidos á la última espresion, á fin de que no pesen sobre la fuente misma de nuestra riqueza, que ahogada en su gérmen, no encuentra espacio para desarrollarse. 


\section{MAQUINAS DE CORTAR ALFALFA}

$\delta$

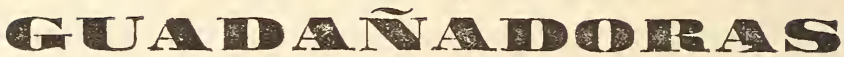

Su mecanismo. - Perfeccion á que ha llegado. Resultado del ensayo. - Otra vez la ((Bookeye) y la ((Wood. ) - Gomparacion entre el precio del trabajo por la máquina y por guadaña. - Rastrillo de caballo para dar vuelta el pasto. - Idem para recogerlo. - Preciosa máquina de Hornsby para afilar las cuchillas.

El mecanismo de estas máquinas es exactamente el mismo que el de las de segar, de que acabamos de ocuparnos. Solo se diferencian en que la cuchilla es mas estrecha y sus dientes tienen filo, en rez de pequeñas cierras, á manera de la hoz; en que no tienen, ni necesitan, la plataforma que sirve para hacer las gavillas; y finalmente, en que cortan mucho mas bajo. Algunas son combinadas y sirven indistintamente para trigo ó para alfalfa, con solo la variacion de la cuchilla, y la remocion ó adicion de la plataforma. 


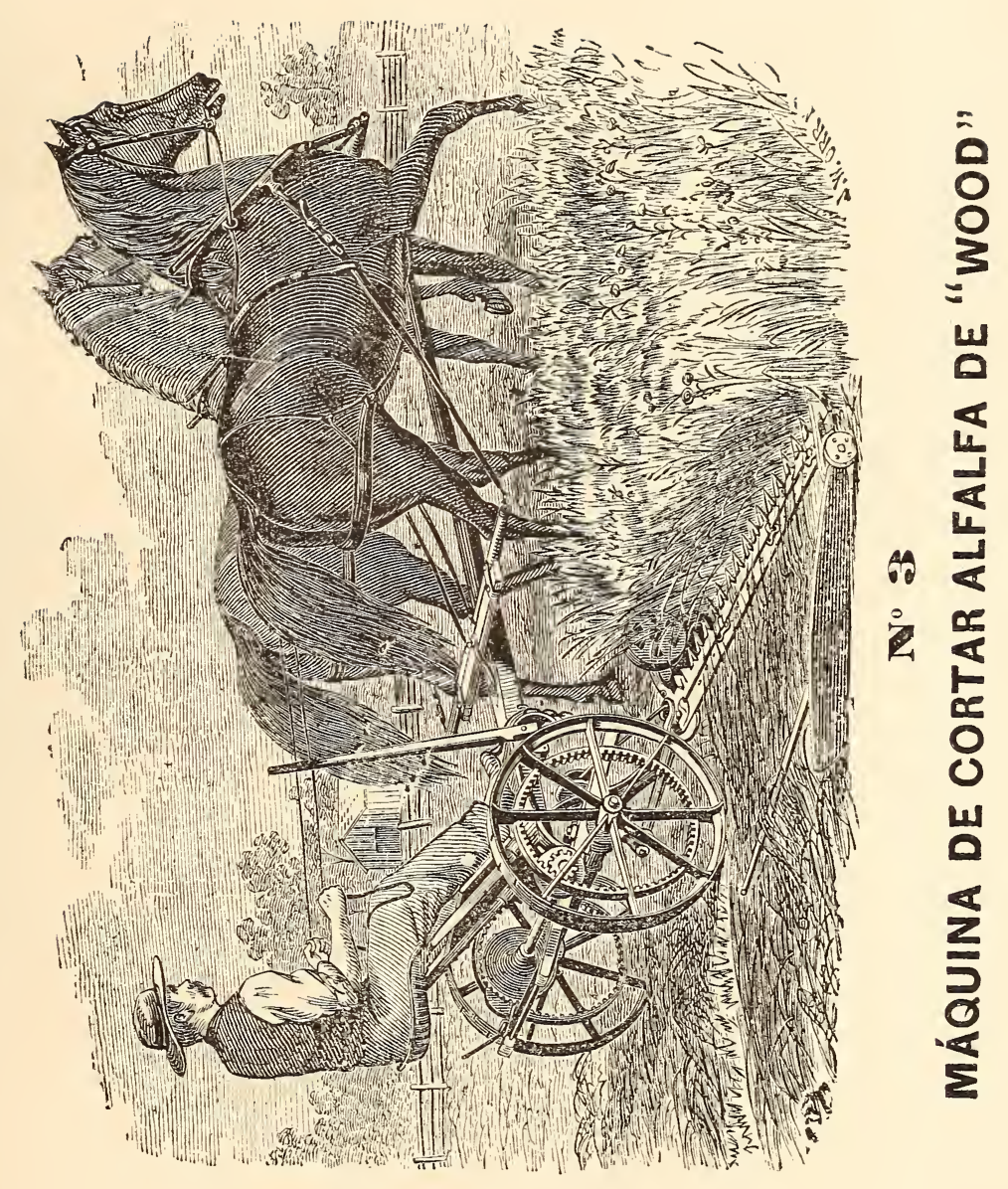






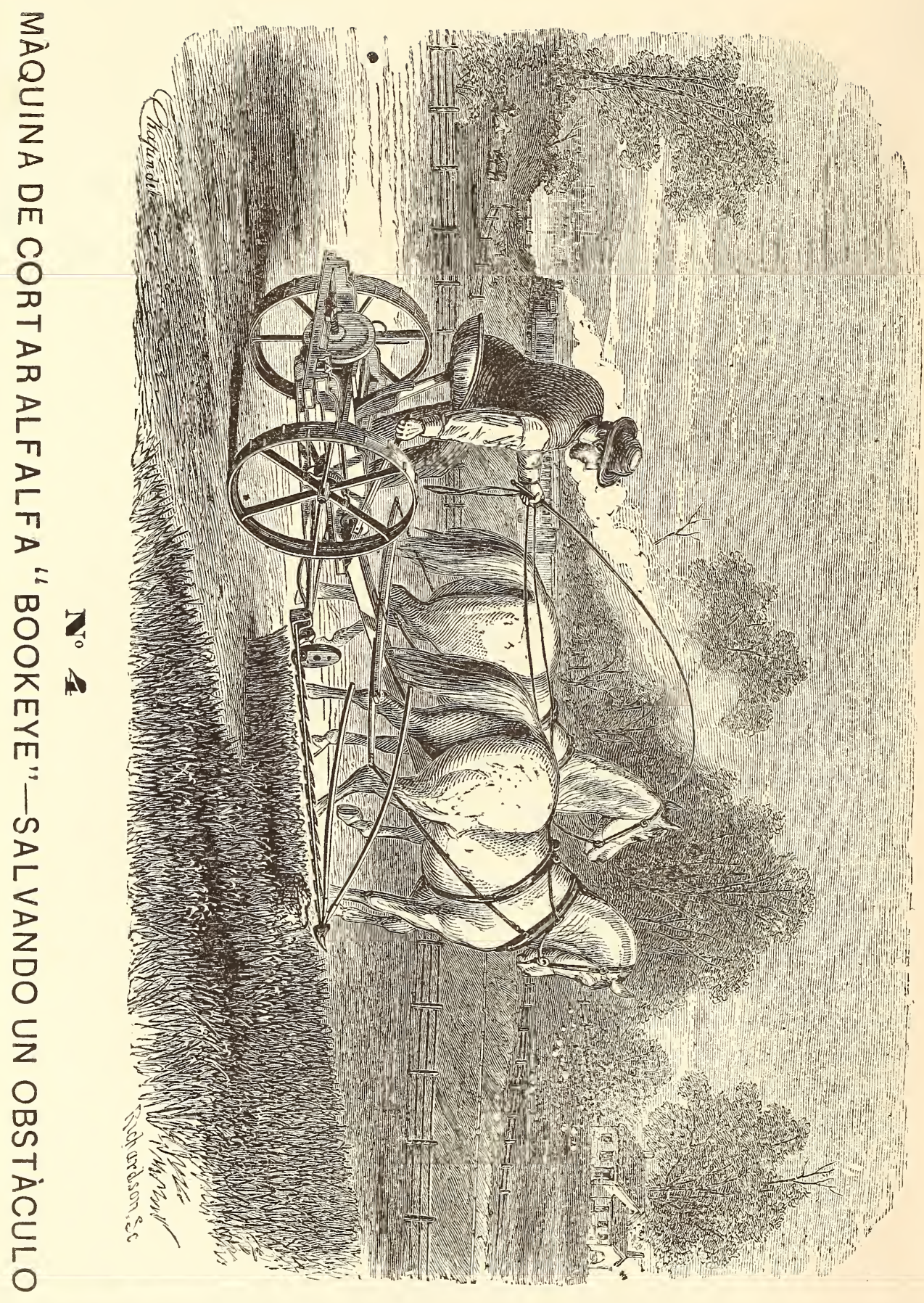


Las máquinas de segar, si bien muy perfectas ya, no han dicho aun su última palabra, puede asegurarse. La caña del trigo ofrece poca resistencia; el brazo de hombre la corta sin esfuerzo; mientras tanto, dos buenos caballos no resisten sin fatiga cuatro horas el trabajo de una segadora. Sobre este punto es indudable que hay todavía mucho que esperar. Una máquina que, sin perjudicar su solidez, fuera mas liviana, y exijiera, por consiguiente, menos fuerza de traccion, marcaria un gran progreso, sobre todo entre nosotros, donde los buenos caballos de tiro ó los bueyes mansos y diestros son escasos. El engavillador, que es la parte débil y dificil, es aun materia de estudio para los constructores, que todos los años anuncian con gran pompa alguna mejora. Las de cortar alfalfa, libres de esta complicacion, pertenecen ya á aquella categoría de instrumentos definitivamente conquistados para la industria, y que han llegado á un grado tal de perfeccion, que solo pueden ser mejorados por el empleo de materiales mas apropiados á la naturaleza del trabajo que de ellos se exije y se espera.

Las 4 ó ö guadañadoras que entraron á la prueba trabajaron todas perfectamente, no obstante que el alfalfar en que se hacia el ensayo no estaba en las mejores condiciones. Distinguiéronse las mismas que mas habian llamado la atencion como segadoras de trigo; la Wood, L. 3, por la rapidez con que hizo su tarea; y la Bookeye, L. 4, por la circunstancia de cortar la alfalfa enteramente á ras de tierra, y por la solidez de su mecanismo, que comprobó el hecho de haber encontrado un hueso formidable que detuvo su marcha, sin causarle el mas pequeño daño.

He tenido ya ocasion de decir que usamos há mas de 2 años cinco de estas máquinas Bookeye en nuestro 
establecimiento de Campana. Han trabajado casi constantemente; algunas piezas se han roto, otras se han gastado, y como es fácil reponerlas, va realizándose con ellas lo que con aquel cuchillo del herrero, que unas reces cambiaba de hoja, y otras de cabo, y quedaba siempre el mismo.

Al ver el servicio perfecto que hacen estas máquinas, es de admirar que se use todavía la guadaña en alfalfares de alguna consideracion. Es fuera de toda duda que cortan mejor, con mas igualdad y mas abajo. Dejan tambien la alfalfa mas estendida, y mejor preparada para secarse; no en gavillas, como la deja la guadaña. No es necesario decir que la diferencia entre el gasto del corte por la máquina ó por la guadaña es inmenso.

Un hombre, mudando caballos ó bueyes cada 4 ó 5 horas, corta de cuadra y media á dos cuadras por dia. Suponiendo que el hombre gane 30 ps., y estimando lo que corresponda al uso de los caballos, y al interés y amortizacion del capital empleado en la máquina, en 60, el corte de una cuadra costará de 4.5 á 60 ps. Mientras tanto, no es posible hacer este trabajo á guadaña por menos de 200 á 300 ps. Habria todavía que tener en cuenta, en faror de la máquina, la rapidez de la operacion, que basta muchas veces por sí sola para salvar una cosecha.

Al mismo tiempo que trabajaban estas máquinas, el representante de la casa de los Sres. Wheelright, del Rosario, dirijia personalmente y con gran maestría un rastrillo revolvedor, cuyo objeto es dar vuelta el pasto, para que se seque mas facilmente. La lám. ํo 5 , mejor que estensas esplicaciones, hará comprender el mecanismo de este ingenioso instrumento. Las puas de acero de que está armado un cilindro, que pone en movimiento el eje de las ruedas con gran velocidad, al rozar la tierra, le- 


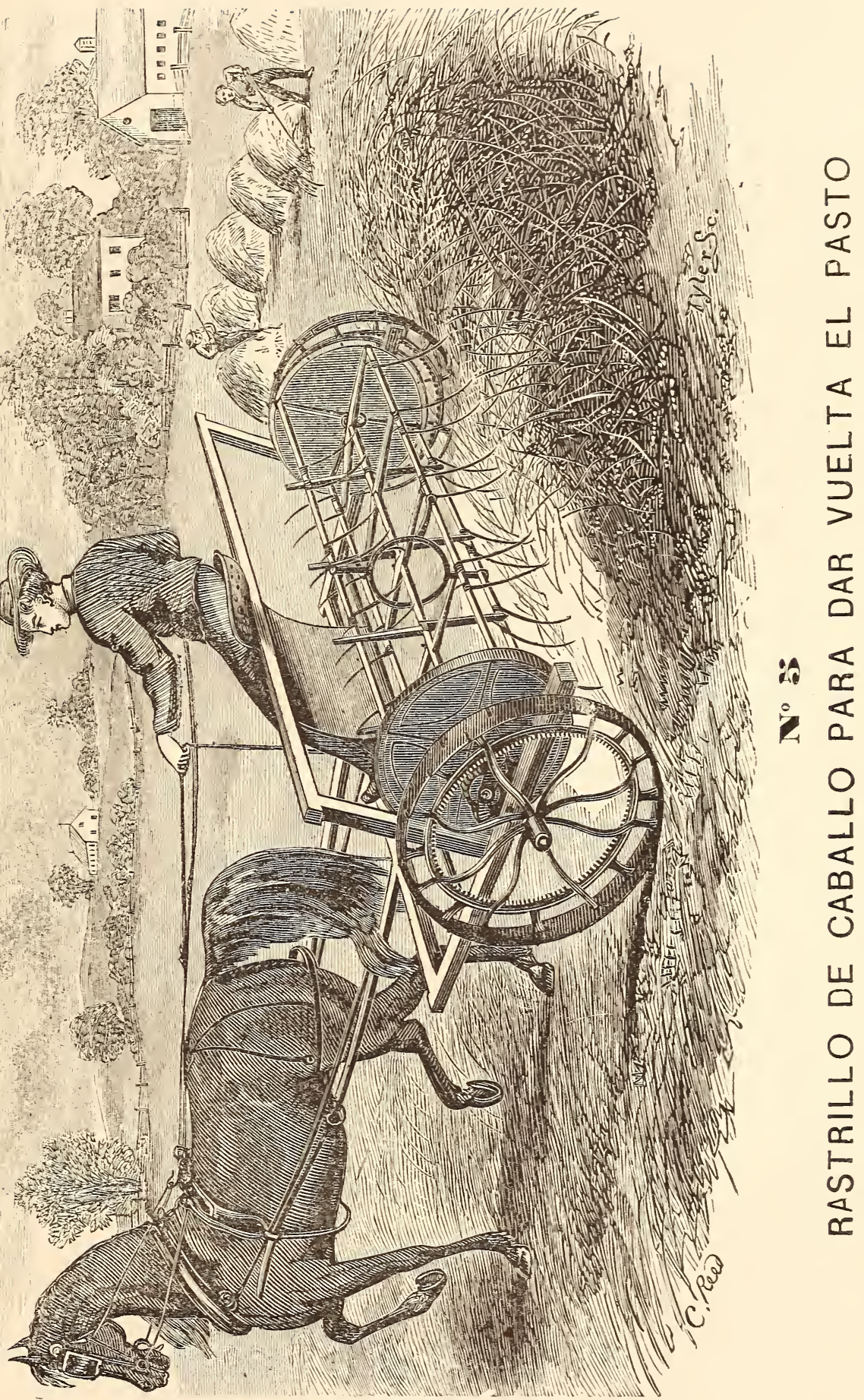






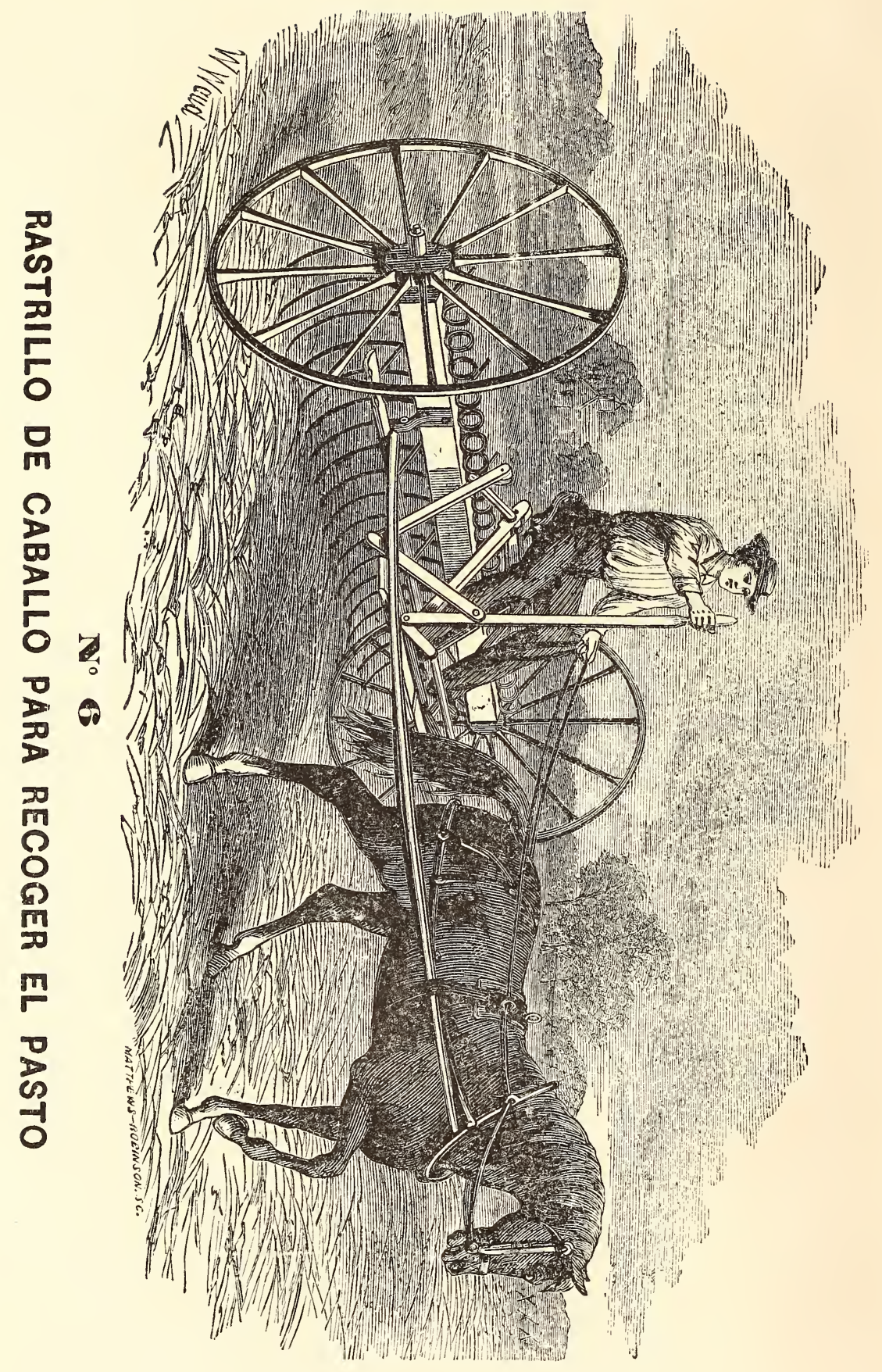


vantan el pasto, que cae como una lluvia para recibir en mejor posicion el aire y el sol que lo ha de secar. Con el sol abrasador de los meses de Noviembre á Febrero, en que se hace entre nosotros la cosecha de alfalfa, poca aplicacion tiene este instrumento. El peligro es mas bien que se seque demasiado. Puede ser, sin embargo, de mucha utilidad en la primavera, cuando el corte es muy abundante, ó en el otoño, cuando los rocíos son fuertes. Tenemos este instrumento en nuestro establecimiento, pero no hemos sentido hasta ahora la necesidad de utilizarlo.

Hay otro rastrillo, que no se probó en los ensayos, de una aplicacion mas inmediata, y de grande utilidad. Con un solo caballo recoge el pasto que ha cortado la máquina, dejándolo acomodado en cordones ó gavillas; y de esta manera facilita inmensamente el trabajo de hacer los montones que preceden á la formacion de la parva. En una esplotacion de alguna importancia, es un instrumento tan necesario como las máquinas de cortar. Por lo menos ahorra el trabajo de 30 peones. Sirve tambien para recoger las espigas que quedan desparramadas despues de levantado el trigo. Persona que lo ha usado para este objeto, me asegura que ha recogido muchas fanegas de un rastrojo en el que se hubiera creido que no existia una sola. Usamos dos de estos preciosos instrumentos, de cuyo uso no comprendemos que pueda prescindirse en trabajos de alguna importancia. Lám. 6 .

No puedo terminar esta parte de mi informe, sin hacer mencion de un pequeño instrumento, que bien puede considerarse como el complemento de la preciosa invencion de que nos venimoś ocupando.

Solo la práctica puede hacer valorar cuanto importa que las cuchillas estén siempre bien afiladas. No solo los caballos ó los bueyes resisten mas, sinó tambien la misma 
máquina sufre menos en su mecanismo. No es, sin em bargo, cosa sencilla el afilarlas. Despues de algunos dias de trabajo, cuando el filo se ha gastado, la lima ó la piedra que usan los guadañadores, es insuficiente; es preciso entonces desmontrar las cuchillas, haciendo saltar los remaches que fijan los dientes á la barra de acero, afilar estos dientes, uno á uno, en una piedra de vuelta, y volverlos á remachar despues. En esta operacion empleábamos dos hombres constantemente. Con el ausilio de la máquina de los Sres. Hornsby, Lám. 7, un hombre solo hace en media hora este trabajo.

Creo prestar un servicio no pequeño á nuestros labradores, haciéndoles saber que pued’n adquirir esta ingeniosa maquinita por la pequeña suma de $400 \mathrm{ps.} \mathrm{m/c.,} \mathrm{ocur-}$ riendo á la calle Defensa $\mathrm{N}^{\circ} .135$.

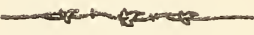




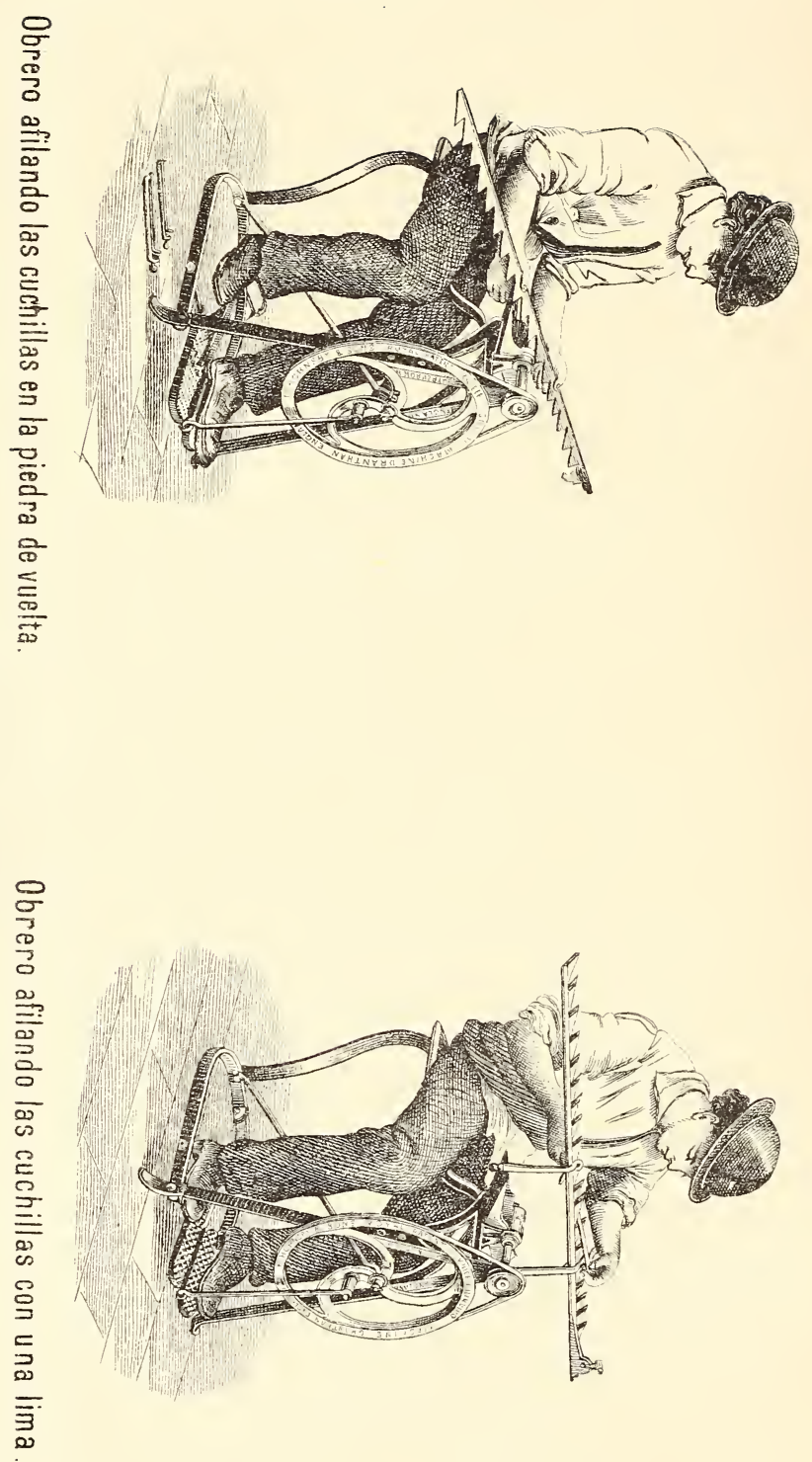


\section{MÁQUINAS DE TRILLAR \\ ó}

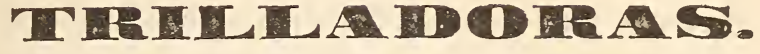

Grande espectativa-Las que se presentaron al concurso-Su invencion-Perfeccion à que han llegado-Causas porque no se han introducido entre nosotros-Resultado del ensayo-Satisfaccion general-Liquidacion completa de la cosecha operada por la máquina-Su mecanismo-Gantidad de trigo que trillan-Número de hombres que ocupan - Precio de su trabajo comparado con el sistema actual-Conveniencia de atar el trigo-Necesidad imperiosa de cortarlo antes de estar maduroCuerdas ó ataduras Lapparent-Diferencia entre el precio del trigo trillado por la máquina y el trillado por las patas de las yeguas.

Eran estas máquinas el grande acontecimiento del dia. Habíanse presentado cuatro; tres de construccion Inglesa, - dos de Garret é hijos, y una de Ruston Procton \& $\mathrm{C}^{\circ}$, afamados construtores de máquinas de Inglaterra, - y la última de Pitts, Americana, que goza de gran reputacion en los Estados Unidos. Las tres primeras es- 
taban aparejadas de sus correspondientes máquinas de vapor portátiles, que con su hermosa cabellera negra suelta al viento, daban vida y animacion al paisage; la Americana debia ser movida por lo que se llama una fuerza de caballos, que lo era de 8.

Aunque los períodicos habian anunciado que en ed campo de esperimentacion, se encontraban reunidas mas de 400 máquinas, eran estas cuatro, las únicas que en realidad interesaban al que tiene alguna práctica y algun conocimiento en estas materias. Impropiamente se clasifica entre las máquinas á los arados, rastras, rastrillos, y demas útiles ó implementos, que se ven en cualquier almacen de agricultura. Los grandes depósitos de los señores Coffin y Roldan son una esposicion permanente, tan interesante como la que ofrecian las márgenes del Rio Segundo. Aun las máquinas de segar.son ya familiares á los agricultores Argentinos. Cálculase que trabajan mas de 2,000 en la Provincia de Buenos Aires, y en las Colonias de Santa Fé se hacen cada dia mas comunes. Mientras tanto, apenas si se ha introducido en la República una media docena de máquinas de trillar. Sucede á este respecto entre nosotros lo contrario de lo que ha sucedido en todas partes.

Fuéinventada la trilladora por el Escoses Andrés Meilke en 1788. Nuy imperfecta al principio, sucesivamente ha ido mejorando, al punto que ha llegado en nuestros dias á un grado tal de perfeccion, que nada deja que desear. Ningun progreso sensible se señala ha muchos años en su construccion, y las mejoras que á grandes voces proclaman siempre los catálogos para llamar la atencion, se reducen á pequeños detalles que no alteran sustancialmente el mecanismo, que con escasas diferencias es el mismo en todas. Despues de la patente de 
Coulsor que sostituye los ejes de fierro, por baras flexibles de madera, que ponen en movimiento las zarandas sin ruido ni sacudimiento; despues del ingenioso mecanismo, patente de Peinne que, con solo abrir ó cerrar un resorte, permite arreglar el cilindro de alambre que hace la última limpieza y clasificacion, al tamaño del grano - la única novedad que veo anunciada, y que ha sido objeto de varios privilegios en los Estados Unidos, es la manera de arreglar automáticamente la corriente de viento que espele la paja. Todo ha de ser automático en esta época. A poco mas, no se ve que ha de quedar á la accion del hombre. Cuando la trilladora trabaja á toda fuerza, el viento que hace el ventilador podria ser demasiado fuerte, y arrojar el grano mezclado con la paja. Para obviar á este inconveniente, se ha provisto á la máquina del medio de hacer su propia policía, mejor que pudiera hacerla el obrero mas cuidadoso. La misma corriente, cuando es demasiado fuerte, pone en movimiento una palanca que abre ó cierra la abertura por donde entra el aire, y la mantiene de esta manera en la intensidad en que la práctica ha enseñado que debe conservarse, y que de antemano se ha arreglado.

Las ventajas que la trilladora ofrece sobre los antiguos sistemas es tan evidente, que en todas partes los ha sustituido completamente. En Inglaterra, en Francia, en Alemania, en los Estados Unidos, no se conoce otra manera de separar el grano de la paja, y aun en aquellos países donde la agricultura está mas atrasada, donde se usa todavia el arado primitivo, y es apenas conocida la máquina de segar, como en España, en Hungría y en la Rumania, las trilladoras son entre todos los instrumentos perfeccionados, los primeros que entran en el uso general. ¿Por qué razon sucede entre no- 
sotros lo contrario? ¿Por qué estraño motivo, cuando vemos llenos los almacenes de instrumentos agrícolas de las últimas y mas acabadas invenciones, no encontramos una sola trilladora? ¿Será que ellas son tan complicadas que estén fuera de los medios de que podamos disponer para manejarlas? ¿Será que nuestro trigo por la calidad de su paja, ó por alguna otra razon oculta, no se preste á su trabajo?

Dos razones encuentro que dan solucion á estas dudas que mas de una vez me han preocupado, como han preocupado á todo el que ha fijado su atencion en los trabajos de la tierra á que está ligado el porvenir de nuestro país. La primera es la notoria pobreza de nuestros agricultores. Las máquinas de trillar con sus motores, ya sea de vapor, ya de fuerza de caballo, representan un valor que por regla general está fuera del alcance de sus escasos medios. El Sr. D. Juan Cobo hizo venir una de estas máquinas, de uno de los mejores fabricantes de Inglaterra, Clayton \& Shuttleworth, con una máquina de vapor portátil de la fuerza de 12 caballos, y á mas un elevador. Puesta en su estancia en el partido de San Pedro, con comisiones, fletes \& ${ }^{\mathrm{a}}$, le costaba 13\%,000 ps. m/c. Una máquina de menos poder, sin el elevador, costaria la mitad ó una tercera parte. ¿Cuántos agricultores se encontrarán en situacion de hacer un desembolso semejante? Pero no es esto solo. El labrador que se propusiese salir de la rutina, tendria que encargar las máquinas y hacer el desembolso consiguiente, con una anticipacion de 6 ú 8 meses; y esto, aun antes de saber si alguna circunstancia imprevista le impediria sembrar su trigo, ó sí, sembrado, llegaria á necesitar trillarlo. Es indudable que, si en el momento preciso hubiera como adquirir una de estas máquinas, muchos agri- 
cultores animados con el aliento y la esperanza de una buena cosecha ya lograda, se animarian á ensayarlas, y el buen resultado que indudablemente obtendrian, las haria muy luego adoptar por todos. Los señores Ramsones, Sims \& Head; Ruston, Proctor \& $\mathrm{C}^{\circ}$; Clayton \& Shutteworth; Robey y C $\mathrm{C}^{\circ}$, Burgess \& Key; Marshall, \&a, $\&$ a, abririan con toda seguridad un mercado, que podria llegar á ser de la mayor importancia, á los productos de sus grandes fábricas, si establecieran un depósito en esta ciudad.

La otra razon que ha detenido á mi juicio la introduccion de esta gran mejora en nuestra agricultura, es el resultado desgraciado de algunos ensayos tentados por hombres animosos y amantes del progreso. Ed Sr. Larroudé, algunos años há, hizo venir una de estas máquinas. No sé porque razon no dió buen resultado; si por falta de hombres competentes para manejarla, ó porque la máquina en sí no era buena. El hecho es que por mucho tiempo esta máquina ha estado abandonada á inmediaciones de la estacion del Caballit). Ella ha sido la piedra de escándalo, por decirlo así, de todos labradores, que en su mayor parte recorren con frecuencia la via del Oeste. Si alguno concebia la idea de mejorar el medio de levantar su cosecha, presentábasele luego al punto la imágen de esa máquina por tanto tiempo abandonada, y que debió costar no pocos pesos. Esa máquina, espuesta así por meses y por años á la vergüenza pública, ha retardado por un cuarto de siglo el progreso de la agricultura Argentina. Hubiera sido un acto de patriótica prevision de parte de nuestros Grobiernos, haberla comprado, y haberla quemado.

El ensayo que iba á practicarse ofrecia, pues, el mas vivo interés. Él iba á resolver una duda que parecia fundada, 
y un problema vital para el porvenir de nuestra industria agrícola. Sabíamos ya que en pocos dias, y con pocos hombres, podía cortarse una campaña de trigo, por grande que fuera. Poco habíamos adelantado, empero, si no habia un medio igualmente eficaz para separar de la paja en que viene envuelto, el grano de ese trigo tan fácilmente cortado.

Apenas principió una de estas máquinas su trabajo, la duda á que solo pudo dar lugar nuestra ignorancia, quedó disipada. Nada mas perfecto, nada mas completo; nada mas grandioso podia presentarse. Un rayo de luz iluminó el rostro de los agricultores allí presentes, que á una voz esclamaron llenos de contento: Eureka! Aleluya!

Nejor que la mas prolija descripcion, la lámina 8 dará una idea de la risueña escena que presenta una trilla en un pueblo civilizado. ¡Qué diferencia entre el dar vuelta eterno de las yeguas, el alarido de los arriadores, la algazara y la griteria de todos! Será esto mas pintoresco, mas característico, si se quiere, pero es sin disputa muy salvaje.

El trigo se echa por la parte superior, de cualquiera manera que venga, ya con la paja ó la espiga de frente, ya atado en gavillas, ó ya suelto. Es luego recibido por un cilindro ó batidor, que gira con una velocidad estraordinaria, de 1000 á 1200 revoluciones por minuto, y que, al forzarlo á pasar por una estrecha abertura, entre el mismo cilindro y unas placas de fierro con canaletas en espiral, de que tambien está armado el cilindro, y que llamaremos contrabatidor, opera el desgrane. El trigo así desgranado pasa por una série de zarandas y por dos aventadores, y sale al fin perfectamente limpio y clasificado, cayendo con tan grande comodidad á la bolsa puesta de antemano para recibirlo, que 
$\mathrm{H}^{2}$ 


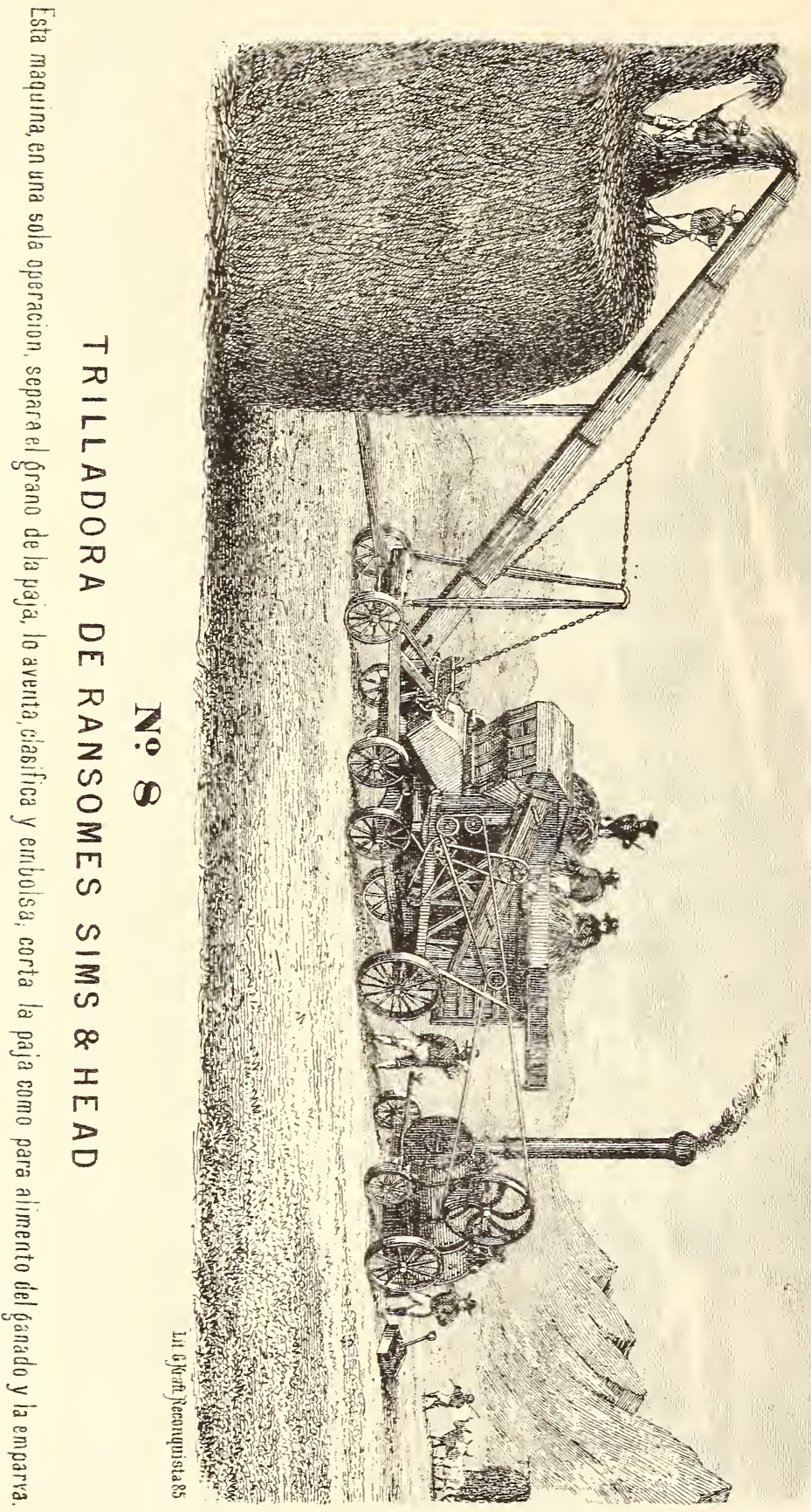


el hombre que la recibe solo tiene el trabajo de retirarla, poniendo préviamente una nueva en otra abertura que se abre al eferto, para que no se pierda un solo grano. La paja sale por la parte de adelante, habiendo sufrido antes la accion de unos sacudidores, á fin de que deje el trigo y las granzas que hubieran podido escapar á las zarandas. Estas granzas son llevadas por el mismo mecanismo á pasar otra vez por el cilindro. La paja menuda que envuelve la espiga, sale por otro caño ó abertura, y puede ser recibida tambien en bolsas. Si se quiere, puede agregarse á esta máquina un elevador, que recibe la paja al caer de los batidores, y haciendo un servicio parecido al de una noria, la lleva hasta la altura de 24. piés, facilitando así la formacion de una parva, y ahorrando el trabajo de 3 hombres, que de otra manera se hubieran ocupado en separar los montones que hacen los batidores, y que acabarian por embarazar su accion.

Por lo espuesto se vé que en una sola operacion estas máquinas admirables hacen una liquidacion completa de la cosecha. Por una parte, entregan el trigo clasificado en varias calidades, pertectamente limpio, sin un grano de tierra, ni una mala semilla, embolsado y pronto para ser remitido al mercado ó al molino ; por otra, despiden la paja menuda, que embolsan tambien si se quiere; y finalmente, dejan la paja acondicionada en una parva, para que sirva en el invierno á la alimentacion del ganado.

La impresion general, repito, no pudo ser mas favorable. Todos daban por compensadas las fatigas de un dia, que habia sido de un calor verdaderamente insoportable, como no he sentido nunca en mi vida, la presenciar aquel grandioso triunfo de la mecánica. Tanto la máquina á vapor, como la trilladora trabajan con una facilidad, y una armonia en todos sus movimientos que encantan. Los que 
tenian alguna práctica de las dificultades que acompañan á la trilla en nuestro sistema actual; de los peligros de que subrevenga una lluvia, mientras se hace la parra, mientras se pisa, y mientras se arenta, no acababan de ponderar las ventajas que este maravilloso mecanismo ofrecia, ni alcanzaban á comprender como es que no se hubiera introducido $\mathrm{y}$ generalizado antes de ahora.

Vamos ahora á ver qué trabajo hacen, cuantos hombres necesitan para funcionar; ramos, en una palabra, á traducir en cifras las ventajas que nos ofrece.

Los Sres. Ransomes, Sims \& Head, cuyas trilladoras obtuvieron el primer premio en la última Exposicion Universal de Paris, dicen en su catálogo que el número de hombres y muchachos empleados debe ser once, y distribuyen la posicion y los deberes de cada uno en la forma siguiente: uno, para alimentar la máquina; dos, para desatar y pasar las gavillas al alimentador; dos, arriba de la parva para echar las garillas á la plataforma de la máquina; uno, para recoger la paja que cae del sacudidor; dos, para apilar la paja; uno, para recoger el hollejo que cae debajo de la máquina, y de cuando en cuando, depositar las granzas que han salido del caño, arriba de la plataforma, para ser̃ trilladas de nuevo ; uno, para quitar los sacos cuando están llenos; y uno, para atender á la locomoril. La posicion de estos operarios se halla perfectamente marcada en el grabado $\mathrm{N}^{\circ}$ 10. El alimentador que ocupa una posicion de mucha responsabilidad, debe ser un hombre activo, teniendo el mando de todos los que se colocan cerca de la máquina. Debe cuidar de hacer la alimentacion en una corriente contínua, sin cesar, estendiendo el trigo con uniformidad sobre el ancho entero del cilindro. Los dos hombres ó muchachos que desatan las gavillas, de- 


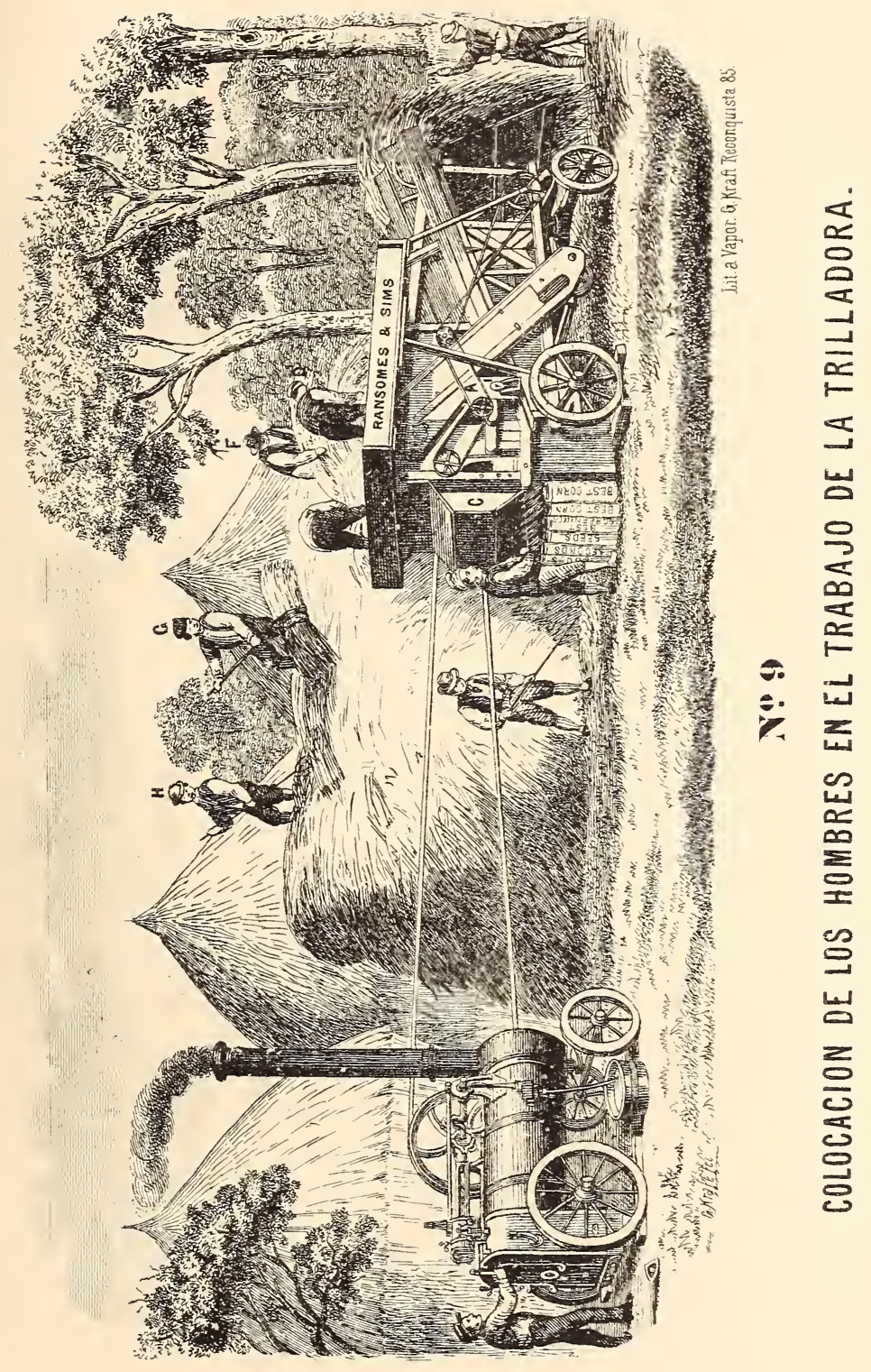



ben colocarse encima de la plataforma, de tal modo que cualquier de los dos pueda pasar al alimentador una gavilla con facilidad pero sin estorbar al otro. Los hombres de la parva cuidan de pasar á los hombres ó muchachos que está encima de la plataforma, sin interrupcion ni escasez las gavillas, de tal modo que estos las pueden alcanzar sin moverse de sus puestos. El que recoge la paja que cae desde el estremo del sacudidor, nunca ha de permitir que esta se vaya acumulando hasta impedir la libre caida de la que viene. Otro tauto se puede decir del encargado de recoger el hollejo de abajo de la máquina, lo que si se descuida, impide la libre accion de la zaranda; este mismo se hace cargo del canasto ó cajon colocado debajo del caño de las granzas, cuidando de depositar su contenido arriba de la plataforma, de modo que sea fácil al alimentador echarlo poco á poco al cilindro para ser trillado de nuevo. El que se encarga de los sacos, debe removerlos antes que lleguen á llenarse tanto que. impidan la salida del grano de los caños, pues sinó, saldrá el trigo limpio entre el chuzo y el desperdicio; durante el tiempo ocupado en llenarse los sacos, tendrá tiempo de reparar la máquina, cuidando de que todos los ejes estén bien lubricados. El encargado de la locomovil debe estar siempre muy alerta en atender á las señales que se le den para parar ó dar movimiento á su máquina.»

El Sr. D. Francisco Ortiz, que es reputado uno de nuestros mas inteligentes agricultores, en una carta que dirige al Sr. Coffin é hijo, y que publica el catálogo de estos Sres., apoyándose en la esperiencia de haber trillado en Chivilcoy 3,000 fanegas con una máquina americana, calcula que el número de trabajadores puede reducirse á 8 .

Sabemos ya qué número de hombres se necesita para 
manejar una de estas máquinas; véamos ahora que trabajo hacen.

La máquina de 8 caballos de Garret trilló en 20 minutos 14.07 libs.

La de Ruston Proctor y $\mathrm{C}^{\mathrm{a}}$., - que se hizo notar por la armonía y regularidad de todos sus movimientos (Iámina 11), 890 en el mismo tiempo.

Segun esta proporcion, la primera de estas máquinas trillaria 187 fanegas en un dia de $\operatorname{diez}$ horas de trabajo, y la $2^{\mathrm{a}}, 118$.

No seria prudente tomar este resultado por definitivo. No es lo mismo el trabajo que se hace en unos pocos minutos de ensayo, bajo el estímulo y la escitacion del premio, que el que se puede esperar y exigir en las largas horas de un dia de verano, bajo los rayos de un sol abrasador.

Debo, sin embargo, observar que una esperiencia posterior me ha hecho ver, que cualquiera de estas máquinas puede trillar de 80 á 100 fanegas al dia. Naturalmente, la cantidad será mayor ó menor, segun sea el trigo. Si ha sido cortado muy bajo, y la paja es muy alta; si las espigas están vanas ó mal granadas, la máquina hará el mismo trabajo, pero el resultado será menor. Y sí las gavillas no tienen sinó paja, es claro que la máquina, por mas perfecto y espeditivo que sea su trabajo, no podrá dar trigo.

La dificultad no está tampoco en que la máquina haga tanto ó cuanto, sinó en darle el alimento bastante. Es increible la velocidad con que despacha el trigo que recibe. Una gran brazada ó una gran gavilla, en un abrir y cerrar de ojos, desaparece; y vese luego que por una parte sale el grano perfectamente limpio y clasificado en varias calidades, segun se quiera; y por otras, la paja, el hollejo, las granzas etc. 


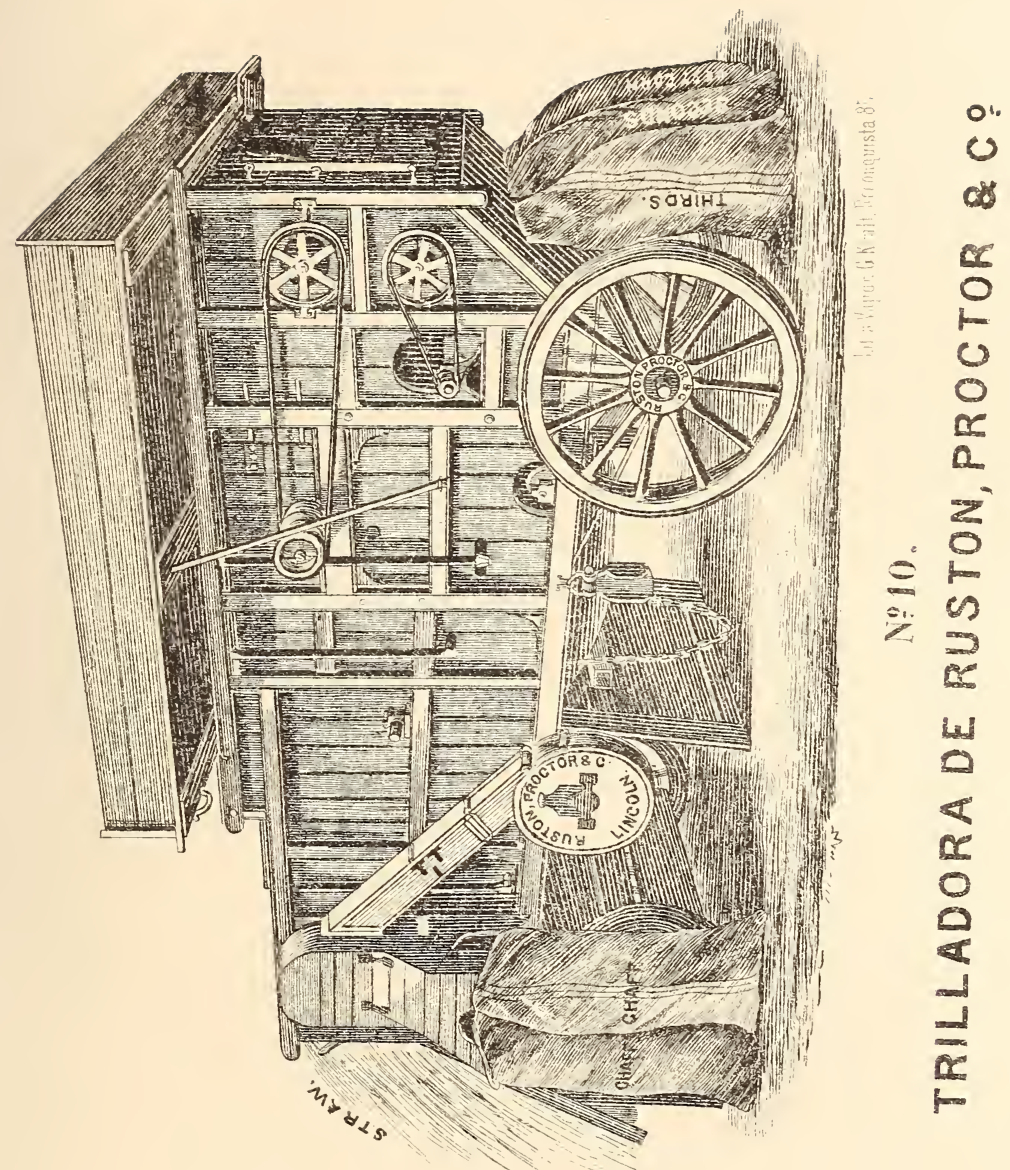



Pero solo aquellos que han tenido ocasion de tocarlo prácticamente, pueden apreciar la cantidad inmensa de paja en que vienen envueltas 100 fanegas de trigo. Es una parva entera, y no pequeña. El trabajo del hombre que recibe las gavillas, ó el trigo suelto para estenderlo sobre el cilindro ó batidor, es tan activo y tan fuerte, que no es fácil que pueda resistirse por mas de dos horas; y para que se lleve con la celeridad y la energia debidas, el alimentador debe ser cambiado con frecuencia.

Despues de haber dicho que la máquina de trillar es entre todos los instrumentos perfeccionados el primero que se introduce aun en aquellos paises donde la agricultura está relativamente atrasada, y qựe su uso es universal, - parecerá escusado poner en paralelo sus ventajas con nuestro sistema actual. En muchos departamentos de Francia, en efecto, la segadora ha penetrado apenas. En otros, alli donde el trabajo es barato y abundantes las cosechas, se discute todavia sus ventajas. Siempre el trabajo del brazo del hombre será mas perfecto, dicen los que aun resisten el uso de la 'segadora, y cuando el trigo está tendido, ó presenta islotes ó manchones ocasionados por las lluvias y los vientos, la máquina será impotente. Cuando el trigo está tendido, contestan sus sostenedores, la máquina cortará de un solo lado; y cuando presente esos manchones ó islotes enredados, se cortarán á mano préviamente, y siempre habrá una ventaja inmensa en favor de la máquina que cortará sin dificultad el resto. En ninguna parte, empero, se ha puesto en duda el grande beneficio que está seguro de recoger el labrador con el uso de la trilladora. En Inglaterra, donde se cultivan estensas superficies, se construyen por millares máquinas de grandes dimensiones, que movidas por motores de diez y doce caballos, pueden trillar doscientos 
y mas fanegas al dia. En Francia donde la propiedad está subdividida al estremo, como es sabido, los constructores han contraido todos sus esfuerzos á ponerlas al alcance de todas las fortunas. Al mas desvalido no se le ocurriria trillar de otra manera, y si no le alcanzaran sus recursos para comprar una, contrataria con algun empresario de trabajos de este género, que no falta nunca. Fuera de desear que entre nosotros se introdujera esta industria. Ningun empleo del capital seria mas reproductivo. $\mathrm{Me}$ aseguran que una máquina que trabajaba en Chivilcoy co-

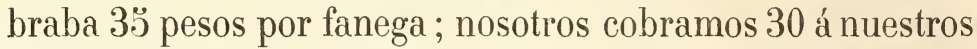
medianeros. Mas adelante se verá que estas cifras dejan todavia una gran márjen al empresario.

Facilitará, por último, en mucho el trabajo de la máquina, y el rinde aumentará en proporcion, si el trigo ha sido atado previamente. Bien sé que esta operacion es costosa, y ha de chocar con la rutina. No concibo por mi parte como pueda hacerse de otra manera un trabajo regular. Atado el trigo, es mas fácil recojer las gavillas en un carro, ó en cueros, si se quiere, y acarrearlas á la máquina. Así se irá trillando á medida que se recoja. Pudiendo la máquina, si es alimentada con regularidad, trillar de 80 á 100 fanegas, que es, mas ó menos, lo que puede emparvarse en un dia, es claro que no habria objeto en hacer una parva para deshacerla al dia siguiente. Solo deberá emparvarse aquel trigo que no pueda trillarse en el período ordinario de la cosecha. Esta sola economía, sin tener en cuenta los peligros de que se moje la parva, basta y sobra á compensar el gasto que hubiera ocasionado la operacion de atar. Las gavillas pasarán de mano en mano con toda facilidad, y la alimentacion de la máquina se hará regularmente sin intermision, doblando su rinde. Si el trigo no se ha atado ¿ cómo se alcanza de los cueros ó de los 
carros al alimentador, que está á una altura considerable? |Cuánto desperdicio, cuánta pérdida de tiempo no costará pasar el trigo suelto, bien en brazadas, bien en horquillas que llevarán apenas unas cuantas espigas! La mitad del trabajo de la máquina será perdido, si no se ha tomado esta precaucion indispensable. En ninguna parte del mundo se trabaja de otra manera, y entre nosotros, aun para el trabajo ordinario de trillar con yeguas, principia á usarse, por los italianos principalmente, llevar en carretas el trigo atado á la era.

Vamos ahora á examinar un poco esta temida cuestion de la atadura.

Desde luego, lo primero que ocurre preguntar es ¿con qué se ata? Y lo primero que tambien ocurre contestar es que con la misma paja del trigo.

Pero esta paja es corta las mas veces, y se rompe cuando está seca.

Este inconveniente, que es realmente sério, se evitará en mucha parte, si el trigo se corta, como debe cortarse, cinco ó seis dias antes de estar maduro. Así la paja tendrá flexibilidad, y resistencia bastante, aun para hacer las cuerdas ó ataduras de dos manejos ó puñados, si no fuera suficientemente larga.

He dicho que el trigo debé cortarse cinco ó seis dias antes de su madurez. Jamás se recomendará bastante á nuestros labradores que antes que retardar, anticipen mas bien este momento precioso de la cosecha, que una vez perdido, no vuelve mas.

Hemos visto siempre principiar la cosecha de nuestros cereales cuando el sol ha dorado sus espigas ; y esperimentamos una resistencia instintiva á cortarlo verde. Error fatal! La ignorancia ó el desprecio de los consejos de la ciencia, nos cuestatodos los años el sacrificio estéril de millares de fane- 


\section{$-62-$}

gas, y de millones de pesos. Creo que no es exajerado decir que una cuarta parte de nuestra cosecha se pierde por no cortarse á tiempo. La espiga demasiado seca deja caer el grano; los pájaros devoran una buena parte ; y los vientos y las lluvias se encargan del resto. Tambien sin exageracion puede decirse que otra cuarta parte se pierde en la era. ¿Cuántas veces no se pierde todo? De manera que sin avanzar demasiado puede asegurarse que la mitad de nuestra cosecha se pierde por no cortarse- y trillarse á tiempo, ó lo que es lo mismo, por falta de la suficiente dotacion de máquinas de segar y de trillar. Con esta mitad perdida habria lo bastante para enriquecer á los labradores; para llenar la campaña entera de máquinas; para cambiar el estado precario en que se arrastra nuestra agricultura; y finalmente, para no necesitar que nos venga del estrangero lo que podemos producir, y lo que en realidad sacrificamos por preocupaciones ó por falta de saber.

Admitido que el trigo deba cortarse antes de su madurez. ¿Cuál es el momento preciso?

Cuestion es esta muy debatida, pero que está hoy definitivamente resuelta con el acuerdo de la esperiencia y de la ciencia.

Es hoy un principio admitido sin discrepancia por los hombres competentes, que la madurez, es decir, el acto de madurar, no es esclusivamente un acto de vejetacion. Es mas bien una combinacion de elementos preexistentes, una especie de reaccion quimica de las materias contenidas dentro del perispermo. «Si se examina en la primavera, con el auxilio de un microscopio, la fécula de los tubérculos del iris de Florencia, dice Mr. Raspail en su nuevo sistema de química orgánica, se verá que el grosor de los granos no pasa de 1/100 de milimetro; si se dejan estos tubérculos al aire, despues de quince dias los granos de fécula habrán 
aumentado tres veces de volúmen. La fécula puede, pues, desarrollarse sin que la planta comunique con el suelo. »

"Cuando la semilla, dice el Dr. Stockhardt, ha adquirido la facultud de reproducir otro individuo igual al que le dió el ser, la planta ha llenado su mision, muere, y la descomposicion principia luego.» Ahora bien, se ha observado que la vida de la planta concluye precisamente por donde habia principiado, es decir por la raiz. ILuerta la raiz, ningun alimento puede dar á la planta, y por consiguiente, el grano de los cereales puede completar su madurez despues de haber sido separado del suelo. Del mismo modo vemos que la mayor parte de las frutas, los duraznos, las naranjas, las manzanas etc., maduran perfectamente fuera del árbol, y algunas, como las peras, muchos meses despues.

Esta cuestion no es nueva, y trae otra vez á la memoria la esclamacion que motivó la segadora de los Galos. «Nada es mas peligroso que el retardo, dice Columella, escritor agrícola, contemporáneo de Séneca;-primero porque el grano es presa de los pájaros y de otros animales; y despues porque los granos y las mismas espigas se desprenden de las cañas, que acaban tambien por tenderse si sobrevienen vientos impetuosos. Esta es la razon porque no se debe esperar demasiado ; debe principiarse la cosecha tan pronto como las espigas tomen un tinte amarillento, y antes que los granos maduren, á fin de que crezcan (grandescant) en el granero mas bien que en el campo, porque es fuera de duda que, si se corta á tiempo, el grano adquiere en seguida desenvolvimiento (incrementum). »

Las observaciones de los agrónomos modernos confirman plenamente esta opinion del escritor Romano: «El corte prematuro, dice Matthieu de Dombasle, evita á menudo una pérdida considerable que ocasiona el des- 
grane, sobre todo en algunas variedades de trigo; y en todas aquellas partes donde se sigue esta práctica, todos convienen en que el trigo segado prematuramente es de mejor calidad para el molino. En algunos mercados los molineros y los panaderos saben bien distinguirlo al simple tacto, $y$ lo pagan ordinariamente mas caro que el grano recojido en su completa madurez. Esta práctica presenta dos ventajas muy importantes: la de poder disponer de mayor número de dias, anticipando una semana el principio de la cosecha; la de ponerse á cubierto un poco antes de los peligros de los temporales y de la piedra, que amenazan los trigos en esta estacion del año, y que con tanta frecuencia devastan algunas provincias, la víspera de la cosecha.»

Cock y Antonio de Roville piensan que el trigo recojido antes de estar maduro contiene menos afrecho.

Opinan que cuando se deja demasiado tiempo en pié, la película se hace mas gruesa á espensas de la sustancia que contiene el grano.

Muchas otras autoridades y muy competentes podria citar para probar que hay mas que utilidad, necesidad, de cortar el trigo antes de que esté completamente maduro. Pero ¿cuál es el momento preciso que aconseja la esperiencia?

Algunos autores creen que es aquel en que el grano no está ya bastante blando para ser aplastado entre los dedos. La opinion de Matthieu de Dombasle es mas precisa y mas exácta: «Se puede, por regla general, dice, cortar el trigo siete ú ocho dias antes de su completa madurez; es decir, cuando la paja, principiando á ponerse blanca y á secarse hácia el pié, comienza á perder su tinte verdoso ; y cuando el grano ha adquirido bastante consistencia para que, si se le apreta entre los dedos, la uña penetre todavia, pero no 
lo corte tan fácilmente como cuando no tiene sinó una consistencia de leche ó de pasta.

Esta indicacion del ilustre agrónomo es tanto mas preciosa, cuanto que ha sido enteramente confirmada por esperiencias recientes.

Por órden de la Sociedad Imperial y real de agricultura de Francia, Mr. Payen, secretario perpétuo de la Sociedad, y Ir. Pommier, miembro de la misma, hicieron estas esperiencias en la chacra Imperial de Fouillense, y obtuvieron los resultados siguientes :

Trigo muy verde cortado 8 ó 10 dias antes de su madurez.

Trigo blanco. Trigo colorado.

Granos verdes (100 espigas) . 138 gr. $51 \quad 146$ gr. 46

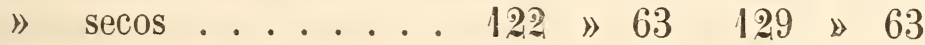
Agua, por ciento de granos. . 12 " 13 12 12 " 86 Peso del litro verde $\ldots . .800$ » $60 \quad 7309$ » 20

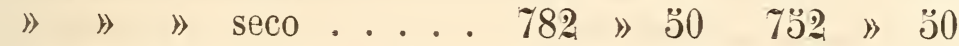

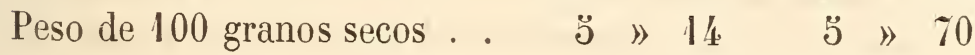

Trigo menos verde, recojido 5 ó 6 dias antes de su madurez.

Trigo blanco. Trigo colorado.

Granos verdes (100 espigas) . 138 gr. $61 \quad 146$ gr. 46

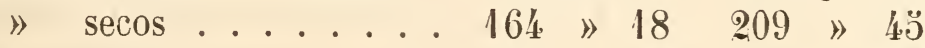
Agua, por ciento..... 12

Peso del litro verde . . . . 898 " 60 74.1 \# 20

" " " seco..... 807 \# $30 \quad 746$ " 20

Peso de 100 granos secos .. 5 " $37 \quad 3$ " 82 
Trigo recojido en su madurez completa.

Trigo blanco. Trigo colorado.

Granos verdes (100 espigas) . 182 gr. $96 \quad 196$ gr. 54

" secos ....... 164" 18 209 \# 4.5

Agua, por ciento de granos. . $\quad \begin{array}{llllll}18 & \text { \# } & 89 & 13 & \text { \# } & 38\end{array}$

Peso del litro verde .... 793 » $00 \quad 803$ » 50

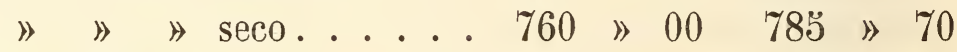

Peso de 100 granos secos .. 5

Estos hechos observados con toda exactitud son concluyentes.

El hectólitro (3 cuartillas próximamente) de granos secos de trigo colorado cortado diez dias antes de su madurez, pesó 78 kil. 20; la misma cantidad de trigo cortado seis dias antes de estar maduro, es decir, en las condiciones que aconseja Matthieu de Dombasle, 80 kil. 73 ; y por último, igual cantidad cortado en su completa madurez, solo 76 kil.; menos que el trigo cortado diez dias antes de estar maduro. No cabe, pues, la menor duda de que es preferible anticipar de dos ó tres dias el momento de la cosecha, antes que retardarlo.

Cadet de Vaux asegura que el trigo recojido antes de estar maduro pesa $\breve{b}$ kilógramos, -10 libras, -mas por hectólitro; y que 1,500 gramas de harina de uno y otro trigo, darian 12.0 gramas mas por la harina del trigo recojido antes de su madurez.

Resulta, pues, evidente que el mejor momento para cortar el trigo, es cinco ó seis dias antes de su completa madurez, y que es todavia preferible cortarlo diez dias antes, en vez de esperar á que esté completamente maduro.

Es bien entendido que este principio no es aplicable á los trigos que se dejan para semilla.

$\mathrm{La}$ esperiencia ha probado tambien que los cereales cor- 
tados anticipadamente, son menos propensos á desgranarse, que los que se han dejado madurar en la planta.

Ie he detenido sobre este punto mas de lo que pareceria corresponder á la naturaleza de este informe, porque lo considero de la mayor importancia para nuestros labradores. Cuando llegan los dias abrasadores de Diciembre, las diversas fases de la vejetacion de los cereales se desenvuelven con una rapidez estraordinaria. El trigo sembrado en Agosto madura casi al mismo tiempo que el que se sembró en Mayo. Solo tiene así el labrador veinte, ó veinticinco dias, á lo sumo, en que cortar su trigo en el momento oportuno. ¡Cuánto no importa entonces que no pierda uno solo! ¡ Qué ventaja inmensa que pueda contar con diez dias mas en una época tan premiosa! |Qué pérdida tan considerable no evitará cortando todo su trigo, antes que se haya desprendido un grano de la espiga!

Pero volvamos ya á la operacion que nos ocupaba antes de esta digresion.

Cortado verde el trigo, es fácil atar la gavilla con la misma paja. Pero esta puede ser corta; es entonces preciso hacer de dos puñados ó manojos uno, y esto alarga y dificulta la operacion, mucho mas cuando es nueva, y hay pocos hombres diestros entre nosotros.

En Europa se siembra, como he dicho, centeno, que dá una paja larga, y se preparan con ella cuerdas ó ligaduras con anticipacion. Entre nosotros debiera hacerse lo mismo; el labrador previsor debiera preparar con anticipacion estas cuerdas, supliendo el centeno con paja ó con junco, si fuese necesario.

« La cosecha, dice Olivier de Serres, padre de la agricultura francesa, es el fin y el coronamiento de los trabajos de la tierra. Debe, pues, el labrador disponer con diligencia sus trabajos para recojer el fruto segun la bendi- 
cion de Dios.» « Se ha comparado á menudo al labrador, dice otro autor distinguido, á un general ; y esta comparacion nos ha parecido exacta. El dia de la cosecha es el dia de la gran batalla que ha de decidir de la suerte de los trabajos del año. El enemigo á combatir y vencer es la lluvia intempestiva; el sol demasiado ardiente; el trigo demasiado maduro, ó tendido por los vientos, ó la piedra ; ó bien, son los hombres que faltan, los instrumentos que se rompen, las máquinas que se descomponen; el enemigo á vencer, en una palabra, son todas las dificultades que se presentan hasta que el trigo esté salvo y seguro en el granero.»

Para el labrador que cuenta con la suficiente dotacion de máquinas de segar y de trillar, la batalla está ganada. La única dificultad que le queda que salvar es la de atar las gavillas, y esta desaparece, si ha preparado de antemano los medios de vencerla.

Antes he recordado que en los Estados Unidos habia obtenido patente una máquina que, al mismo tiempo que cortaba y hacia las gavillas, las ataba. Seria esto sin duda un gran progreso, pero no es hasta ahora mas que wna esperanza.

En un interesante artículo que publica el Journal d'Agriculture practique, en el número del 10 de Febrero del año próximo pasado, un agricultor francés, Mr. Goussard de Mayolles, recomienda mucho unas cuerdas ó ligaduras automáticas, inventadas por Mr. H. de Lapparent, que dice haber usado muchos años con el mejor éxito. Segun asegura, con estas ligaduras la operacion de atar se facilita en estremo, á términos de que pueden ocuparse en este trabajo mujeres y muchachos; y de esta manera ha podido reducirse á un céntimo el precio de atar una gavilla. Estas ataduras, segun dice el mismo agricultor, tienen ademas la 
ventaja de desatarse con la mayor facilidad, y parecen hechas ex-profeso para la trilladora á vapor. Sirven muchas veces en una misma cosecha, y duran 5,6 ó mas años. Su precio es $5 \mathbf{4}$. francos, $\mathbf{2} 70$ pesos moneda corriente por millar, y el domicilio de Mr. Lapparent, Saint-Eloi de Gy, cerca de Bourges. He encargado algunas de estas ligaduras, que espero poder ensayar en la próxima cosecha. Nada hay indiferente ni pequeño tratándose de agricultura. En los mas insignificantes detalles se cuenta por millones. Mr. Manoury D'Ectot, apoyado en prolijos datos estadísticos, estima en $80.000,000$ de francos, 400.000,000 de nuestra moneda, el gasto que hace la Francia anualmente en estas ligaduras de paja con que ata las $2.000,000,000$ de gavillas que recoje! La invencion de Mr. Lapparent reduciria á la mitad por lo menos esta enorme suma.

El precio corriente en Francia para atar una hectárea de trigo es ocho francos, lo que equivale, mas ó menos, á 100 pesos de nuestra moneda por cuadra. Aunque fuera el doble, y aun el triple entre nosotros, habria siempre tan grande economía en todas las operaciones sucesivas, que estaria compensado con usura.

En un trabajo regular y con una cosecha mediana de 20 fanegas por cuadra, p. ej., una trilladora correspondiente á una locomobil de la fuerza de seis caballos, que es á mi juicio la que mas conviene para nuestro país, trillará de 60 á 100 fanegas en 10 horas de trabajo. Tomando el mínimun, resultará todavia una diferencia inmensa en favor de la máquina, segun es fácil verlo.

Tomamos por punto de partida el hecho comun á uno y otro sistema, de que el trigo esté en la parva, ó se traiga al costado de la máquina, lo que supondria que se habia evitado el gasto de hacer la parva, y estableceria desde luego una gran ventaja en favor de la mecánica. Tenemos enton- 
ces para el trabajo de la máquina, segun Ransomes Sims. 1 Maquinista ....................... 50 10 peones á 30 pesos................ 360

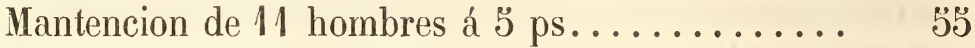

Carbon, 300 libras................. 150

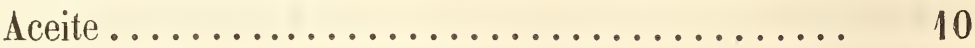

Un hombre para acarrear agua............ 30

Interes y amortizacion del costo de la máquina, que estimaremos en 50,000 pesos moneda corriente en relacion á 40 dias de trabajo en un año, al dia 300 Reparaciones é imprevistos............ 160

Lo que equivale á 16 pesos por fanega.

Muy difícil es, sinó imposible, calcular cuanto costará este mismo trabajo por el sistema actual, pues todo depende que no llueva mientras se hace y se trilla la parva, y de que haga viento para aventarla. Suponiendo, lo que rara, muy rara vez sucede, que una parva que represente de 60 á 100 fanegas, se trille en un dia y se avente en dos, tendremos lo siguiente:

Preparacion de la parva.............. 150

Yeguarizo: es sabido que cada año suben los precios de una manera estraordinaria, por la escasez y el alto precio de las yeguas............ 600 10 hombres á 30 pesos, 3 dias............ 900 Mantencion ...................... 150

Es decir-27 pesos por fanega.

Es bien sabido que esto es bajo por demas. Pocos son los labradores que no darian la mitad de su cosecha al que la levantára. Los gastos de cortar, usando la máquina, son insignificantes, no mas de 3 ó 4 pesos por fanega, y 
sí solo se usa la hoz, no pasarán nunca de 15 ; siendo el precio del trigo por término medio 150 pesos, es evidente que los labradores no estiman en menos de 50 pesos el costo de trillar una fanega. Resulta entonces que aun dadas las condiciones mas desfavorables para la máquina y las mas favorables para el sistema actual, hay siempre una ventaja inmensa en favor de la máquina.

Pero hay todayia una consideracion de la mayor importancia en su favor. El trigo trillado por la máquina vale 15 ó 20 pesos mas en el mercado. Una partida trillada en nuestro establecimiento de Campana por una Pitts, se pudo vender al precio mas alto, no obstante que solo pesaba 8 arrobas 12 libras; al mismo precio porque se vendian trigos que daban 9 arrobas 15 libras. Si á esto se agrega que la separacion del grano de la paja se hace mucho mejor, no pudiendo estimarse en menos de un 10 á un 15 por ciento el aumento en el rinde, tendremos al fin que el uso de la trilladora comparado con el sistema actual, no solo es mas económico, sinó que paga sus gastos con la mejora que produce en el precio y en el rinde, y deja todavia una ganancia al labrador. ¿Qué mas puede exijirse, ni qué mas puede desearse? 


\section{TRILLADORA PITTS}

Ensayo desgraciado - Revindicacion - Motores de vapor y de fuerza de caballo - Razones que aconsejan entre nosotros el uso de los primerosSencillez del mecanismo de esta máquina - Su precio - Condiciones que la hacen la mas adecuada para nuestro país.

Ensayóse en seguida una máquina de construccion americana de la afamada fábrica de Pitts, de Buffalo en el Estado de Nueva York, que merece una mencion especial (Lám. 11.) En vez de ser movida por vapor, lo era por una una fuerza de ocho caballos. Fácil fué ver desde luego la diferencia entre uno y otro motor. Las máquinas inglesas con sus locomobiles habian trabajado admirablemente, sin vacilacion, sin un solo entorpecimiento. Mientras tanto, el encargado de dirijir las cuatro parejas que debian dar movimiento á la fuerza de caballo, se ajitaba en vano para conseguir que el tiro fuera igual y seguido. Unas veces iban demasiado á prisa los caballos, otras se paraban, otras se enredaban en los arreos ; hasta que al fin se rompió por segunda ves el piñon de un engrenaje, y terminó el ensayo, bajo 


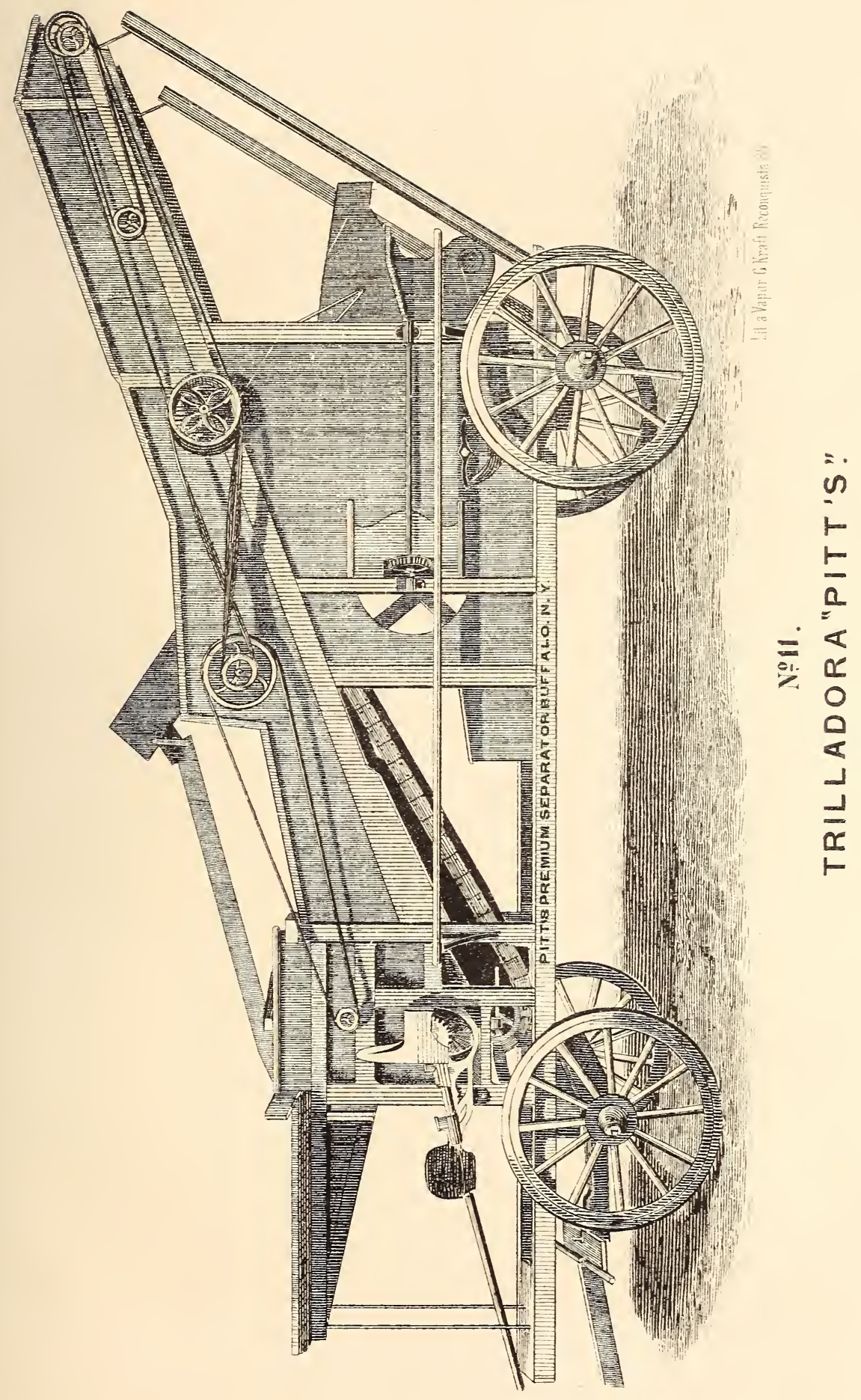



una impresion desfavorable. Obsérvase tambien que esta máquina rompia en estremo el grano.

Es una cosa singular lo que entre nosotros sucede. En el país donde, segun se ha observado, apenas se dá un paso á pié, donde todo se hace á caballo, donde se pesca, se caza, y hasta se pide limosna á caballo, es lo mas difícil encontrar caballos educados al trabajo. No habrá tal vez un solo hacendado ó labrador que tenga las diez parejas que exije la trilladora Pitts; digo diez, porque no es posible que los caballos trabajen todo el dia sin mudarse, y porque es indispensable tomar repuesto, en prevision de que alguno se canse ó se enferme. En los Estados Unidos estas fuerzas de caballo se usan muy generalmente y con preferencia al vapor. Son mas baratas y mas económicas, puesto que no exijen el gasto del combustible. Pero allí, todos los trabajos de la labranza se hacen con caballos, que se mantienen perfectamente á pesebre, y que el uso y el cuidado domestica y amanza. Mientras nosotros no nos encontremos en igual caso, debemos preferir los motores á vapor, cuyo trabajo, es por otra parte, mucho mas regurar y mas eficaz, y que merecen por su importancia un estudio especial.

He tenido ocasion de presenciar el trabajo de una de estas trilladoras Pitts, y me complazco en revindicar para ella el honor que dejó comprometido en los campos de Córdoba. No era posible que en los Estados Unidos, granero del mundo, y donde tantos progresos ha hecho la mecánica, el instrumento que tiene mas aceptacion y que se espende por millares, fuera un instrumento defectuoso, que tuviera que avergonzarse ante la perfeccion de las máquinas inglesas.

En la última cosecha trillamos en nuestro establecimiento como 1,000 fanegas de trigo con una máquina Pitts del modelo mas grande, movida por una locomobil inglesa de 
la fuerza de 12 caballos. Nada mas sencillo, mas perfecto, mas admirable. La máquina de vapor trabajaba solo con la mitad de su fuerza ; fácilmente hubiera podido poner en movimiento dos máquinas iguales. El consumo de carbon no era considerable, alcanzaria apenas á la sesta parte de una tonelada al dia.

Como es sabido, con muy raras escepciones, la cosecha fué malísima el año último, á consecuencia de las fuertes heladas que sobrevinieron en Noviembre. La mitad de las espigas no tenia grano; no fué posible, por consiguiente, formar un cálculo exacto acerca de la cantidad que esta máquina podria trillar. La impresion de todos los que la vieron fué, sin embargo, que podria hacer con un trigo en regulares condiciones mas de $\mathbf{1 0 0}$ fanegas en diez horas de trabajo con toda facilidad. Algunas veces observamos - con el reloj en la mano, que llenaba una bolsa en cinco minutos, y aun en menos.

La gran dificultad, como lo he observado antes, es alimentar con bastante rapidez el cilindro desgranador, que girando aun con mayor velocidad que en las máquinas inglesas, 1,300 revoluciones por minuto, arrebata como un furioso torbellino las brazadas que recibe, por grandes que sean, haciéndolas desaparecer como en una vertijinosa vorájine.

Al principio el grano salia bastante quebrado, pero este defecto que visiblemente provenia de la aspereza de los dientes ó puas del desgranador, fué gradualmente desapa= reciendo á medida que con el mismo uso se gastaban los filos de aquellas puas, y ya al último el grano quebrado era muy poco. Solo una vez fué necesario suspender el trabajo para hacer una pequeña reparacion. El grano salia perfectamente limpio, y no obstante su quebradura, y que solo pesaba 8 arrobas 12 libras, ha sido considerado ecep- 
cional en el mercado, y ha obtenido el precio mas alto. Las autoridades de los partidos vecinos y muchos de sus principales habitantes vinieron á presenciar este ensayo. Hombres prácticos todos, y que personalmente han luchado con las dificultades que veian vencidas como por encanto, no se cansaban de admirar aquella maravilla de la industria.

En mi opinion, es esta la trilladora que mas convendria introducir entre nosotros. Las de fabricacion inglesas, son sin đuda mas perfectas, la rotura del grano es menor, y la paja sale mas entera; pero á la vez, su mecanismo es mas complicado, y por consiguiente mas dificil de reparar. En la máquina Americana todo está á la vista, y cuando por algun accidente deja de funcionar con debida regularidad, cualquier obrero medianamente intelijente, ve luego donde está el mal, y sin trepidacion puede remediarlo. A esta ventaja que para nuestro país es inapreciable, hay que agregar que son mucho mas livianas, pudiendo trasportarse con toda facilidad á largas distancias con uno ó dos caballos; y por último, que son mas baratas, circunstancia que tampoco es indiferente, atendida la proverbial pobreza de nuestros agricultores. La trilladora Pitts á que he hecho referencia, costaba en la fábrica de Buffalo con sus repuestos, 320 pesos fuertes; el flete, comisiones etc., hicieron elevar esta cifra á $1 \%, 000$ ps. m/c., y no obstante que los derechos fueron liberalmente dispensados por el Gobierno Nacional, al llegar á Campana hubo que aumentar todavia unos 4,000 pesos mas, que con escasa diferencia triplicaron el costo primitivo.

La lámina núm. 12 dá una idea de esta máquina, cuya estructura es realmente orijinal. Sobre la pequeña plataforma que está en la parte de adelante, se pára el hombre que recibe el trigo suelto ó en gavillas, siendo, como hemos visto, esto último mil veces preferible. En las máquina 
inglesas el obrero que recibe el trigo está arriba de la máquina á considerable elevacion, lo que hace mas dificil alcanzárselo. El cilindro desgranador jirando con estraordinaria velocidad de 1,200 á 1,300 revoluciones por minuto, fuerza el trigo á pasar entre unas puas, que pueden compararse á las de los desgranadores de maiz, si bien mucho mas pronunciadas; y que están calculadas para que solo quede entre unas y otras el espacio necesario, y que puede graduarse segun la calidad del grano. Desecha la espiga en esta operacion, cae el grano mezclado con la paja, que tambien ha sido un tanto despedazada, á una faja de lona del ancho del cajon de la máquina, que gira sobre unas pequeñas poleas colocadas de trecho en trecho á lo largo de la máquina. Esta faja ó lona, tiene pegadas fuertemente á lo ancho unas pequeñas tablas á una distancia de una pulgada una de otra. El grano, y las granzas caen dentro de las cavidades que dejan entre sí estas pequeñas tablas, y al llegar á la altura del ventilador donde la tela sin fin concluye, caen por su propio peso sobre una zaranda, recibiendo al caer una poderosa corriente de aire que se lleva la paja menuda. Despues de pasar por una zaranda, igual á la que vemos en los ventiladores ó limpiadores ordinarios, el trigo sale ya perfectamente limpio por un agujero que se advierte por entre los rayos de la rueda, y cae á la bolsa, que puede ya mandarse al mercado ó al molino.

La paja que no ha sido bastante desmenuzada, y es casi toda, pasa de la faja sin fin, ya descrita, á otra mas pequeña, que la arroja por la parte mas elevada. Esta paja se aglomera con grande rapidez, y es indispensable retirarla, porque sinó entorpeceria el juego de la zaranda y del ventilador. Es este el trabajo mas penoso; pues la paja sale con mucha fuerza, y los trabajadores necesitan 
algunas veces cubrirse la cara con un pañuelo fino ó un linó. Este inconveniente se salvaria con el elevador que lleva la paja á una gran distancia y puede emparvarla, si se quiere; ó bien, arrastrando los montones de paja con un caballo á la manera en que se llevan los de alfalfa para hacer.la parva.

Diré al terminar con respecto á estas máquinas lo que decia relativamente á las de construccion inglesa. Si los señores Brayley, sucesores de Pitts, tuviesen un depósito en esta ciudad, abririan un mercado muy importante para los productos de su gran fábrica de Buffallo. 


\section{MÁQUINAS DE VAPOR AMBULANTES \\ ó}

\section{HOCOMT OTEETLES}

$\mathrm{Su}$ introduccion - Su mecanismo - Gastos de carbon - Idem de agua - Su precio - Idem de las trilladoras y elevadores.

Hemos visto que la falta de buenos caballos de tiro hace preferible entre nosotros el uso de las máquinas de vapor, que deben asi considerar como una parte integrante de las de trillar, y merecen por consiguiente, un estudio especial.

Es esta máquina una invencion moderna-Recien en la Exposicion Universal de 1851 llamó definitivamente la atencion, apareciendo en la forma que ha conservado hasta ahora, y que puede llamarse clásica, L. 13.-Desde entonces se ha hecho general, y se construye por millares. Solo los grandes talleres de Clayton y Shuttleworth, cuyo modelo ha sido adoptado por todos, concluyen y espenden una por dia.

Ransomes Sims y Head; Ruston, Proetor y Ca, Robey y 


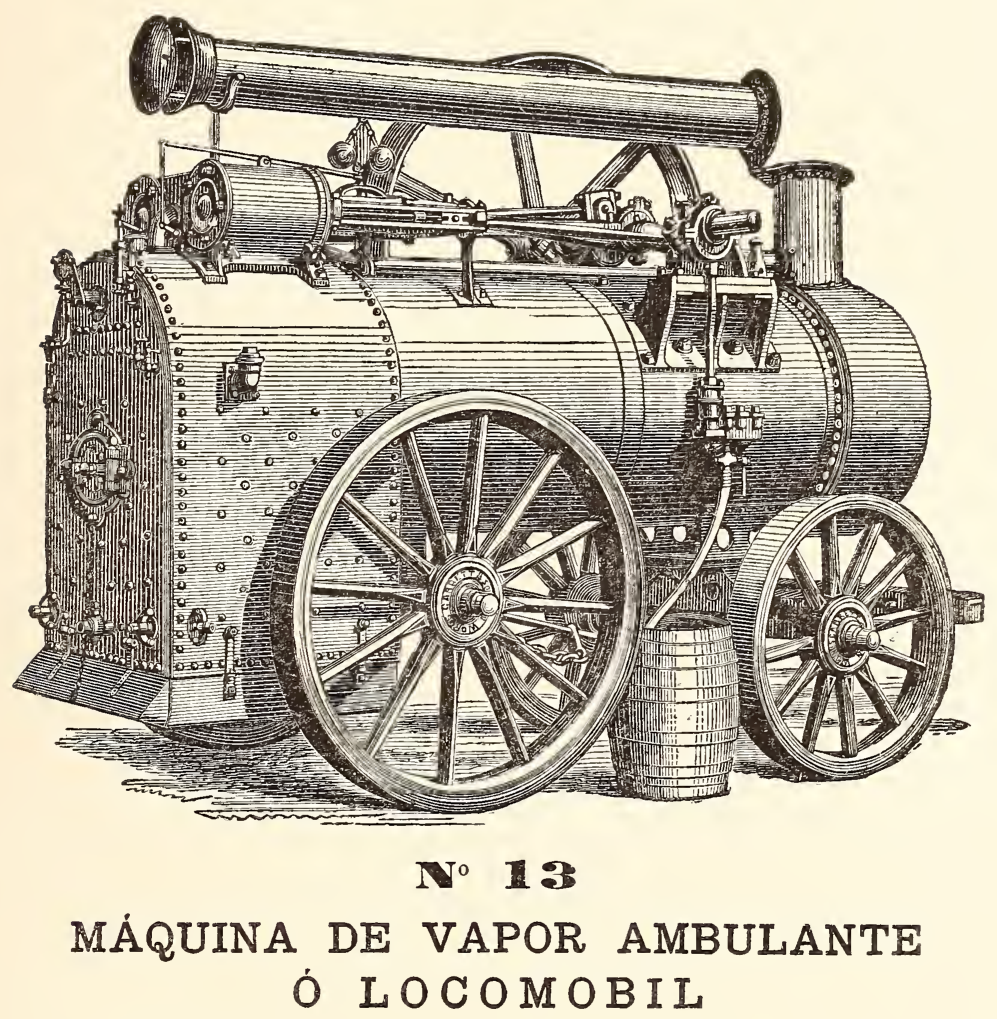



Ca, Marshall, Garret, Howard, Horusby ete., etc., constructores no ménos importantes y afamados, - se empeñan á porfia en mejorar este precioso instrumento de trabajo, que es hoy tan perfecto en todos sus detalles, como las máquinas fijas. Todo está previsto y perfectamente calculado. Su mecanismo se ha simplificado á términos de que cualquier obrero medianamente inteligente en un par de horas lo comprende y puede dirijirlo.

El peligro de esplosion es tan remoto, que puede considerarse poco menos que imposible, no solo por el empleo de los mejores materiales, y la prueba á que han sido sujetadas las calderas, sometiéndolas á una presion tres veces mayor que las que están destinadas á sufrir en su trabajo ordinario, - sinó por la mas perfecta combinacion de válvulas de seguridad, una de las que está bajollave, para ponerla á cubierto de la imprevision ó imprudencia del conductor.

Como en toda máquina de vapor, hay que distinguir en la locomobil, la caldera y el mecanismo propiamente dicho.

La caldera generatriz del vapor, es del sistema tubular, pues importa que tenga el menor vólumen posible.

Consiste en un gran cilindro de planchas de fierro, hueco en el centro. En este centro hueco está la hornalla. Al llegar el humo y la llama á la recámara que forma el fondo del cilindro, vuelven por unos tubos que están dentro del cilindro, y por consiguiente dentro del agua, y antes de salir por la chimenea que se vé encima de la hornalla, dejan mucha parte de su calor, que se aprovecha de esta manera.

El mecanismo motor está colocado encima de la caldera, y consiste en un cilindro en el que la accion del vapor pone en movimiento un piston, que mueve á su vez la rueda á la que se fija la correa destinada á comunicar su impulso á la máquina que se quiere hacer trabajar, ya sea de trillar, ya de acerrar madera, ya de hacer ladrillos etc. etc. 
La bomba que alimenta la caldera, segun el último sistema, hoy adoptado por todos, hace la alimentacion automáticamente, y á medida que el agúa se va consumiendo por la salida del vapor-Básta que por medio de un tubo de goma elástica se la ponga en comunicacion con el depósito del agua.

A mas de estos órganos esenciales, hay varias otras pequeñas é ingeniosas combinaciones que sirven para arreglar el movimiento de la máquina, para indicar el nivel de agua en la caldera, y hasta para avisar al conductor por un silvido agudo y prolongado que hay necesidad de alimentarla. Esto último es hoy innecesario por el nuevo sistema de alimentacion contínua á que he hecho referencia.

Cuando la máquina anda con demasiada velocidad, los globos de fierro del regulador, que, ligadas por un sistema sencillo de engrenage á los órganos principales, participan del movimiento general, se abren ó se apartan, obedeciendo á la fuerza centrífuga, y cerrando la válvula por donde entra el vapor al cilindro, moderan el impulso de la máquina, que, sin este freno, presentaria el espectáculo de un caballo desbocado, siempre que faltára la resistencia que encuentra en su trabajo ordinario, ó se produjera demasiado vapor en la caldera.

Calcúlase que hay mas de 20,000 de estas máquinas locomobiles en actividad. Su uso se hace cada dia mas y mas general, y puede decirse que es hoy tan indispensable en una esplotacion agrícola de mediana importancia, como la máquina de segar y la de trillar. Esto solo prueba que no es difícil manejarlas. La guerra del Paraguay fué entre nosotros una grande escuela de maquinistas, que no tienen hoy ocupacion, y se felicitarian de que los labradores utilizaran sus servicios. Los fabricantes dan siempre con la máquina prolijas instrucciones impresas, que facilitan mucho su manejo. 
En la última exposicion de Paris se presentaron mas de cien de estas máquinas. - Sometidas á un estudio sério para apreciar el combustible que gastaban, se obturo el resultado siguiente:

Constructores.
Fuerza de la máquina. Consumo por hora por cada caballo.

$\begin{array}{lrrrr}\text { Ramtomes, Sims \& Head } & 10 \text { caballos } & 1 \text { kilóg. } & 631 \\ \text { Marshall . . . . . . } & 8 & \text { id } & 3 \text { id } & 171 \\ \text { Girard . . . . . . } & 6 & \text { id } & 2 \text { id } & 174 \\ \text { Allen, etc., etc. . . . . } & 6 & \text { id } & 3 \text { id } & 360\end{array}$

Vése asi que el consumo de carbon varia entre 4 y 6 libras por la fuerza de cada caballo por hora. Es decir que una máquina de la fuerza de 6 caballos, por ej., tomando el término medio, consumiria 30 libras de carbon por hora, ó sea 300 en un dia de 10 horas de trabajo.-Calculando en 900 pesos el precio de una tonelada de carbon en cualquier punto de la campaña no muy distante de los ferro-carriles, estas 300 libras representarán 150 pesos. Si en vez de carbon de piedra se quema leña, se necesitará doble peso, esto es, 600 libras al dia. Se ha pretendido que estas máquinas trabajan solo con la paja del trigo. No me parece posible que sin un combustible mas fuerte pueda mantenerse la presion necesaria. Pienso sí que lo que se llama leña de ovejas, que hoy abunda tanto, puede suplir muy bien el carbon.

El agua que la máquina evapora es consịderable, y puede estimarse en algunos barriles por dia, cuyo trasporte exigirá la ocupacion de un hombre, si no estuviese cerca.

En todos los catálogos que tengo á la vista y son mu- 
chos, el precio de estas máquinas, es invariablemente el mismo :

De un cilindro y 4. cab. de f'za... £150 ó sea m/c 1837.

\begin{tabular}{|c|c|c|c|c|c|c|}
\hline & $\breve{~}$ & " & $\pi$ & « 163 & " & 20212 \\
\hline & 6 & $"$ & " & \& 180 & $"$ & 22050 \\
\hline & 7 & 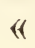 & * & 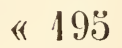 & « & 23887 \\
\hline & 8 & « & \# & «2:10 & « & 25720 \\
\hline & 9 & « & * & \# 230 & « & 28175 \\
\hline & 10 & « & « & « 240 & * & 29400 \\
\hline & 12 & « & \# & \& 270 & * & 3307 \\
\hline
\end{tabular}

TRILLA D O RAS.

Para una máquina de 4 cab... $£ 80$ ó sea $\mathrm{m} / \mathrm{c} 9800$

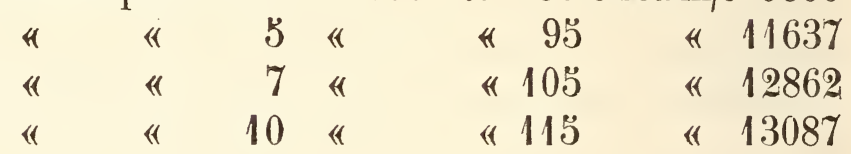

ELEVA D O RES.

Para subir la paja á 2ૅ piés y en cualquier direccion ........ £ 42 ó sea $\mathrm{m} / \mathrm{c} 5145$

Segun he dicho antes estos precios, con fletes, comisiones etc., etc., deben aumentarse en un 50 ó un $60 \%$, para no hacer cálculos que puedan resultar fallidos.

Creo que la máquina que mas conviene á nuestro país es la de 6 caballos.-Con ella se hará muy probablemente el mismo trabajo que con una de 12, y no solo el gasto será menor, sinó tambien el inconveniente que ofrece siempre el trasporte de masas de un peso considerable. 


\section{$-83-$}

Los Sres. Tomkinson y Jones de Montevideo, agentes de Ruston, Procton y Ca , vendieron por 1,600\$ bol., 4.0,000 $\$ \mathrm{~m} /$ c. al Sr. D. Miguel Argüello una preciosa máquina de fuerza de 6 caballos con su trilladora correspondiente, que se exhibia en los campos del Rio ${ }^{\circ}$. - Introducida para la Exposicion, no habia pagado derechos, ni gastos de trasporte.-Creo que por la misma suma, y mas bien, por algo mas, para no equivocarse, se tendrá una máquina igual en esta ciudad. 


\section{ARADOS}

$\mathrm{Su}$ ínvencion - Su progreso- Su importancia como base del cultivo - Jefferson y Webster-Condiciones desfavorables en que se hacia el ensayoArados Americanos - Sulky gang plough y praisie gang plough, ó arados de pradera múltiples Ventajas que ofrecen para nuestro pais.

El dia 17 tuvo lugar el ensayo de los arados.

La esposicion en esta parte era numerosa é intęresante. Veíanse alinados en una larga fila, arados Ingleses de los mas perfeccionados y de los mas acreditados fabricantes, de una, de dos y hasta de 3 rejas, es decir, para hacer uno, dos y tres surcos á la vez. La América estaba tambien bien representada, desde los modelos mas pequeños y baratos, hasta los magníficos de Collins de acero bruñido y reluciente como un espejo.

El arado es el primero entre todos los instrumentos agrícolas. Su invencion valió á Triptolemo, á quien se atribuye, ser colocado entre el número de los dioses de los tiempos mitológicos.

El progreso del arado ha debido ser lento. La lámina 14 da una idea de la escala que ha debido recorrer su 

perfeccionamiento, desde su forma primitiva, que fué probablemente la rama de algun árbol, hasta los poderosos instrumentos que pone en movimiento el vapor. En la última esposicion de Paris se presentó una coleccion de arados desde la mas remota antigüedad hasta nuestros dias, que mereció ser premiada, y que debia ser verdaderamente orijinal.

Ningun instrumento ha escitado tanto la inventiva del hombre, - desde el peon que lo maneja, hasta las inteligencias mas esclarecidas.

Jefferson, tercer Presidente de los Estados Unidos, con la misma mano con que trazó el acta de la Independencia de esta gran Nacion, que con justicia podria llamarse, la pájina mas gloriosa de la humanidad, - dirigió en 1793 una memoria al Instituto de Francia, fijando reglas matemáticas para la construccion de la volcadera. Asi tambien Pascal no desdeñó descender de las sublimes contemplaciones de Port-Royal á darnos la humilde carretilla de mano, que le debe la forma que hasta hoy conserva.

Daniel Webster, el grande orador de lus tiempos modernos, en 1836, hizo construir un arado de su invencion para abrir un surco de 14. pulgadas de profundidad y 21. de ancho, que se ve todavia en la chacra de su amigo P. Harvey. El mismo en su lenguaje enérjico y acentuado nos da cuenta de su ensayo. "Cuando empuné la mansera de mi grande arado (big plough ), tirado por cuatro yuntas de bueyes, dice el célebre estadista, yo oí como crujian las raices, y ví como desaparecian los troncos en las profundidades del surco, y observé como la superficie quedaba deshecha y unida, - sentí mayor satisfaccion por mi obra, que la que nunca me fué dado experimentar en las grandes luchas parlamentarias de Whashington. »

El genio Americano á imitacion de sus grandes hombres 
no descansa. Calcúlase que la oficina de Washington espide por dia una patente dirijida á mejorar con mas ó menos éxito, ya la volcadera, ya el timon, ya la cuchilla \&a. En 1869 se solicitaron 255 , - y se diria sin embargo, que el arado Americano habia llegado á la perfeccion, considerado el trabajo á que es destinado!

Y no sin razon se preocupan los hombres pensadores de mejorar el instrumento que es la base de todo buen cultivo .

El arado que permitiera remover la tierra á una pulgada mas de profundidad, aumentaria en mucho la riqueza de una Nacion.

El comisario de agricultura de los E. U., Horacio Crapon, calcula que por cada pulgada que se profundizara mas el cultivo, aumentarian en $150.000,000$ de duros las cosechas de la Union.

El arado es á la vez el instrumento mas dificil de apreciar en una esposicion agricola. Al estimar sus ventajas ó inconvenientes, no es posible dejar de valorar cuidadosamente las condiciones del país en que ha de usarse. A mas de la naturaleza del suelo, es preciso tener en cuenta los elementos de traccion, y la intelijencia de los hombres de que se puede disponer. El uso de los buenos arados supone buenos animales de traccion y labradores inteligentes, en una palabra, una agricultura adelantada. Solo la Inglaterra, la Alemania, la Belgica, la Francia y los Estados Unidos usan ảrados perfeccionados, el resto del mundo, mas de la mitad, no ha podido salir todavia del arado primitivo, que vemos figurar entre los geroglíficos de los monumentos del Ejipto.

La introduccion del arado Americano para nuestra agricultura, fué ya una gran mejora. Segun la juiciosa apre- 


\section{ARADOS AMERICANOS}
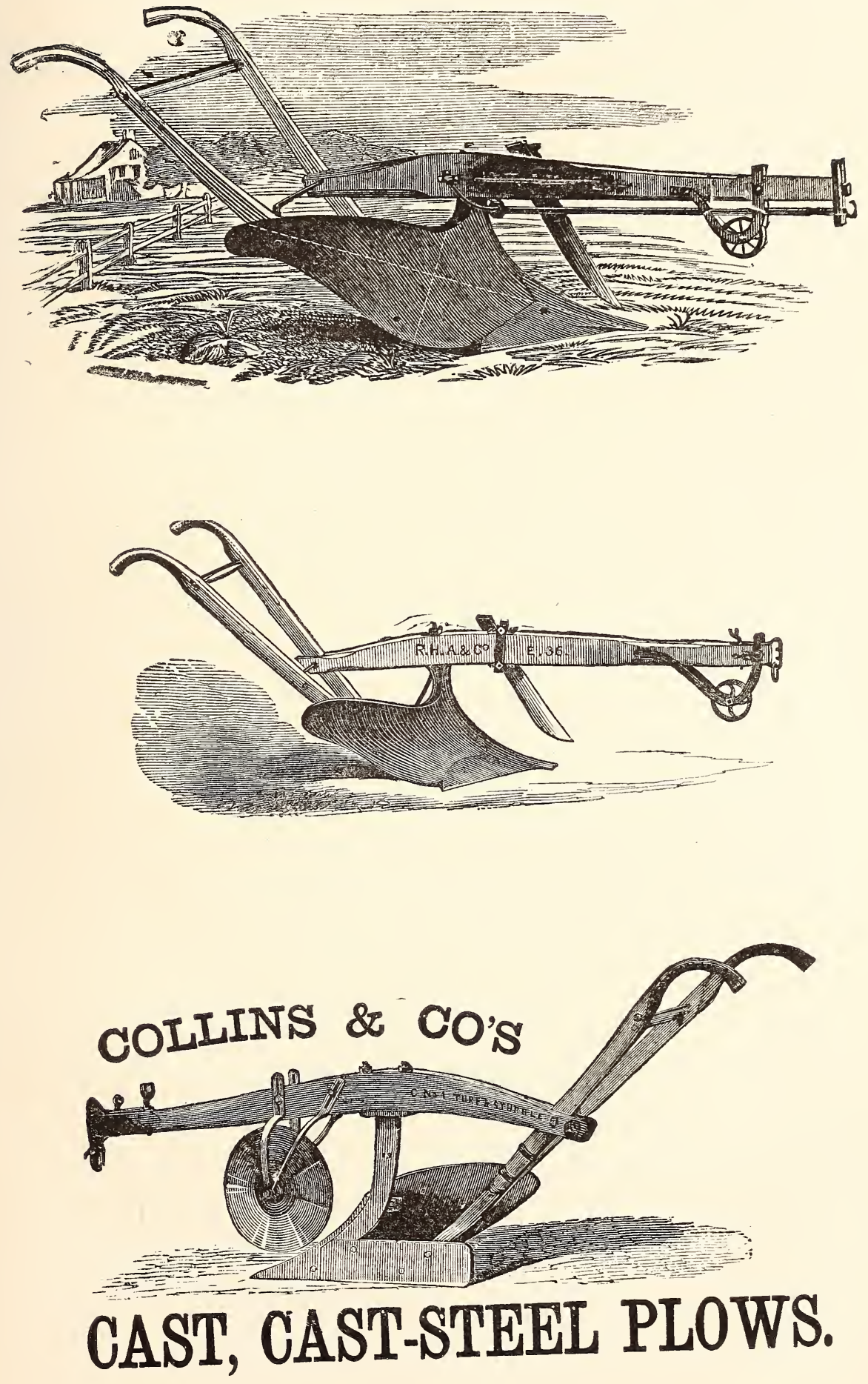



\section{$-87-$}

ciacion de Mr. Crapon, ella ha debido aumentar, nuestra produccion en algunos millones.

El arado Americano responde suficientemente, por ahora, á las condiciones de nuestros cultivos, y considero muy difícil que por mucho tiempo podamos abandonarlo para adoptar otro mejor. A un precio módico, que lo pone al alcance de todos, reune la ventaja de ser liviano y fácil de manejar. Es bien notoria la manera como trabaja, casi la totalidad de nuestros agricultores. El que tiene bueyes bastantes y no se ve obligado á recurrir al remedio de amansar novillos, es muy feliz. El año que los bueyes encuentran algo que comer en el campo y no se mueren de hambre, es tambien escepcional y de felicitacion. El hecho es que bueyes mantenidos con el pasto tierno d $\lrcorner$ invierno, que despues del trabajo se encierran en un corral á recibir las heladas, con el barro hasta la rodilla las mas veces, no estan en situacion al dia siguiente do hacer grandes tareas. Dia á dia se van debilitando, y aunque hayan principiado en buen estado y solo trabajen medio dia, como generalmente se acostumbra, es infalible que llegan postrados al fin de la jornada, si ha sido de regular importancia. No es fácil que en mucho tiempo estas condiciones cambien; está todavia remota la época en que nuestros agricultores tengan pastos artificiales, forrajes secos y galpones para abrigo; $y$ mientras esto no suceda, no es posible, á mı juicio, que entren en el uso general, esos admirables instrumentos aratorios que remueven una masa considerable de tierra, pero que, sin contar con la intelijencia del que los maneja, exijen una poderosa fuerza de traccion.

No daba por esta razon grande importancia á la prueba á que iban á ser sometidos los numerosos instrumentos que se habian exhibido. La mayor parte eran inadecua- 
dos para nuestra agricultura. Por otra parte, el ensayo se hacía bajo las condiciones mas desfavorables. Despues de una seca de 8 meses, la tierra estaba dura y compacta á términos de no ser posible un trabajo regular. Si á esto se agrega la mas visible desigualdad en la habilidad de los que dirijian los arados, y en la fuerza y destreza de los caballos; y por último, que el trabajo exijido duraba apenas unos pocos minutos, se comprenderá que no era fácil hacer un juicio ni aun aproximado, con respecto al mérito relativo de cada uno. Debo sin embargo decir que en el ensayo que se hizo en tierra que habia sido regada algun tiempo atras y que estaba bastante suelta, llamó justamente la atencion un arado Inglés llamado antifriccional ó sin friccion ó roce. Es verdad que era manejado por un Irlandes que parecia acostumbrado á luchar en concursos, y que en cualquiera llevaria gran probabilidad de ganar el premio, aunque trabajara con el peor arado.

Para que el concurso de estos instrumentos pudiera dar resultados prácticos para nuestro país, deberia, en mi opinion, circunscribirse á aquellos que, como antes he dicho, la generalidad de nuestros agricultores deberá usar por mucho tiempo aun; y estos mismos deberian dividirse en varias categorías. Convendria, por ejemplo, someter á una prueba séria, los arados de una misma marca, diremos 0 y D, que son los que mas generalmente se usan. Los agricultores ganarian mucho sabiendo cual daba vuelta mejor la tierra, cual profundizaba mas con el mismo tiro, y cual era de construccion mas sólida, siendo este el punto débil en casi todos.

Ensayáronse á la vez otros dos arados que escitaron grande interés y son realmente dignos de un estudio especial; el «Sulky gang phough» presentado por el Sr. Wheelright, 


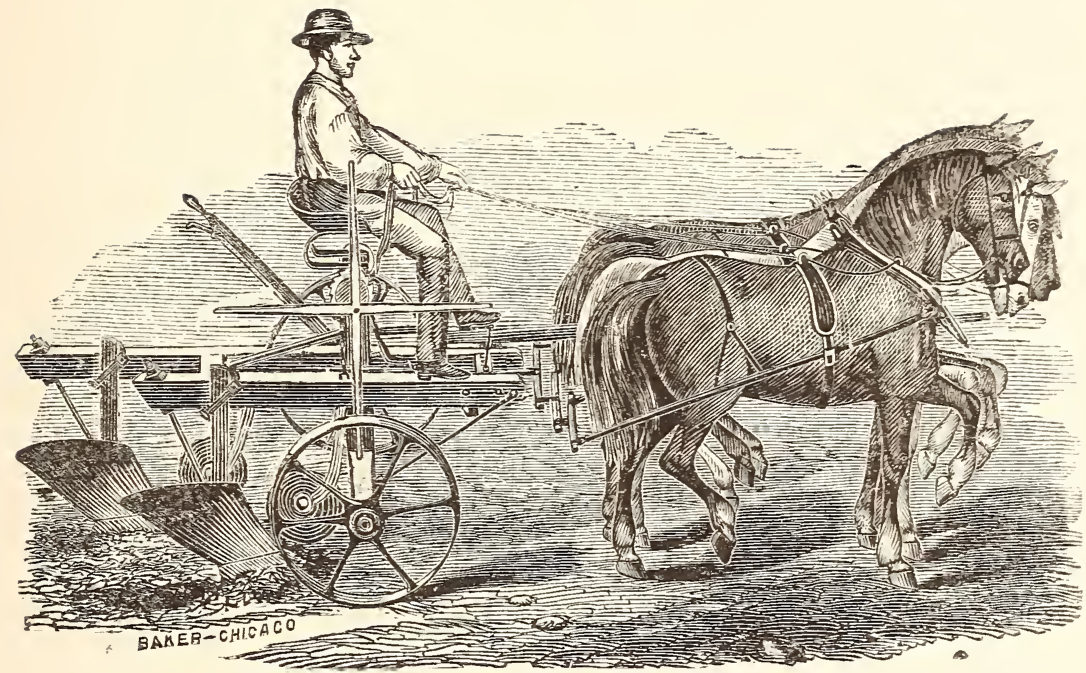

No 直

GANG-PLOUGH-ARADO SOBRE RUEDAS 

del Rosario, y el ' prairie gang plough ", de Collins, por el Sr. Roldan de Buenos Aires. L. 14.

Estos arados estan calculados para dos yuntas de bueves ó caballos. Segun se re el labrador los maneja desde un cómodo asiento. Abren dos surcos de 8 pulgadas de profundidad y 12 de ancho cada uno, y como al dar ruelta, una de las ruedas, que es un poco mas alta que la otra, va por el terreno que ha preparado el mismo arado, el trabajo se hace con la mayor regularidad. No he tenido ocasion de juzgar prácticamente de las rentajas de este arado, y no me atreveria á abrir un juicio definitiro á su respecto. Solo diré que el informe del comisario de Agricultura de los E. U. antes citado, recomienda mucho su uso, que afirma ser cada dia mas general, especialmente en los Estados del Oeste. Calculase que hacen de 3 á ŏ acres por dia, es decir, próximamente una de nuestras cuadras. Los informes que he podido adquirir de las pocas personas que lo han ensayado entre nosotros, concuerdan con este dato. $\mathrm{Su}$ introduccion seria entonces una gran mejora en nuestros cultivos.

Desgraciadamente su precio, 3 วั00 pesos, es demasiado alto, y no ha de permitir que se generalice por mucho tiempo. Si se tiene en cuenta, sin embargo, que para hacer una cuadra en un dia se necesita emplear por lo menos, 4 ó

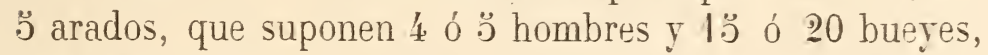
mientras que con el gang plough, ó arado múltiple en cuestion, un hombre con 8 bueves hace el mismo trabajo,se advierte claramente que este último ofrece una rentaja inmensa en el ahorro de salarios, y que, aun su mayor costo, está compensado con la economía de 8 bueves, cuyo valor es tanto ó mayor. En un par de meses, el ahorro del sueldo y mantencion de cuatro peones, habrá pagado el valor de este precioso instrumento. Dificil es, por 
otra parte, que nuestros paisanos se entiendan con los pesados arados Ingleses, que exijen mucha destreza y gran fuerza muscular; pero no hay ninguno que no sepa picar una carreta, y esto es todo lo que se necesita para manejar el gang plough.

Bajo todo respecto es, pues, muy digno de fijar la atencion de nuestros agricultores este precioso instrumento. $\mathrm{Su}$ introduccion podria ser de la mayor importancia para nuestro país. La tierra se prepara mejor, á mayor probidad y á menos costo. Escuso decir que la produccion y los beneficios del labrador aumentarian, y que aun las secas serian menos temidas y desastrosas. 


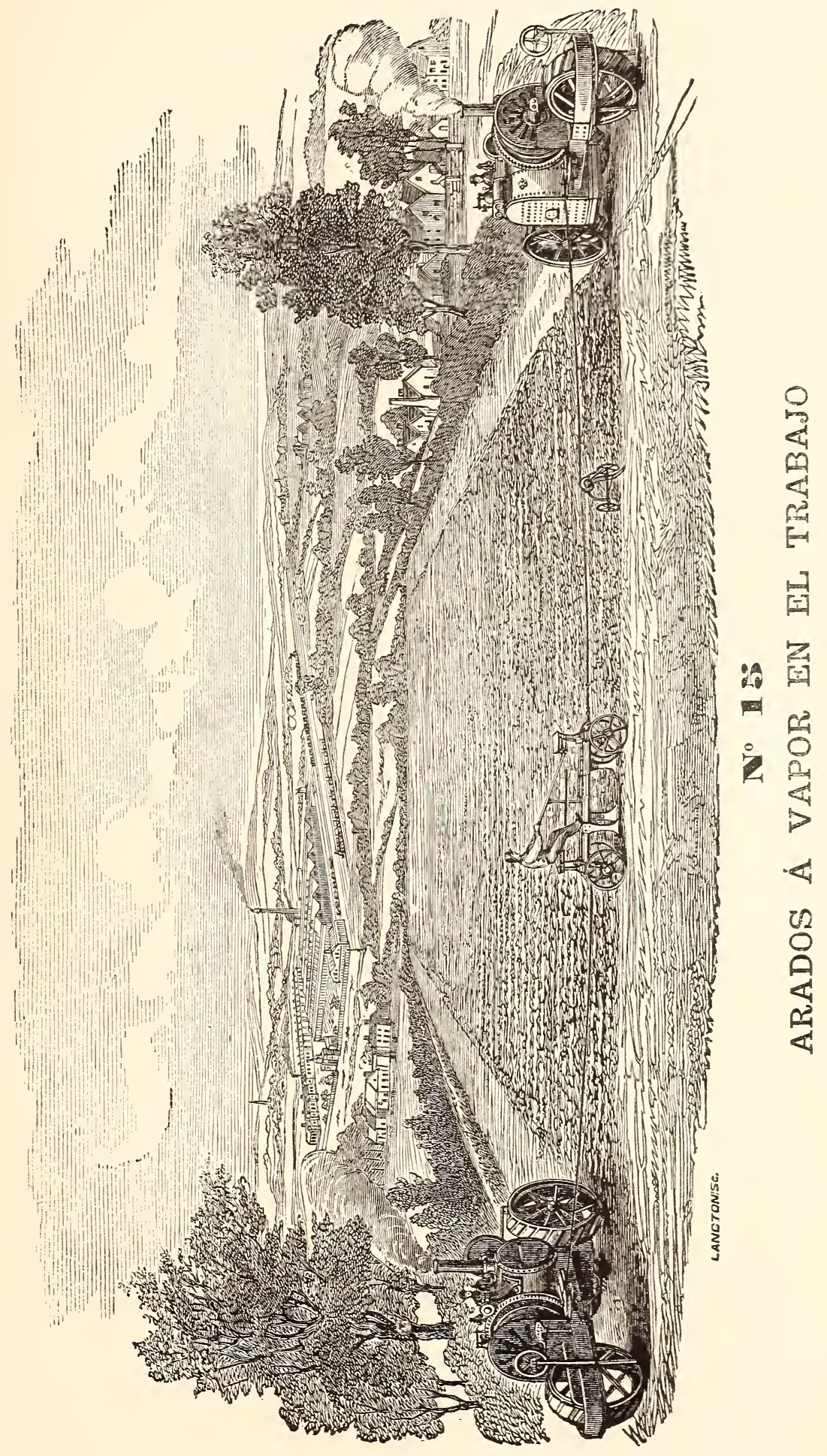




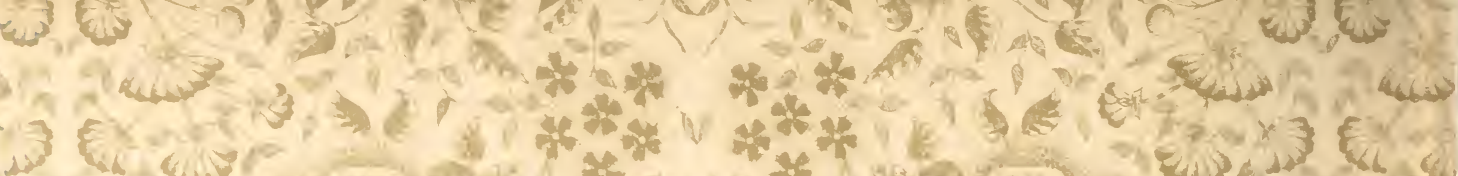

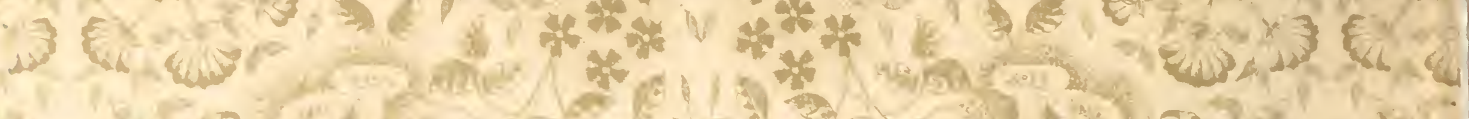

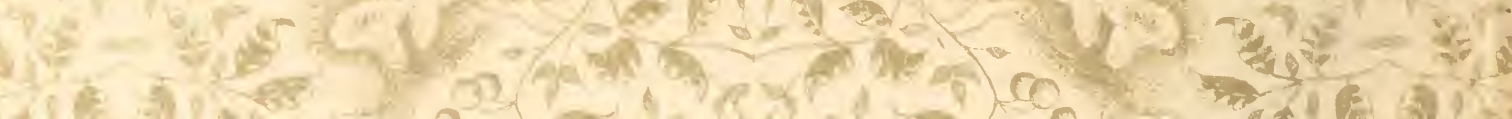

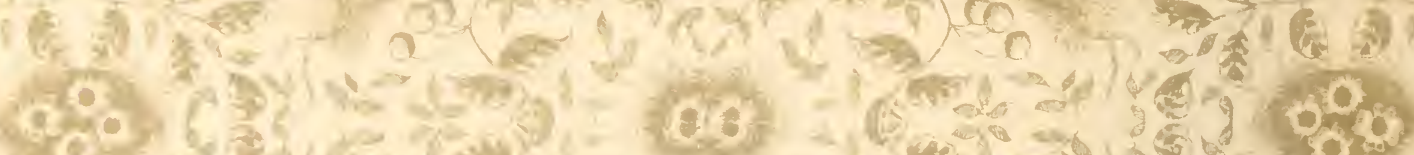

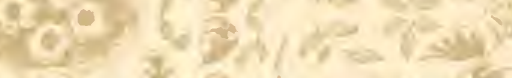

Ne 8 $\left(6, \frac{3}{2}+\frac{7}{2}\right)$

3 ह

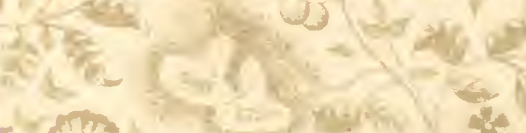

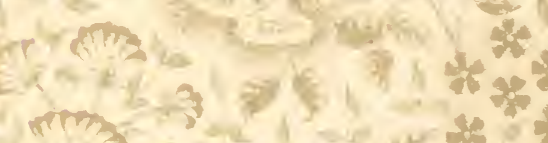

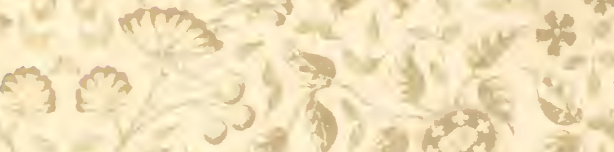

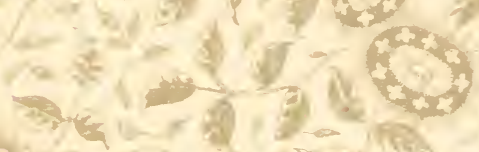
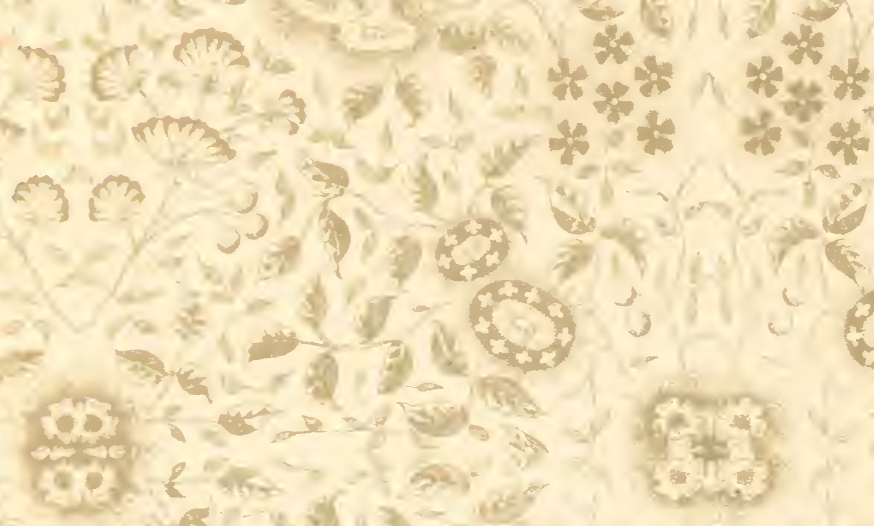

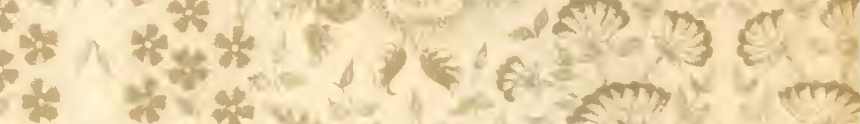

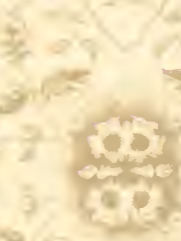

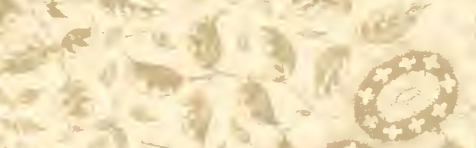

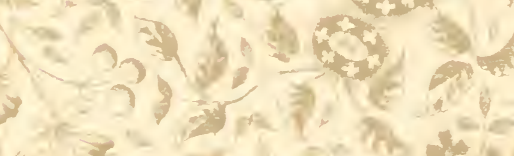

E.

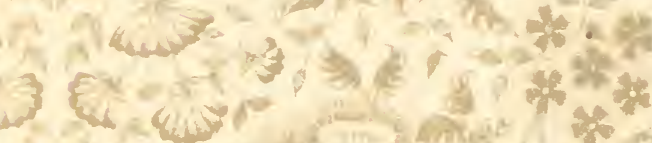

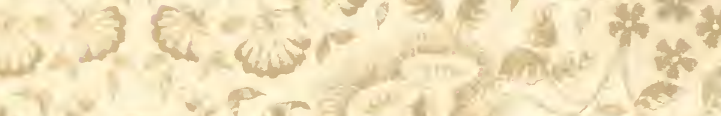

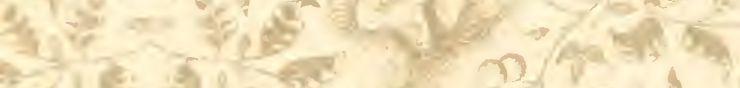

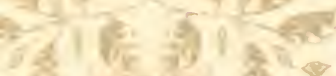

ase

380

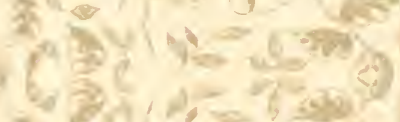

setes?

20.

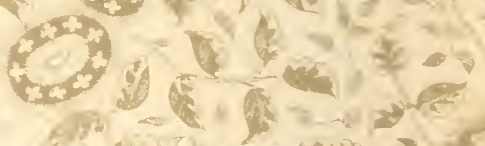

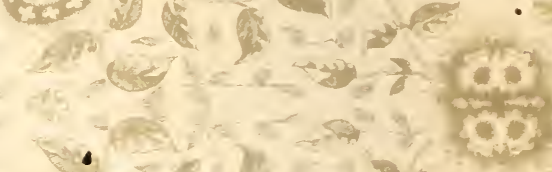

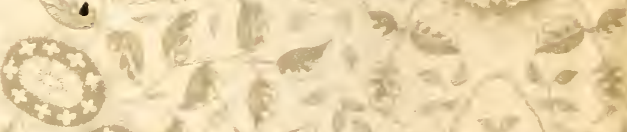

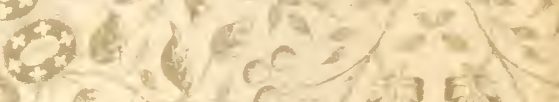

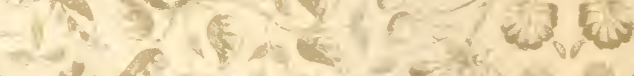

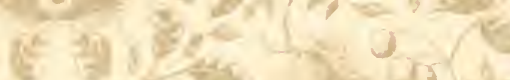

\section{$\left.x^{2}+4\right)^{2}=0$}

Q at and

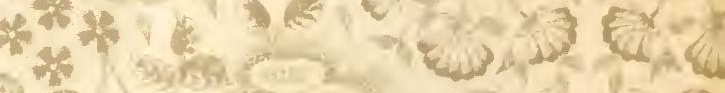

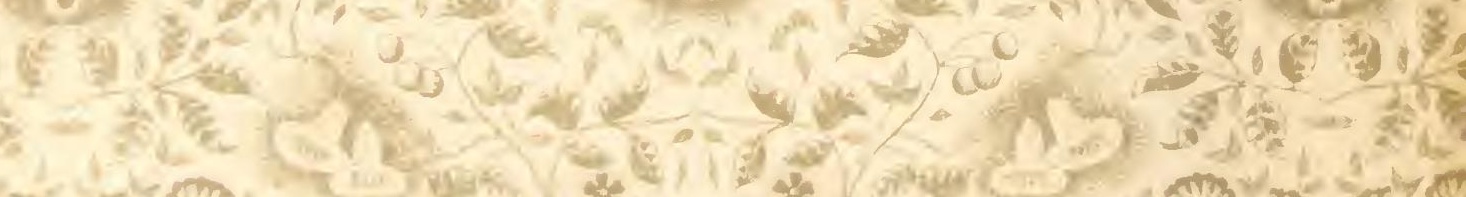

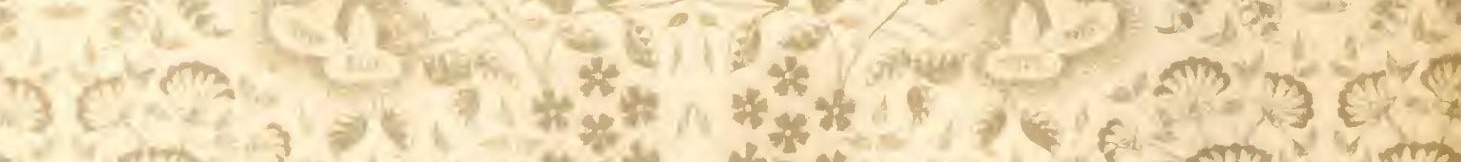

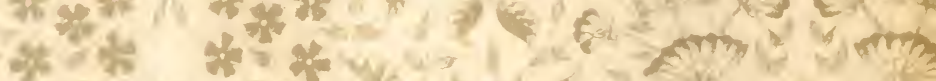

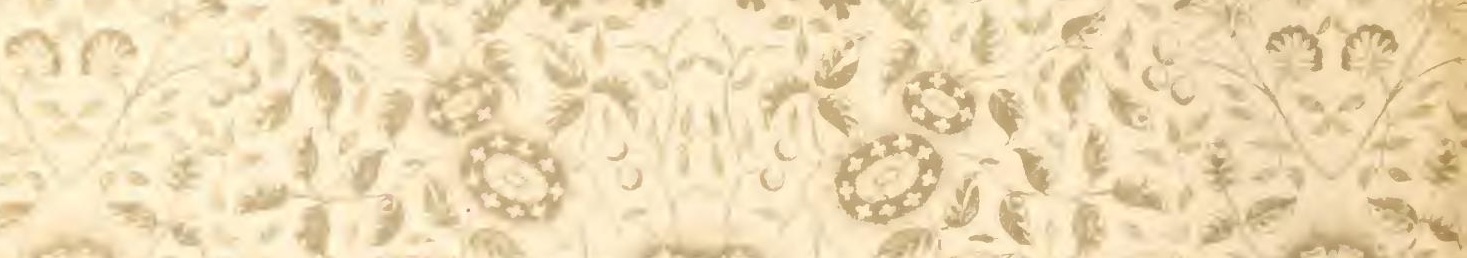
ars 30 $7+\frac{1}{10}$

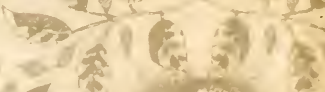

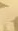




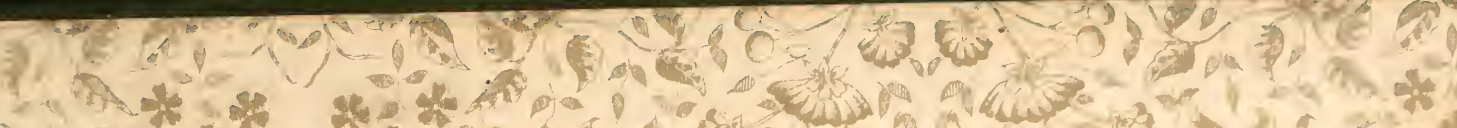

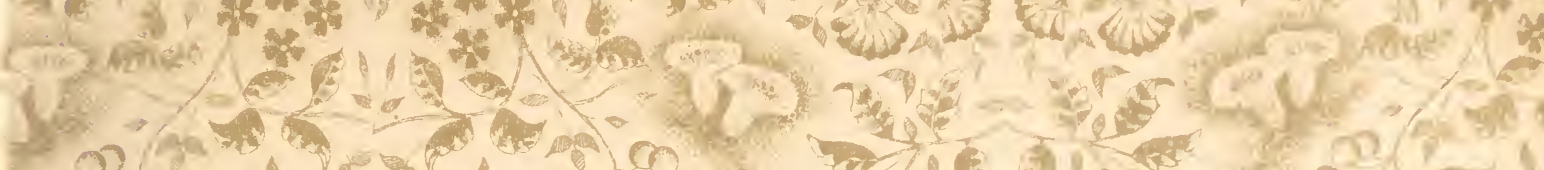

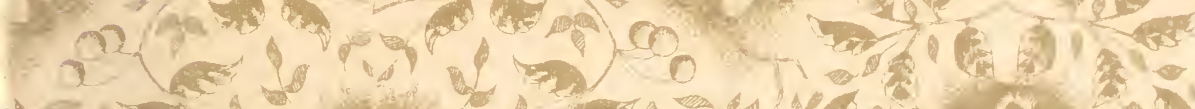

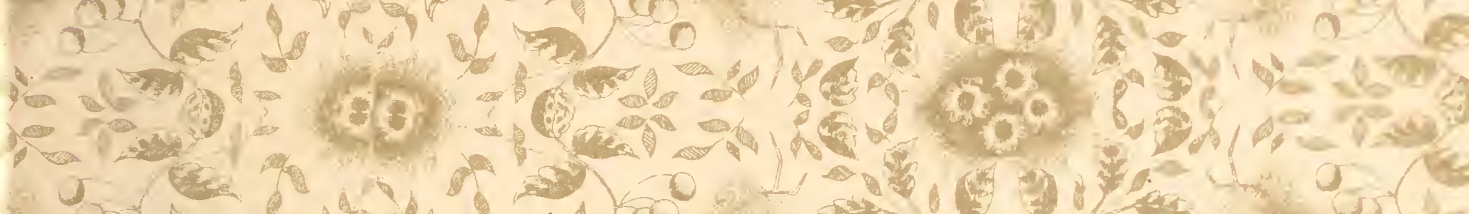

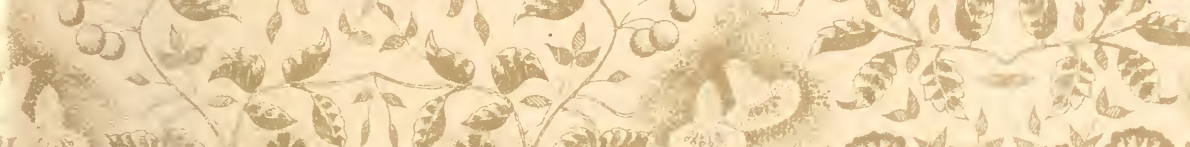

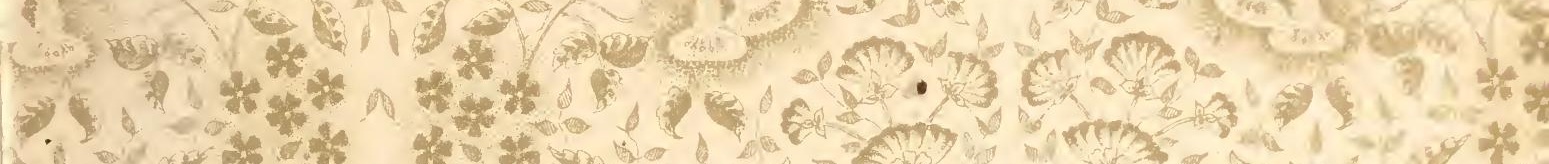

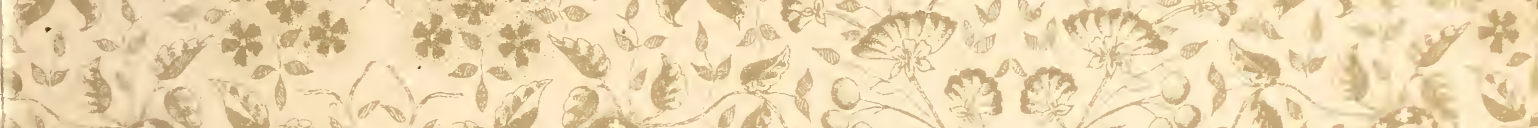

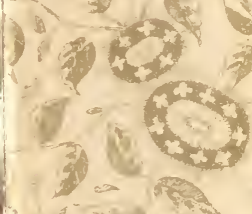

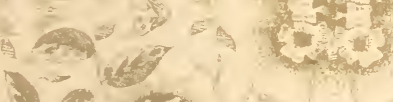
(2)

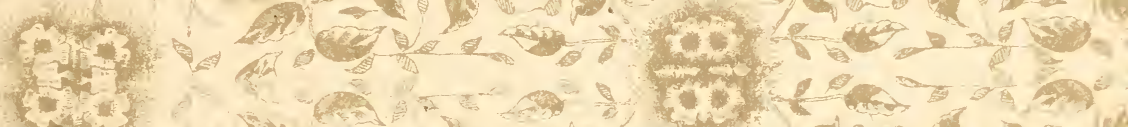
$2=40$

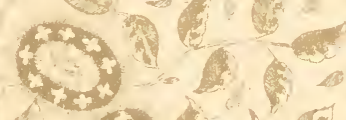
$\int_{0}-x^{2}+2$

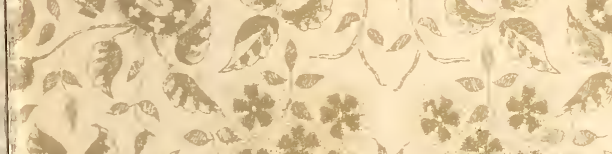

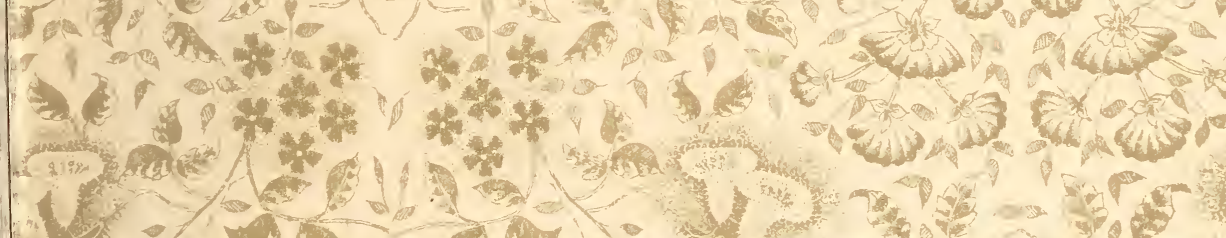

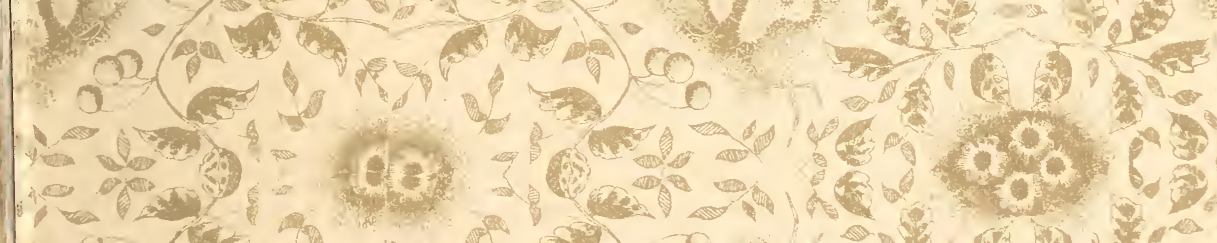
2 tor 80

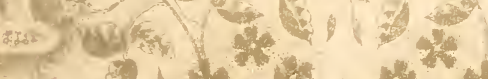

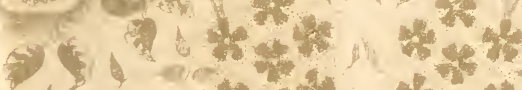

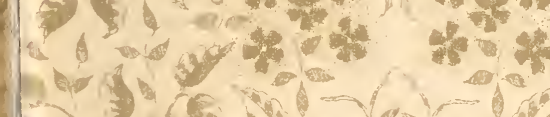
s. ant (a) $18+$

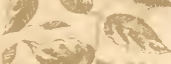


LIBRARY OF CONGRESS

||||||||||||||||||||||||||||||||||||||||

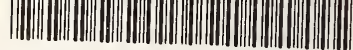

000091 36962 